\title{
Numerical model for determining the wetting front in a clay layer of a leaking composite barrier
}

\author{
Mustafa Eftelioglu \\ West Virginia University
}

Follow this and additional works at: https://researchrepository.wvu.edu/etd

\section{Recommended Citation}

Eftelioglu, Mustafa, "Numerical model for determining the wetting front in a clay layer of a leaking composite barrier" (2001). Graduate Theses, Dissertations, and Problem Reports. 2363.

https://researchrepository.wvu.edu/etd/2363

This Dissertation is protected by copyright and/or related rights. It has been brought to you by the The Research Repository @ WVU with permission from the rights-holder(s). You are free to use this Dissertation in any way that is permitted by the copyright and related rights legislation that applies to your use. For other uses you must obtain permission from the rights-holder(s) directly, unless additional rights are indicated by a Creative Commons license in the record and/ or on the work itself. This Dissertation has been accepted for inclusion in WVU Graduate Theses, Dissertations, and Problem Reports collection by an authorized administrator of The Research Repository @ WVU.

For more information, please contact researchrepository@mail.wvu.edu. 


\title{
NUMERICAL MODEL FOR DETERMINING THE WETTING FRONT IN A CLAY LAYER OF A LEAKING COMPOSITE BARRIER
}

\author{
By \\ Mustafa Eftelioglu \\ Dissertation submitted to the \\ College of Engineering and Mineral Resources \\ at West Virginia University \\ in partial fulfillment of the requirements for the degree of
}

\section{Doctor of Philosophy}

in

Civil and Environmental Engineering

\author{
Hema J. Siriwardane, Ph.D., Chair \\ John J. Bowders, Ph.D. \\ William J. Head, Ph.D. \\ Andrzej Karwowski, Ph.D. \\ Juan D. Quiroz, Ph.D. \\ Department of Civil and Environmental Engineering
}

Morgantown, West Virginia University

2001

Keywords: Compbar, Composite barrier, Slit, Wetting front Copyright 2001 Mustafa Eftelioglu 


\title{
ABSTRACT \\ Numerical Model for Determining the Wetting Front in a Clay Layer of a Leaking Composite Barrier
}

\author{
Mustafa Eftelioglu
}

Composite barriers for hazardous and solid waste landfills are designed to minimize hydraulic transport of the contaminant leachate of the landfill; however, the geomembrane can be damaged during construction or otherwise contain imperfections from manufacturing. It is desirable to estimate the discharge characteristics and the flow width of such a leachate should leaks in the geomembrane occur.

Numerical solutions of the flow equations for unsaturated soil barriers can provide an understanding of the movement of a leachate through a composite barrier. The purpose of this investigation was to develop a computer model that simulated two-dimensional migration of leachate beneath holes in a geomembrane in the composite barrier profile. The solution of this problem aids the determination of the time required for a wetting front to reach the leachate detection system. An approximate model of a composite barrier with a damaged geomembrane was considered. The top of the geomembrane and bottom of the leachate detection system were the boundaries for simulation, and then the soil profile was analyzed. Finally, finite elements were utilized accounting for leachate placed on top of the clay barrier. The flow through the soil below a slit was computed using Richards' equation.

A computer code to evaluate leakage through composite barriers was presented. The code, COMPBAR (composite barrier), simulates highly nonlinear, two-dimensional movement of leachate in unsaturated composite barriers with damaged geomembranes. A finite element approximation of Richard's equation describing flow through unsaturated porous media was incorporated. Galerkin's method and Picard iteration were utilized to solve Richard's equation. The governing equation reflected barrier heterogeneity and the dependence of hydraulic properties on the degree of saturation. The time required for the wetting front to reach the leachate detection layer and the time necessary for a stationary flow to develop in the soil barrier were computed.

Outputs of the developed COMPBAR program compared well with outputs of the SOILINER and SEEP programs. Design charts and guidelines were developed that can be used by designers to estimate the effective life of composite barriers and to aid study of various parameters that affect wetting front movement in the composite barrier. 


\section{ACKNOWLEDGEMENT}

I wish to thank my former research advisor Prof. John Bowders for his interest, guidance, support and endless patience during my Ph.D program at West Virginia University.

I would particularly like to thank my new advisor Prof. Hema Siriwardane for his support and help as the chairman of the examining committee. I would also like to express my sincere appreciation to him for his friendship and patience.

I would like to thank Prof. William Head, member of the examining committee, for his financial support during the first two years of my Ph.D. program.

I would like to express my sincere appreciation to Prof. Andrzej Karwowski and Dr. Juan Quiroz for their help and for serving as members of the examining committee. I would also like to thank former committee member Prof. Mohammad Gabr.

Special thanks to Hani A.Salim who served and assisted selflessly and tirelessly for many years.

Thanks to Christine Shaw for her grammatical corrections of my dissertation.

I would like to thank Marlene and Diego Ayala for their friendship and help throughout my Ph.D. program.

I thank all my friends and coworkers for their help and support during my Ph.D. program at the Department of Civil and Environmental Engineering at West Virginia University.

Finally, I would like to thank my wife, Nilufer, my son, Ahmet and my daughter, Ebru for their endless encouragement and support during my academic career. 


\section{TABLE OF CONTENTS}

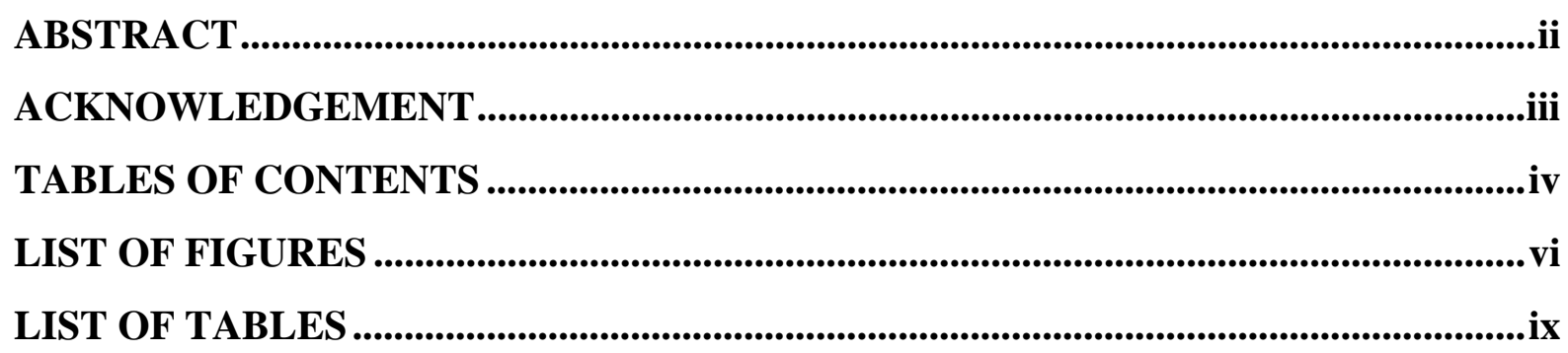

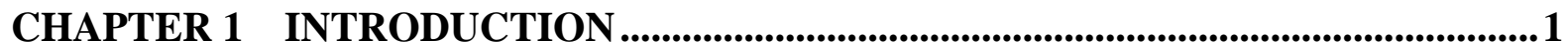

CHAPTER 2 LITERATURE REVIEW ...................................................................................6

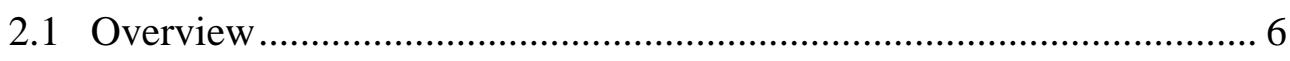

2.2 Landfill Construction and Barrier Systems ...................................... 6

2.2.1 Geomembrane Barriers ................................................. 7

2.2.2 Soil Barriers ................................................................. 7

2.2.3 Composite Barriers ........................................................ 8

2.2.3.1 Vapor Transmission .......................................... 10

2.2.3.2 Slits in the Geomembrane.................................. 10

2.2.3.3 Degraded Soil Component .................................. 11

2.2.3.4 Composite Action ........................................... 12

2.3 Leaking Barriers...................................................................... 13

2.4 Numerical Modeling of Unsaturated Flow ...................................... 14

2.5 Finite Element Method ............................................................. 17

CHAPTER 3 MATEMATICAL MODEL ............................................................... 19

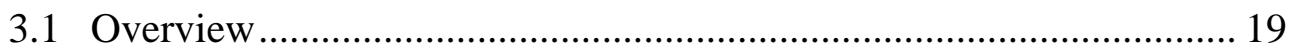

3.2 Mathematical Model of Flow Through Geomembrane Slits .............. 19 
3.3 Overlap of Wetting Fronts: Boundary and Initial Conditions ............. 29

3.4 Assembly of Computer Code ........................................................ 36

3.5 Evaluation of the Accuracy of the Code .......................................... 40

3.5.1 SOILINER Hypothetical Case ......................................... 41

3.6 Parametric Analyses.................................................................... 42

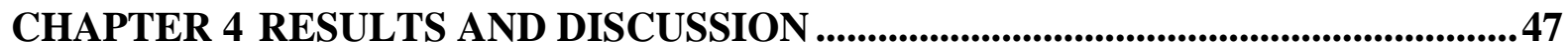

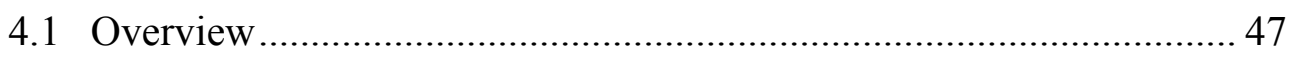

4.2 Results of COMPBAR ........................................................ 67

4.3 Comparison with SOILINER Results for a Hypothetical Case .......... 67

4.4 Comparison with SEEP Program.................................................. 69

4.5 Stability of COMPBAR Computer Program ................................... 74

4.6 Results of Parametric Analyses................................................... 79

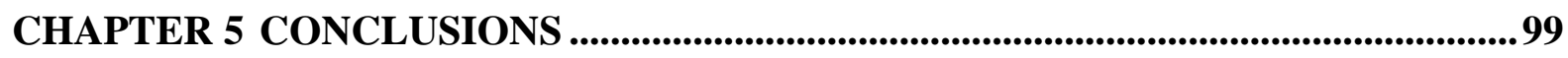

CHAPTER 6 RECOMMENDATIONS.................................................................... 101

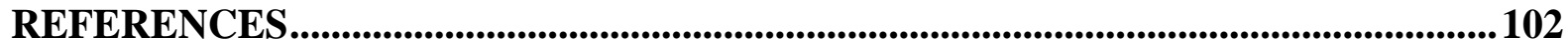

APPENDIX A COMPUTER PROGRAM.............................................................. 108

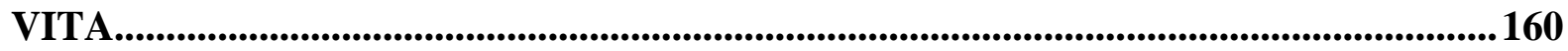

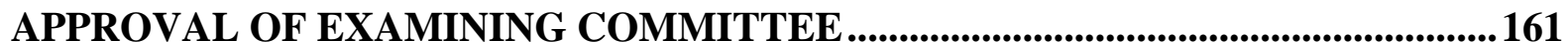




\section{LIST OF FIGURES}

Figure 1.1 Schematic diagram of the composite barrier............................................. 3

Figure 2.1 Sketch of a soil barrier system .......................................................... 8

Figure 2.2 Sketch of a composite barrier system.................................................. 9

Figure 3.1 Composite barrier with a damaged geomembrane ...................................... 20

Figure 3.2 Moving wetting front for the composite barrier with a damaged

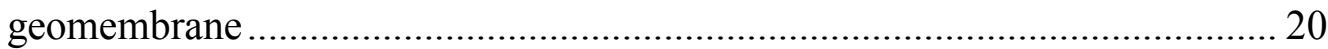

Figure 3.3 Distribution of leachate head on top of the soil ....................................... 22

Figure 3.4 Infinite horizontal composite barrier................................................... 23

Figure 3.5 Hydraulic conductivity $(\mathrm{K})$ versus pressure head $(\psi)$............................... 24

Figure 3.6 Characteristic curves of volumetric moisture content versus

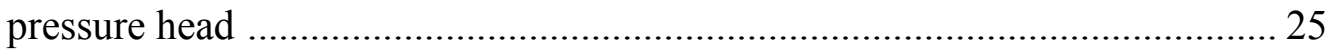

Figure 3.7 Typical plot of soil-retention curve based on Mualem's model ..................... 26

Figure 3.8 Relationship between hydraulic conductivity $(\mathrm{K})$ and volumetric moisture

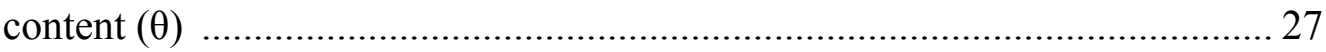

Figure 3.9 Contribution of the several slits to the pressure head distribution.................. 30

Figure 3.10 Overlap of the wetting fronts for geomembrane with several slits ............... 31

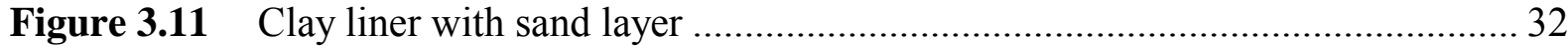

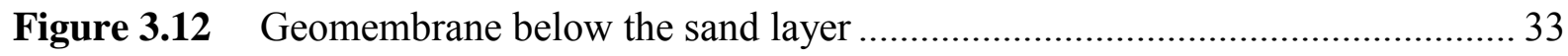

Figure 3.13 Groundwater table at the bottom of the sand layer ................................... 34

Figure 3.14 Groundwater table within the clay barrier .............................................. 35

Figure 3.15 Finite element discretization of the flow through slit ............................... 36

Figure 3.16 Flow chart of COMPBAR computer program ......................................... 40

Figure 3.17 A two liner system as simulated with SOILINER and COMPBAR .............. 41

Figure 3.18 Location of the slits and properties of the soil ........................................ 43 
Figure 3.19 Equipotential flow lines of a leachate through a composite barrier.............. 45

Figure 3.20 Mesh of the composite liner profile .......................................................... 46

Figure 4.1 Variations of pressure head with depth below the slit. .............................. 50

Figure 4.2 Variations of volumetric moisture content with depth below the slit ........... 51

Figure 4.3 Variations of hydraulic conductivity with depth below slit of Example 1. ....52

Figure 4.4 Variations of flow rate with depth below the slit of Example-1 . ............... 53

Figure 4.5 Wetting front movement with different time intervals ............................... 56

Figure 4.6 Variations of pressure head with depth below the slit of Example-2 ............ 60

Figure 4.7 Variations of volumetric moisture content with depth below the

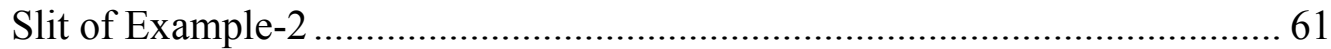

Figure 4.8 Variations of hydraulic conductivity with depth below the slit of Example-2 62

Figure 4.9 Variations of flow rate with depth below the slit of Example-2 ................... 63

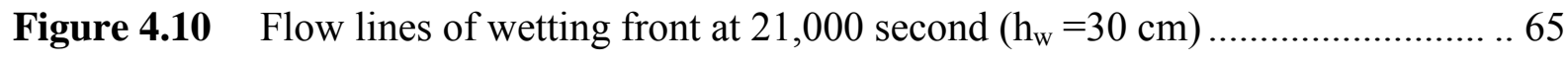

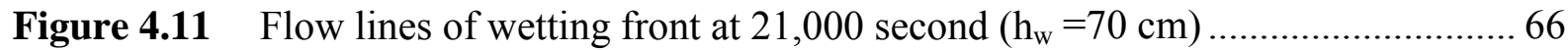

Figure 4.12 Variation of pressure head for SOILINER EXAMPLE ............................... 70

Figure 4.13 Depth versus moisture content variations for using SOILINER and $\quad$......

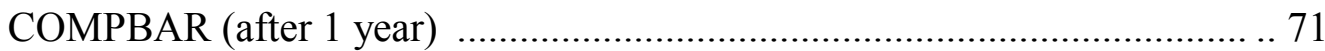

Figure 4.14 The variations of total stress with depth ........................................... 72

Figure 4.15 Variation of pressure head with depth below the slit with or without slit on geomembrane at saturated soil ..................................... 73

Figure 4.16 The variables and conditions of the soil profile......................................... 75

Figure 4.17 Volumetric moisture content variation with $3 \mathrm{~cm}$ leachate height ............... 76

Figure 4.18 Volumetric moisture content variation with $30 \mathrm{~cm}$ leachate height .............. 77

Figure 4.19 Volumetric moisture content variation with $300 \mathrm{~cm}$ leachate height ............ 78

Figure 4.20 Change of volumetric moisture content with depth below

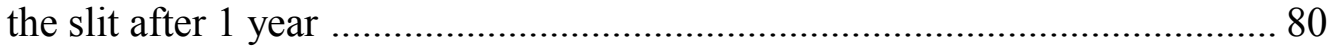

Figure 4.21 Change of volumetric moisture content with depth below the slit after 8 years 81 
Figure 4.22 Change of volumetric moisture content with depth below

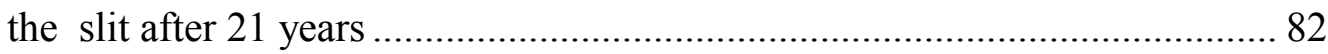

Figure 4.23 Volumetric moisture content variation using a $100 \mathrm{~cm}$ grid size

Figure 4.24 Volumetric moisture content variation using a $300 \mathrm{~cm}$ grid size

Figure 4.25 Volumetric moisture content variation using a $600 \mathrm{~cm}$

grid size

Figure 4.26 Comparison of poor and good soil-geomembrane contact

for one slit and $30 \mathrm{~cm}$ of leachate height

Figure 4.27 Comparison of poor and good soil-geomembrane contact for one slit and $70 \mathrm{~cm}$ of leachate height. 88

Figure 4.28 Comparison of pressure head for poor and good soil-geomembrane contact for five slits and $30 \mathrm{~cm}$ of leachate height.

Figure 4.29 Comparison of pressure head for poor and good soil-geombrane contact for five slits and $70 \mathrm{~cm}$ of leachate height 90

Figure 4.30 Comparison of the pressure head variations for loose and compacted soil...... 91

Figure 4.31 The pressure head variations for $0.03,0.3$, and $3 \mathrm{~cm}$ leachate heights............ 92

Figure 4.32 Comparison of pressure head with different leachate heights for good contact and one slit

Figure 4.33 Comparison of pressure head with several sizes of slits for one slit and poor soil-geomembrane contact of condition 94

Figure 4.34 Comparison of pressure head variations for loose and compacted soil 95 


\section{LIST OF TABLES}

Table 3.1 Physical properties of different types of soil...................................................29

Table 3.2 Physical properties of soil materials ...........................................................42

Table 4.1 Selected values of pressure head with depth below the slit of Example-1 $\quad \ldots . . . .48$

Table 4.2 Selected values of volumetric moisture content along the depth of the

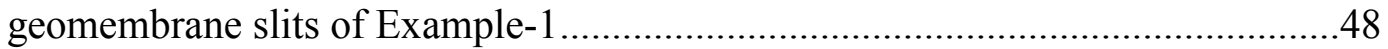

Table 4.3 Selected values of hydraulic conductivity along the depth of the geomembrane slits of Example-1

Table 4.4 Selected values of flow rate along the depth of the geomembrane slits of Example-1

Table 4.5 Selected values of pressure head along the depth of the geomembrane slits of Example-2

Table 4.6 Selected values of volumetric moisture content along the depth of the geomembrane slits of Example-2

Table 4.7 Selected values of hydraulic conductivity $(\mathrm{K})$ along the depth of the geomembrane slits of Example-2

Table 4.8 Selected values of flow rate along the depth of the geomembrane slits of Example-2

Table 4.9 Time calculated by using $\mathrm{Q}=\mathrm{kiA}$ and the finite element method COMPBAR code 


\section{CHAPTER 1 \\ INTRODUCTION}

The possibility of groundwater contamination by a landfill depends on many parameters. The two most significant factors are the amount of leachate migration out of the landfill and the corresponding contaminant concentrations. The first component is controlled by design, construction, and maintenance of the landfill, while the second component depends on the waste characteristics, available moisture, and mean annual temperature of the landfill site. Transient rates of leakage through the soil profile depend on previous moisture conditions, soil properties, the soil barrier, and the rainfall intensity.

New hazardous and municipal solid waste landfill liners are built with a composite barrier. A composite barrier has two elements, a geomembrane (flexible membrane liner, FML) as the top element and a low hydraulic conductivity material (such as clay or clayey soil) as the bottom element. A sand layer is placed above the FML to facilitate lateral flow of the leachate towards collection pipes. Geomembranes are becoming the most commonly utilized material for lining containment facilities such as landfills, water basins, and chemical or waste lagoons. The use of geomembranes to line waste containment facilities, e.g. hazardous waste landfills and leachate impoundments, is mandatory in some nations (Giroud and Bonaparte 1989b). A geomembrane as a part of the composite barrier is required for all hazardous waste facilities and acts as the primary liner (Miller and Mishra, 1989).

Composite barriers are increasingly used for leachate accumulation and waste control facilities.

First, the landfill liner is constructed including the composite barrier (if required). Then the waste is placed in an attempt to reduce leachate generation and potential groundwater contamination. Leakage through a composite barrier can result from flow through geomembrane slits. A geomembrane can be damaged during construction and installation. The objective of the composite barrier sys tem is to use two different barrier materials, where any holes in the geomembrane will be cut off by the underlying clay, making it more difficult for leachate to leak 
through the holes. Precipitation that infiltrates a solid or hazardous waste landfill can potentially increase the rate and total volume of leachate generated if the water is not collected or drained properly.

There are two primary mechanisms of leakage through geomembranes: fluid permeation through an intact geomembrane or flow through gomembrane punctures, holes or tears (Giroud and Bonaparte 1989b). Leakage rates due to flow through geomembrane holes are usually much higher than the leakage rates due to fluid permeation through intact geomembranes (Giroud and Bonaparte 1989 a, b). If a geomembrane with a hole is placed on a layer of low hydraulic conductivity soil to form a composite barrier, the soil significantly blocks the flow of leachate through the slit, provided that the geomembrane is in close contact with the soil. The mechanism of leakage through a damaged geomembrane with a slit is as follows: the leachate first migrates through the hole in the geomembrane. After that, the leachate may travel laterally some distance in the space between the geomembrane and the soil. Then, the leachate migrates vertically into and, ultimately, through the soil. Finally, the leakage is detected in the leachate detection and collection layer. The schematic representation of leakage through a composite barrier is shown in Figure 1.1.

If a geomembrane with a hole is overlain and underlain by high hydraulic conductivity materials (such as geonet or coarse gravel), flow of the leachate can be considered as free flow through an orifice and the leakage rate is governed by the size of the hole. If a geomembrane contains a hole and is placed on a high hydraulic conductivity material, but is overlain by a sandy or a fine gravel layer, flow through the hole may be somewhat impeded (Giroud and Bonaparte 1989b).

The rate of leakage in the case of a composite barrier is affected by the types of damage in the geomembrane, e. g. , slit hole, pin hole, and punch hole (Brown et al. 1987). Previous research work indicates that a key factor influencing the rate of leakage through a composite barrier is the quality of contact between the geomembrane and low hydraulic conductivity soil (Giroud and Bonaparte 1989 a, b; Giroud et al. 1989). Giroud and Bonaparte (1986) reported experimentaland analytical estimates of the flow through damaged geomembranes. They 


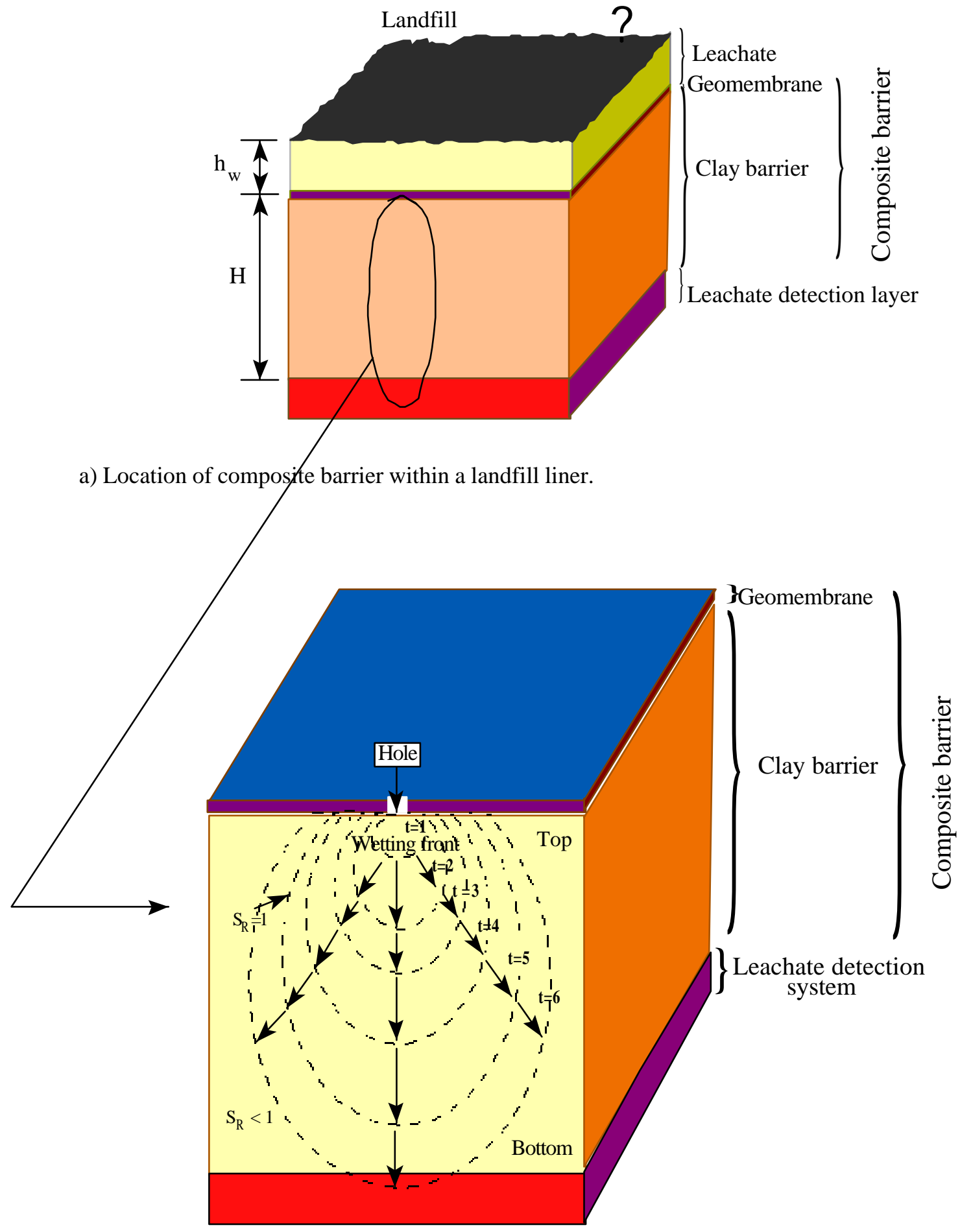

b) Progression of wetting front extending from a hole in the geomembrane through the compacted soil barrier ( $\mathrm{t}=$ time, $\mathrm{S}_{\mathrm{R}}=$ saturation).

Figure 1.1 Schematic diagram of a composite barrier 
provided a relationship between the size of the leakage beneath the geomembrane and the head of the leachate level above the geomembrane. They also proposed a method of interpolation between the various experimental and theoretical results, which leads to the evaluation of the leak rates through composite barriers.

In the literature, there are several computer programs related to unsaturated or saturated soil profiles, but to date only a few have studied composite barriers with a damaged geomembrane underlain by an unsaturated soil profile. Flow through composite barriers with damaged geomembranes has not been well established. However, Giroud et al. (1989) gave useful guidelines about flow through holes in a geomembrane. The significance of the present investigation is the development of a finite element model to analyze the nonlinear flow of leachate and the progress of a wetting front in a composite barrier with a damaged geomembrane.

Objectives of this research were: (1) to study the progress of a wetting front in a soil barrier without a geomembrane (one-dimensional nonstationary unsaturated flow), (2) to analyze the progress of a wetting front in a composite barrier with a geomembrane damaged during installation at the site or during manufacturing process (two-dimensional nonstationary, unsaturated flow), (3) to predict in both cases, the time in which the wetting front reaches the leachate collection and detection, (4) to develop a finite element computer program that is capable of simulating flow through damaged geomembranes, and (5) to study different composite barrier scenarios with damaged geomembranes which illustrates the usefulness of the developed program.

The finite element program developed to achieve these objectives is called COMPBAR (composite barrier). COMPBAR simulates nonlinear two-dimensional movement of leachate water in unsaturated composite barriers with damaged geomembranes, and one and/or twodimensional transient nonlinear flow through a soil barrier system. This program can determine the time required for the wetting front to reach the leachate collection layer and estimate the 
time necessary for stationary flow to develop in the soil barrier. This user-friendly computer program, COMPBAR, was developed to achieve this goal.

The scope of this investigation was limited to computer simulation of the design model. In Chapter 2, Literature Review, soil barrier and composite barrier systems are presented. A review of the literature on numerical modeling of unsaturated soil and the finite element method is also presented. Chapter 3 presents the research plan of this study. In Chapter 4, several example results, which are obtained from the COMPBAR program, and comparisons with SOILINER and SEEP programs are presented. Actually, both of these programs deal with leachate migration through an unsaturated soil. Stability analysis of COMPBAR code and results of a parametric analysis are also provided in this chapter. Conclusions and recommendations are presented in Chapter 5 and Chapter 6, respectively. The COMPBAR computer program (main program and subroutines) with data input and output for Example 1 are presented in Appendix A. 


\section{CHAPTER 2 \\ LITERATURE REVIEW}

\subsection{Overview}

A predominant issue of landfills is the potential contamination of groundwater and surface waters. Many controls must be designed and implemented to minimize infiltration through the landfill profile, maximize the leachate detection efficiency of the liner system, and prevent the migration of contaminants into groundwater. Consequently, to evaluate the design of hydraulic barriers, it is important to have design tools that can determine water-balance components and estimate leachate movement into, through, and out of landfill systems. Rainfall that infiltrates solid or hazardous waste landfills increases the rate and total volume of leachate produced. A soil hydraulic barrier or a composite barrier is typically placed below (i.e., liner) and above (i. e., cover) a waste landfill to reduce leachate generation and potential groundwater contamination (Peyton, 1988). Gray (1984) determined that no single convenient lining material appears appropriate for the long-term impoundment of waste materials. Composite barriers are mandated by regulatory agencies. Without the geomembrane water may reach the leachate detection system very rapidly. Application of the geomembrane on top of the soil hydraulic barrier decreases the leakage rate. When a slit forms in the geomembrane, the presence of low hydraulic conductivity soil in intimate contact with the geomembrane decreases the rate of leakage through the slit. A more suitable design strategy would be a performance-based design (Shackelford, 1992).

\subsection{Landfill Construction and Its Barrier Systems}

A hydraulic barrier is a low hydraulic conductivity material utilized to drastically slow down the flow of liquid. Low hydraulic conductivity materials utilized in civil engineering applications to assemble barriers include: clays, silty clays, clayey sand, silty sand, and geosynthetics such as 
geomembranes. Typical waste containment liner systems are briefly addressed in the following sections.

\subsubsection{Geomembrane Barriers}

Geomembranes are extraordinarily low hydraulic conductivity $\left(1 \times 10^{-13} \mathrm{~m} / \mathrm{s}\right.$ to $\left.1 \times 10^{-14} \mathrm{~m} / \mathrm{s}\right)$ membrane barriers. They are often used with soils to control fluid movements in a structure or system. Geomembranes are used in the construction of water reservoirs, canals, municipal and hazardous solid waste landfills, leachate impoundments, landfill covers, and spill containment systems. Geomembranes include asphalted membranes and polymeric membranes. Some examples of polymeric membranes are high-density polyethylene (HDPE), linear medium density polyethylene (LMDEP), polyvinyl chloride (PVC), or chlorosulfaonated polyethylene (CSPE). They are thin prefabricated membranes produced in thickness ranging typically from 0.5 millimeters (20 mils) to 2.5 millimeters (100 mils).

\subsubsection{Soil Barriers}

A low hydraulic conductivity soil barrier layer without a geomembrane is shown in Figure 2.1. The physical laws governing leachate movement downward through a low hydraulic conductivity soil barrier are more complicated than those governing leachate movement through sand and gravel layers with high hydraulic conductivity. The microscopic pores that exist in clay soils causes water to move not only by an induced hydraulic head under saturated conditions but also by capillary forces under unsaturated conditions. The smaller the pore radius, the larger the capillary force. Thus, soils with high clay content will have more micro pores and large capillary forces. As the pore size of the soil increases, the capillary force decreases. Thus, silty soils have lower capillary forces than clays. 


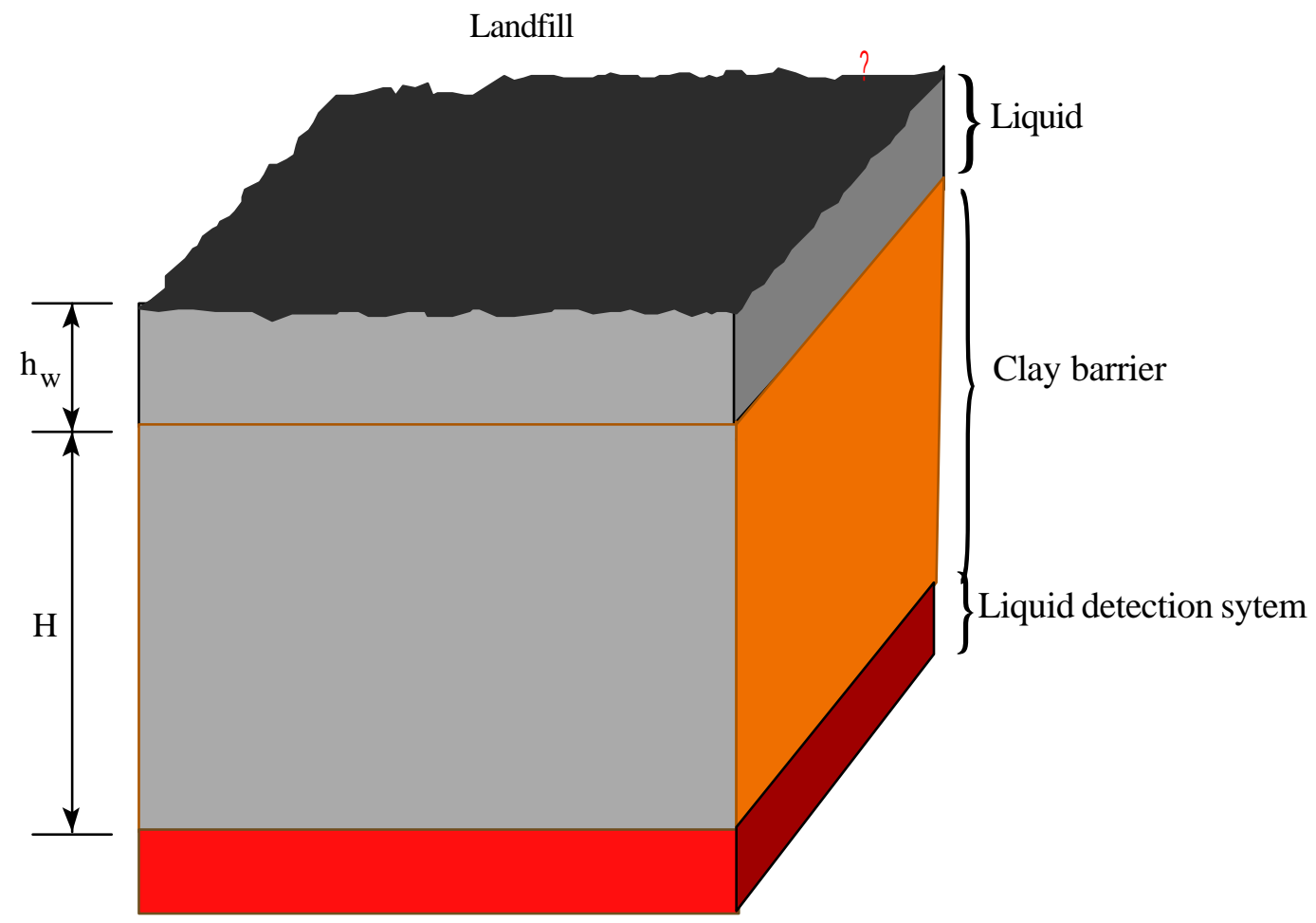

Figure 2.1 Sketch of a soil barrier system

\subsubsection{Composite Barriers}

A composite barrier has two elements: a geomembrane upper element and a low hydraulic conductivity soil layer as the lower element (Figure 2.2). Leakage through a composite barrier result from flow through small slits in the geomembrane and subsequently through the soil layer, or from vapor transmission through the geomembrane and again subsequently through the soil layer. In the case of leakage through a composite barrier, vapor transmission through intact geomembranes is significantly less than the rate of leakage through an imperfection in a geomembrane placed on a high hydraulic conductivity soil (Brown et al. , 1987; Jayawickrama et al. , 1988; Bonaparte et al. , 1989; Giroud and Bonaparte, 1989b; Giroud et al, 1989). Giroud and Bonaparte (1989 a) determined that the rate of leakage due to vapor transmission through an 


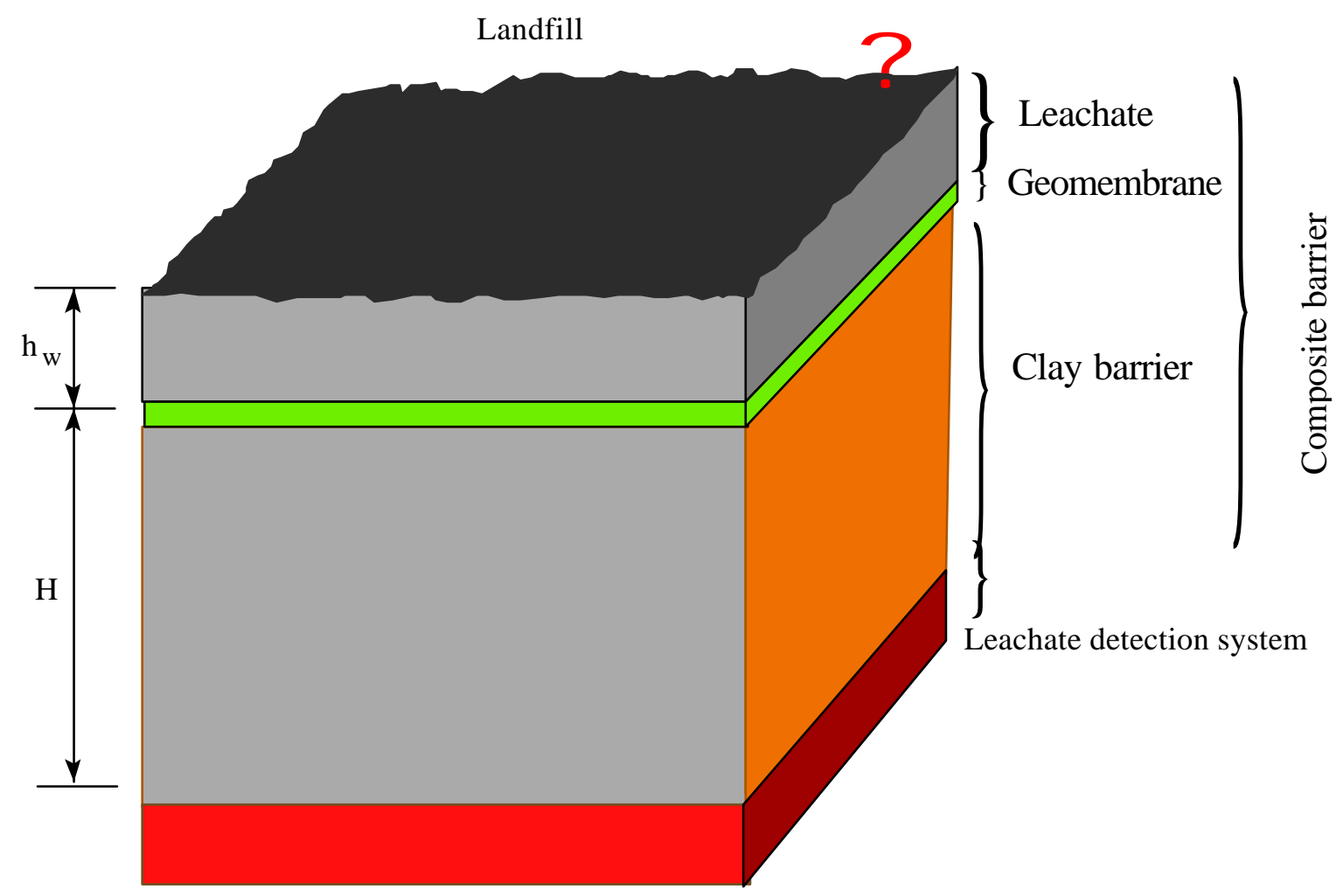

Figure 2.2 Sketch of a composite barrier system

intact geomembrane is not significantly different whether the geomembrane is placed on a low hydraulic conductivity soil or a high hydraulic conductivity soil.

To institute a method for evaluating the rate of leakage through composite barriers with slits in the geomembrane, Giroud and Bonaparte (1989a, b) reviewed the results of composite barrier model tests conducted by Sherard (1985), Fukuoka (1985), and Brown et al. (1987). They found that a key factor influencing the rate of leakage through a composite barrier was the quality of contact between the geomembrane and the soil barrier. Giroud \& Bonaparte (1989b) based their findings on a combination of theoretical analyses and large-scale model tests. Brown et al. (1987) performed laboratory experiments and developed predictive equations to quantify leakage rates through various sized holes in composite barriers. They assumed a uniform, vertical percolation rate equal to the saturated hydraulic conductivity through a circular 
cross sectional area of the soil barrier directly beneath the slit. They developed predictive equations for the radius of this flow cross section as a function of slit size, depth of leachate pounding, and saturated hydraulic conductivity of the barrier soil. They found that the radius of saturated flow was greater than the radius of the hole in the composite barrier.

The flow of leachates through a composite barrier can be categorized into vapor transmission, flow through slits in the membrane, flow through the degraded soil component, and a combined action. These types of flow are briefly discussed below.

\subsubsection{Vapor Transmission}

In the literature, for most vapor transmission cases, steady-state saturated flow conditions are usually assumed (Shackelford, 1992), where leachate is placed on top of the geomembrane of the composite barrier. If there is a hole in the geomembrane, the leachate flows first through the geomembrane hole, then laterally some distance between the geomembrane and the lowhydraulic conductivity soil. Finally, the liquid infiltrates the soil and flows vertically down into the low hydraulic conductivity soil layer. Flow at the soil-geomembrane interface is called interface flow, and the area covered by the interface flow is called the wetted area. There is no interface flow if the geomembrane and soil are in perfect contact, however, this is an ideal case, extremely difficult to achieve in practice (Giroud and Bonaparte 1989 a, b; Fukuoka 1988; Brown 1987; Giroud et al. 1992). Other considerations affecting the rate of flow through a composite barrier are: the size of the hole, hydraulic conductivity of the soil underlying the geomembrane, and the head of leachate on top of the geomembrane.

\subsubsection{Slits in the Geomembrane}

Geomembranes are used for waterproofing hydraulic structures because of their low hydraulic conductivity. Due to their small thickness, leaks might occur easily as a result of ruptures from construction/installation, inherent imperfections or imperfect welding of seams or joints. Thus, geomembranes do not guarantee a completely impervious barrier. The hole in the geomembrane can vary in size and shape such as a slit, a punch, or a pin hole. When the hole is small, it has 
little influence on the leakage rate. It is reasonable to expect three to five geomembrane holes per hectare (one or two slits per acre). (Giroud and Bonaparte 1989 a).

According to Giroud et al. (1992) holes should be distinguished from pin holes, and can be defined as openings having a dimension (diameter) about as large as, or larger than, the geomembrane thickness. For holes, the flow in the low hydraulic conductivity soil layer is perpendicular to the plane of the geomembrane. Leakage rates through geomembrane holes are affected by the material underlying the geomembrane. Two extreme cases can be considered:

1) high hydraulic conductivity soil, such as a granular drainage medium, and 2) low hydraulic conductivity soil, such as a clay layer. In the case of a geomembrane hole, the rate of leakage through a composite barrier (geomembrane and a low hydraulic conductivity soil) is significantly less than the rate of leakage through a similar hole in a geomembrane placed on high hydraulic conductivity soil (Giroud et al., 1992). Equation for leakage rate for the case of small geomembrane holes can be derived by considering circular or square holes. These equations are given by Bonaparte et al. , (1989); Giroud and Bonaparte, (1989 b) and Giroud et al., (1989).

\subsubsection{Degraded Soil Component}

When a geomembrane has a rupture, the flow is governed by the low hydraulic conductivity soil underlying the geomembrane. The flow below the geomembrane will depend on hydraulic conductivity of the soil, the depth of the water table, and the boundary conditions, i. e. , permeable or impervious barrier at a specific depth. Large volumes of leakage can occur if the geomembrane is placed on a pervious medium and subjected to a large hydraulic head. The geomembrane component decreases the leakage rate, while the low hydraulic conductivity soil component increases the breakthrough time. On the other hand, while the presence of lowhydraulic conductivity soil in contact with the geomembrane decreases the rate of leakage through a hole in the geomembrane.

Some chemicals have higher rates of permeation through geomembranes than rate for water (August and Tatzky, 1984; Hoax et al. , 1984). The leachate in contact with the geomembrane may be a pure chemical, a mixture of pure chemicals, or a dilute aqueous solution. Most 
leachates from municipal solid waste landfills (i.e., leachates) and other nonhazardous solid waste containment facilities fall into the latter category with low concentration of a large number of chemical constituents. Leachates primarily consist of soluble, partially soluble, or miscible components removed from the concentrated leachate. This leachate can also affect hydraulic conductivity characteristics of the soil barrier (Bowders and Daniel 1987; Daniel and Liljestrand 1984). Non-water based solutions are not considered in this study.

\subsubsection{Composite Action}

A composite barrier is composed of a geomembrane and an underlying layer of low hydraulic conductivity soil placed in close contact with each other. Therefore, flow migrates first through the geomembrane and then through the soil. Leakage through a composite barrier can result from flow through geomembrane holes or vapor transmission through the geomembrane. In the case of a geomembrane hole, the rate of leakage through a composite barrier is significantly less than the rate of leakage through a similar slit in a geomembrane placed on a high hydraulic conductivity soil, as discussed by Giroud and Bonaparte (1989 a, b). The soil significantly impedes the flow of leachate through the slit, assuming that the geomembrane is in close contact with soil such as clay or clayey soil.

Generally, some lateral flow occurs between the geomembrane and the underlying soil. Giroud and Bonaparte (1989 a, b) and Giroud et al. (1992) examined the experimental and theoretical results of other researchers. They studied flows for perfect, good, and poor contact between the geomembrane and the soil. Their studies led to the following two empirical equations for the rate of leakage through a hole in the geomembrane component of a composite barrier:

For good contact conditions:

$\mathrm{Q}=0.21 \mathrm{a}^{0.1} \mathrm{~h}^{0.9} \mathrm{k}_{\mathrm{s}}^{0.74}$

For poor contact conditions: 
$\mathrm{Q}=1.15 \mathrm{a}^{0.1} \mathrm{~h}^{0.9} \mathrm{k}_{\mathrm{s}}^{0.74}$

where $\mathrm{Q}=$ rate of leakage through a slit in the geomembrane component of the composite barrier; $\mathrm{a}=$ area of the slit in the geomembrane, $\mathrm{h}=$ head of leachate on top of the geomembrane, and $\mathrm{k}_{\mathrm{s}}=$ hydraulic conductivity of the low hydraulic conductivity soil component of the composite barrier. These two empirical equations are not dimensionally homogeneous and can only be used with the following units: $\mathrm{Q}\left(\mathrm{m}^{3} / \mathrm{s}\right), \mathrm{a}\left(\mathrm{m}^{2}\right), \mathrm{h}(\mathrm{m})$ and $\mathrm{k}_{\mathrm{s}}(\mathrm{m} / \mathrm{s})$.

The use of these equations should be restricted to cases where hydraulic conductivity of the soil is less than $1 \times 10^{-6} \mathrm{~m} / \mathrm{s}$. Also, these equations should be restricted to cases in which the head of leachate on top of the geomembrane is less than the thickness of the soil layer.

The good contact condition corresponds to a geomembrane with few wrinkles and a soil barrier, which has been sufficiently compacted, and smoothed on the upper surface. The poor contact condition corresponds to a geomembrane with wrinkles, laid over an uneven soil surface. These two contact conditions can be considered as typical field conditions.

\subsection{Leaking Barriers}

The rate of leakage through a composite barrier is independent of the overlying material. The flow is essentially governed by the soil underlying the geomembrane. The head loss at the geomembrane hole is negligible compared to the head loss in the underlying soil. Therefore, if the material overlying the geomembrane is more permeable than the soil of the composite barrier, no significant head loss will take place in the overlying material. Therefore, the presence of overlying material will not significantly affect the leakage rate unless fine particles migrating from the overlying material clog the geomembrane hole and the space between the geomembrane hole and underlying soil.

There is typically a leachate collection system above the geomembrane. The objectives of the leachate collection system are to accumulate the leachate that has seeped through solid waste 
and transport it to a sump from where it is drained and collected from the waste containment system. Thus the hazard of leakage is minimized by preventing leachate accumulation on top of the barrier.

\subsection{Numerical Modeling of Unsaturated Flow}

A review of the literature on numerical modeling of unsaturated flow through porous media was conducted during the development of this code. Based on this review, a model was developed to study the flow of leachate through the composite barrier and the progression of the wetting front to the underlying leachate detection system.

Mathematical modeling of the leakage through soil barriers or composite barriers has been attempted by Remson, et al. (1968), Fen, et al. (1975), Perrier and Gibson (1980), Skaggs (1980), Miller (1984), Schroeder (1984), Schroeder et al., (1984), and Paniconi et al. (1991). The first three of these researchers used the water balance method without considering the mechanism of the fluid flow through the soil profile to calculate leakage rates. This approach grossly underestimates field conditions such as a homogeneous mass of clay with uniform hydraulic properties (Gee, 1981; Gibson and Malone, 1982). Skaggs (1980) improved over the earlier attempts by incorporating Darcy's law in his model to compute the rate of moisture movement through the saturated soil profile. Miller (1984), Schroeder (1984), and Schroeder et al. (1984) used a quasi two dimensional, deterministic approach to model the saturated clay barrier. Miller's model also covers the full range of saturation. His model assumed that the surface inputs (i.e., flow rate boundary condition) have been solved for a priority using a model of surface hydrology.

For all of these studies, it was assumed that the clay barrier was homogeneous with uniform hydraulic properties. Daniel (1984) found that fluid moves much faster through actual clay barriers than predicted by using laboratory determined values of hydraulic conductivity. He found that the actual hydraulic conductivities of the clay barriers, calculated from field leakage rates, were from 5 to 10,000 times larger than those obtained from the laboratory tests on 
undisturbed clay samples. Daniel (1984), and Boynton and Daniel (1985) attributed the increased hydraulic conductivity in the field to the presence of the macro-pores in the clay mass.

Edwards, et al. (1979) reported that Gardner (1962) also showed that the holes and the cracks that are open at the surface can move significant volumes of the surface water much deeper and faster than that calculated by Darcy-type solutions alone. The tracer studies of Ritchie et al. (1972), Blake et al. (1973), and Quisenberry and Phillips (1976) also revealed that surface applied water flows through the interconnected macropores.

Some general features are common to many landfills and are assumed to exist in the hypothetical landfill for which the numerical model was formulated. These features are: (1) the local groundwater table is well below the landfill, and the leachate drains freely to the leachate detection system, (2) precipitation provides the only additional source of leachate to the landfill, apart from the liquid (moisture content) of the waste, and (3) the leachate detection system is designed to prevent the pounding of water within the landfill.

Most analytic solutions related to unsaturated flow through porous media appear in infiltration studies. In this study, infiltration is defined as the wetting of a vertical soil profile from the surface to lower portions. Parlange and Aylor (1972) presented analytical solutions for both the specified moisture conditions and specified flux conditions as the upper boundary. A twoparameter infiltration model for arbitrary rainfall rates was also introduced by Parlange (1975).

Skaggs (1980) presented a more rigorous approach to the barrier problem. His model considers only saturated flow through the clay barrier and does not couple the transport mechanism of the various landfill layers. Perrier and Gibson (1980) developed a computer model, Hydrologic Simulation of Solid Waste Disposal Sites (HSSWDS), to simulate transport through landfill covers based on water balance concepts.

The solution to the general flow equation for an unsaturated clay barrier yields moisture content profiles in the clay barrier at different times and also the rate of seepage flux through the barrier at different locations as a function of time. Notable among the available programs to solve the 
unsaturated flow equation in a hydraulic barrier system is a finite difference program, "SOILINER" developed by Goode and Smith (1986). SOILINER is a finite difference approximation of the nonlinear, governing equation for one-dimensional, unsaturated flow in the vertical dimension. SOILINER was designed to simulate the dynamic processes of an infiltration event across a compacted soil barrier system beneath impounded leachate. Since the governing equation reflects barrier heterogeneity and the dependence of barrier properties on the degree of saturation, SOILINER is capable of representing infiltration for a variety of soil (e. g. , clay) barrier scenarios. Important features inherent to the SOILINER model include the ability to simulate multilayered systems, variable initial moisture contents, and changing conditions on the boundaries of the compacted soil barrier flow domain.

Another computer model, the Hydraulic Evaluation of Landfill Performance model (HELP), simulates the effects of hydraulic processes on the water balance for landfills by performing daily sequential analyses using a quasi-two dimensional, deterministic approach (Schroeder et. al., 1987). The main hydraulic considerations include precipitation of any form, surface storage, surface evaporation, runoff, snow melt, infiltration, vegetation, plant root depth, plant transpiration, soil evaporation, soil moisture storage, soil moisture potential, unsaturated flow, and vertical and lateral saturated flow. The code handles each of these considerations, often in a simplified manner, to estimate runoff, evapotranspiration, vertical drainage to lower barriers, percolation through barriers, and lateral drainage.

Also, the two-dimensional finite element model, UNSAT2, developed by Neuman (1973) and Neuman et al. (1975), simulates moisture movement through laboratory columns and a fieldscale cover design. The model uses a Galerkin type, finite element method to simulate twodimensional, nonsteady flow of water in incompressible, saturated-unsaturated soils. Evaporation and water uptake by roots are also considered.

The unsaturated flow problem for land fill barriers is particularly hard to approach analytically because of the strong nonlinearities in the soil moisture, hydraulic conductivity and suction relationships. In addition, the initial conditions are not spatially constant and the boundary conditions may be time-dependent. Fenn et al. (1975) adopted a strategy, which is similar to the 
agricultural type water balance used for scheduling irrigation. The balance uses primary precipitation components to account for the precipitation that ultimately appears as leachate. Gibson and Malone (1982) applied Fenn's water balance method to a landfill test cell and reported that the predicted annual leachate accumulation is underestimated by $20 \%$.

The volume of moisture passing through the topsoil layer represents the maximum possible volume of leakage through the soil barrier. The volume of leakage from an individual rainfall event depends upon the duration of the rainfall and the rate of leakage through the topsoil layer. This transient rate of leakage through the topsoil layer depends on antecedent moisture conditions, soil properties, soil cover, and rainfall intensity. Calculation of the rate and volume of percolation is critical since it represents the primary input to leachate generation. A numerical model based on Richard's equation uses the partial differential equation governing vertical flow in an unsaturated soil profile to simulate fluid movement in the clay and waste layer. In this study, a computer program was developed to solve Richards' equations.

Richards' equation for flow through an unsaturated soil profile (Richards 1931) is as follows:

$$
\frac{\partial}{\partial x}\left(K_{x}(\psi) \frac{\partial \psi}{\partial x}\right)+\frac{\partial}{\partial y}\left(K y(\psi) \frac{\partial \psi}{\partial y}\right)+\frac{\partial}{\partial z}\left(K_{z}(\psi)\left(\frac{\partial \psi}{\partial z}+1\right)\right)=C(\psi) \frac{\partial \psi}{\partial t}
$$

where $K_{x}(\psi)$, Ky $(\psi)$, and $K_{z}(\psi)$ are the unsaturated hydraulic conductivities (which are functions of pressure head, $\psi$ ) in the three coordinate directions $\mathrm{x}, \mathrm{y}, \mathrm{z}$ where the $\mathrm{z}$ axis is assumed to be vertical and $\theta=\theta(\psi)$ is the volumetric moisture content of the soil barrier, and $\mathrm{C}(\psi)$ is the specific moisture capacity.

\subsection{Finite Element Method}

Finite element and finite difference methods are the most common numerical procedures for modeling groundwater problems. Finite difference methods are based on a discretization of the 
flow domain into a grid that is typically rectangular, where the potential or head is determined at the grid points by solving the differential equation in a finite difference form throughout the grid.

Another numerical method is the finite element method. It is more flexible than the standard form of the finite difference method. The finite element method differs from finite difference method in two ways. First, the field is discretized into a grid (mesh) of finite elements of any shape such as triangles or rectangles. Second, the differential equation is not solved immediately but replaced by several equations. For the finite element method used in groundwater flow problems, the flow domain is subdivided into small elements, for which the flow in each element is characterized in terms of the hydraulic head at the nodal points. Then, a system of equations is acquired from the barrier system so that the flow must be continuous at each node.

Analytical methods and numerical methods can be used to obtain solutions for groundwater flow. Analytical methods require a functional representation of the solution of the partial differential equation (e.g. , a mathematical expression that gives hydraulic head as a function of position and time in the soil). The primary limitation of analytical methods is that solutions can only be obtained by imposing strict limiting assumptions about soil properties, boundary conditions, or initial conditions.

Numerical methods do not need restrictive assumptions. It is possible to obtain numerical solutions for the case of anisotropic and nonhomogeneous soils and for problems with complicated and time-dependent boundary conditions. The finite element method was employed in this study. 


\section{CHAPTER 3 \\ MATHEMATICAL MODEL}

\subsection{Overview}

Giroud's (et al. 1989 a, b) work on leakage through the slits in geomembranes is considered as the basis for this research. In his investigation Giroud studied leakage through a single slit in the geomembrane in a composite barrier. In the present study, Giroud's results are extended to examine transient flow through an unsaturated clay barrier with geomembrane damaged by multiple slits.

The composite barrier with a geomembrane slit and the moving wetting front is presented in Figures 3.1 and 3.2, respectively. The liquid on top of the clay barrier enters into the boundary conditions of the problem. If there is no geomembrane, the boundary condition at the top of the soil profile is $\Psi=\mathrm{h}_{\mathrm{v}}$ for all point on the surface. The analyses is carried out using finite element method which takes into account barriers with different type, size and number of slits in the geomembrane.

\subsection{Mathematical Model of Flow Through Geomembrane Slits}

To be able to calculate the leakage and the progressive movement of the wetting front through composite barrier, it is necessary to understand the behavior of the flow through the geomembrane slit. The results of Giroud et al. (1989 a, b) give us the variable boundary condition on top of the geomembrane as shown in Figure 3.2. The presence of more than one slit in the geomembrane and the resulting overlap of the wetting fronts is the main focus of this work. The initial conditions necessary to analyze flow through the composite barrier can be obtained from the conditions under which the composite barrier was constructed. 


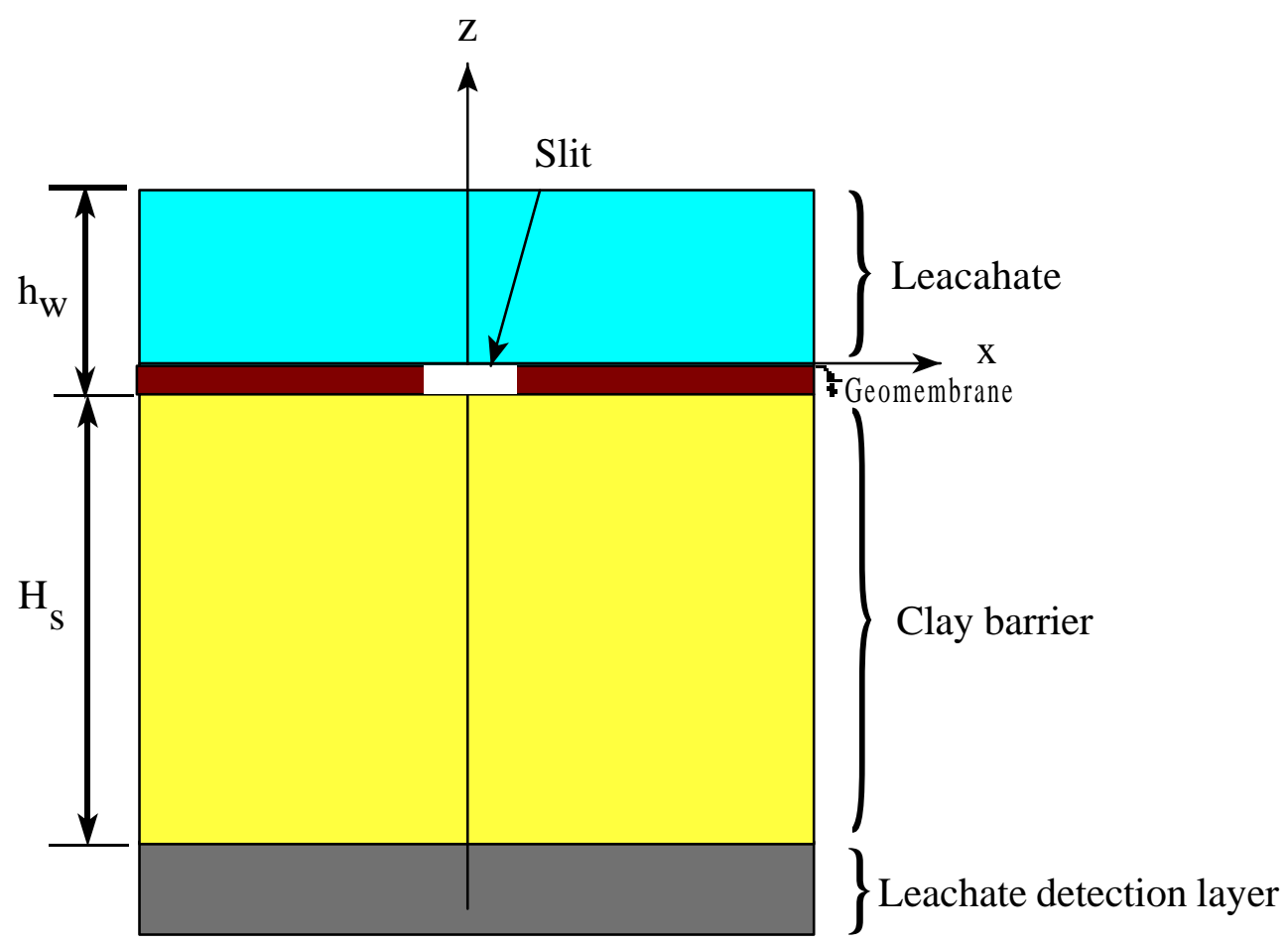

Figure 3.1 Composite barrier with a damaged geomembrane

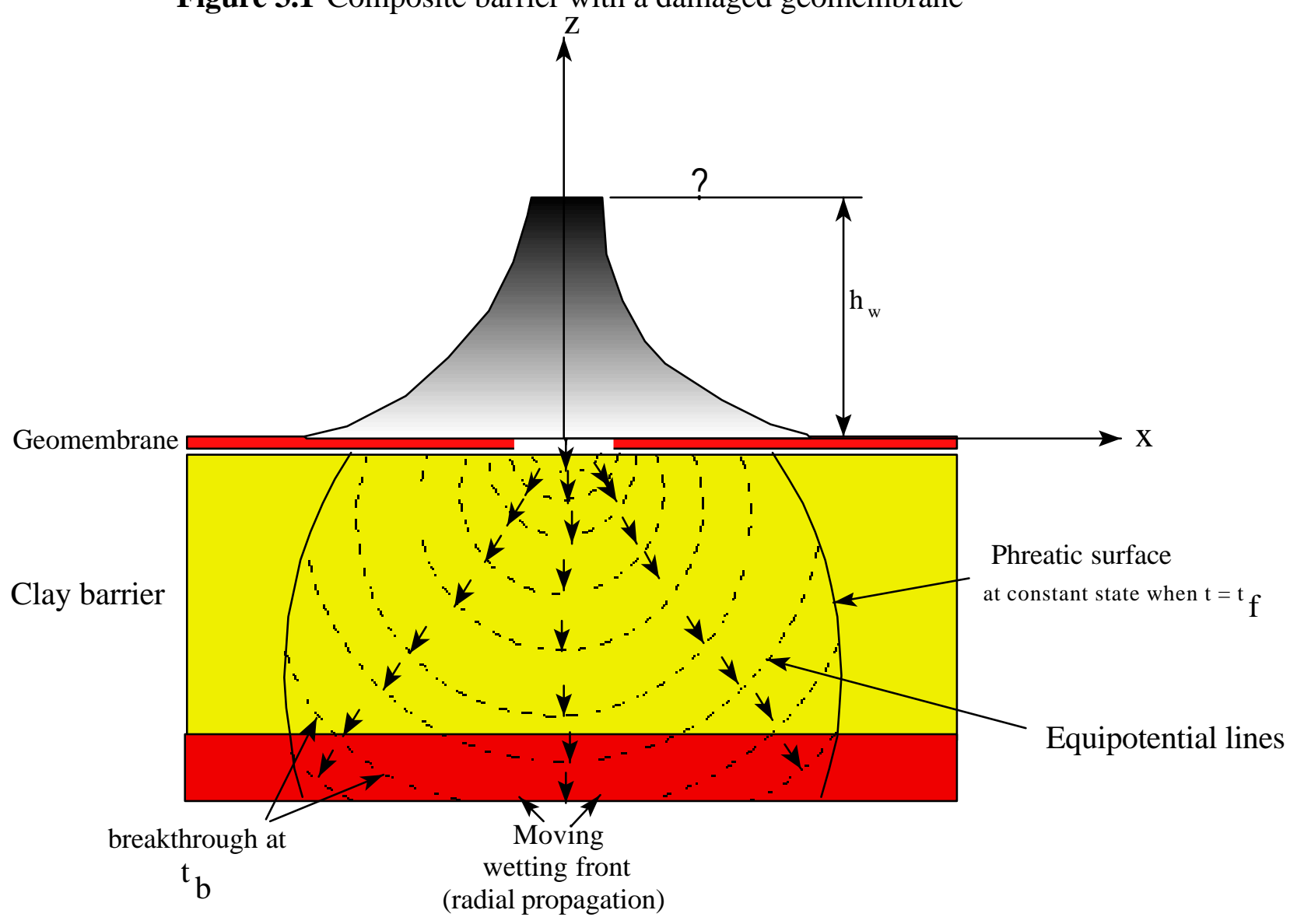

Figure 3.2 Moving wetting front for the composite barrier with a damaged geomembrane 
According to experimental studies, (See Giroud and Bonaparte 1989) the head of liquid on top of the soil corresponding to a single slit decreases progressively from a maximum value $\left(h_{\mathrm{v}}\right)$ over the slit itself to zero at the edge of the wetting area (Figure $3.3 \mathrm{a}$ ). The top of the soil barrier is a reference level for the pressure head. The origin of the $\mathrm{x}$-axis, perpendicular to the slit, is on the soil surface at the center of the slit. $\mathrm{R}$ is the width of the wetting area, $\mathrm{R}_{0}$ is the width of the slit in geomembrane, and $h_{w}$ is pressure head on top of the soil layer (Figure $3.3 \mathrm{~b}$ ). The relationship between the head of liquid $\mathrm{h}(\mathrm{x})$ and the distance $(\mathrm{x})$ form the center of the slit is given by Equation 3.1 .

$h(x)=\left\{\begin{array}{lll}h_{w} & \text { if } & |x| \leq R_{0} \\ h_{w} \frac{\left[\ln \left(\frac{R}{x}\right)\right]}{\ln \left(\frac{R}{R_{0}}\right)} \text { if } & |x| \geq R_{0}\end{array}\right.$

The empirical width of wetting area obtained by Giroud and Bonaparte (1989 a, b) for various slits and contact conditions is as follows:

1. Poor contact:

$\mathrm{R}=0.61 \mathrm{R}_{0}^{0.1} \mathrm{~h}_{\mathrm{w}}^{0.45} \mathrm{~K}_{0}^{-0.13}$

2. Good contact:

$\mathrm{R}=0.26 \mathrm{R}_{0}^{0.1} \mathrm{~h}_{\mathrm{w}}^{0.45} \mathrm{~K}_{0}^{-0.13}$

where $\mathrm{K}_{0}$ is the hydraulic conductivity of the saturated soil. 


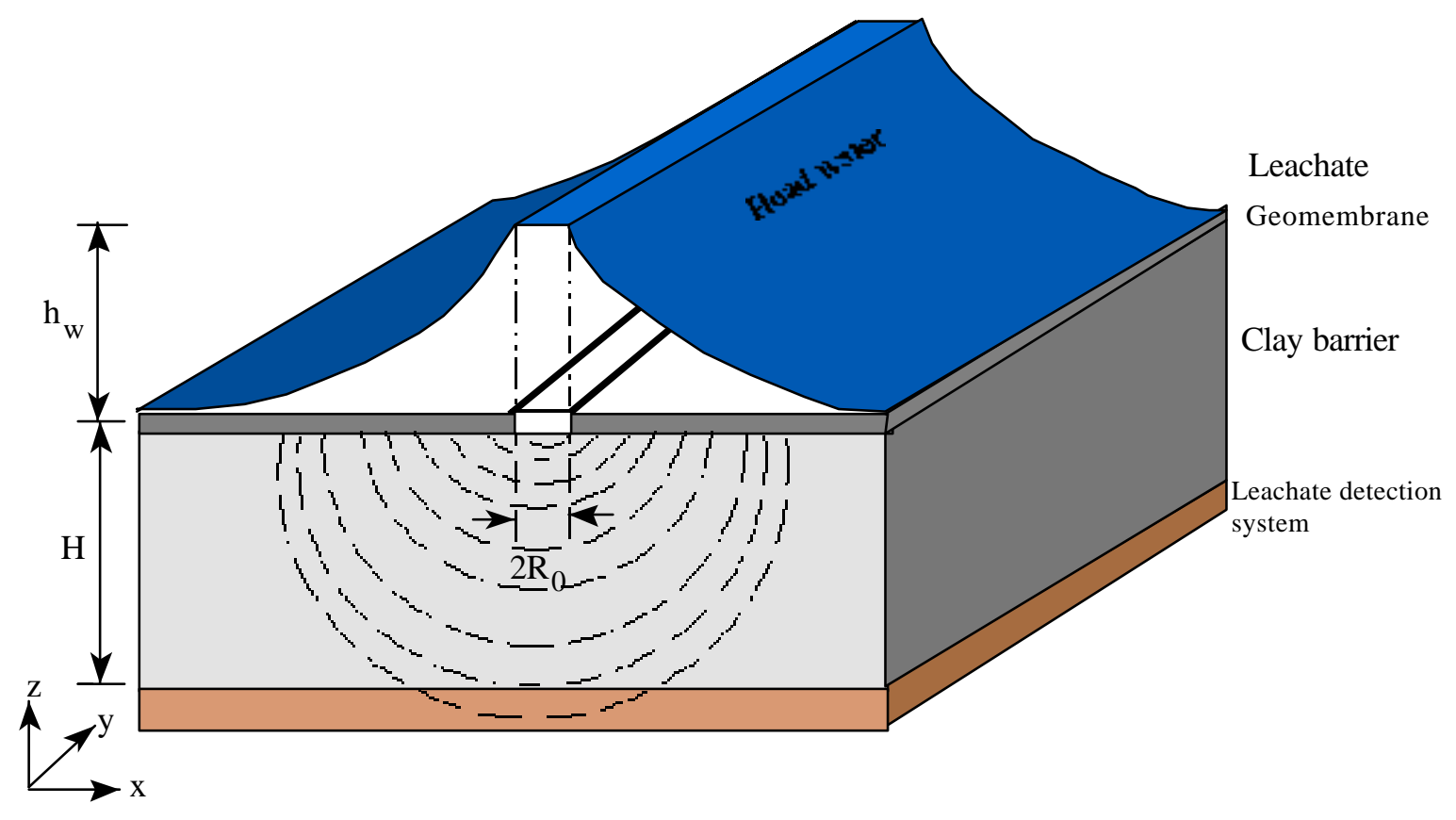

a) Giroud's analysis

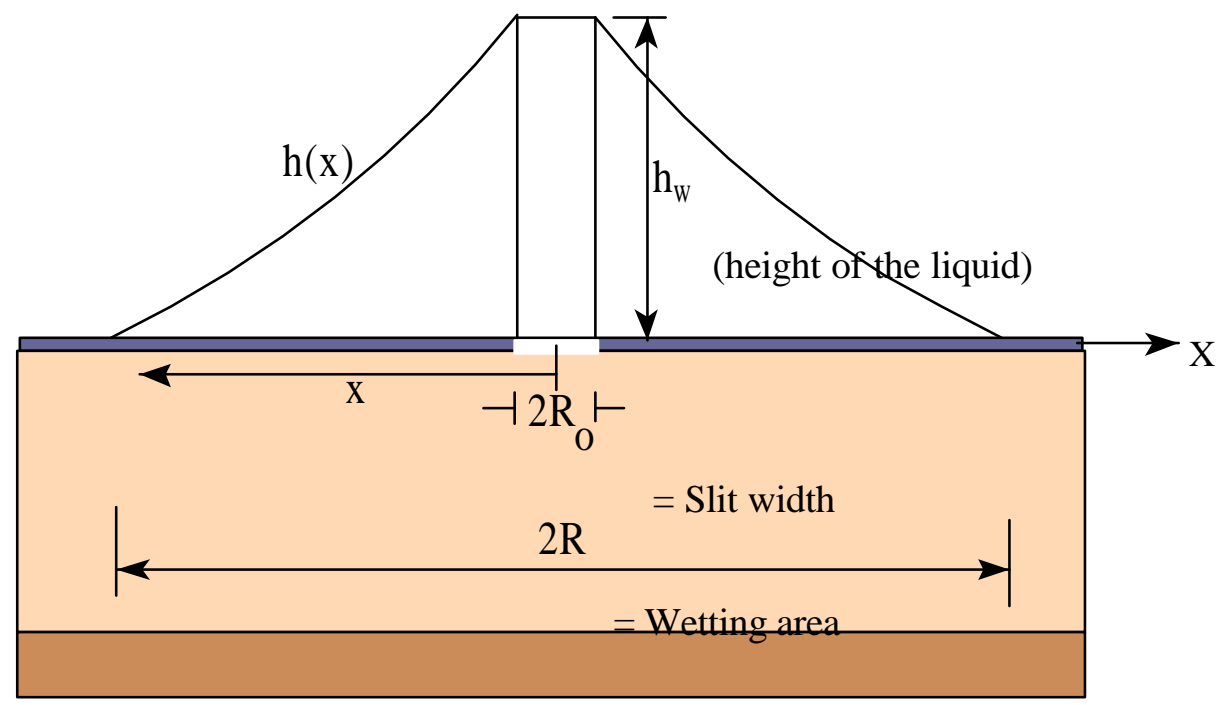

b) 2-D cross-section

Figure 3.3 Distribution of leachate head on top of the soil 
We analyze a nonstationary flow through a soil profile shown in Figure 3.4.

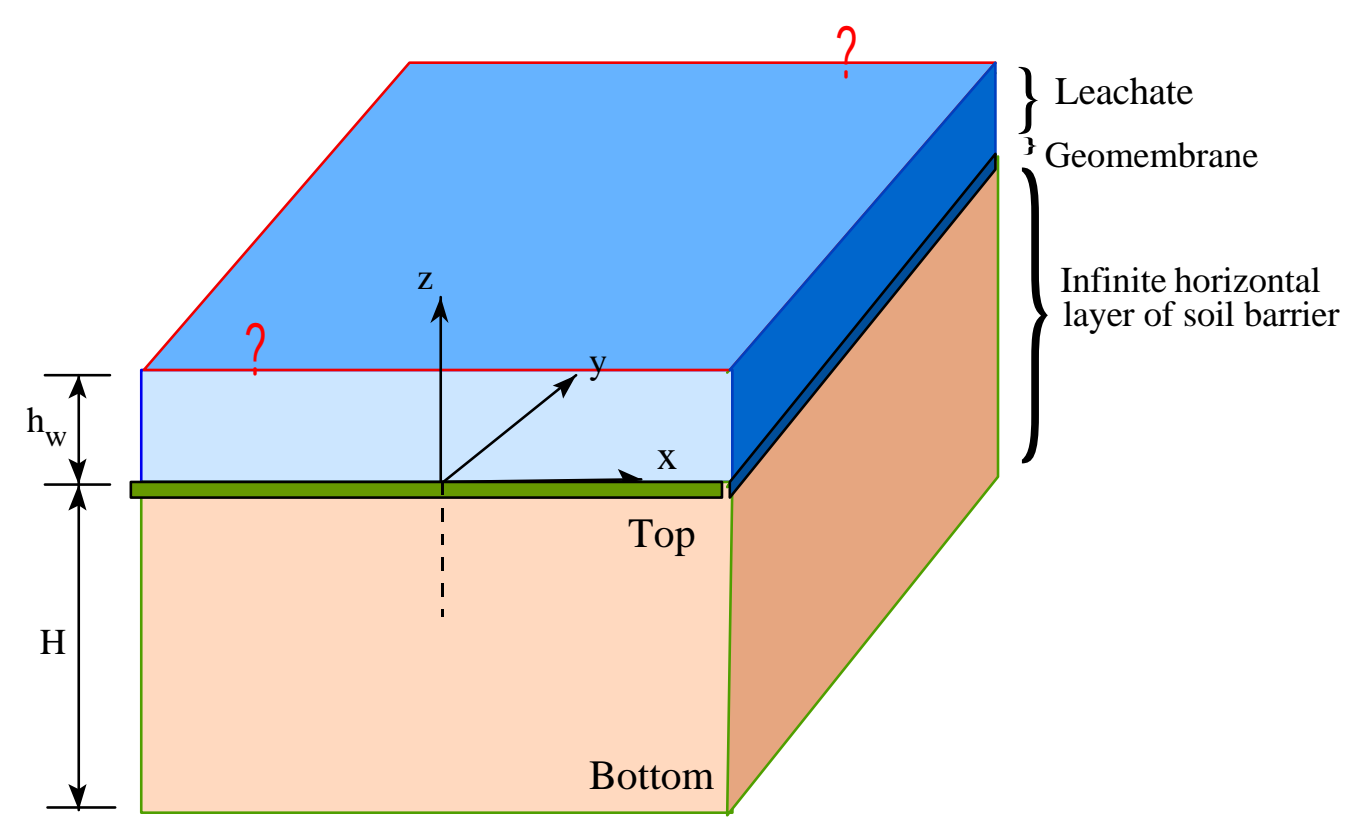

Figure 3.4 Infinite horizontal composite barrier

The Richards equation governing the flow through an unsaturated soil is,

$$
\frac{\partial}{\partial x}\left(K(\psi) \frac{\partial \psi}{\partial x}\right)+\frac{\partial}{\partial y}\left(K(\psi) \frac{\partial \psi}{\partial y}\right)+\frac{\partial}{\partial z}\left(K(\psi)\left(\frac{\partial \psi}{\partial z}+1\right)\right)=C(\psi) \frac{\partial \psi}{\partial t}
$$

where $\psi$ is the pressure head, $\mathrm{K}(\psi)$ is the unsaturated hydraulic conductivity and $\mathrm{C}(\psi)$ is the specific moisture capacity. The qualitative behavior of $\mathrm{K}(\psi)$ is shown in Figure 3.5. 


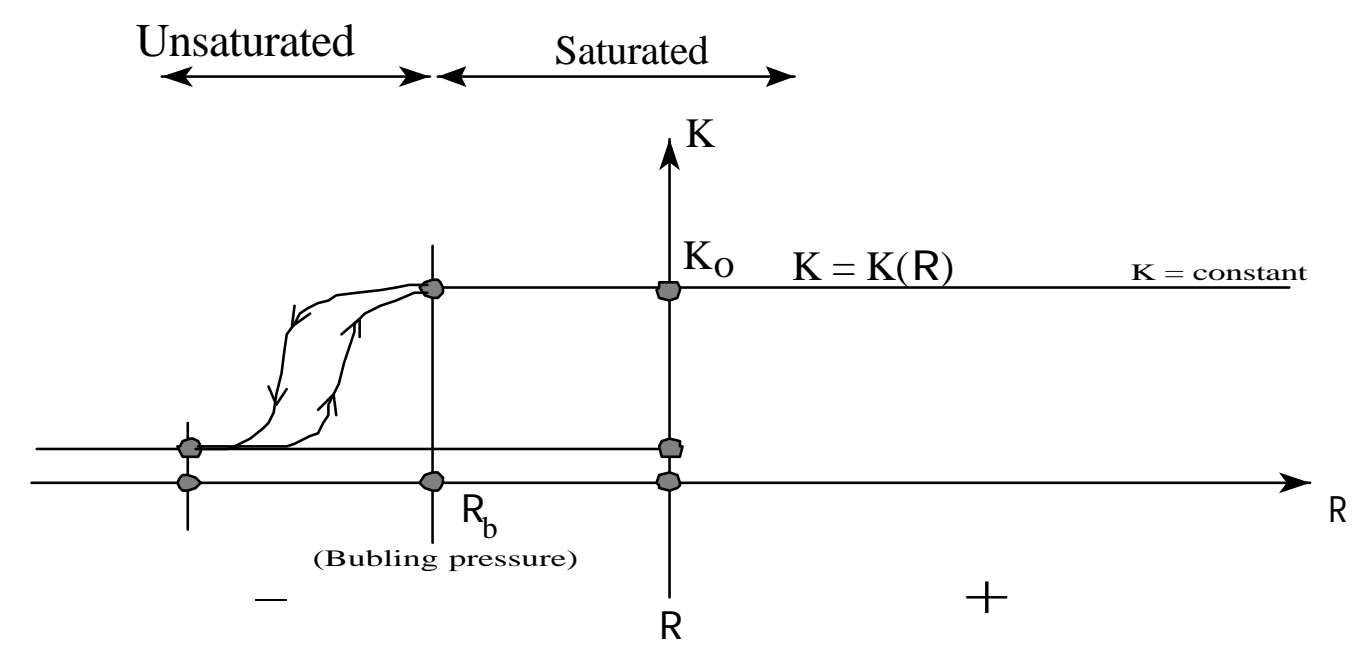

Figure 3.5 Hydraulic conductivity (K) versus pressure head (R) (Freeze and Cherry 1979)

The volumetric moisture content, $\theta(\psi)$ is defined as the volume of the water divided by the volume of at the containing it soil $\mathrm{V}_{\mathrm{w}} / \mathrm{V}_{\mathrm{s}}$. A typical hysteretic relationship between $\theta$ and $\psi$ for a sandy soil is shown in Figure 3.6. The slope of this characteristic curve represents the specific moisture capacity and is defined as $C(\psi)=d \theta / d \psi$. For fine-grained soils, pressure head $\psi$ is slightly larger than the air entry pressure head, $\psi_{\mathrm{a}}$. The corresponding pressure, $\mathrm{p}_{\mathrm{a}}$, is called the air entry pressure or the bubbling pressure. As an example, a typical plot of the soil-retention curve based on Mualem's model is given in Figure 3.7.

In the saturated soil the hydraulic conductivity, $\mathrm{K}$ and porosity $\theta$ are constant parameters. In the unsaturated zone these parameters become function of the $\psi$. The qualitative dependence of $\mathrm{K}$ on $\theta$ is shown in Figure 3.8. 


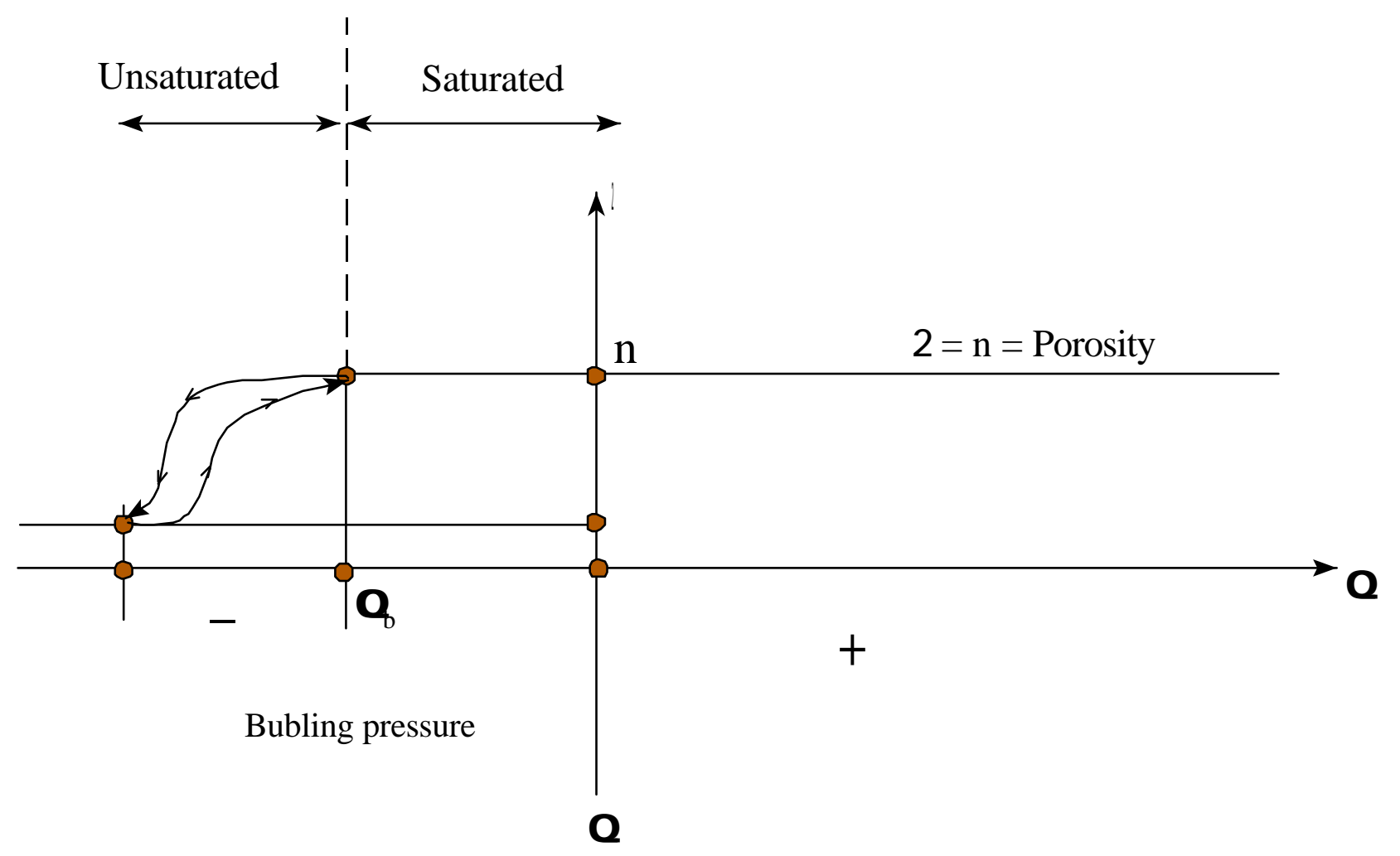

Figure 3.6 Characteristic curves of volumetric moisture content (2) versus pressure head (R) (Freeze and Cherry 1979) 


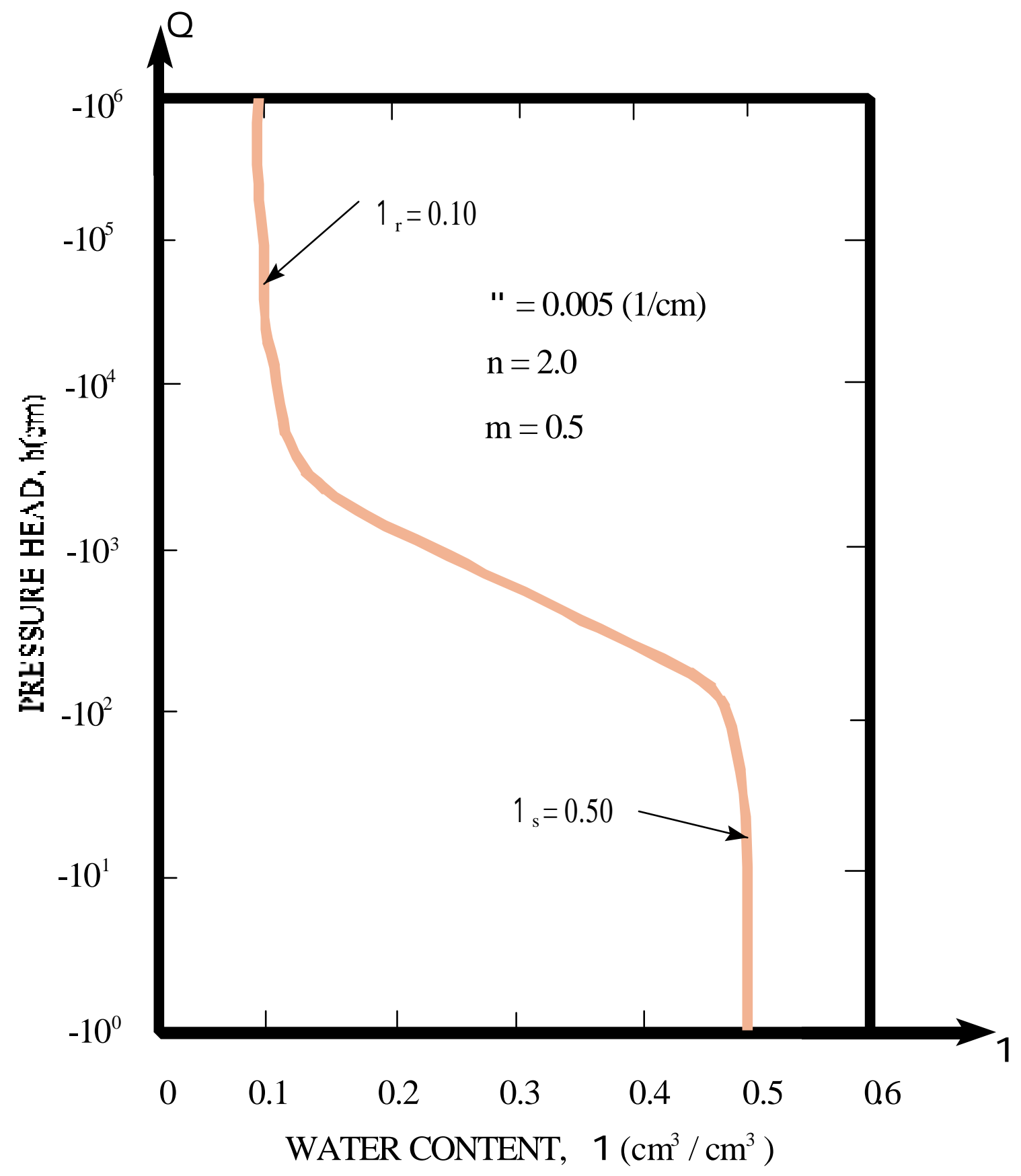

Figure 3.7 Typical plot of the soil-retention curve based on Mualem's model (Mualem, 1976) 


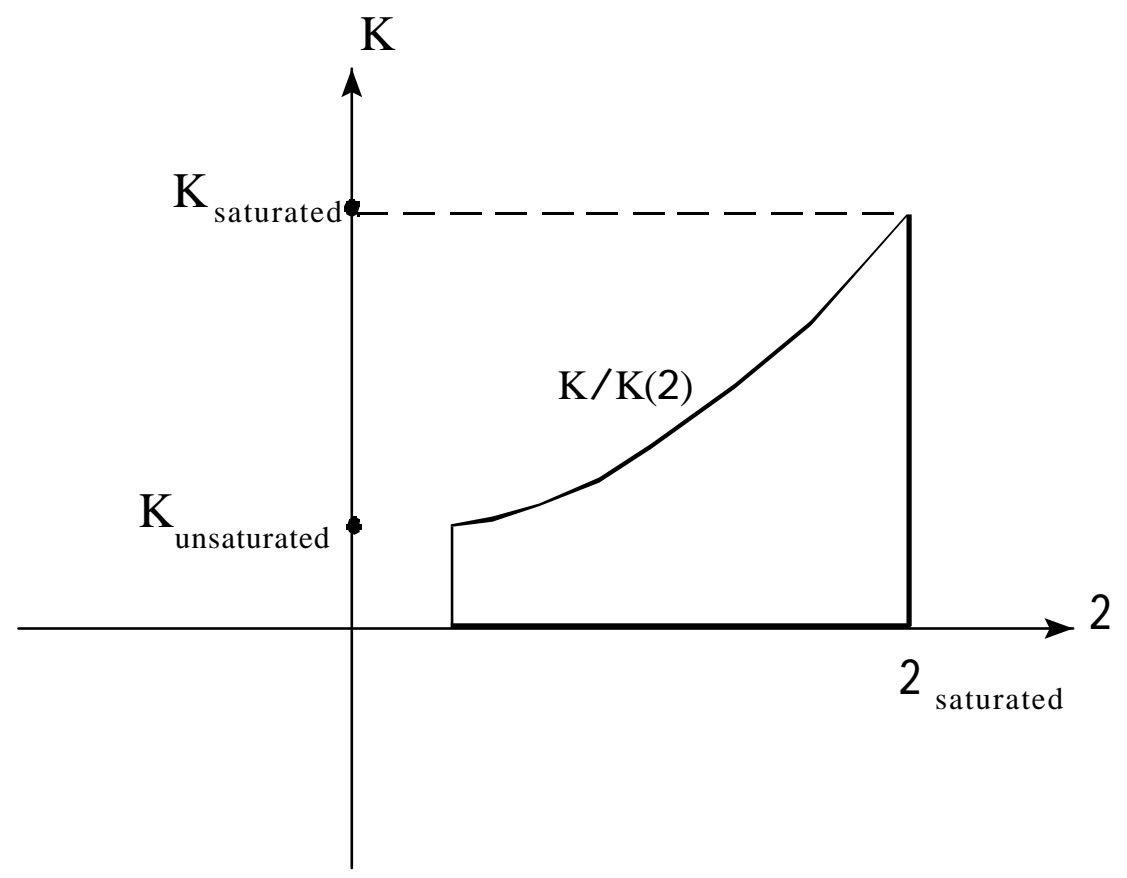

Figure 3.8 Relationship between hydraulic conductivity (K) and volumetric moisture content (2) (Philip 1969)

The Richards' equation (Richards 1931) represents the principle of conservation of mass for the fluid flow in a porous medium. The functions $\mathrm{K}(\psi)$ and $\theta(\psi)$ are determined empirically for each kind of soil. In this work, van Genuchten's (1980) equations are used to determine K( $\psi$ ) and $\theta(\psi)$. Based on the van Genuchten model (Mualem, 1976),

$$
K(\psi)=K_{0} \frac{1-(\alpha \psi)^{n-2}\left[1+(\alpha \psi)^{n}\right]^{-m}}{\left[1+(\alpha \psi)^{n}\right]^{2 m}}
$$




$\theta(\psi)=\theta_{x}+\frac{\left(\theta_{s}-\theta_{r}\right)^{m}}{\left[1+(\alpha \psi)^{n}\right]}$

$C(\psi)=\frac{d \theta}{d \psi}(\psi)=-m\left[\frac{1}{1+(\alpha \psi)^{n}}\right]^{m-1} \frac{-n \alpha(\alpha \psi)^{n-1} \alpha}{\left[1+(\alpha \psi)^{n}\right]^{2}}$

where $\theta_{\mathrm{r}}$ and $\theta_{\mathrm{s}}$ are the residual and the saturated values of the volumetric water content, $\alpha$ and $\mathrm{n}$ are the shape parameters related to the air entry pressure $\mathrm{p}_{\mathrm{a}}$ and the pore size distribution of the soil, and

$$
m=1-\frac{1}{n}
$$

The values of the above parameters are presented Table 3.1 (Van Genuchten, 1980). 
Table 3.1 Physical properties of the different types of soil (van Genuchten, 1980).

\begin{tabular}{||c|c|c|c|c|c||}
\hline Soil Name & $\begin{array}{c}\theta_{\mathrm{s}} \\
\left(\mathrm{cm}^{3} / \mathrm{cm}^{3}\right)\end{array}$ & $\begin{array}{c}\theta_{\mathrm{r}} \\
\left(\mathrm{cm}^{3} / \mathrm{cm}^{3}\right)\end{array}$ & $\begin{array}{c}\mathrm{K}_{\mathrm{s}} \\
(\mathrm{cm} / \mathrm{day})\end{array}$ & $\begin{array}{c}\alpha \\
\left(\mathrm{cm}^{-1}\right)\end{array}$ & $\mathrm{n}$ \\
\hline Hygiene Sandstone & 0.25 & 0.153 & 108 & 0.0079 & 10.4 \\
\hline Touchet Silt Loam & 0.469 & 0.19 & 303 & 0.005 & 7.09 \\
\hline Silt Loam & 0.396 & 0.131 & 4.96 & $2.00 \mathrm{e}-04$ & 2.06 \\
\hline $\begin{array}{c}\text { Gualph Loam } \\
\text { (drying) }\end{array}$ & 0.52 & 0.218 & 31.6 & 0.0115 & 2.03 \\
\hline $\begin{array}{c}\text { Gualph Loam } \\
\text { (wetting) }\end{array}$ & 0.434 & 0.218 & --- & 0.02 & 2.76 \\
\hline \begin{tabular}{c} 
Belt Netofa Clay \\
\hline
\end{tabular} & 0.446 & 0 & 0.082 & 0.000500 & 1.17 \\
\hline
\end{tabular}

\subsection{Overlap of Wetting Fronts: Boundary and Initial Conditions}

If a geomembrane (with slits) rests on the top of the soil barrier, pressure head can no longer be determined from Equation 3.1 alone. An approximation must be made must to account for overlapping pressure heads corresponding to neighboring slits in the geomembrane (Figure 3.9 and 3.10). According to Giroud (1992) the wetting areas do not overlap if the distance between the slits is greater than $2 R$. If the wetting areas do overlap the pressure head from equations (3.2) and (3.3) must be added together for all points that experience the overlap. It is assumed that the geomembrane had several slits. A subroutine was written to obtain the curve $\mathrm{h}$ (x) (Equation 3.1) for every slit and to add the values of the pressure head at each point $X$. The resultant pressure head $\mathrm{h}(\mathrm{x})$ forms a boundary condition for Richards' equation for $\mathrm{z}=0$ and depends on the relative position of the slits in geomembrane. 


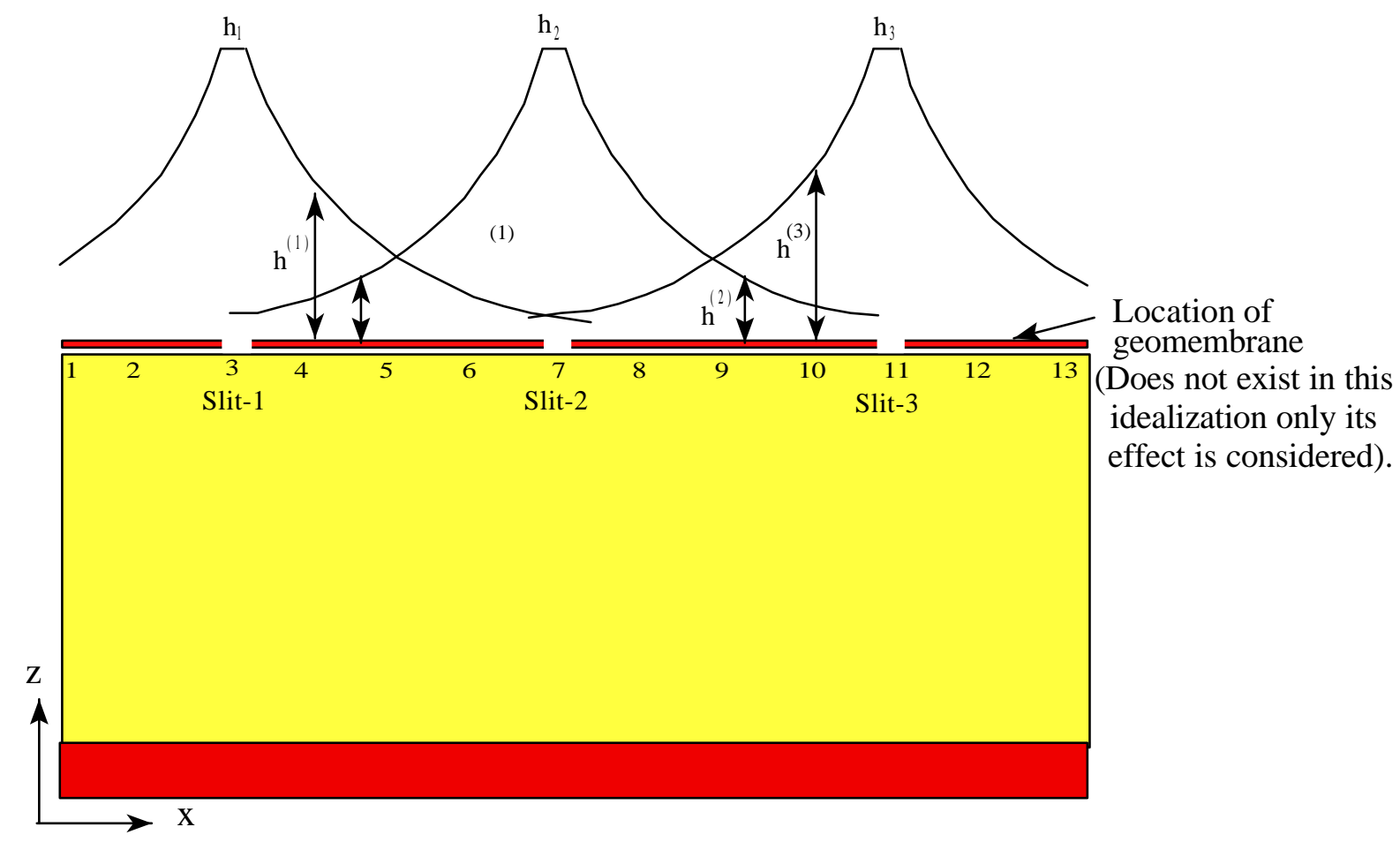

Figure 3.9 Conribution of the several holes to the pressure head $(\mathrm{R})$ distribution

For the problem of overlapping slits the Richards' equation has the form

$$
\frac{\partial}{\partial x}\left(K(\psi) \frac{\partial \psi}{\partial x}\right)+\frac{\partial}{\partial z}\left(K(\psi)\left(\frac{\partial \psi}{\partial z}+1\right)\right)=C(\psi) \frac{\partial \psi}{\partial t}
$$

where $\mathrm{R}(\mathrm{x}, \mathrm{z}, \mathrm{t})$ is a function of $\mathrm{x}, \mathrm{z}$ and $\mathrm{t}$ alone. The boundary and initial conditions for Equation (3.9) are as follows. 


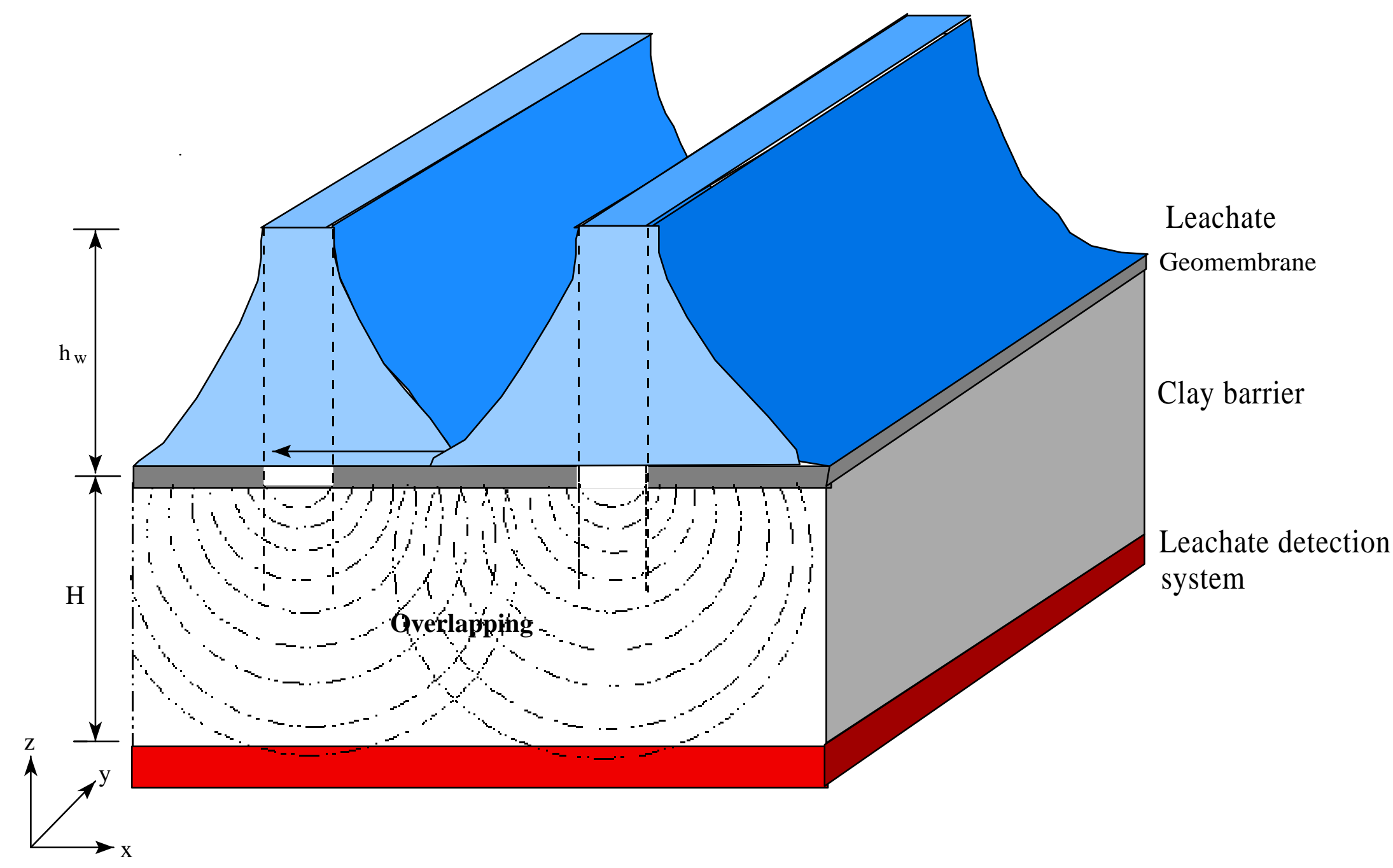

Figure 3.10 Overlap of the wetting fronts for geomembrane with several slits 


\section{Clay Liner with a Sand Layer}

Leachate with height $h_{w}$ is above the clay liner which overlays the sand layer as shown on (Figure 3.11). In this case the boundary and the initial conditions are:

$\mathrm{R}(\mathrm{x}, 0, \mathrm{t}) \equiv \mathrm{h}_{\mathrm{w}}$ for all $\mathrm{t}>0$ and $\mathrm{z}=0$,

$\mathrm{R}(\mathrm{x},-\mathrm{H}, \mathrm{t}) \equiv-\mathrm{C}$ for all $\mathrm{t}>0$ and $\mathrm{z}=-\mathrm{H}$,

$\mathrm{R}(\mathrm{x}, \mathrm{z}, 0) \equiv-\mathrm{C}$ for all $\mathrm{t}=0$ (initial condition).

The value of $\mathrm{C}$ was assumed to be $\mathrm{C}=75 \mathrm{~cm}$.

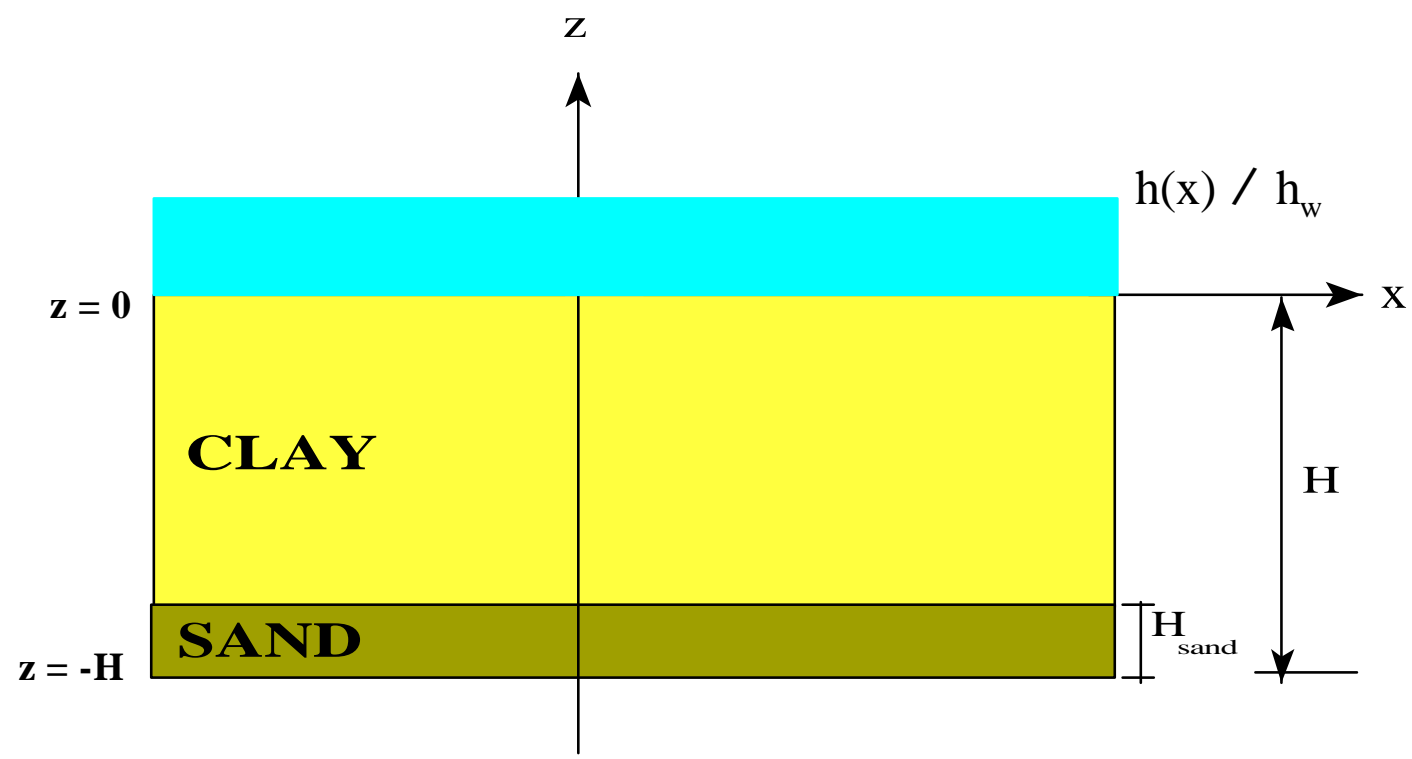

Figure 3.11 Clay liner with sand layer 


\section{Geomembrane Below the Sand Layer}

If the geomembrane with no defect is placed below the sand layer then the boundary conditions are (Figure 3.12) :

$R(x, 0, t)=h_{w}$ for all $t>0$ and $z=0$,

$\mathrm{q}=\mathrm{K}(\partial \mathrm{R} / \partial \mathrm{z}+1)$ for all $\mathrm{t}>0$ and $\mathrm{z}=-\mathrm{H}$,

and the initial condition is:

$R(x, z, 0)=-C=-75 \mathrm{~cm}$.

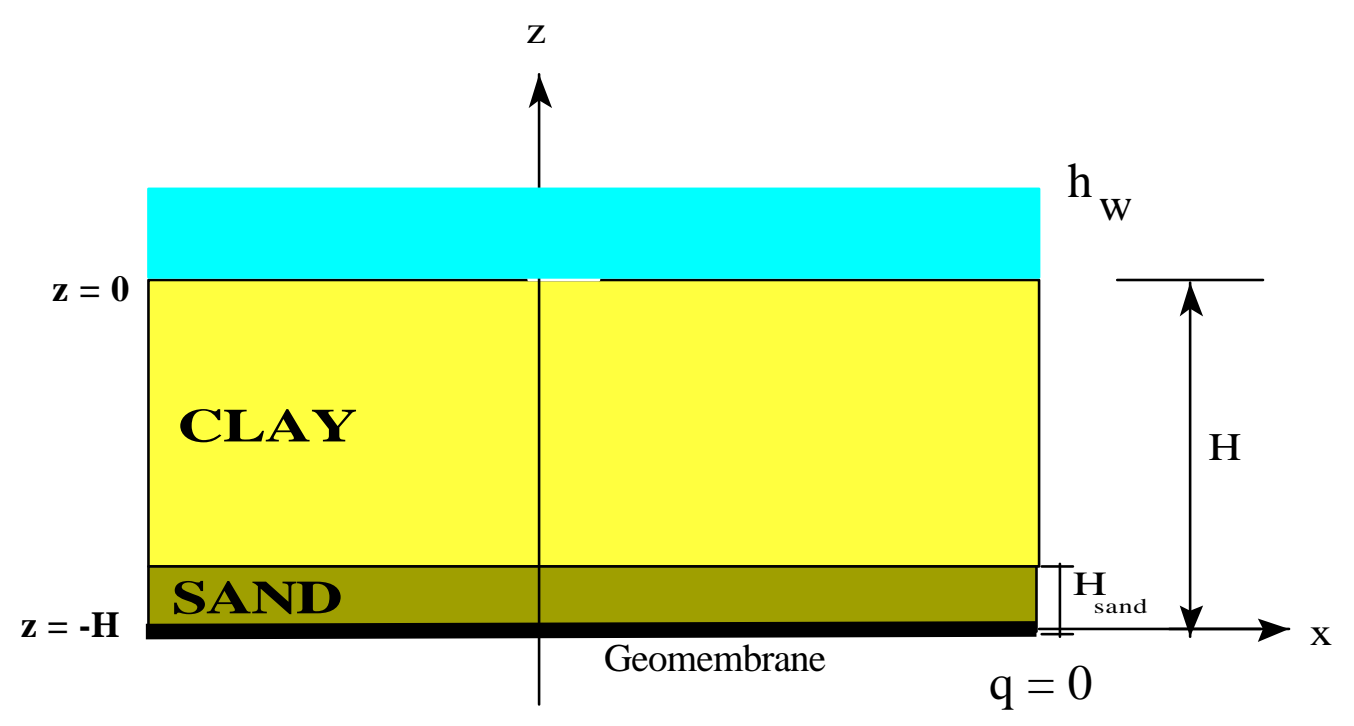

Figure 3.12 Geomembrane below the sand layer 


\section{Groundwater Table at the Bottom of the Sand Layer}

If the groundwater table is placed at the bottom of the sand layer then (Figure 3.13), the boundary conditions are:

$\mathrm{R}(\mathrm{x}, 0, \mathrm{t})=\mathrm{h}(\mathrm{x}) \quad$ for all $\mathrm{t}>0$ and $\mathrm{z}=0$,

$\mathrm{R}(\mathrm{x},-\mathrm{H}, \mathrm{t})=0$ for all $\mathrm{t}>0$ and $\mathrm{z}=-\mathrm{H}$,

and the initial condition is:

$R(x, z, 0)=-C=-75 \mathrm{~cm}$.

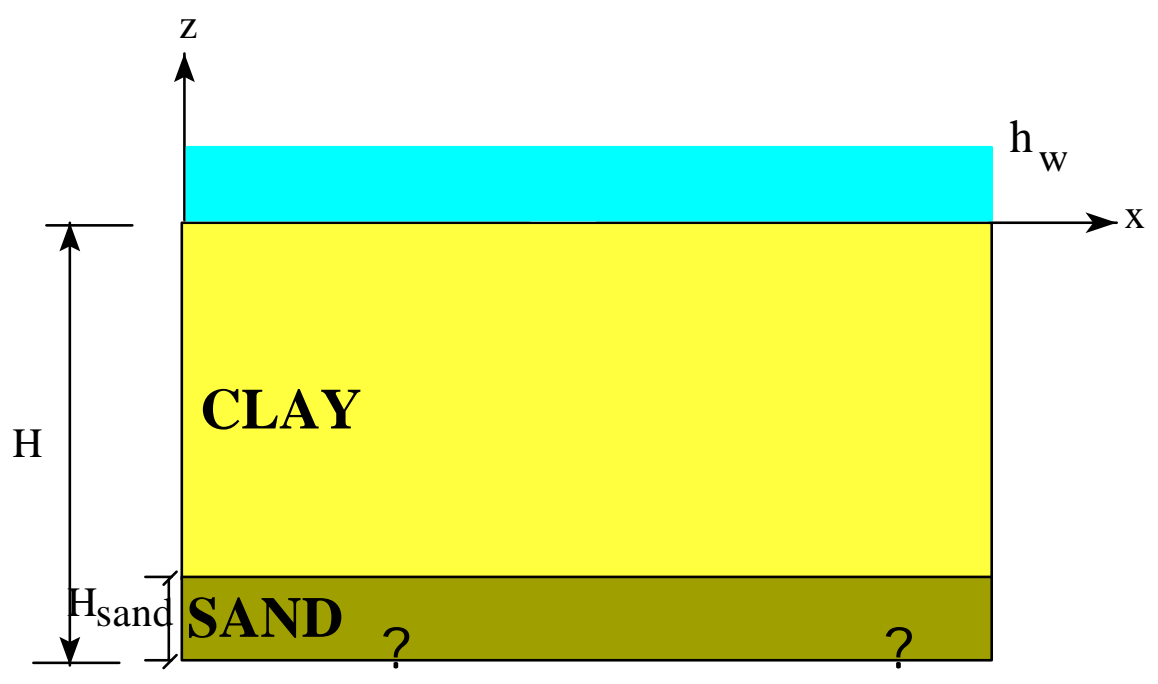

Figure 3.13 Groundwater table at the bottom of the sand layer 


\section{Groundwater Table within the Clay Barrier}

If the groundwater table is within clay barrier then (Figure 3.14), the boundary conditions are:

$\mathrm{R}(\mathrm{x}, 0, \mathrm{t}) \equiv \mathrm{h}(\mathrm{x})$ for all $\mathrm{t}>0$ and $\mathrm{z}=0$,

$\mathrm{R}\left(\mathrm{x},-\mathrm{H}_{\mathrm{w}}, \mathrm{t}\right) \equiv \mathrm{C} \quad$ for all $\mathrm{t}>0$ and $\mathrm{z}=-\mathrm{H}_{\mathrm{w}}$,

and the initial condition is:

$\mathrm{R}(\mathrm{x}, \mathrm{z}, 0) \equiv-\mathrm{C}=75 \mathrm{~cm}$.

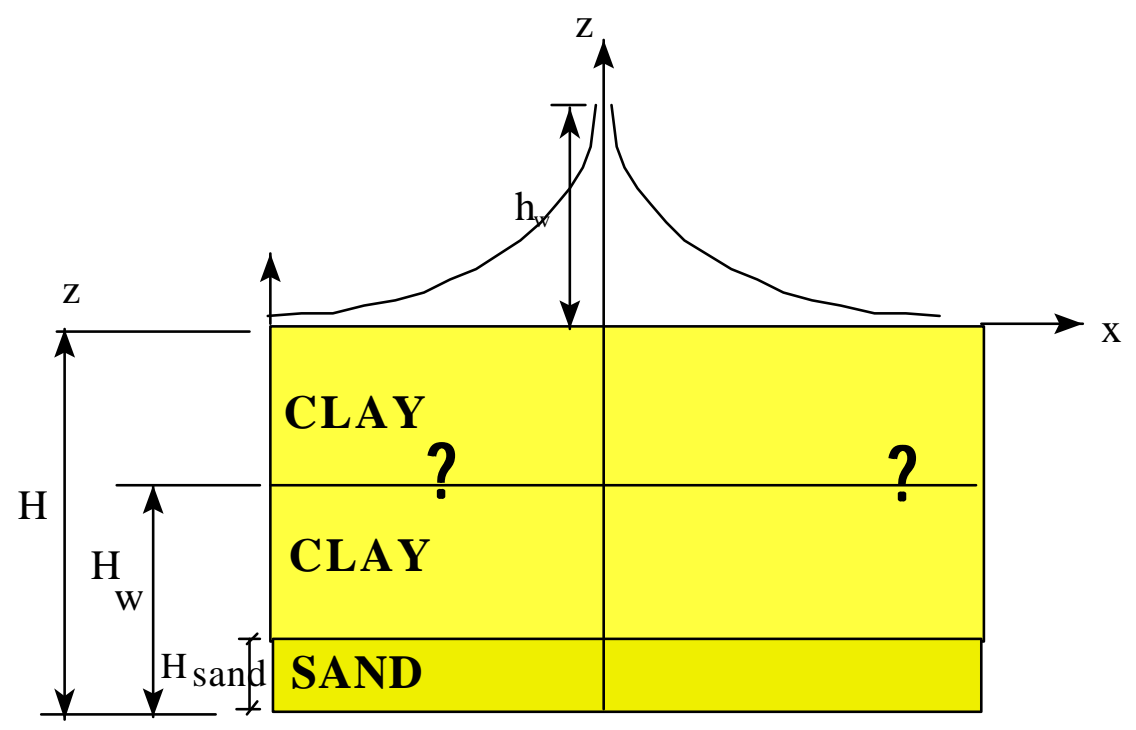

Figure 3.14 Groundwater table within the clay barrier

The appropriate hydraulic conductivity and specific moisture capacity parameters are chosen according to Van Genunchten model. 


\subsection{Assembly of Computer Code}

In this section, a description of the computer program is presented. The main elements of this work that must be coupled in order to develop the numerical procedure are Richards' equation and the results of Giroud's experimental work. The parabolic partial differential equation characterizing fluid flow in unsaturated porous media, is generated by Darcy's law and the continuity equation (Philip, 1969). The two-dimensional form of the equation for groundwater flow through unsaturated soil is described by Equation 3.9 in Section 3.3.

The solution of this equation is carried out by the finite element method. Mathematical details of the finite element formulation can be found in the literature (Bear, 1979; Istok, 1989). The scheme used to descritize the problem is presented in Figure 3.15. A summarized flow chart of the COMPBAR computer program is presented in Figure 3.16. A listing of the computer program is given in Appendix A.

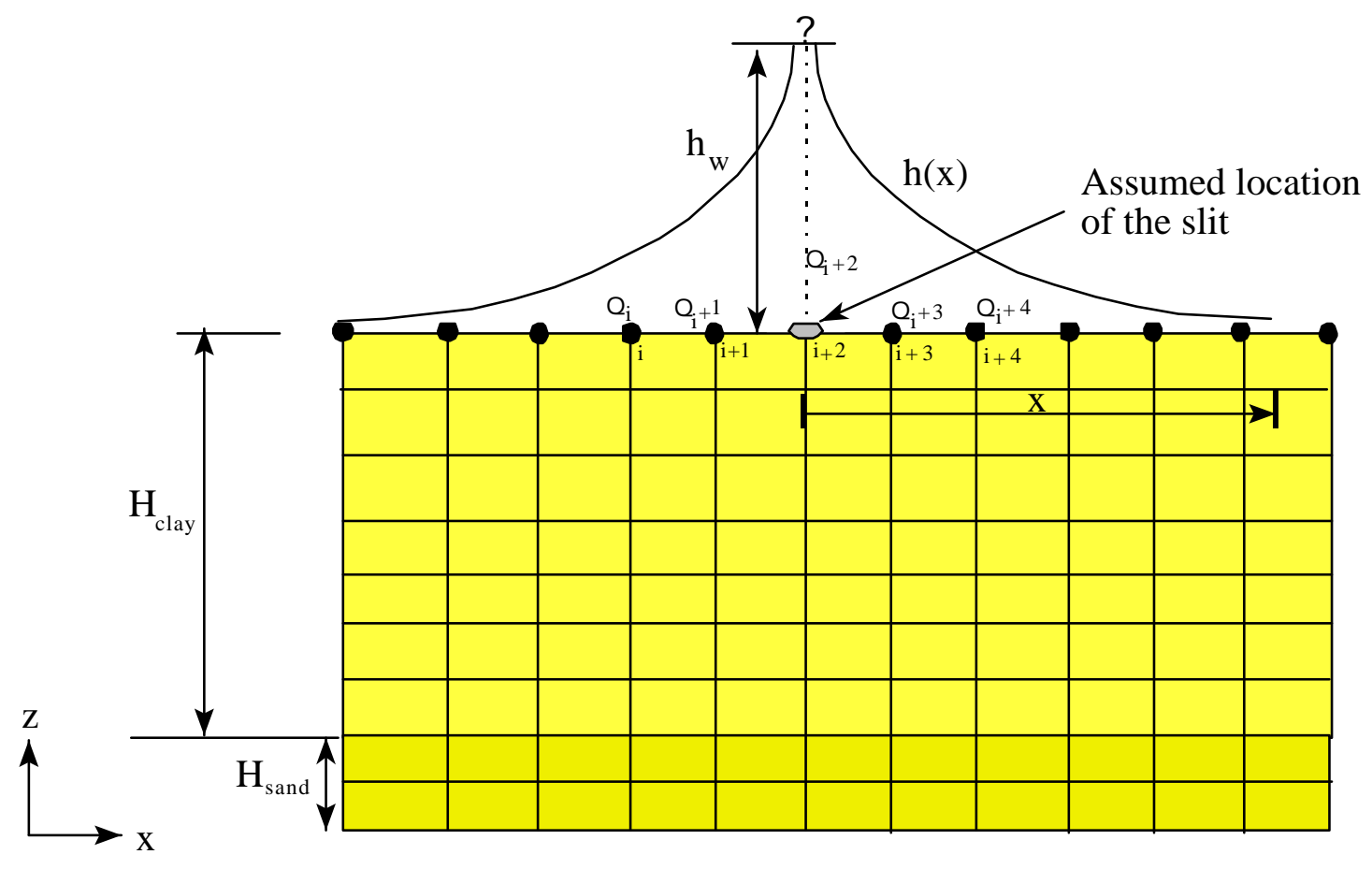

Figure 3.15 Finite element discrezation of the flow through a geomembrane slit 
Program COMPBAR

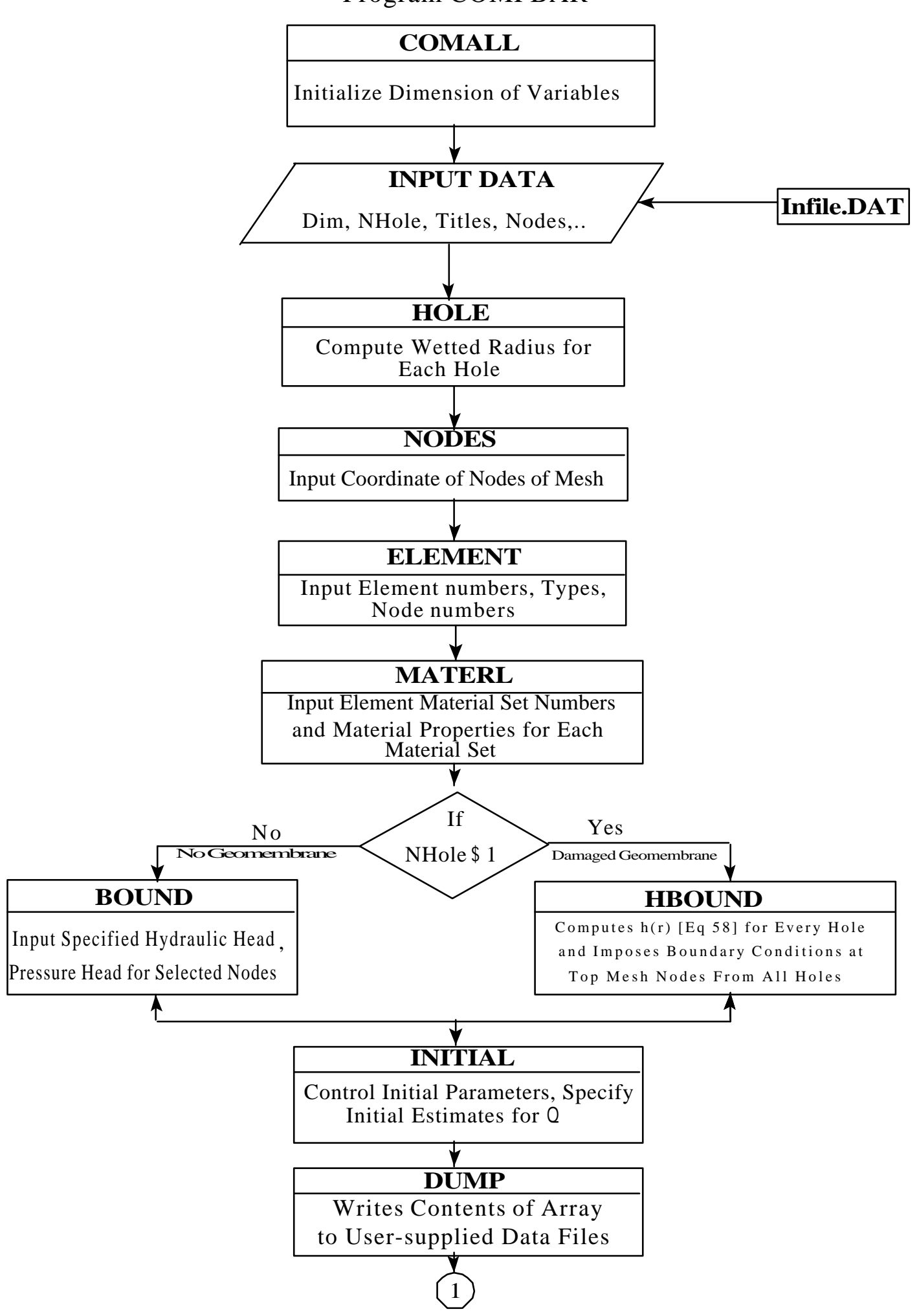




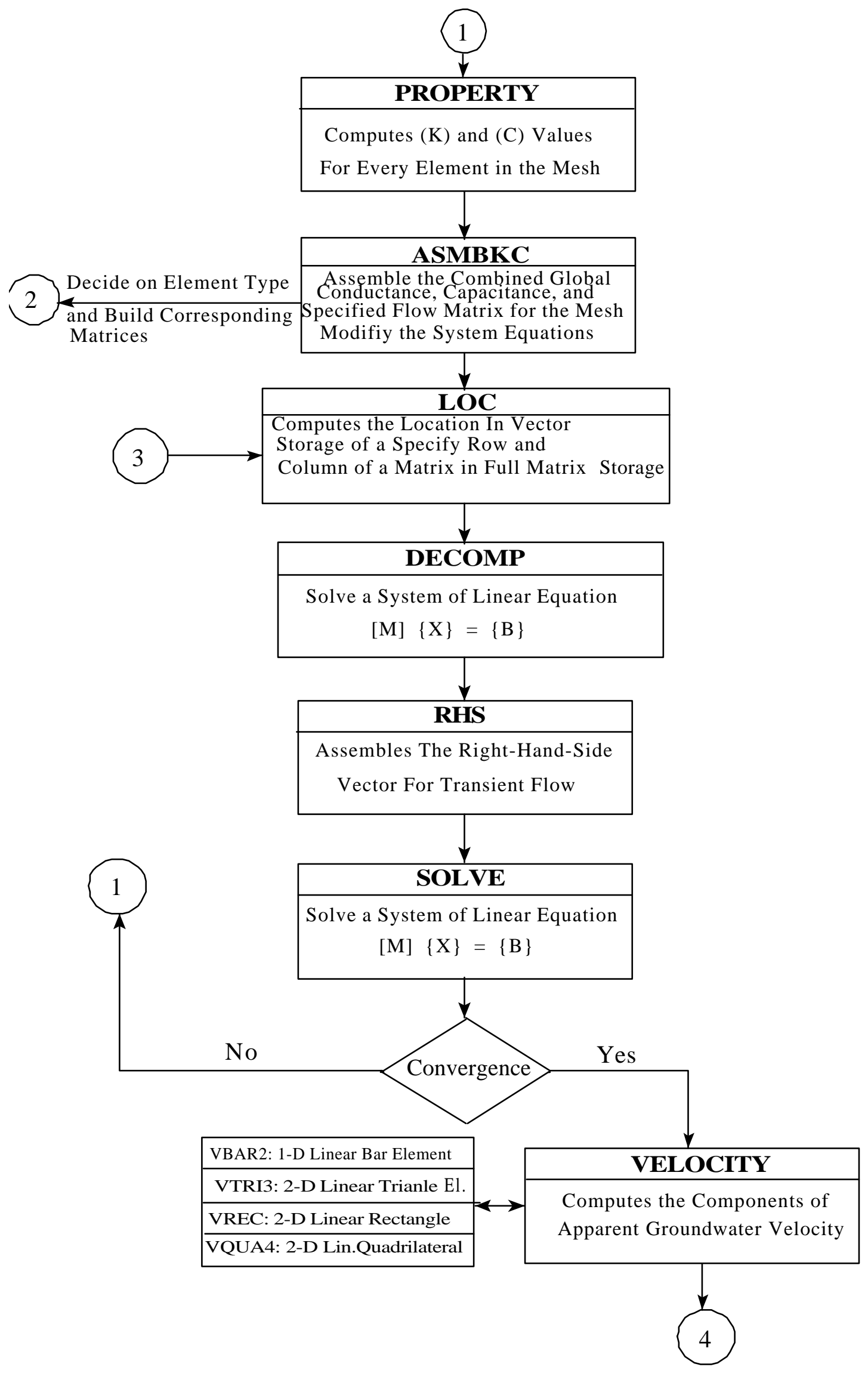




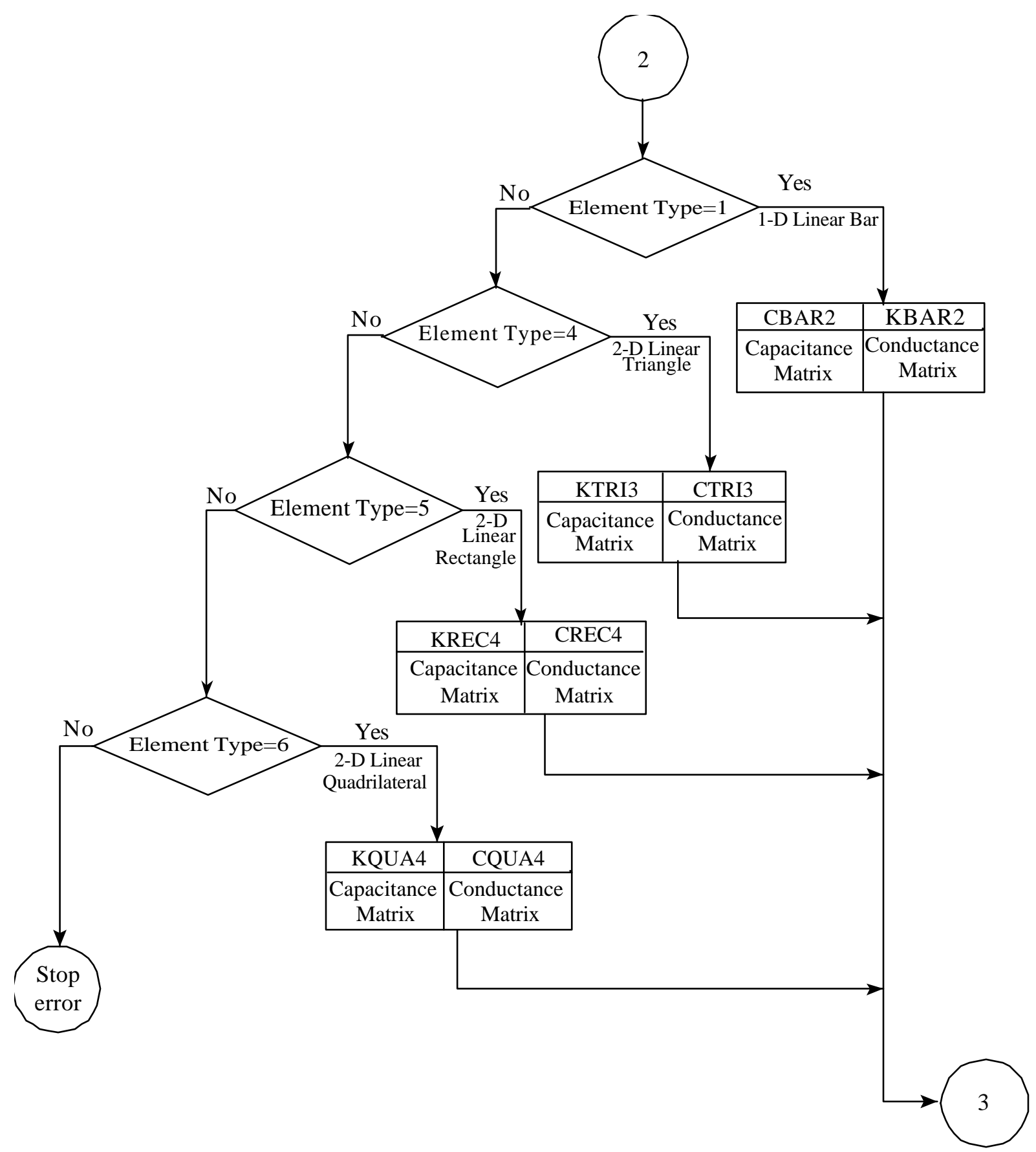




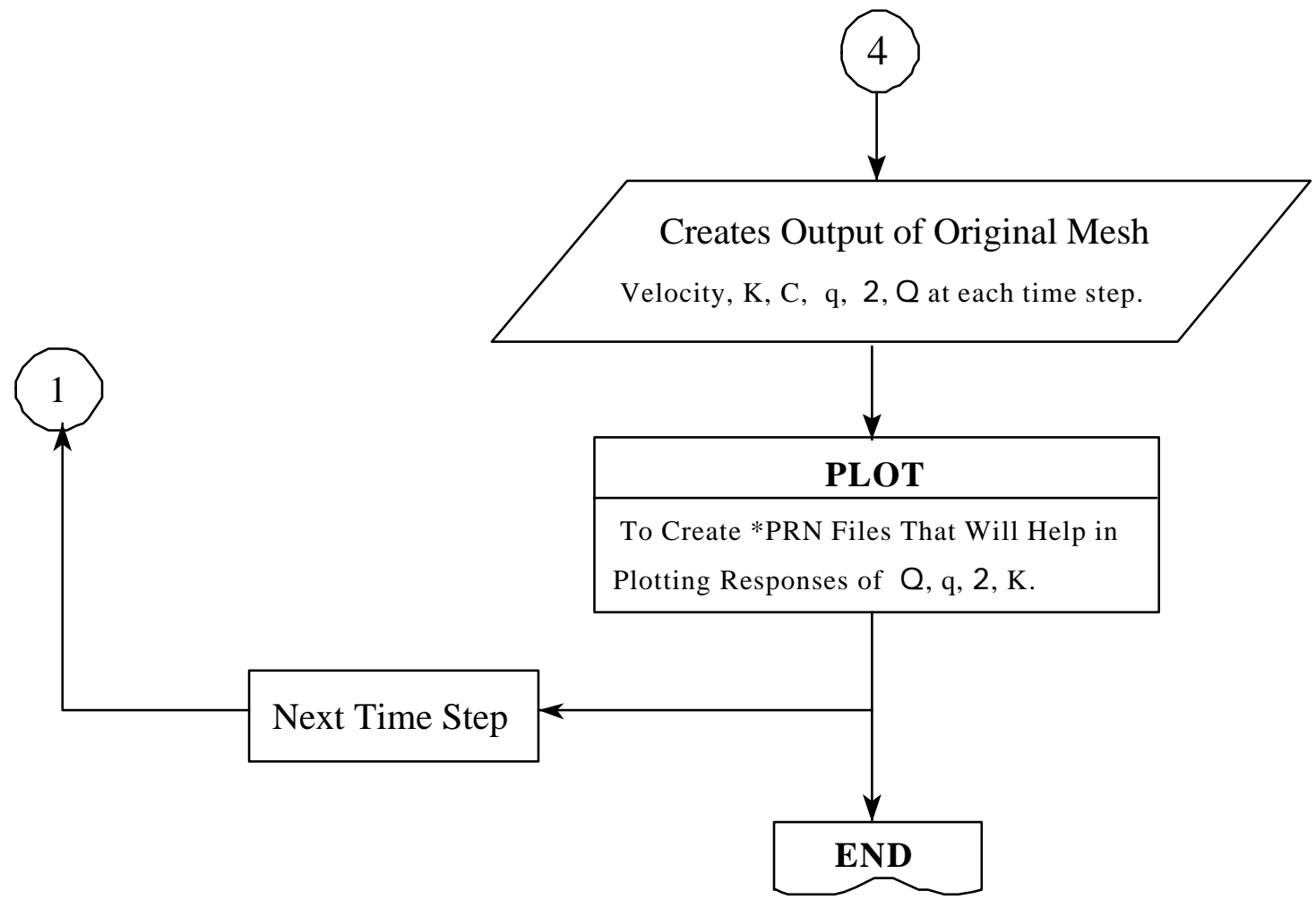

Figure 3.16 Flow chart of COMPBAR computer program

\subsection{Evaluation of the Accuracy of the Code}

As a verification for the model developed in this work results from the numerical programs SOILINER and SEEP are used. Giroud et al. (1989 a, b) established two empirical equations for the calculation of the flow rate as given in Equation 2.1 and 2.2 in Chapter 2. Once the flow rate $(\mathrm{Q})$ is computed for a soil profile using these equations, then the time required for the liquid to migrate through a certain depth can be predicted as the follows: 
$\mathrm{Q}=\mathrm{k}$ i A, $\quad \mathrm{v}=\mathrm{Q} / \mathrm{A}, \quad \mathrm{t}=\mathrm{s} / \mathrm{v}, \quad$ and $\quad \mathrm{A}=\mathrm{B} \times 1=30 \times 1=30 \mathrm{~m}^{2}$,

where $\mathrm{k}$ is the hydraulic conductivity, $\mathrm{i}$ is the hydraulic gradient, $\mathrm{A}$ is the area of the cross section of flow, $\mathrm{B}$ is the width of the cross section of flow, $\mathrm{v}$ is the Darcy velocity, $\mathrm{t}$ is time, $\mathrm{s}$ is the thickness of the soil profile. The calculation of the overall flow rate (Q) from the empirical equations and the exact flow rate through the depth determined by COMPBAR is given in Table 4.9 in Chapter 4.

\subsubsection{SOILINER Hypothetical Case}

To evaluate the accuracy of the COMPBAR program, the same example as presented in the SOILINER manual (Example 1) was calculated using COMPBAR. A sketch for this example is presented in Figure 3.17. The comparison of both calculations is presented in Chapter 4.

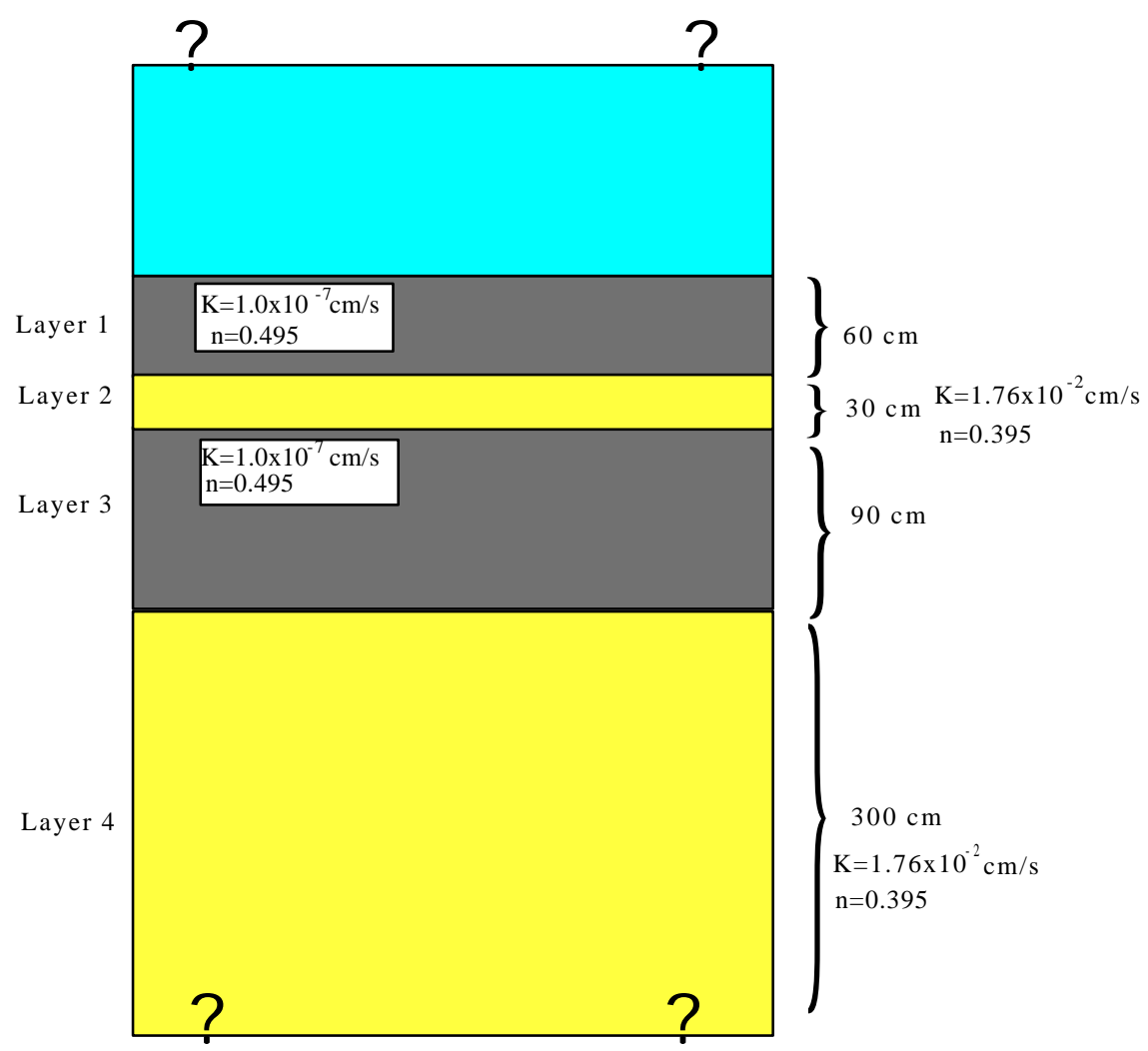

Figure 3.17 A two liner systems as simulated with SOILINER and COMPBAR (after Goode, 1986) 


\subsection{Parametric Analyses}

Twenty different cases of a composite barrier (Figure 3.18) with a damaged geomembrane were considered. In all of these examples the initial volumetric moisture content $\left(\theta_{\mathrm{i}}\right)$ in the soil barrier was assumed constant and the value of the pressure head $(\psi)$ at top of the geomembrane was taken as $-75 \mathrm{~cm}$. The following assumptions were also made:

1) The geomembrane is $1 \mathrm{~mm}$ (40 mils) thick, with one or five slits having a width $\left(\mathrm{R}_{0}\right)$ of 1.0 to $4.5 \mathrm{~cm}$.

2) The average liquid depth at the top of the geomembrane is $30 \mathrm{~cm}$. The liquid is assumed to be water.

3) The thickness $(\mathrm{H})$ of the clay barrier beneath the geomembrane is $90 \mathrm{~cm}$ and its hydraulic conductivity is $\mathrm{K}_{\mathrm{s}}=1.0 \times 10^{-7} \mathrm{~cm} / \mathrm{sec}$.

4) The liquid detection system is constructed from a high hydraulic conductivity material.

5) The hydraulic head at top of the clay barrier, just below a geomembrane slit is assumed to vary as described earlier (See Figure 3.15).

6) Locations of the multiple slits are chosen at $400 \mathrm{~cm}, 900 \mathrm{~cm}, 1400 \mathrm{~cm}, 2000 \mathrm{~cm}$, and $2600 \mathrm{~cm}$ along $\mathrm{x}$ axis as shown in Figure 3.18.

Physical properties of the different types of soil materials are given in Table 3.1 and Table 3.2 in this chapter.

Table 3.2 Physical properties of the soil materials (Istok, 1989).

\begin{tabular}{|l|c|c|c|c|}
\hline Material & $\begin{array}{c}\text { Hydraulic Conductivity, } \mathrm{K}_{\mathrm{s}} \\
(\mathrm{m} / \mathrm{sec})\end{array}$ & $\begin{array}{c}\text { Specific Storage, } \mathrm{S}_{\mathrm{s}} \\
\left(\mathrm{m}^{-1}\right)\end{array}$ & Porosity, $\mathrm{n}$ & $\begin{array}{c}\text { Bulk Density, } \\
\rho_{\mathrm{b}}\left(\mathrm{kg} / \mathrm{m}^{3}\right)\end{array}$ \\
\hline Sand & $10^{-2}-10^{-6}$ & $0.1-0.4$ & $0.25-0.55$ & $1300-1900$ \\
\hline Silt & $10^{-3}-10^{-7}$ & $0.2-0.4$ & $0.35-0.60$ & $1200-1800$ \\
\hline Clay & $10^{-7}-10^{-10}$ & $0.05-0.2$ & $0.35-0.55$ & $1000-1600$ \\
\hline
\end{tabular}




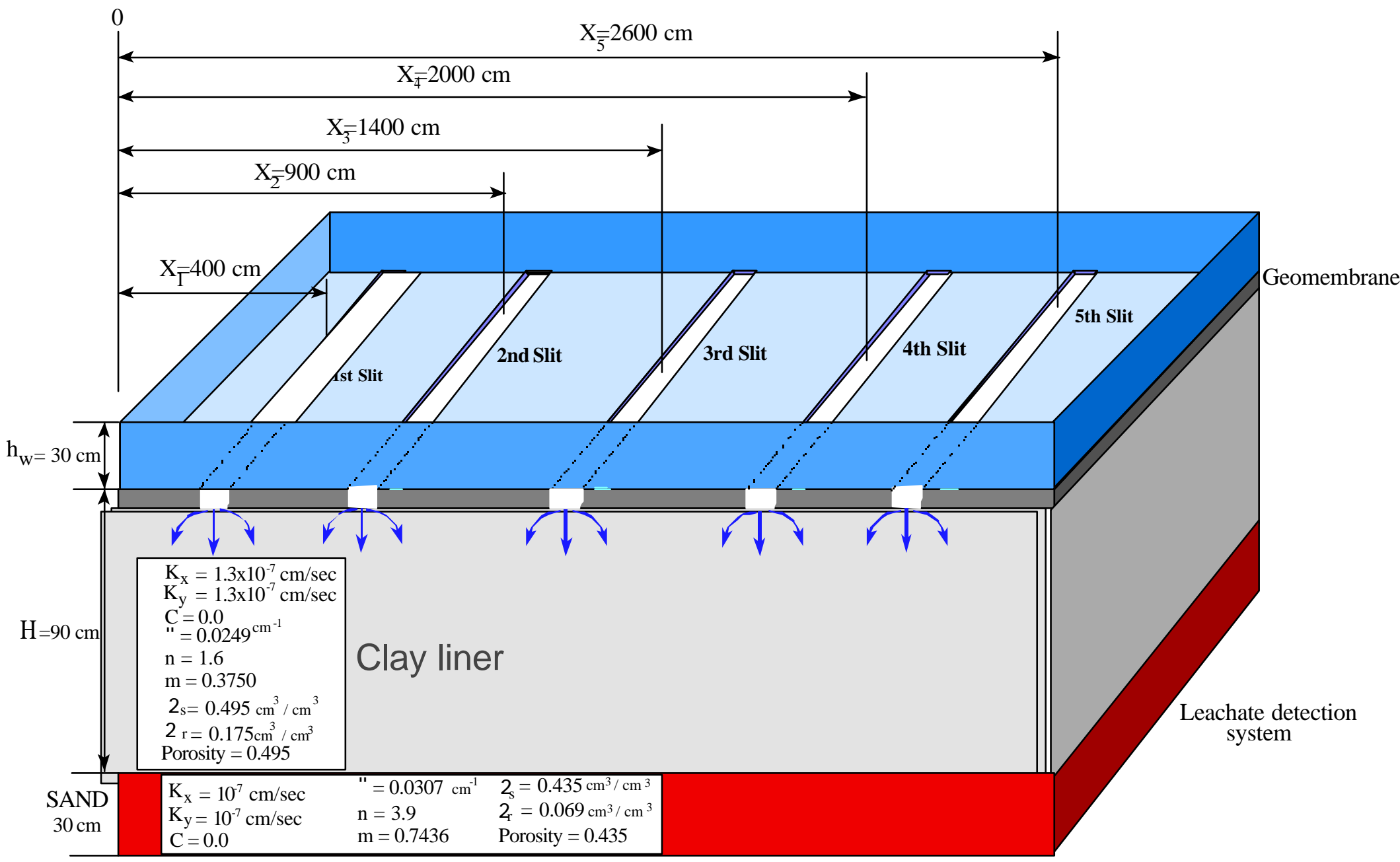

* Slit sizes are exaggerated.

Figure 3.18 Locations of the slits and properties of the soil 
Equipotential lines of the two-dimensional case are given in Figure 3.19. There is horizontal flow between the geomembrane and the underlying clay barrier. Phreatic surface separates the soil which is not saturated from the soil where no flow occurs. The flow in the soil is assumed to be vertical in the plane and $\mathrm{R}$ is the width of the wetting area.

A two-dimensional soil profile was analyzed using the method described in Chapter 3. The finite element mesh employed is shown in Figure 3.20. To improve results around the second slit (distance from the slit center, $X_{1}=900 \mathrm{~cm}$ ), the mesh was refined. This mesh was used for all the examples in the study. 


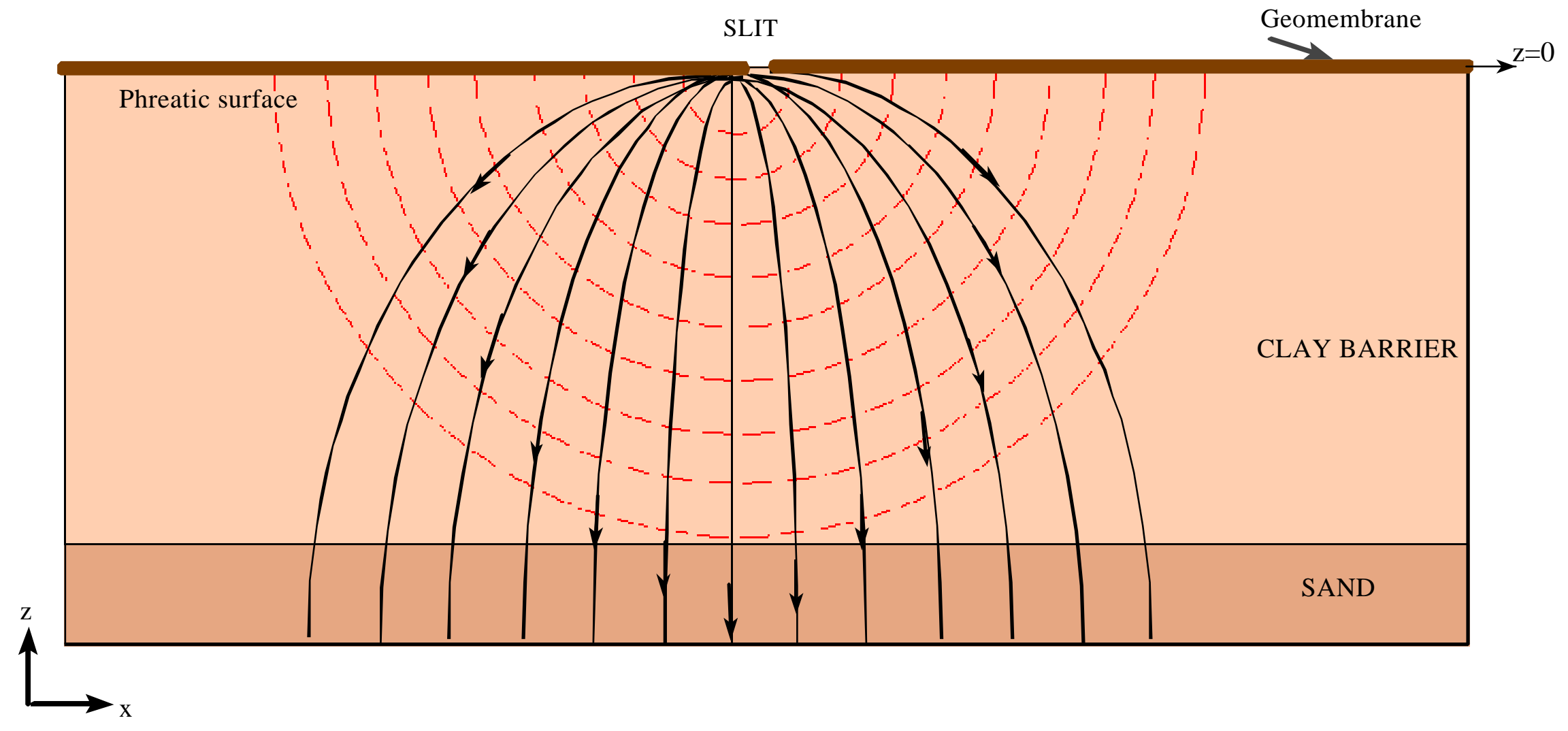

Figure 3.19 Equipotential flow lines of the leachate through a composite barrier. 


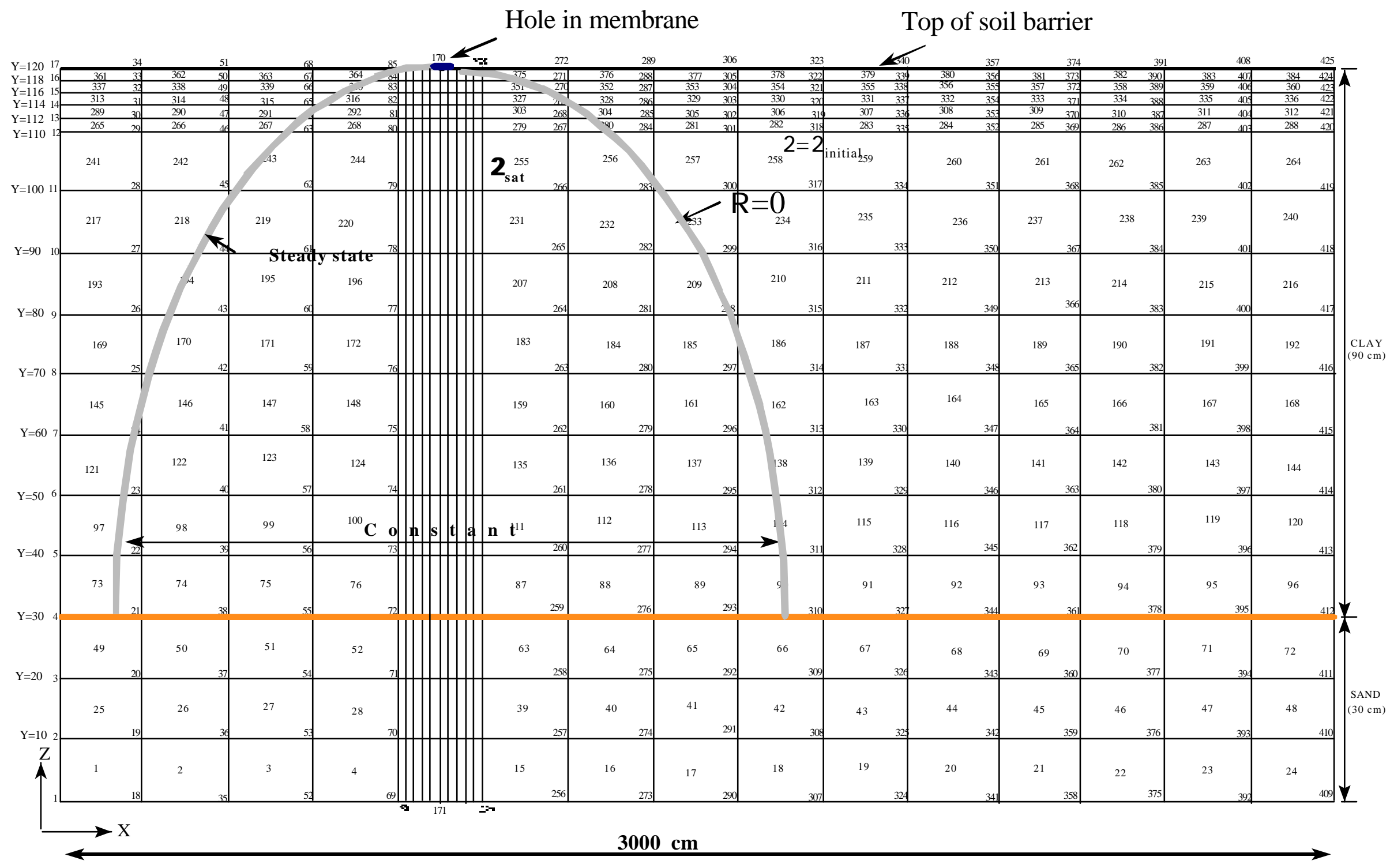

Figure 3.20 Mesh of the composite liner profile (Geomembrane, underlain by $90 \mathrm{~cm}$ of soil and $30 \mathrm{~cm}$ of sand, liquid detection system) and refined geomembrane hole area, the distance from $\mathrm{z}$ axis, $\mathrm{x}=900 \mathrm{~cm}$. 


\section{CHAPTER 4 \\ RESULTS AND DISCUSSIONS}

\subsection{Overview}

The computer code as described in Chapter 3 was used to calculate hydraulic heads, breakthrough times for the wetting front, and seepage fluxes for two cases in order to evaluate the accuracy of the model. The outcomes of the COMPBAR program simulations are presented in Section 4.2. The results of this study are compared with SOILINER and SEEP models in Sections 4.3 and 4.4, respectively. Finally, a stability and parametric analysis of the COMPBAR computer code are discussed in Sections 4.5 and 4.6, respectively.

\section{Examples}

In this section, two examples are presented. The complete input and output data files of Example 1 are given in the Appendix A.

\section{Example 1}

In this example, leakage through a composite barrier due to five slits in the geomembrane is considered. The geomembrane is assumed to be in good contact with the underlying clay. The selected values of pressure head $(\psi)$, volumetric moisture content $(\theta)$, hydraulic conductivity $(\mathrm{K})$, and flow rate $(\mathrm{q})$ beneath the geomembrane slit for Example 1 are given in Tables 4.1 through 4.4 and Figures 4.1 through 4.4. These values are plotted for the clay layer of the composite barrier. 
Table 4.1 Selected values of the pressure head $(\mathrm{R})$ with depth below the slit of Example 1 ( the distance from $\mathrm{z}$ axis, $\mathrm{x}=900 \mathrm{~cm}$ ).

\begin{tabular}{|c|c|c|c|c|c|c|c|c|c|c|}
\hline El.No. & $\mathbf{x}(\mathbf{c m})$ & $\mathbf{z}(\mathbf{c m})$ & 4.0 & 4.8 & 9.0 & 13.4 & 16.0 & 18.0 & 20.6 & 26.0 (years) \\
\hline 170 & 900 & 90 & -81.28 & -4.57 & -2.94 & 0.06 & 0.17 & 0.30 & 0.42 & 0.78 \\
\hline 169 & 900 & 80 & -75.03 & -27.21 & -18.96 & -8.37 & -8.03 & -7.60 & -7.21 & -6.10 \\
\hline 168 & 900 & 70 & -75.02 & -61.61 & -39.10 & -16.55 & -15.85 & -14.97 & -14.15 & -11.97 \\
\hline 167 & 900 & 60 & -75.00 & -75.11 & -74.91 & -40.35 & -36.70 & -32.48 & -29.24 & -22.49 \\
\hline 166 & 900 & 50 & -74.16 & -12.44 & -8.97 & -3.40 & -3.20 & -2.96 & -2.74 & -2.11 \\
\hline 165 & 900 & 40 & -36.39 & 0.35 & 1.09 & 2.83 & 2.92 & 3.03 & 3.13 & 3.41 \\
\hline 164 & 900 & 30 & -1.94 & 4.16 & 4.74 & 6.06 & 6.13 & 6.21 & 6.29 & 6.51 \\
\hline 163 & 900 & 20 & 4.64 & 8.94 & 9.33 & 10.24 & 10.29 & 10.34 & 10.39 & 10.54 \\
\hline 162 & 900 & 10 & 14.03 & 16.10 & 16.29 & 16.75 & 16.77 & 16.80 & 16.82 & 16.90 \\
\hline 161 & 900 & 8 & 16.44 & 18.09 & 18.24 & 18.61 & 18.63 & 18.65 & 18.67 & 18.73 \\
\hline 160 & 900 & 6 & 19.15 & 20.38 & 20.50 & 20.77 & 20.79 & 20.80 & 20.82 & 20.86 \\
\hline 159 & 900 & 4 & 22.23 & 23.05 & 23.13 & 23.31 & 23.32 & 23.33 & 23.34 & 23.37 \\
\hline 158 & 900 & 2 & 25.80 & 26.21 & 26.25 & 26.34 & 26.34 & 26.35 & 26.35 & 26.37 \\
\hline 157 & 900 & 0 & 30.00 & 30.00 & 30.00 & 30.00 & 30.00 & 30.00 & 30.00 & 30.00 \\
\hline
\end{tabular}

Table 4.2 Selected values of the volumetric moisture content (2) with depth below the slit of Example 1 ( the distance from $\mathrm{z}$ axis, $\mathrm{x}=900 \mathrm{~cm}$ ).

\begin{tabular}{lllllllllll} 
El.No. & $\mathbf{z}(\mathbf{c m})$ & $\mathbf{z}(\mathbf{c m})$ & $\mathbf{1 . 3}$ & $\mathbf{4 . 0}$ & $\mathbf{4 . 8}$ & $\mathbf{9 . 0}$ & $\mathbf{1 2 . 4}$ & $\mathbf{1 6 . 0}$ & $\mathbf{1 8 . 2}$ \\
\hline 369 & 890 & 85 & 0.4950 & 0.4950 & 0.4950 & 0.4950 & 0.4950 & 0.4950 & 0.4950 \\
345 & 890 & 75 & 0.4950 & 0.4950 & 0.4950 & 0.4950 & 0.4950 & 0.4950 & 0.4950 \\
321 & 890 & 65 & 0.4950 & 0.4950 & 0.4950 & 0.4950 & 0.4950 & 0.4950 & 0.4950 \\
297 & 890 & 55 & 0.4950 & 0.4950 & 0.4950 & 0.4950 & 0.4950 & 0.4950 & 0.4950 \\
273 & 890 & 45 & 0.4950 & 0.4950 & 0.4950 & 0.4950 & 0.4950 & 0.4950 & 0.4950 \\
249 & 890 & 35 & 0.4950 & 0.4950 & 0.4950 & 0.4950 & 0.4950 & 0.4950 & 0.4950 \\
225 & 890 & 25 & 0.4950 & 0.4950 & 0.4950 & 0.4950 & 0.4950 & 0.4950 & 0.4950 \\
201 & 890 & 15 & 0.4574 & 0.4950 & 0.4950 & 0.4950 & 0.4950 & 0.4950 & 0.4950 \\
177 & 890 & 9 & 0.3875 & 0.4935 & 0.4945 & 0.4950 & 0.4950 & 0.4950 & 0.4950 \\
153 & 890 & 7 & 0.3677 & 0.4842 & 0.4887 & 0.4939 & 0.4941 & 0.4943 & 0.4950 \\
129 & 890 & 5 & 0.3711 & 0.4600 & 0.4736 & 0.4886 & 0.4894 & 0.4901 & 0.4950 \\
105 & 890 & 3 & 0.3705 & 0.4103 & 0.4400 & 0.4763 & 0.4782 & 0.4801 & 0.4905 \\
81 & 890 & 1 & 0.3706 & 0.3770 & 0.3921 & 0.4346 & 0.4462 & 0.4541 & 0.4812 & 0.450 \\
& & & & & & & & 0.4950 \\
\end{tabular}


Table 4.3. Selected values of hydraulic conductivity $(\mathrm{K})$ with depth below the slit of Example 1 ( the distance from $\mathrm{z}$ axis, $\mathrm{x}=900 \mathrm{~cm}$ ).

\begin{tabular}{lllllllllll} 
El.No. & $\mathbf{x}(\mathbf{c m})$ & $\mathbf{z}(\mathbf{c m})$ & $\mathbf{1 . 3}$ & $\mathbf{4 . 0}$ & $\mathbf{6 . 1}$ & $\mathbf{1 1 . 6}$ & $\mathbf{1 4 . 0}$ & $\mathbf{1 8 . 4}$ & $\mathbf{2 3 . 5}$ & $\mathbf{2 5 . 2}(\mathbf{y e a r s})$ \\
\hline 369 & 890 & 85 & 0.0112 & 0.0112 & 0.0112 & 0.0112 & 0.0112 & 0.0112 & 0.0112 \\
345 & 890 & 75 & 0.0112 & 0.0112 & 0.0112 & 0.0112 & 0.0112 & 0.0112 & 0.0112 \\
321 & 890 & 65 & 0.0112 & 0.0112 & 0.0112 & 0.0112 & 0.0112 & 0.0112 & 0.0112 \\
297 & 890 & 55 & 0.0112 & 0.0112 & 0.0112 & 0.0112 & 0.0112 & 0.0112 & 0.0112 \\
273 & 890 & 45 & 0.0112 & 0.0112 & 0.0112 & 0.0112 & 0.0112 & 0.0112 & 0.0112 \\
249 & 890 & 35 & 0.0022 & 0.0112 & 0.0112 & 0.0112 & 0.0112 & 0.0112 & 0.0112 \\
225 & 890 & 25 & 0.0112 & 0.0112 & 0.0112 & 0.0112 & 0.0112 & 0.0112 & 0.0112 \\
201 & 890 & 15 & 0.0012 & 0.0112 & 0.0112 & 0.0112 & 0.0112 & 0.0112 & 0.0112 \\
177 & 890 & 9 & 0.0015 & 0.0112 & 0.0084 & 0.0112 & 0.0112 & 0.0112 & 0.0112 & 0.0112 \\
153 & 890 & 7 & 0.0002 & 0.0040 & 0.0050 & 0.0078 & 0.0079 & 0.0081 & 0.0092 & 0.0112 \\
129 & 890 & 5 & 0.0021 & 0.0016 & 0.0026 & 0.0051 & 0.0052 & 0.0053 & 0.0062 \\
105 & 890 & 3 & 0.0001 & 0.0004 & 0.0009 & 0.0029 & 0.0030 & 0.0032 & 0.0042 \\
81 & 890 & 1 & 0.0001 & 0.0001 & 0.0002 & 0.0009 & 0.0010 & 0.0012 & 0.0112 \\
\end{tabular}

Table 4.4. Selected values of flow rate (q) with depth below the slit of Example 1 ( the distance from $\mathrm{z}$ axis, $\mathrm{x}=900 \mathrm{~cm}$ ).

\begin{tabular}{|c|c|c|c|c|c|c|c|c|c|c|}
\hline El.No. & $\mathbf{x}(\mathbf{c m})$ & $\mathbf{z}(\mathbf{c m})$ & 1.3 & 4.0 & 0.8 & 0.2 & 1.6 & 4.0 & 0.6 & 26.0 (years) \\
\hline 369 & 890 & 85 & 2.1547 & 2.1771 & 2.1844 & 2.1844 & 2.1846 & .1850 & 2.1855 & 2.1863 \\
\hline 345 & 890 & 75 & 1.9247 & 1.9921 & 1.9986 & 2.0140 & 2.0147 & 2.0158 & 2.0174 & 2.0196 \\
\hline 321 & 890 & 65 & 1.7101 & 1.8225 & 1.8333 & 1.8590 & 1.8601 & 1.8619 & 1.8646 & 1.8683 \\
\hline 297 & 890 & 55 & 1.5085 & 1.6658 & 1.6809 & 1.7169 & 1.7185 & 1.7210 & 1.7247 & 1.7300 \\
\hline 273 & 890 & 45 & 1.3178 & 1.5201 & 1.5395 & 1.5858 & 1.5878 & 1.5910 & 1.5958 & 1.6026 \\
\hline 249 & 890 & 35 & 0.1635 & 0.2310 & 0.2374 & 0.2527 & 0.2534 & 0.2544 & 0.2560 & 0.2583 \\
\hline 225 & 890 & 25 & 0.0082 & 0.1248 & 0.1355 & 0.1607 & 0.1618 & 0.1635 & 0.1662 & 0.1699 \\
\hline 201 & 890 & 15 & -0.0673 & 0.0373 & 0.0527 & 0.0868 & 0.0883 & 0.0907 & 0.0943 & 0.0996 \\
\hline 177 & 890 & 9 & -0.0227 & -0.0386 & -0.0235 & 0.0234 & 0.0253 & 0.0283 & 0.0330 & 0.0396 \\
\hline 153 & 890 & 7 & -0.0152 & -0.0735 & -0.0653 & -0.0319 & -0.0303 & -0.0278 & -0.0235 & -0.0168 \\
\hline 129 & 890 & 5 & -0.0164 & -0.0691 & -0.0762 & -0.0646 & -0.0635 & -0.0618 & -0.0587 & -0.0534 \\
\hline 105 & 890 & 3 & -0.0162 & -0.0344 & -0.0543 & -0.0 .767 & -0.0 .767 & -0.0765 & -0.0758 & -0.0736 \\
\hline 81 & 890 & 1 & -0.0162 & -0.0185 & -0.0248 & -0.0534 & -0.0 .576 & -0.0617 & -0.0681 & -0.0739 \\
\hline
\end{tabular}




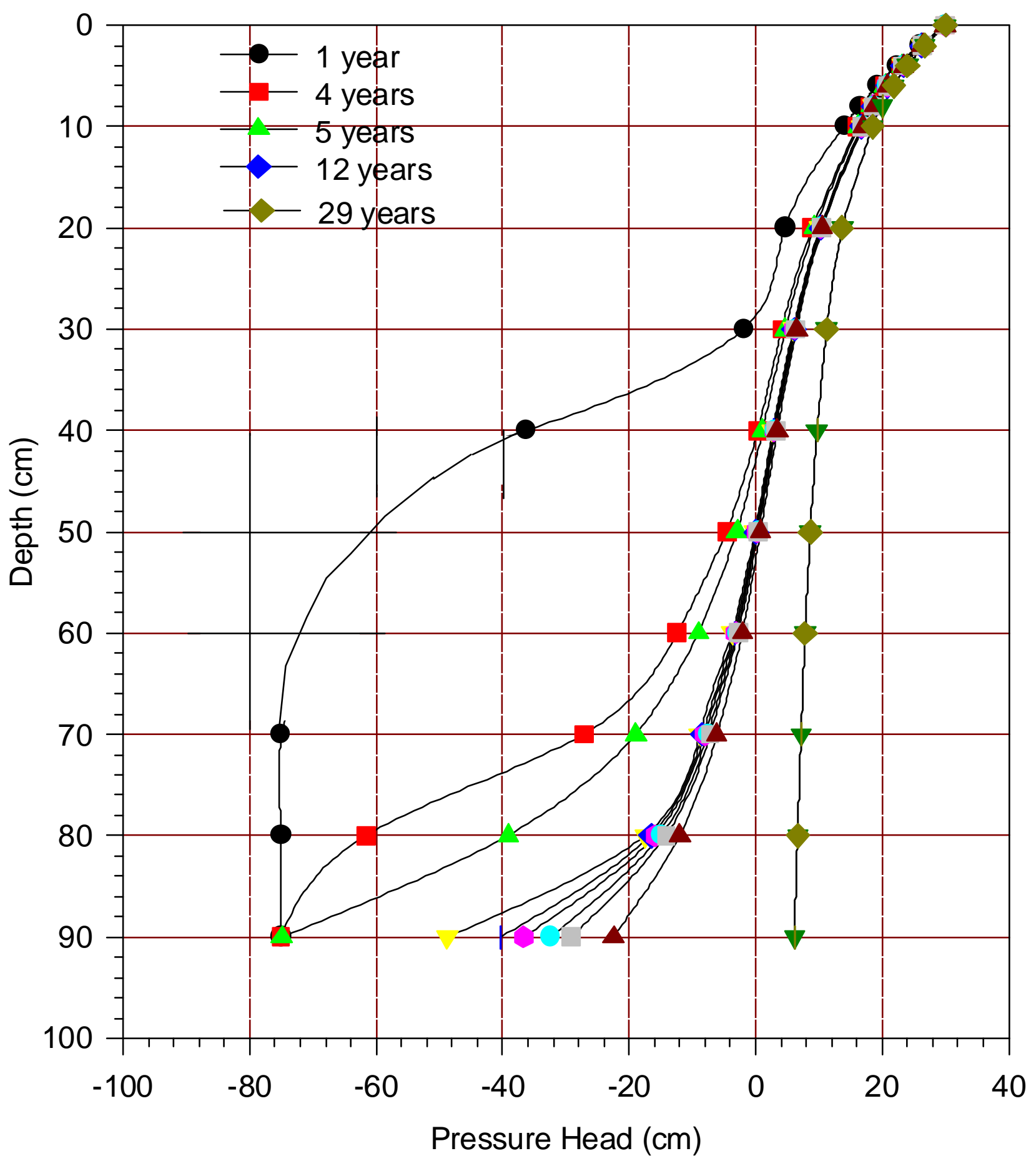

NOTE: The distance from $\mathrm{z}$ axis below the slit at $\mathrm{x}=900 \mathrm{~cm}$.

Figure 4.1 Variation of pressure head with depth below the slit 


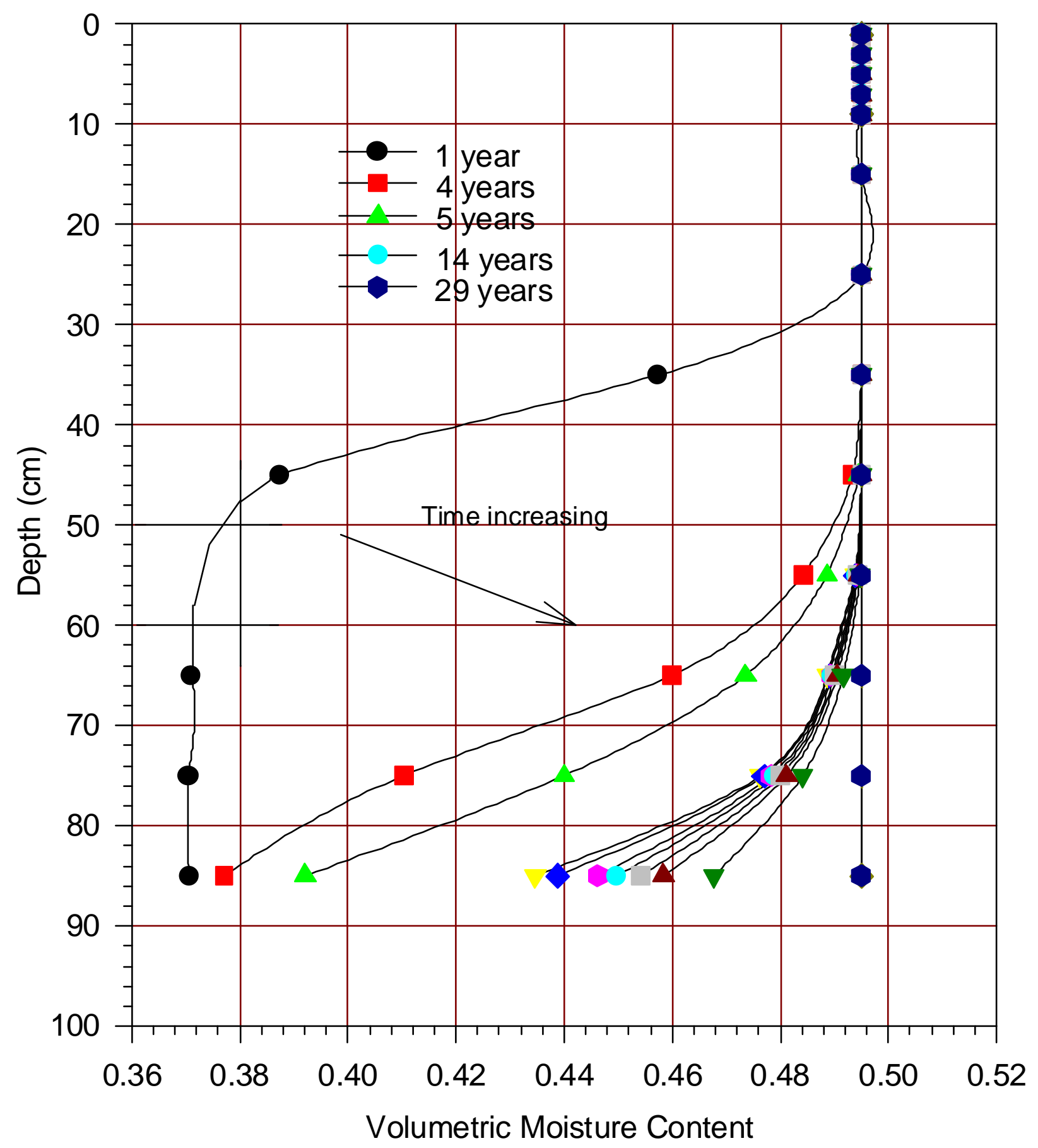

NOTE: The distance from $\mathrm{z}$ axis below the slit at $\mathrm{x}=900 \mathrm{~cm}$.

Figure 4.2 Variation of the volumetric moisture content with depth below the slit 


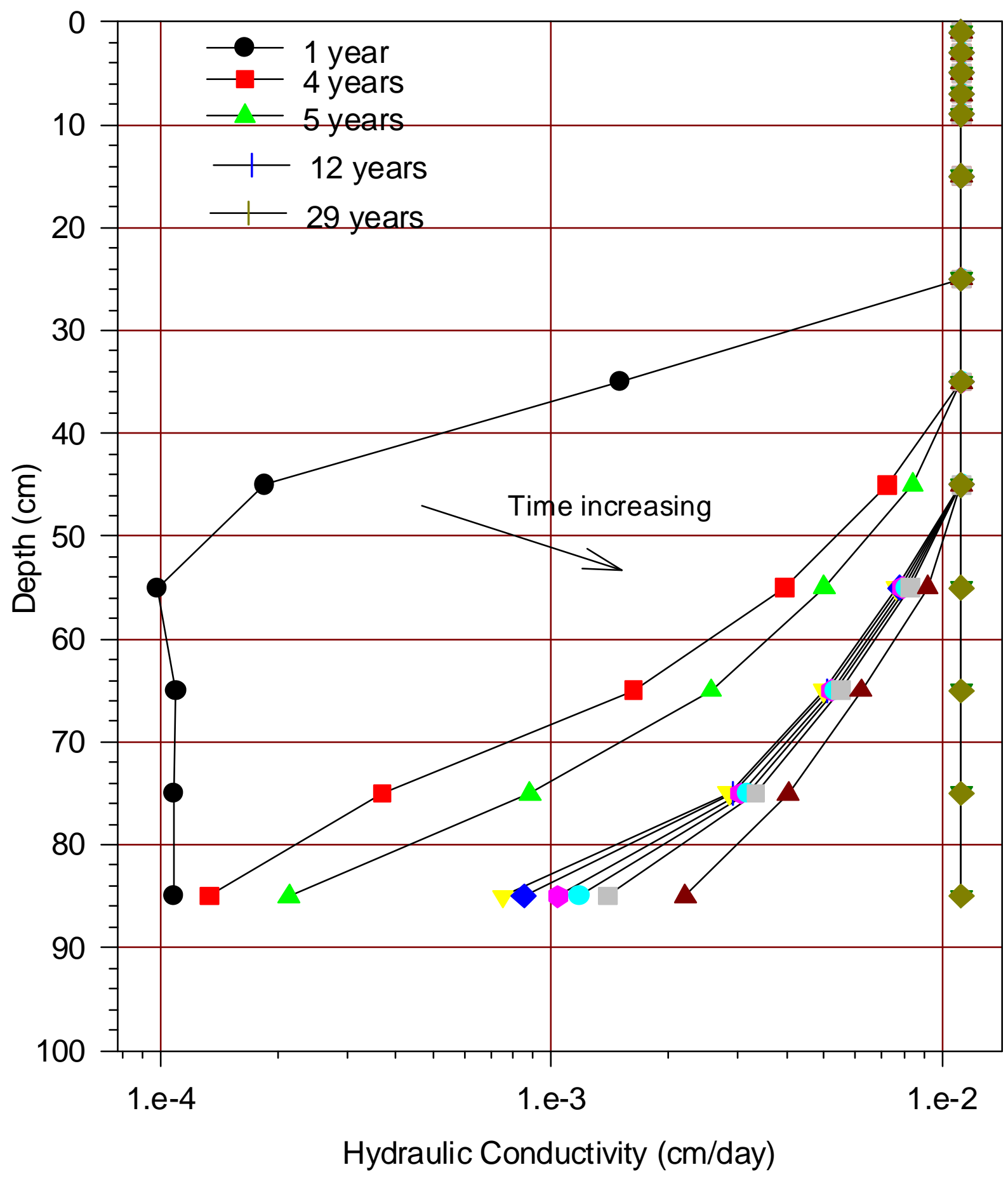

NOTE: The distance from $\mathrm{z}$ axis below the slit at $\mathrm{x}=900 \mathrm{~cm}$.

Figure 4.3 Variation of hydraulic conductivity with depth below the slit of Example 1 


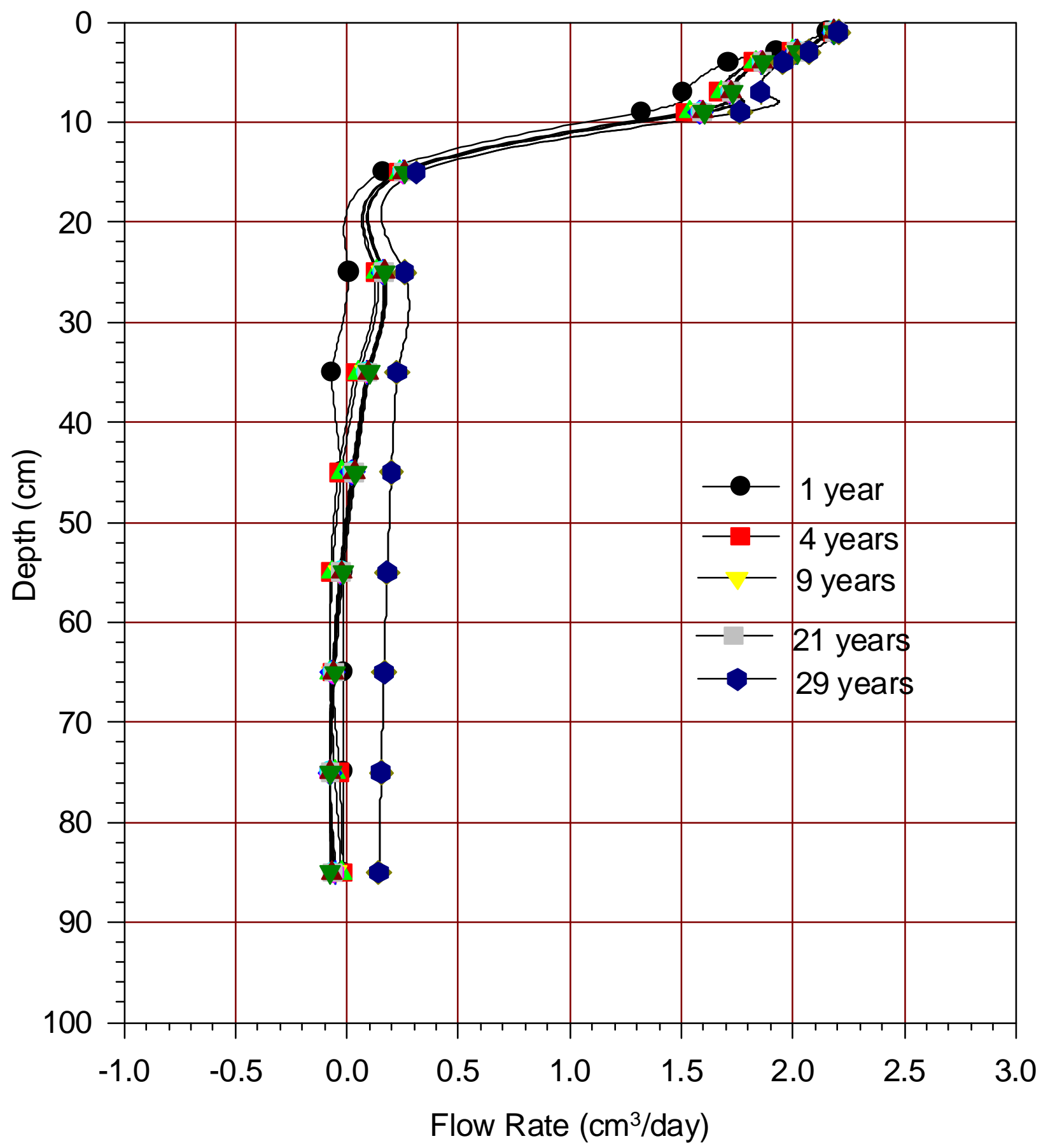

NOTE: The distance from $\mathrm{z}$ axis below the slit at $\mathrm{X}=900 \mathrm{~cm}$.

Figure 4.4 Variation of the flow rate with depth below the slit of Example 1 
The values of pressure head $(\psi)$, which are obtained at the nodes of the mesh, are presented in Table 4.1. These pressure heads are given at constant values of $\mathrm{X}$ (slit location of the geomembrane) and $\mathrm{Y}$ value is varied from $0 \mathrm{~cm}$ at the geomembrane to $120 \mathrm{~cm}$ at the base of the sand layer (leachate detection layer). In Figure 4.1, the pressure head $(\psi)$ is maximum (positive) at the top of the clay layer and decreases in a nonlinear fashion to its minimum value, which is at the bottom of the clay layer $(90 \mathrm{~cm})$. It can be seen from Figure 4.1 that pressure head $(\psi)$ values were initially $-75 \mathrm{~cm}$ at the base of the clay layer and start shifting gradually to the right to approach zero and eventually to become positive after 29 years. The shift to the right indicates that the soil is moving from an unsaturated condition to a saturated condition. For example, at a level of $50 \mathrm{~cm}$ and after 1.0 year, pressure head $(\psi)$ is $-82 \mathrm{~cm}$, and for the same depth after 29 years it is $+8 \mathrm{~cm}$, which means the soil profile was saturated at this depth. It can also be explained that after 1.0 year the soil is saturated on top of the clay barrier to depth of 30 $\mathrm{cm}$, and beyond this depth the soil is still unsaturated. After 9 years the soil is saturated up to 50 $\mathrm{cm}$ and unsaturated below this depth. It is assumed that at the boundary (top of clay barrier) pressure head $(\psi)$ stays constant with time, but moving away from the boundary, pressure head lines of Figure 4.1 start separating. After 29 years the entire soil profile was saturated and pressure head $(\psi)$ values were all greater than zero. There are numerous different time intervals with various pressure head $(\psi)$ values between the interval of 1 year and 29 years. As time increases the depth at which pressure head $(\psi)$ values is greater than zero increases, which indicates that soil saturation increases with depth.

The values of volumetric moisture content $(\theta)$ at the center of each element are given in Table 4.2 and in Figure 4.2. Since volumetric moisture content $(\theta)$ is approximated from pressure head $(\psi)$, which was obtained from the COMPBAR analysis, volumetric moisture content $(\theta)$ trends are similar to the pressure head $(\psi)$ trends in the soil profile, i.e. maximum values occur at the top of the clay barrier and then decrease in a nonlinear fashion to minimum values at the base of the clay barrier. It can be seen from Figure 4.2 that up to a depth of $25 \mathrm{~cm}$ the soil has volumetric moisture content $(\theta)$ level equal to the saturated volumetric moisture content level at 29 years, which indicates fully saturated conditions. The volumetric moisture content $(\theta)$ values are lower than the saturated $\theta$ values below a depth of $30 \mathrm{~cm}$. Therefore, with increasing time, 
the unsaturated clay approaches saturated conditions. For example, after 4 years the soil is fully saturated up to a depth of $45 \mathrm{~cm}$ and is unsaturated below that point. After 29 years, volumetric moisture content $(\theta)$ is 0.495 throughout the soil profile, which is equal to porosity, and indicates that all the pores in the soil are saturated.

The values of hydraulic conductivity $(\mathrm{K})$ approximated at the center of the each element are given in Table 4.3. A selected part of this output at geomembrane slit located at $x=900 \mathrm{~cm}$ (see Figure 3.18) is plotted in Figure 4.3. Hydraulic conductivity (K) values are maximum, about $1.1 \times 10^{-3} \mathrm{~cm} /$ day, at the top, and minimum of about $2.0 \times 10^{-4} \mathrm{~cm} /$ day at a depth of $85 \mathrm{~cm}$ into the clay barrier. In general, saturated hydraulic conductivity $(K)$ values are higher than unsaturated values due to the presence of air bubbles within the soil matrix which impede flow, thus yielding lower $\mathrm{K}$ values. Initially, the clay layer is not saturated, and as time progresses the soil's volumetric water content increases which results in larger hydraulic conductivity values. For example, after one year, the depth of $35 \mathrm{~cm}$ hydraulic conductivity is $1.5 \times 10^{-3}$ $\mathrm{cm} /$ day. After one year, and at a depth of $45 \mathrm{~cm}$, hydraulic conductivity the value is $3.0 \times 10^{-4}$ $\mathrm{cm} /$ day and for the same depth after four years hydraulic conductivity is $7.0 \times 10^{-3} \mathrm{~cm} /$ day. After four years, hydraulic conductivity value at $45 \mathrm{~cm}$ is higher because of a higher saturation level then after twenty six years hydraulic conductivity is $1.1 \times 10^{-2} \mathrm{~cm} /$ day, which is equal to the saturated hydraulic conductivity.

Table 4.4 shows the approximated values of flow rate in the elements. These values are also plotted in Figure 4.4. Initially, flow rate has a peak value of $2.2 \mathrm{~cm}^{3} /$ day at the top of the soil profile because the soil is saturated. Then, flow rate drops drastically to $-0.3 \mathrm{~cm}^{3} /$ day at a depth of $15 \mathrm{~cm}$ under steady state conditions with no significant change below $15 \mathrm{~cm}$. After one year, since the values of hydraulic conductivity are low, the leachate has reached the leachate detection system. Beyond the depth of $20 \mathrm{~cm}$, flow rate increases with increasing time. For example, at the depth of $25 \mathrm{~cm}$ after fourteen years, flow rate was about $-0.2 \mathrm{~cm}^{3} /$ day whereas after twenty six years it was about $0.3 \mathrm{~cm}^{3} /$ day.

The wetting front movement of this example is plotted in Figure 4.5. The wetting front was produced by plotting contour lines of equal pressure head $(\psi)$ in the soil layer. The graph 


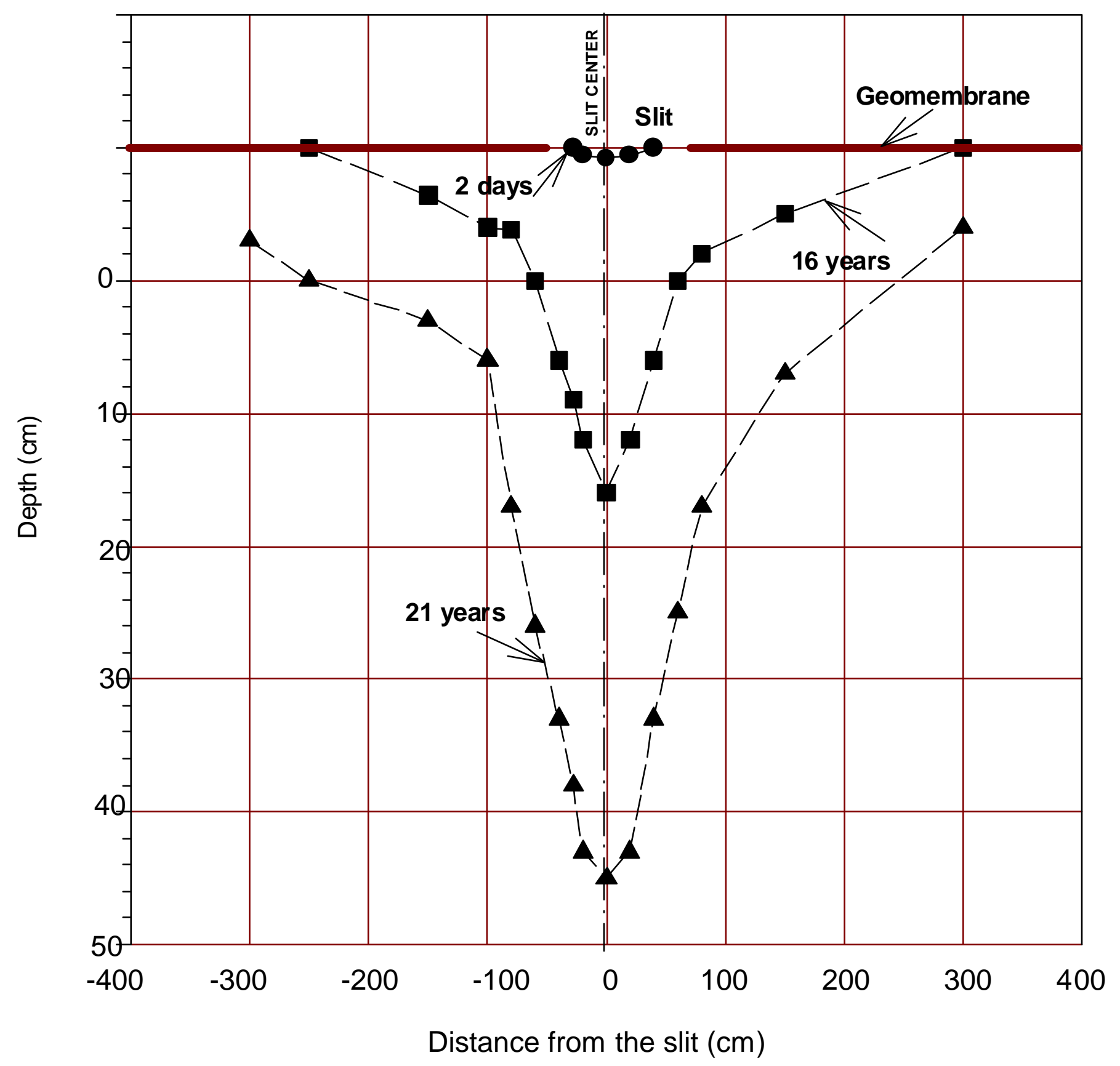

Figure 4.5 Wetting front movement with different time intervals 
indicates the location of the leachate moving down through the soil profile. It can be seen from Figure 4.5 that after two days the wetting front remains just beneath the geomembrane. After sixteen years the wetting front directly under a slit reached a depth of $18 \mathrm{~cm}$ but decreases laterally away form the hole. After twenty one years the wetting front reached a depth of $45 \mathrm{~cm}$ and also decreased away from the centerline of the hole.

\section{Example 2}

In the second example, only one slit in the geomembrane was considered, and the geomembrane had poor contact with the underlying clay barrier. The selected output values and graphs for Example 2 are presented in Tables 4.5 through 4.8 and Figures 4.6 through 4.9. At the location of the slit, similar to Example 1, $\mathrm{x}$ values are kept constant and $\mathrm{z}$ values are changed from 0 to $120 \mathrm{~cm}$ below the slit.

In Table 4.5, values of pressure heads $(\psi)$ are listed at different time intervals at nodes of the mesh. Part of this output is plotted in Figure 4.6. This figure shows that the pressure at the top of the soil barrier is at a maximum, and it decreases nonlinearly to a minimum value at the bottom of the clay barrier. After 1 year at a depth of $50 \mathrm{~cm}$, pressure head was $-85 \mathrm{~cm}$. After 25 years pressure head at the same depth was $-0.2 \mathrm{~cm}$. After 1 year, the soil is saturated between $0 \mathrm{~cm}$ to $28 \mathrm{~cm}$. Beyond this depth the soil remains unsaturated. After 4 years the soil is saturated to a depth of $44 \mathrm{~cm}$ and unsaturated below this depth.

The values of volumetric moisture content $(\theta)$ at the center of each element are presented in Table 4.6 and in Figure 4.7. Figure 4.7 shows that, after one year, the soil profile was saturated (i.e., $\theta=0.495)$ up to a depth of $28 \mathrm{~cm}$, then volumetric moisture content $(\theta)$ value sharply decreases to about 0.37 at depths between $55 \mathrm{~cm}$ to $85 \mathrm{~cm}$. As time increases, the saturation front approaches full saturation. For example, after four years, $\theta$ at a depth of $65 \mathrm{~cm}$ increases to 0.472 . Then, after twenty nine years volumetric moisture content value increases to 0.495 indicating full saturation. 
Table 4.5 Selected values of pressure head (R) with depth below the slit of Example 2 ( the distance from $\mathrm{z}$ axis, $\mathrm{z}=900 \mathrm{~cm}$ ).

\begin{tabular}{|c|c|c|c|c|c|c|c|c|c|c|}
\hline El.No. & $\mathbf{x}(\mathbf{c m})$ & $\mathrm{z}(\mathbf{c m})$ & 4.0 & 4.8 & 9.0 & 13.4 & 16.0 & 8.0 & 20.6 & 26.0 (years) \\
\hline 170 & 900 & 90 & -75.00 & -75.09 & -69.88 & -56.25 & -50.38 & -47.41 & -34.67 & -33.33 \\
\hline 169 & 900 & 80 & -75.05 & -51.89 & -15.65 & -14.56 & -14.78 & -14.83 & -13.78 & -13.54 \\
\hline 168 & 900 & 70 & -74.91 & -20.52 & -7.56 & -.6 .61 & -6.72 & -6.73 & -6.21 & -6.10 \\
\hline 167 & 900 & 60 & -74.51 & -8.72 & -2.52 & -1.86 & -1.91 & -1.92 & -1.61 & -1.55 \\
\hline 166 & 900 & 50 & -80.83 & -2.14 & -0.89 & 1.26 & 1.23 & 1.24 & 1.37 & 1.40 \\
\hline 165 & 900 & 40 & -26.76 & 1.84 & 3.90 & 4.23 & 4.22 & 4.22 & 4.33 & 4.36 \\
\hline 164 & 900 & 30 & -1.45 & 5.79 & 7.33 & 7.61 & 7.60 & 7.60 & 7.69 & 7.71 \\
\hline 163 & 900 & 20 & 5.60 & 10.56 & 11.59 & 11.79 & 11.78 & 11.78 & 11.84 & 11.85 \\
\hline 162 & 900 & 10 & 14.92 & 17.36 & 17.87 & 17.97 & 17.97 & 17.97 & 18.00 & 18.01 \\
\hline 161 & 900 & 8 & 17.26 & 19.21 & 19.62 & 19.70 & 19.70 & 19.70 & 19.72 & 19.73 \\
\hline 160 & 900 & 6 & 19.85 & 21.31 & 21.62 & 21.68 & 21.68 & 21.70 & 21.70 & 21.70 \\
\hline 159 & 900 & 4 & 22.77 & 23.74 & 23.94 & 23.99 & 23.99 & 23.99 & 24.00 & 24.00 \\
\hline 158 & 900 & 2 & 26.11 & 26.60 & 26.70 & 26.72 & 26.72 & 26.72 & 26.73 & 26.72 \\
\hline 157 & 900 & 0 & 30.00 & 30.00 & 30.00 & 30.00 & 30.00 & 30.00 & 30.00 & 30.00 \\
\hline
\end{tabular}

Table 4.6 Selected values of volumetric moisture content (2) with depth below the slit of Example 2 (the distance from $\mathrm{z}$ axis, $\mathrm{z}=900 \mathrm{~cm}$ ).

\begin{tabular}{llllllllll} 
El.No. & $\mathbf{x}(\mathbf{c m})$ & $\mathbf{z}(\mathbf{c m})$ & $\mathbf{1 . 3}$ & $\mathbf{4 . 0}$ & $\mathbf{6 . 2}$ & $\mathbf{9 . 5}$ & $\mathbf{1 1 . 2}$ & $\mathbf{1 5 . 3}$ & $\mathbf{1 7 . 3}$ \\
\hline 369 & 890 & 85 & 0.4950 & 0.4950 & 0.4950 & 0.4950 & 0.4950 & 0.4950 & 0.4950 \\
345 & 890 & 75 & 0.4950 & 0.4950 & 0.9550 & 0.4950 & 0.4950 & 0.4950 & $0.4($ years $)$ \\
321 & 890 & 65 & 0.4950 & 0.4950 & 0.4950 & 0.4950 & 0.4950 & 0.4950 & 0.4950 \\
297 & 890 & 55 & 0.4950 & 0.4950 & .0950 & 0.4950 & 0.4950 & 0.4950 & 0.4950 \\
273 & 890 & 45 & 0.4950 & 0.4950 & 0.4950 & 0.4950 & 0.4950 & 0.4950 & 0.4950 \\
249 & 890 & 35 & 0.4950 & 0.4950 & 0.4950 & 0.4950 & 0.4950 & 0.4950 & 0.4950 \\
225 & 890 & 25 & 0.4950 & 0.4950 & 0.4950 & 0.4950 & 0.4950 & 0.4950 & 0.4950 \\
201 & 890 & 15 & 0.4692 & 0.4950 & 0.4950 & 0.4950 & 0.4950 & 0.4950 & 0.4950 \\
177 & 890 & 9 & 0.3948 & 0.4949 & 0.4950 & 0.4950 & 0.4950 & 0.4950 & 0.4950 \\
153 & 890 & 7 & 0.3675 & 0.4894 & 0.4946 & 0.4949 & 0.4949 & 0.4949 & 0.4950 \\
129 & 890 & 5 & 0.3710 & 0.4720 & 0.4903 & 0.4915 & 0.4915 & 0.4914 & 0.4949 \\
105 & 890 & 3 & 0.3706 & 0.4254 & 0.4792 & 0.4815 & 0.4814 & 0.4811 & 0.4914 \\
81 & 890 & 1 & 0.3706 & 0.3830 & 0.4165 & 0.4280 & 0.4308 & 0.4372 & 0.4811
\end{tabular}


Table 4.7 Selected values of hydraulic conductivity (K) with depth below the slit of Example 2 ( the distance from $\mathrm{z}$ axis, $\mathrm{z}=900 \mathrm{~cm}$ ).

\begin{tabular}{lllllllllll} 
El.No. & $\mathbf{x}(\mathbf{c m})$ & $\mathbf{z}(\mathbf{c m})$ & $\mathbf{1 . 3}$ & $\mathbf{4 . 0}$ & $\mathbf{6 . 1}$ & $\mathbf{1 1 . 6}$ & $\mathbf{1 4 . 0}$ & $\mathbf{1 8 . 4}$ & $\mathbf{2 3 . 5}$ \\
\hline 369 & 890 & 85 & 0.0112 & 0.0112 & 0.0112 & 0.0112 & 0.0112 & 0.0112 & 0.0112 \\
345 & 890 & 75 & 0.0112 & 0.0112 & 0.0112 & 0.0112 & 0.0112 & 0.0112 & 0.0112 \\
321 & 890 & 65 & 0.0112 & 0.0112 & 0.0112 & 0.0112 & 0.0112 & 0.0112 & 0.0112 \\
297 & 890 & 55 & 0.0112 & 0.0112 & 0.0112 & 0.0112 & 0.0112 & 0.0112 & 0.0112 \\
273 & 890 & 45 & 0.0112 & 0.0112 & 0.0112 & 0.0112 & 0.0112 & 0.0112 & 0.0112 \\
249 & 890 & 35 & 0.0022 & 0.0112 & 0.0112 & 0.0112 & 0.0112 & 0.0112 & 0.0112 \\
225 & 890 & 25 & 0.0112 & 0.0112 & 0.0112 & 0.0112 & 0.0112 & 0.0112 & 0.0112 \\
201 & 890 & 15 & 0.0022 & 0.0112 & 0.0112 & 0.0112 & 0.0112 & 0.0112 & 0.0112 \\
177 & 890 & 9 & 0.0098 & 0.0112 & 0.0112 & 0.0112 & 0.0112 & 0.0112 & 0.0112 \\
153 & 890 & 7 & 0.0054 & 0.0088 & 0.0097 & 0.0097 & 0.0096 & 0.0096 & 0.0112 \\
129 & 890 & 5 & 0.0025 & 0.0056 & 0.0061 & 0.0061 & 0.0060 & 0.0060 & 0.012 \\
105 & 890 & 3 & 0.0006 & 0.0032 & 0.0035 & 0.0035 & 0.0035 & 0.0035 & 0.0062 \\
81 & 890 & 1 & 0.0002 & 0.0004 & 0.0006 & 0.0007 & 0.0008 & 0.0008 & 0.0036
\end{tabular}

Table 4.8 Selected values of flow rate (q) with depth below the slit of Example 2 ( the distance from $\mathrm{z}$ axis, $\mathrm{x}=900 \mathrm{~cm}$ ).

\begin{tabular}{|c|c|c|c|c|c|c|c|c|c|c|}
\hline El.No. & $\mathbf{x}(\mathbf{c m})$ & $\mathbf{z}(\mathbf{c m})$ & 1.3 & 4.0 & 4.8 & 10.2 & 11.6 & 14.0 & 23.5 & 25.2 (years) \\
\hline 369 & 890 & 85 & 2.3041 & 2.3309 & 2.3365 & 2.3377 & 2.3377 & 2.3377 & 2.3380 & 2.3381 \\
\hline 345 & 890 & 75 & 2.0774 & 2.1577 & 2.1745 & 2.1783 & 2.1782 & 2.1783 & 2.1790 & 2.1794 \\
\hline 321 & 890 & 65 & 1.8639 & 1.9978 & 2.0259 & 2.0321 & 2.0320 & 2.0321 & 1.0332 & 1.0339 \\
\hline 297 & 890 & 55 & 1.6616 & 1.8491 & 1.8884 & 1.8971 & 1.8969 & 1.8971 & 1.8987 & 1.8996 \\
\hline 273 & 890 & 45 & 1.4686 & 1.7100 & 1.7605 & 1.7716 & 1.7714 & 1.7716 & 1.7737 & 1.7749 \\
\hline 249 & 890 & 35 & 0.1898 & 0.2709 & 0.2877 & 0.1913 & 0.2912 & 0.2913 & 0.2020 & 0.2924 \\
\hline 225 & 890 & 25 & 0.0274 & 0.1659 & 0.1937 & 0.1996 & 0.1994 & 0.1996 & 0.2007 & 0.2014 \\
\hline 201 & 890 & 15 & -0.0746 & 0.0770 & 0.1157 & 0.1234 & 0.1232 & 0.1234 & 0.1249 & 0.1258 \\
\hline 177 & 890 & 9 & -0.0261 & -0.0084 & -0.0471 & 0.0559 & 0.0557 & 0.0559 & 0.0578 & 0.0590 \\
\hline 153 & 890 & 7 & -0.0152 & -0.0615 & -0.0190 & -0.0099 & -0.0102 & -0.0074 & -0.0067 & -0.0056 \\
\hline 129 & 890 & 5 & -0.0163 & -0.0761 & -0.0595 & -0.0539 & -0.0541 & -0.0541 & -0.0522 & -0.0513 \\
\hline 105 & 890 & 3 & -0.0162 & -0.0460 & -0.0765 & -0.0757 & -0.0 .758 & -0.0758 & -0.0752 & -0.0749 \\
\hline 81 & 890 & 1 & -0.0162 & -0.0215 & -0.0381 & -0.0480 & -0.0510 & -0.0558 & -0.0626 & -0.064 \\
\hline
\end{tabular}




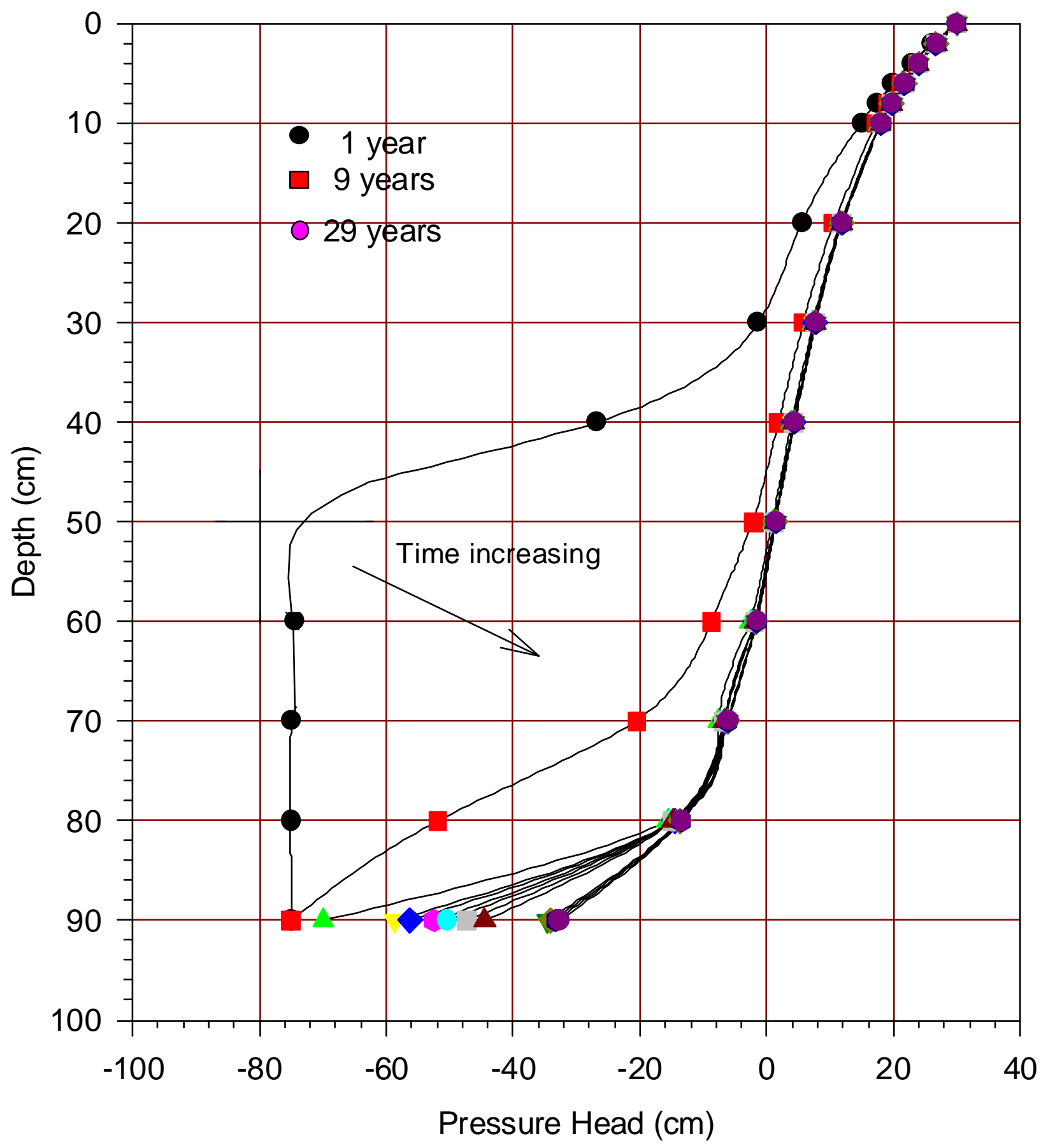

NOTE: The distance from $\mathrm{z}$ axis below the slit $\mathrm{x}=900 \mathrm{~cm}$.

Figure 4.6 Variation of pressure head with depth below the slit of Example 2 


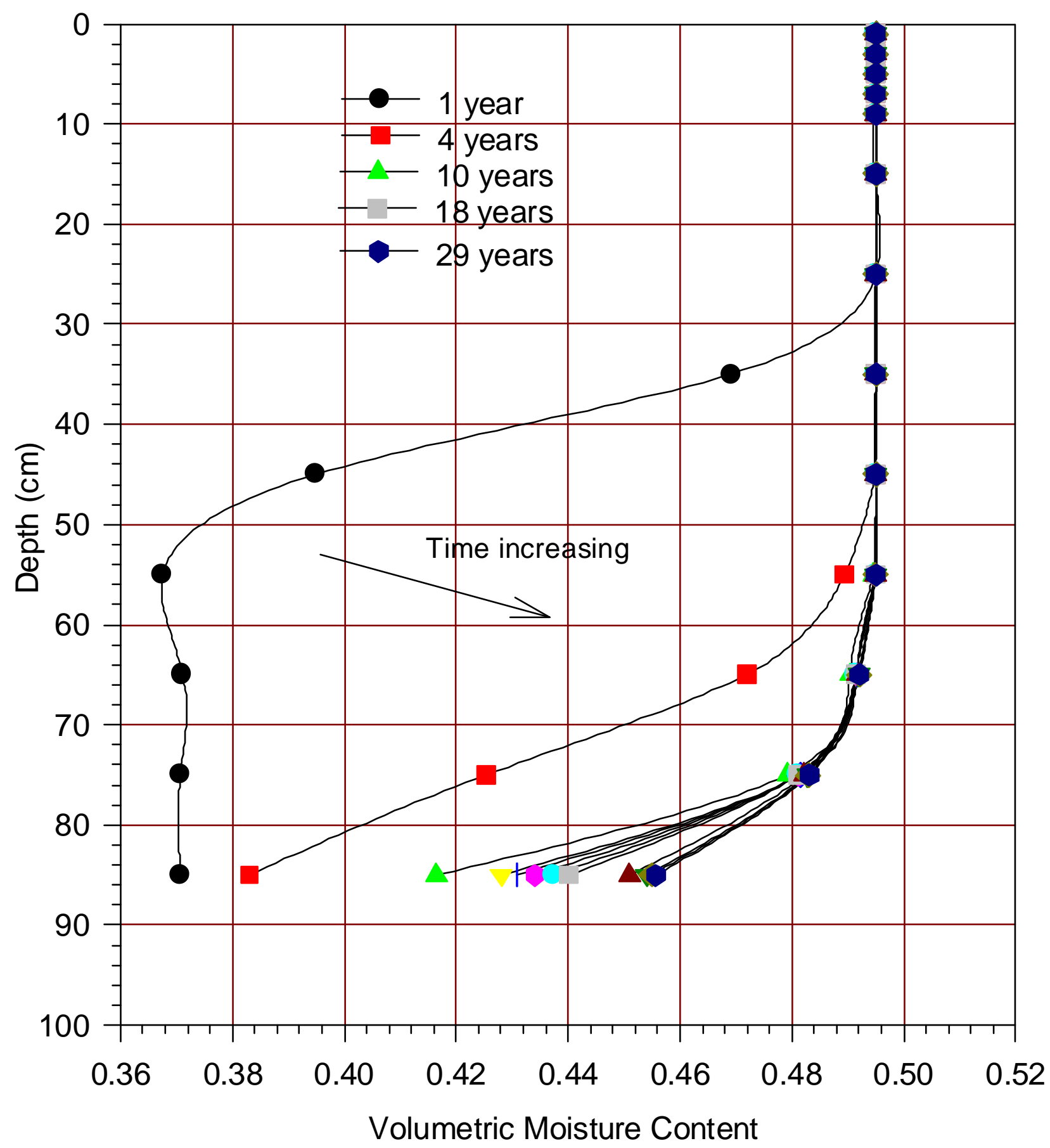

NOTE: The distance from $\mathrm{z}$ axis below the slit at $\mathrm{x}=900 \mathrm{~cm}$.

Figure 4.7 Variation of the volumetric moisture content with depth below the slit of Example 2 


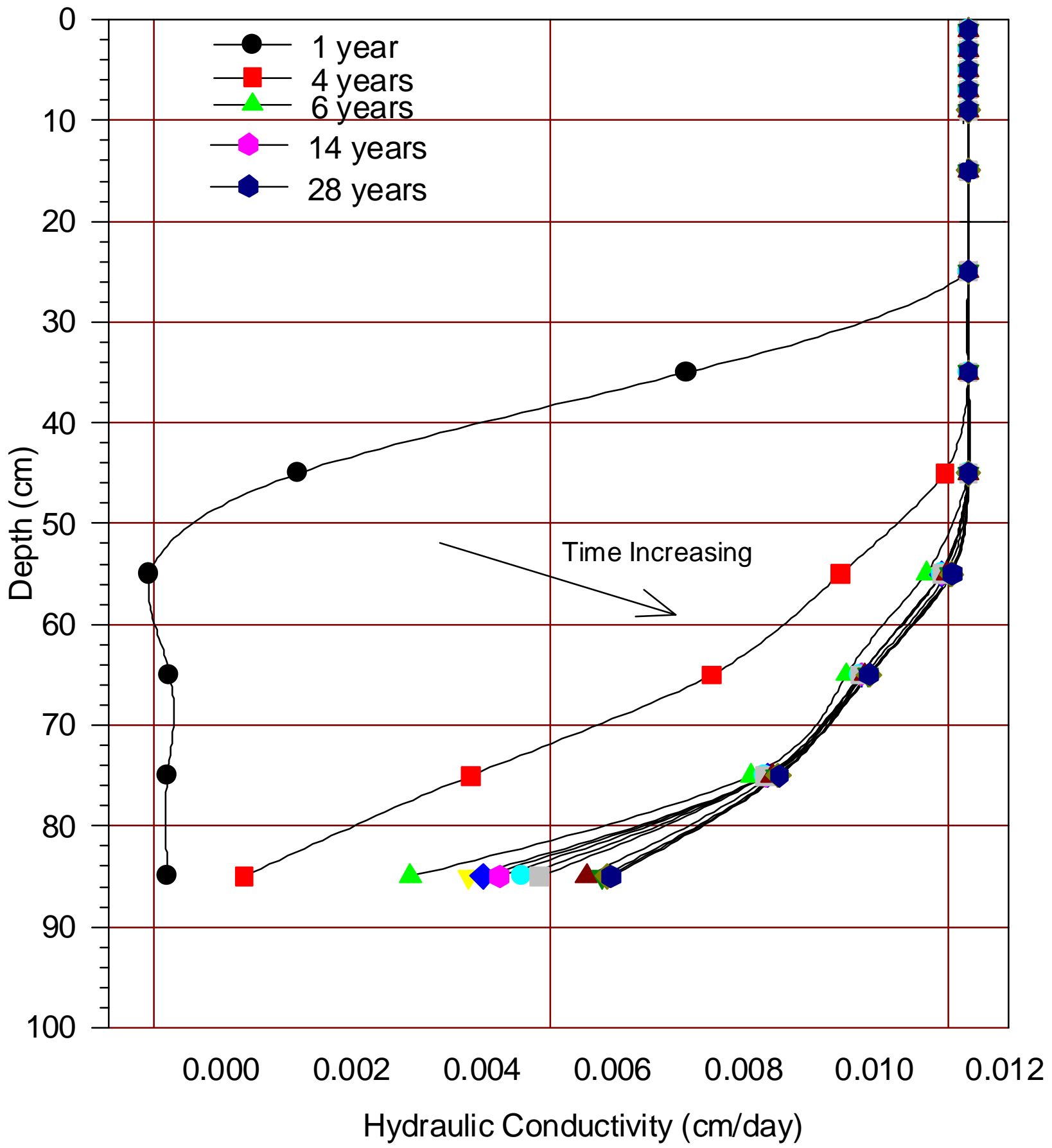

NOTE: The distance from $\mathrm{z}$ axis below the slit at $\mathrm{x}=900 \mathrm{~cm}$.

Figure 4.8 Variation of hydraulic conductivity with depth below the slit of Example 2 


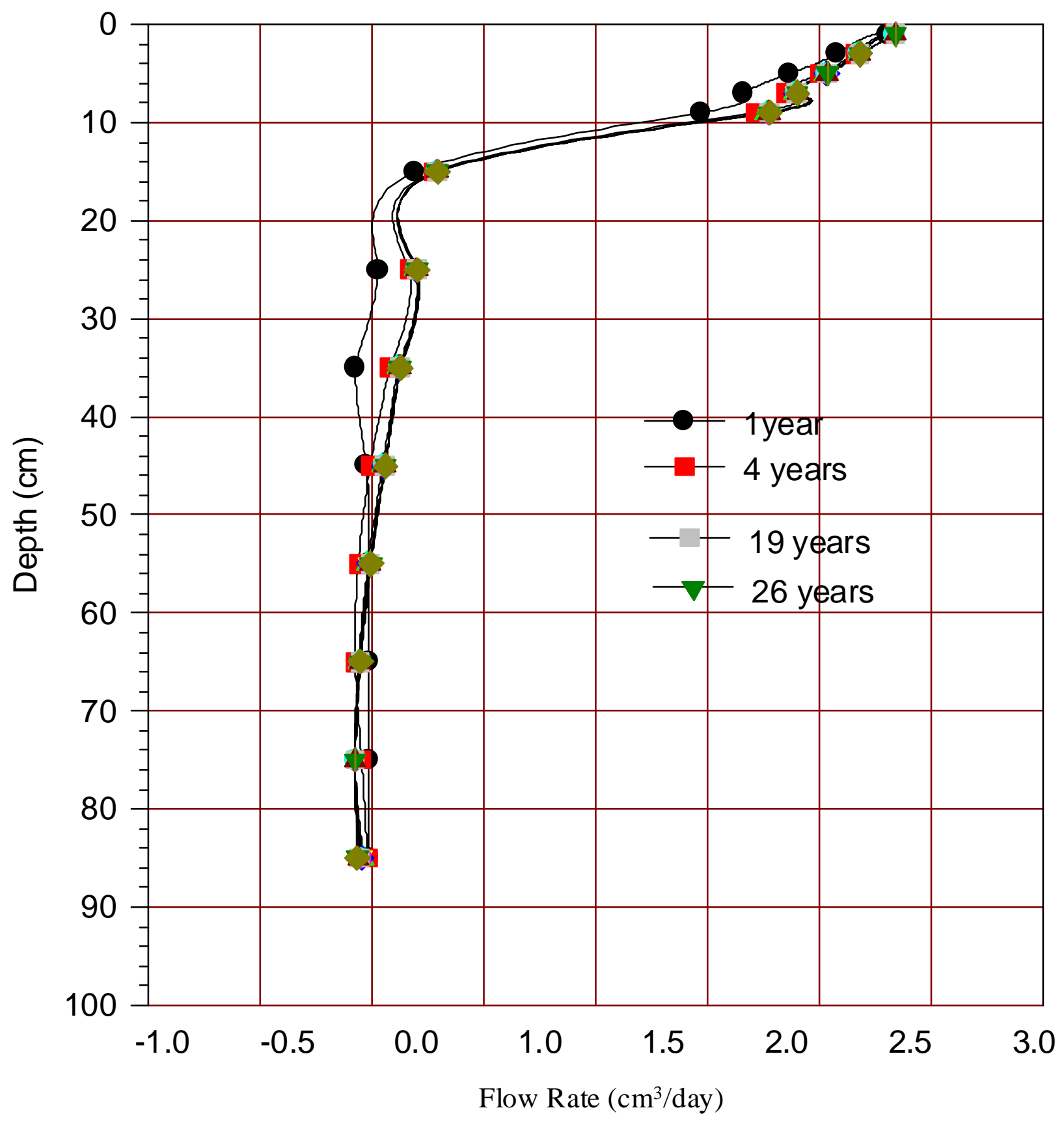

NOTE: The distance from $\mathrm{z}$ axis below the slit at $\mathrm{x}=900 \mathrm{~cm}$.

Figure 4.9 Variation of flow rate (q) with depth below the slit of Example 2 
Hydraulic conductivity (K) values for Example 2 are given in Table 4.7 and Figure 4.8. After 1 year at the depth of $35 \mathrm{~cm}$, hydraulic conductivity is about $2.0 \times 10^{-3} \mathrm{~cm} /$ day. For the same depth after 4 years, hydraulic conductivity is $1.1 \times 10^{-2} \mathrm{~cm} /$ day, and after 25 years it is the same.

The selected values of flow rate (q) for Example 2 are given in Table 4.8. These values are plotted in Figure 4.9. Flow lines of the wetting front at $21,000 \mathrm{sec}$ with $30 \mathrm{~cm}$ and $70 \mathrm{~cm}$ leachate heads are given in Figure 4.10 and 4.11, respectively. It can be seen from these figures that the flow lines are closer at the bottom than at the top locations. Both figures show that the higher the pressure head, the greater initial lateral spreading which is followed by a narrowing as it migrates downward. 


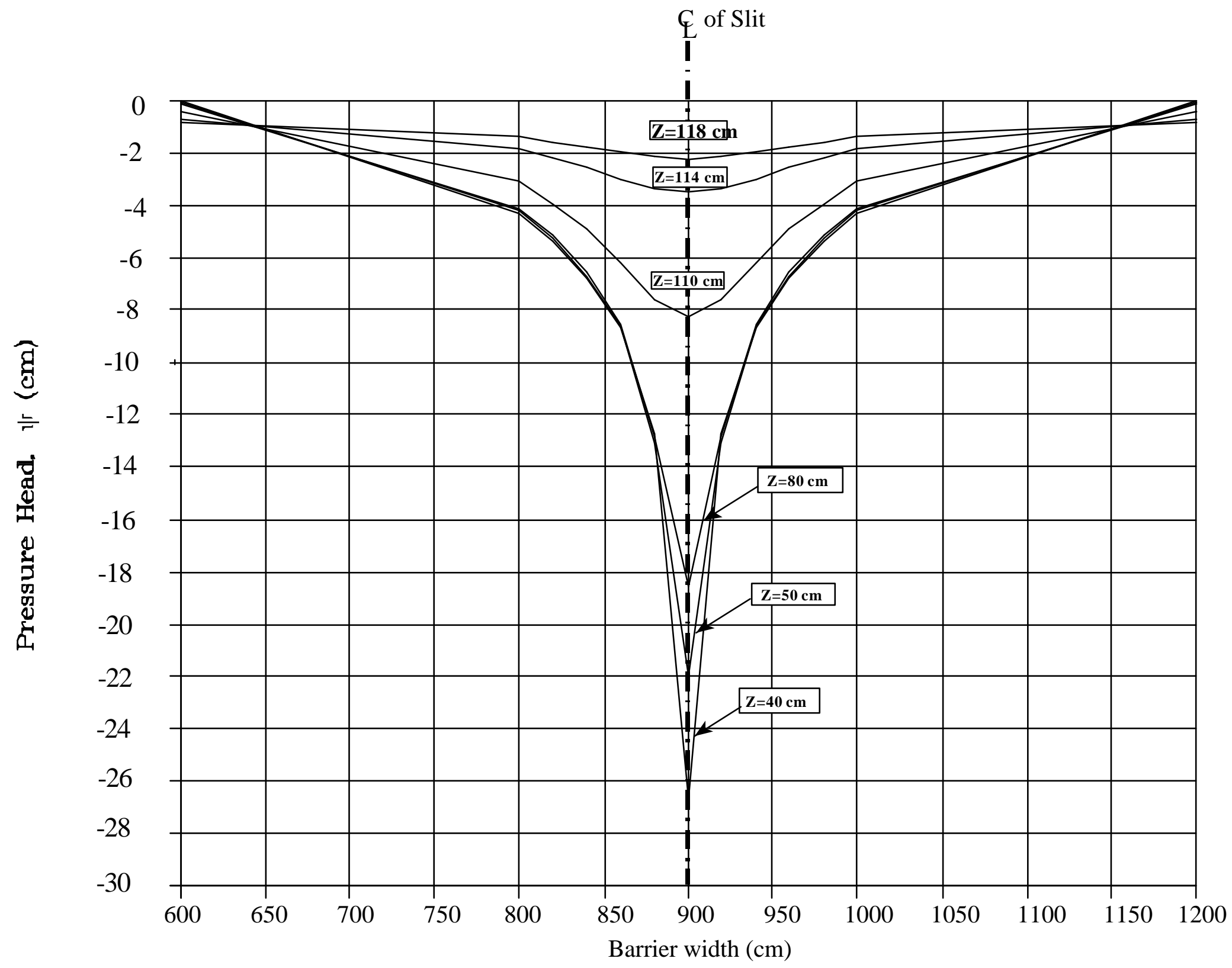

Figure 4.10 Flow lines of wetting front at 21,000 seconds (6 hours) $\left(\mathrm{h}_{\mathrm{w}}=30 \mathrm{~cm}\right)$ 
E

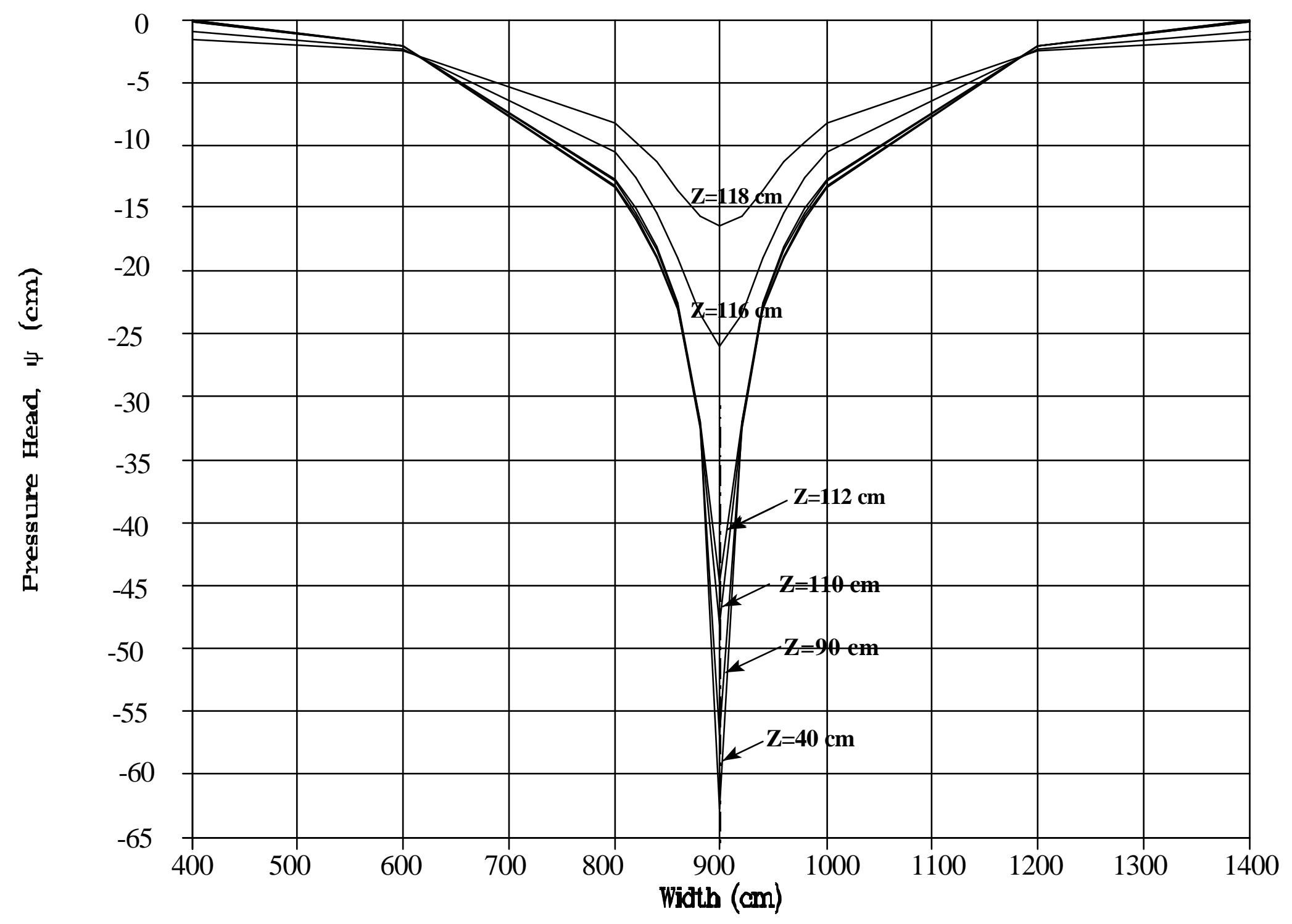

Figure 4.11 Flow lines of the wetting front at 21,000 sec. (6 hours) $\left(\mathrm{h}_{\mathrm{W}}=70 \mathrm{~cm}\right)$ 


\subsection{Results of COMPBAR}

Two empirical equations for the determination of flow rate through the soil profile for good and poor contact conditions were developed by Giroud et al. (1989 a, b) and are presented in Equation 2.1 and 2.2 in Chapter 2. These equations were coupled with the finite element method to analyze the transient flow through an unsaturated compacted clay barrier. The technique can also be used to predict the time required for a wetting front to migrate completely through the clay barrier. This time will determine the effective life of a composite barrier. The ability to determine the life of a composite barrier system has significant implications for forecasting the time that a landfill can be used efficiently, and for preventing the contamination of the ground water table. To determine when the wetting front reaches the leachate detection layer, the nodes in the mesh which are located adjacent to the sand layer should be monitored closely. When the nodes have attained a pressure head $(\psi)$ value of zero, this indicates that saturated conditions and the wetting front have reached the leachate detection layer. As a verification, the results obtained from this technique were compared with results reported by Giroud et. al. (1989). The calculation of overall flow rate (Q) values from the empirical equations, flow rate values through the soil profile calculated using COMPBAR, and the time required to reach the leachate detection system for both cases are presented in Table 4.9.

The time estimation using the COMPBAR program was based on the time required time for the wetting front (pressure head values equal to zero) to reach the leachate detection layer. The time calculation using Girouds' results were based on Equation 3.1. It can be seen from data in Table 4.9 that, in most cases, the time estimation for the wetting front to reach the sand layer is about the same.

\subsection{Comparison with SOILINER Results for a Hypothetical Case}

The example given in the SOILINER code manual (Goode et al 1986) was analyzed using the technique developed in this study. A sketch of the barrier for this example was presented in Chapter 3, Section 3.5.1. Pressure head $(\psi)$ and volumetric moisture content $(\theta)$ values from 
Table 4.9 Time calculated by using Darcy's law, Q=kiA and the finite element method (i.e., COMPBAR computer code).

\section{G I R R O U U D' S $\quad$ P R O C C E D U R E}

\begin{tabular}{|c|c|c|c|}
\hline $\begin{array}{l}\text { Example Name } \\
(\text { COMPBAR) }\end{array}$ & $\begin{array}{l}\text { Bulk value of Flow rate }(Q) \\
\text { obtained by using } Q=k i A \\
\qquad\left(\mathrm{~m}^{3} / \mathrm{sec}\right)\end{array}$ & $\begin{array}{l}\text { Time obtained from the bulk } \\
\text { values of Flow rate }(Q) \\
\text { (years) }\end{array}$ & $\begin{array}{l}\text { Time calculated by finite } \\
\text { element method } \\
\text { (years) }\end{array}$ \\
\hline Example 1 & $3.75 \times 10^{-08}$ & 22.80 & 22.80 \\
\hline Example 2 & $4.11 \times 10^{-08}$ & 21.00 & 25.00 \\
\hline Example 3 & $2.05 \times 10^{-07}$ & 4.20 & 4.10 \\
\hline Example 4 & $8.05 \times 10^{-08}$ & 10.60 & 10.80 \\
\hline Example 5 & $4.41 \times 10^{-07}$ & 19.00 & 20.50 \\
\hline Example 6 & $2.39 \times 10^{-07}$ & 3.60 & 4.00 \\
\hline Example 7 & $6.23 \times 10^{-06}$ & 0.14 & 0.17 \\
\hline Example 8 & $4.73 \times 10^{-09}$ & 181.00 & 167.00 \\
\hline Example 9 & $7.51 \times 10^{-09}$ & 114.00 & 109.00 \\
\hline Example 10 & $4.21 \times 10^{-08}$ & 20.00 & 19.50 \\
\hline Example 11 & $4.78 \times 10^{-08}$ & 17.80 & 18.60 \\
\hline Example 12 & $8.82 \times 10^{-08}$ & 9.70 & 10.50 \\
\hline Example 13 & $6.82 \times 10^{-06}$ & 0.13 & 0.14 \\
\hline Example 14 & $1.61 \times 10^{-08}$ & 53.00 & 48.00 \\
\hline Example 15 & $4.78 \times 10^{-08}$ & 17.90 & 18.60 \\
\hline Example 16 & $1.24 \times 10^{-06}$ & 0.69 & 0.80 \\
\hline Example 17 & $2.67 \times 10^{-06}$ & 0.32 & 0.40 \\
\hline Example 18 & $9.46 \times 10^{-10}$ & 905.00 & 850.00 \\
\hline Example 19 & $1.50 \times 10^{-11}$ & 5110.00 & 5700.00 \\
\hline Example 20 & $1.19 \times 10^{-10}$ & 7189.00 & 7100.00 \\
\hline
\end{tabular}


SOILINER and COMPBAR results are plotted along the depth shown in Figures 4.12 and 4.13, respectively. It is observed from these figures that pressure head and volumetric moisture content values estimated from SOILINER computer programs are similar and have similar trends. As seen in Figure 4.13, both programs show that the leachate migrates vertically, then laterally, and vertically again. Also the pressure head behaves in a similar fashion, increasing as the depth increases, Figure 4.12.

It can be seen from the Table 4.9 that in most cases, the time estimated for the wetting front to reach the sand layer is almost the same. As a matter of fact that the times obtained from the COMPBAR program are more reliable because the flow rate changes with the depth as a function of time.

\subsection{Comparison with SEEP Program}

Another type of verification has been conducted assuming steady-state, saturated conditions. The initial degree of saturation of the soil profile was assumed as $100 \%$. The variations of total stress with depth for a saturated soil and leachate placed on top of the soil profile are shown graphically in Figure 4.14 (a) and (b). Figure 4.14 a shows $90 \mathrm{~cm}$ of saturated soil, with the groundwater table at the top. For this case, total stress is zero at the top of the saturated soil and increases linearly with depth. Figure 4.14 b shows $90 \mathrm{~cm}$ of an unsaturated soil liner with $30 \mathrm{~cm}$ of leachate placed on top of soil liner. The same mesh, as shown in Figure 3.20, was used. The initial pressure head $(\psi)$ values were assumed as zero, which indicates saturation, and several cases were analyzed. A comparison of COMPBAR and SEEP computer results was made to show that both programs give similar linear results with a saturated soil profile. Only COMPBAR, however, can provide results for a geomembrane placed on top of a slit, under unsaturated soil conditions.

The first case assumed that there was no geomembrane between the leachate impoundment and the clay barrier. The results for this case are shown in Figure 4.15. The variation of pressure head with depth is linear to a depth of $30 \mathrm{~cm}$ at the top of the clay barrier, and continues linearly to a depth of $90 \mathrm{~cm}$. The same result was also obtained using the SEEP program. 


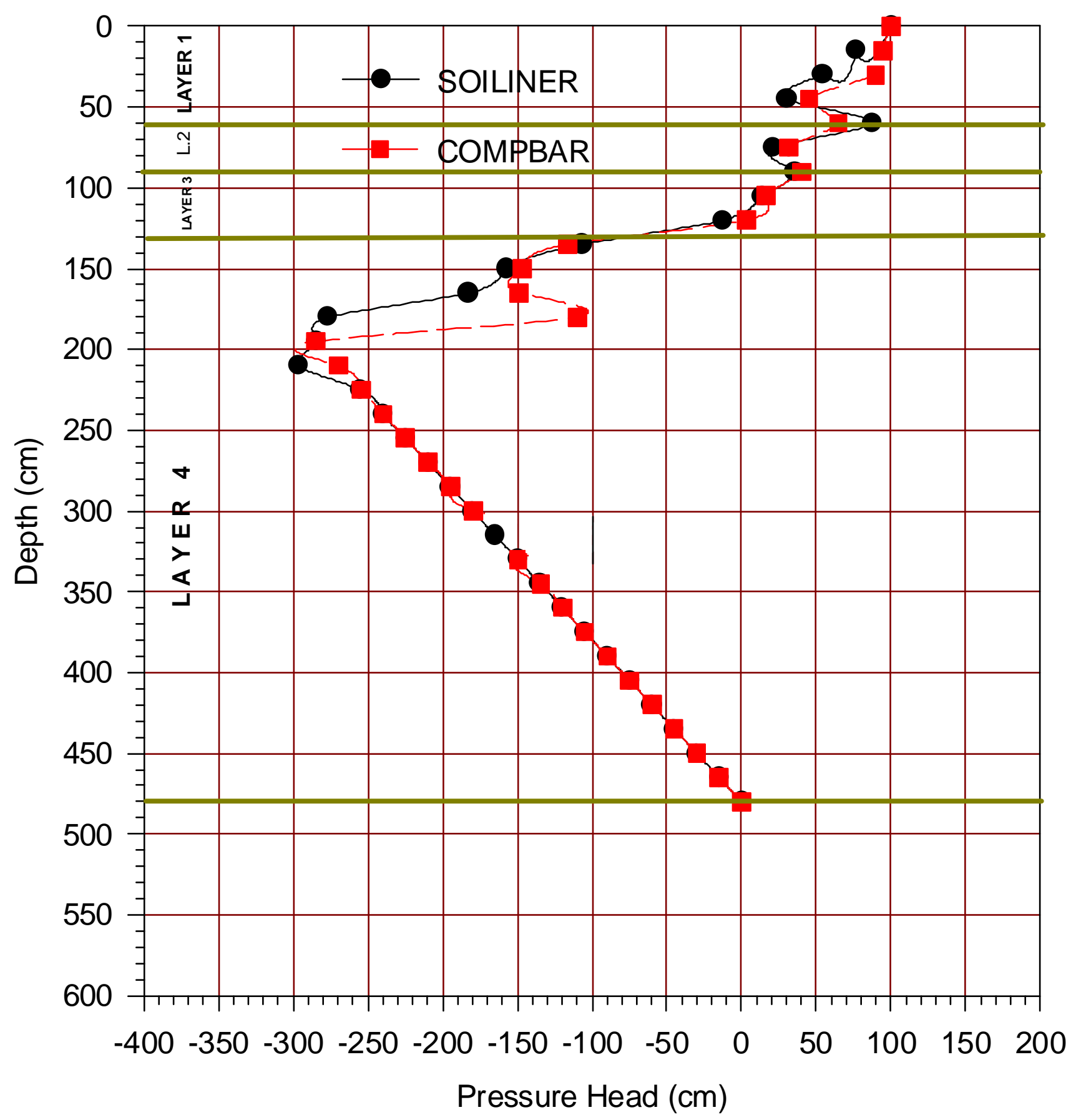

Figure 4.12 Variation of presssure head for Example 1 by using both SOILINER and COMPBAR programs (after 1 year) 


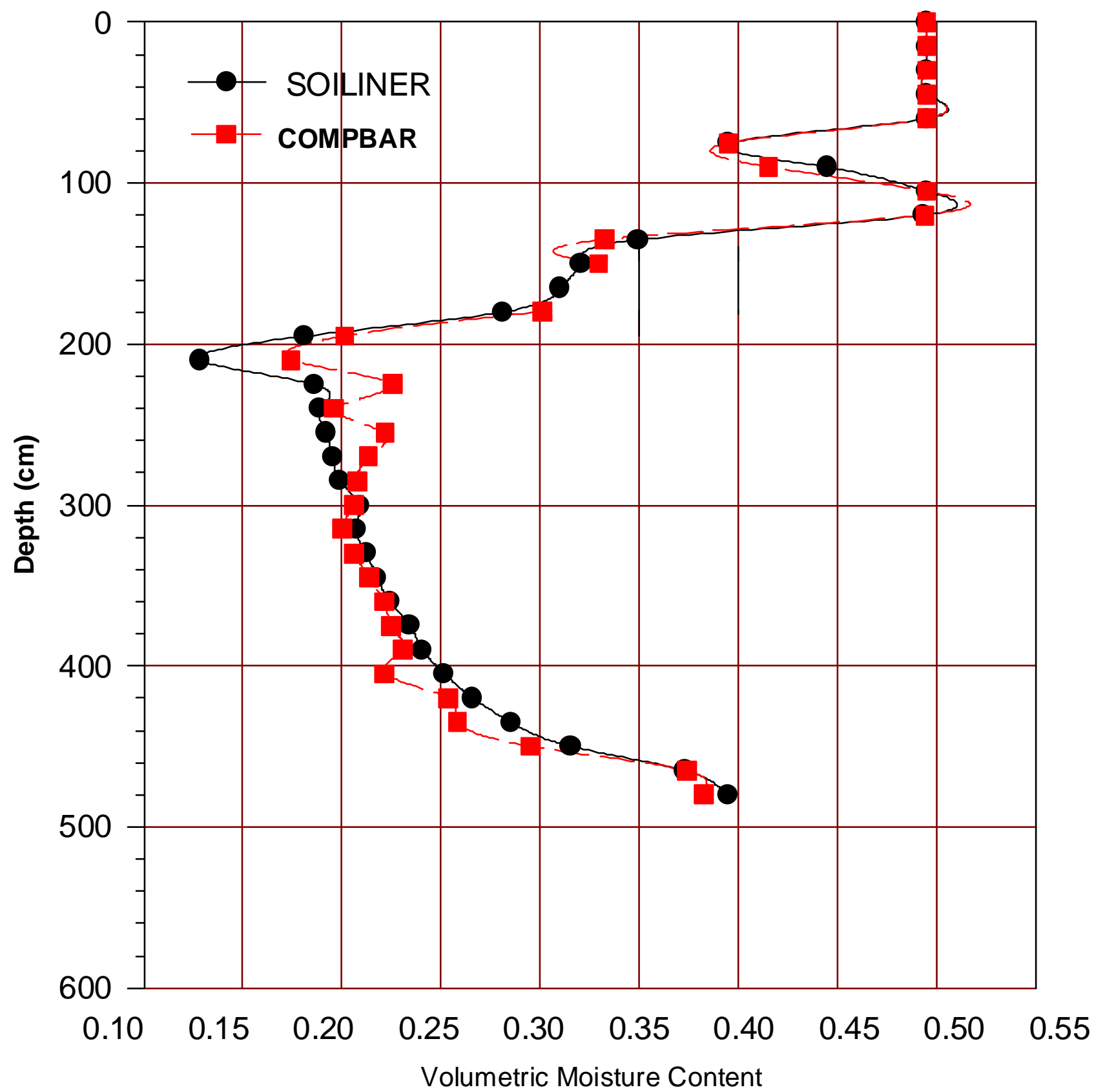

Figure 4.13 Depth versus moisture content variations for using SOILINER and COMPBAR programs (after 1 year) 


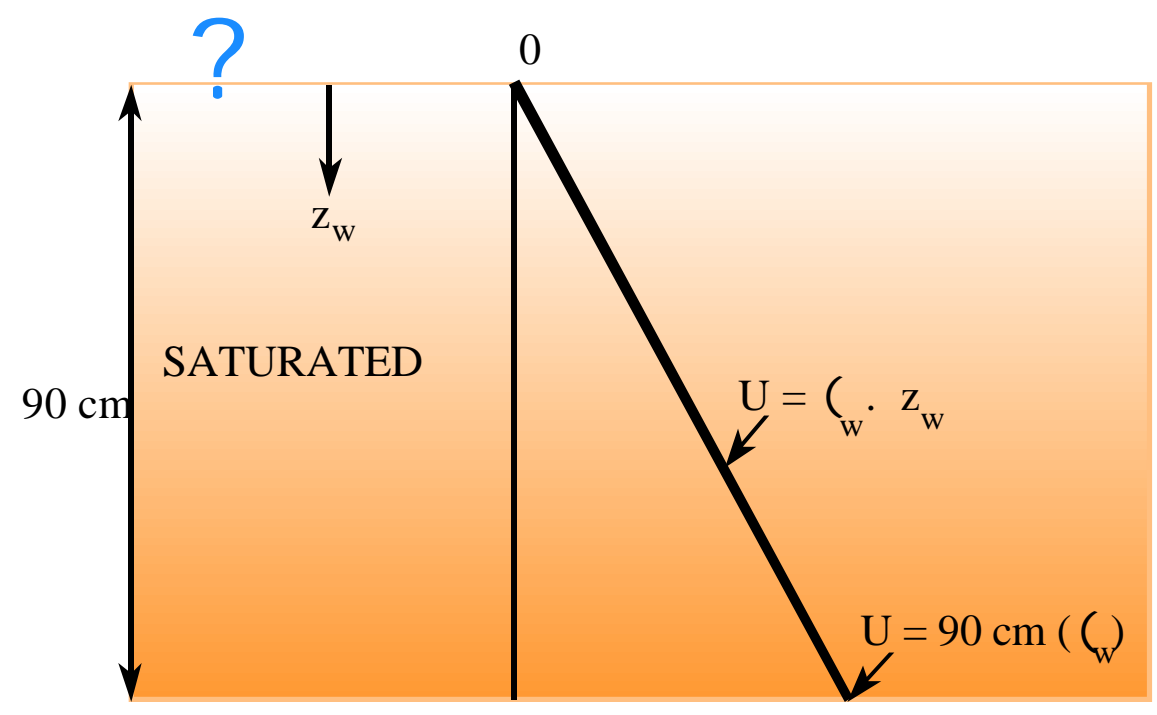

(a) For a saturated soil

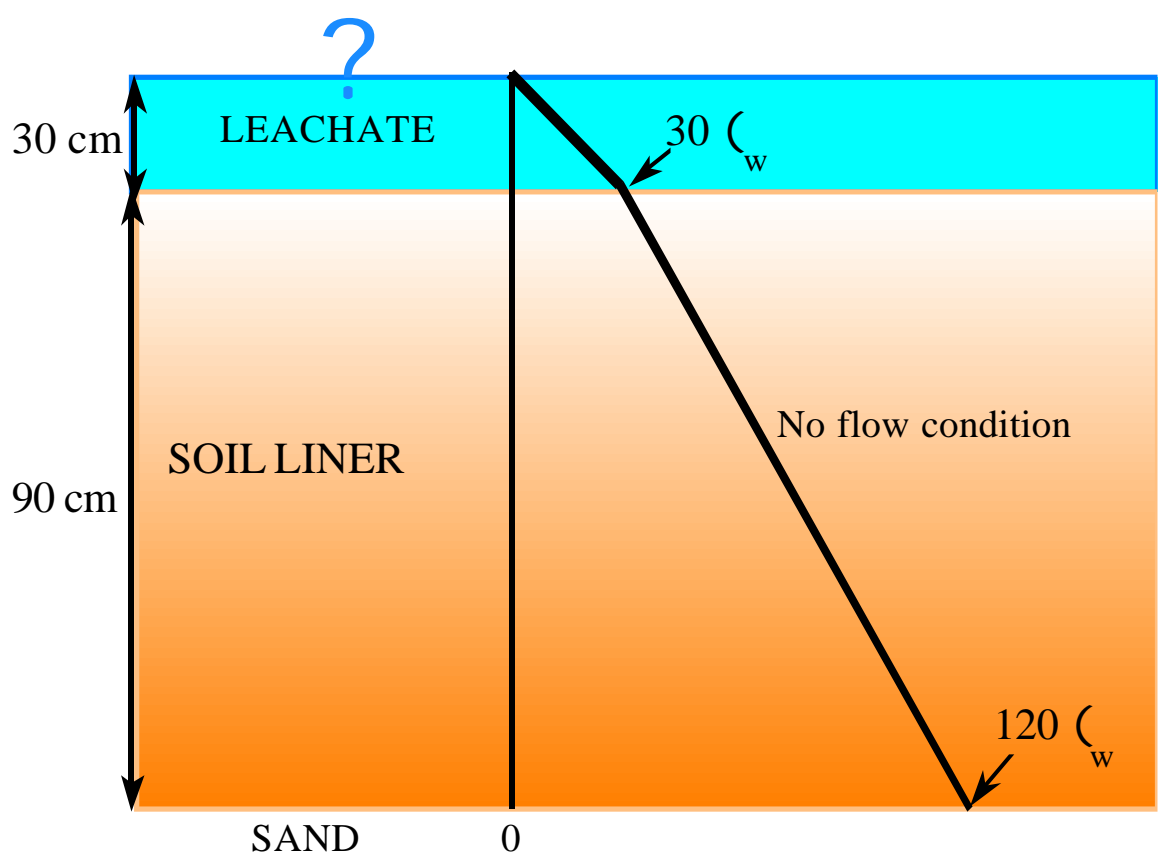

(b) For the soil profile with $30 \mathrm{~cm}$ leachate placed on top of it

Figure 4.14 The variations of total stress with depth 


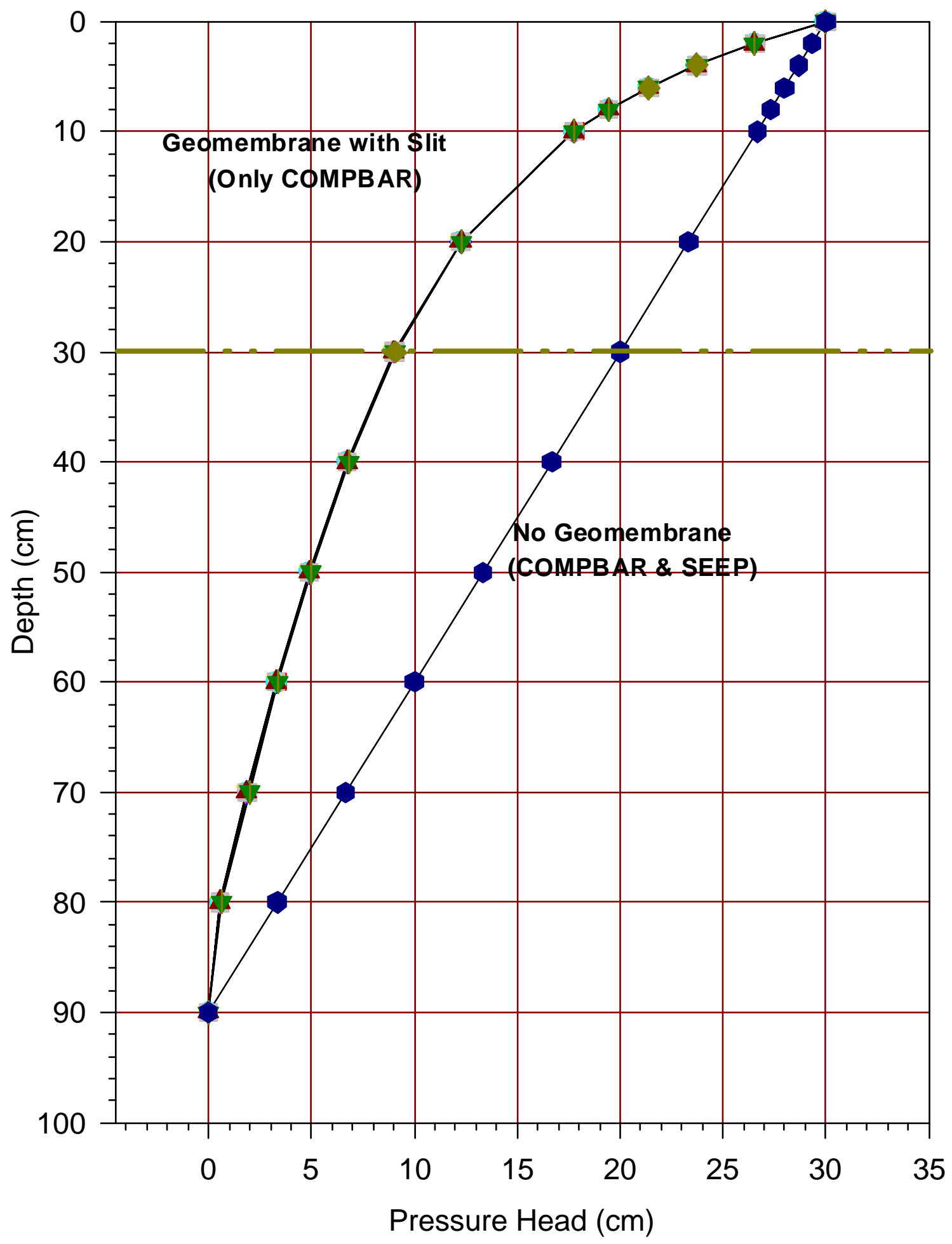

Figure 4.15 Variation of pressure head with depth below the slit with or without slit on geomembrane at saturated soil 
Another case shown in Figure 4.15 was evaluated. The soil liner was saturated, and a damaged geomembrane was placed on the top of it. The variations of pressure head with depth are nonlinear and the values are smaller than those for no geomembrane case. For example, at the depth of $30 \mathrm{~cm}$, pressure head for the no geomembrane case was $20 \mathrm{~cm}$, and for the case with the damaged geomembrane was $9 \mathrm{~cm}$. For the case of no geomembrane on the top of the soil profile, there is linear decrease in head. However, for the case of a geomembrane with a slit on the top of the soil liner, there is non-linear decrease in soil because the soil liner is unsaturated which impedes flow.

Consequently, SEEP and COMPBAR give the same results for the no geomembrane case. Thus, COMPBAR appears to result in correct values for saturated flow conditions. With the geomembrane on top of the soiliner case, the head loss rate is greater than for the no geomembrane case.

\subsection{Stability of COMPBAR Computer Program}

Three different modeling parameters were used to study stability of the COMPBAR program for the case with a slit in the geomembrane. These parameters included the head of the leachate impoundment, the value of the saturated hydraulic conductivity, and the size of the grid. The variables and conditions of the soil profile are given in Figure 4.16. The results of these evaluations are shown in Figures 4.17 through 4.25.

The effect of head of the impounded leachate was evaluated first. The head of the leachate on the top of the geomembrane was varied as $3 \mathrm{~cm}, 30 \mathrm{~cm}$, and $300 \mathrm{~cm}$ in Figures 4.17, 4.18, and 4.19. The value of the pressure head at the top of the clay barrier increases as the impoundment head increases, and decreases as the impoundment head decreases.

As time progresses the soil approaches full saturation (i. e., towards saturated levels of 0.40) as the wetting leachate front moves down into the soil. Volumetric moisture content $(\theta)$ is equal to the saturated level $\left(\theta_{\mathrm{s}}\right)$ at the top of the geomembrane and decreases nonlinearly downward through the soil profile for each leachate head. As time increases, volumetric moisture content 


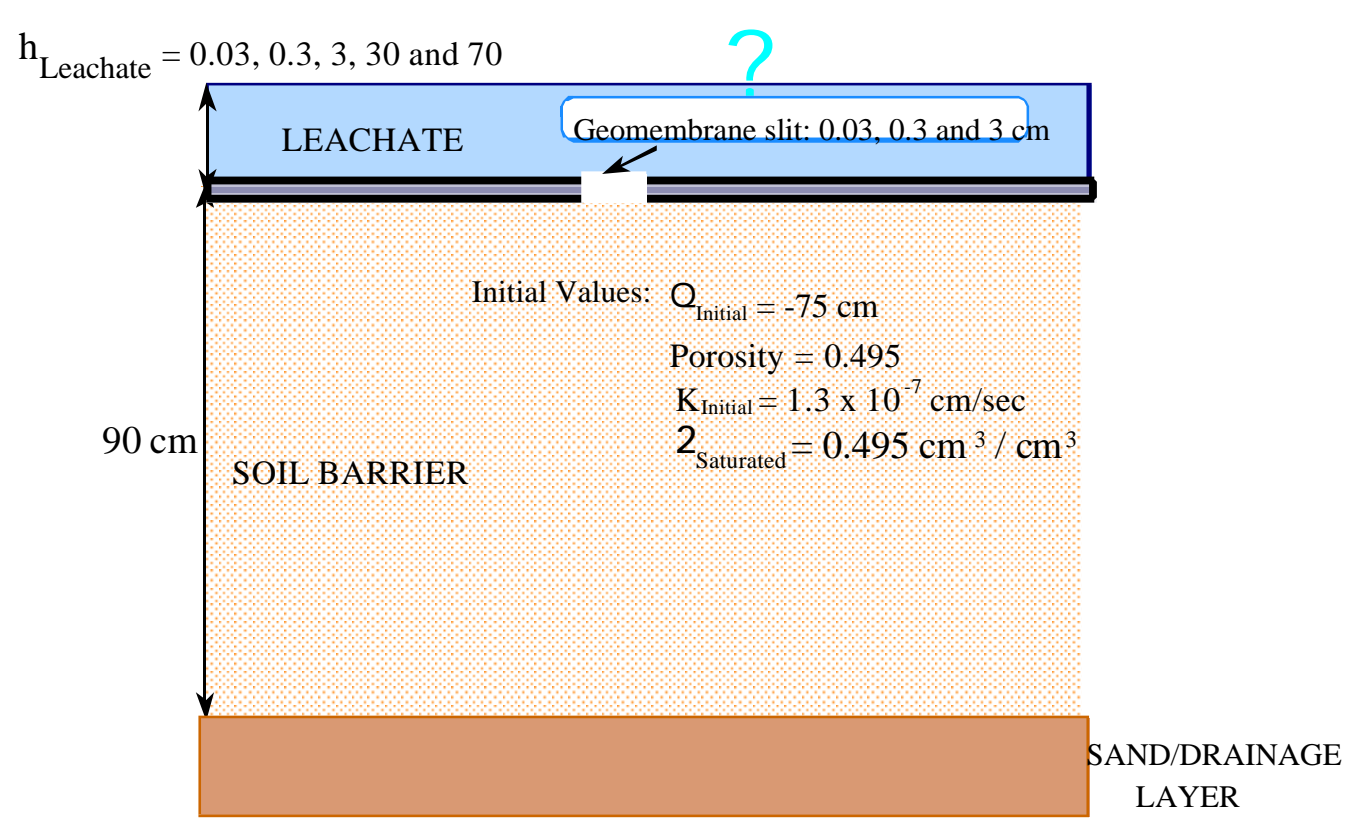

Figure 4.16 The variables and conditions of the soil profile

(and degree of saturation) increases as the wetting area progresses down into the soil. The degree of saturation $(S)$ can be defined as the ratio of the volume of water $\left(V_{w}\right)$ to the volume of voids $\left(\mathrm{V}_{\mathrm{v}}\right), \mathrm{S}=\mathrm{V}_{\mathrm{ow}} / \mathrm{V}_{\mathrm{v}}$. Figure 4.17 shows that after one year for $3 \mathrm{~cm}$ of leachate head the soil profile is saturated $(\theta=0.40)$ to a depth of $10 \mathrm{~cm}$, and then $\theta$ value sharply decreases to about 0.013 at depths between $28 \mathrm{~cm}$ and $85 \mathrm{~cm}$. As time increases, the saturation front is progressing downward through the soil profile reaching full saturation. For example, after eight years, at a depth of $65 \mathrm{~cm}, \theta$ has a value of 0.367 and continues to increase towards full saturation as indicated by the "19 years" curve. Figures 4.18 and 4.19, with $30 \mathrm{~cm}$ and $300 \mathrm{~cm}$ leachate head, respectively, show that the wetting front progresses faster down into the soil profile with increasing leachate head. After 19 years, full saturation reached a depth of about 50 $\mathrm{cm}$. For the $30 \mathrm{~cm}$ of leachate head (Figure 1.1) after 20 years, the clay barrier is saturated up to a depth of about $80 \mathrm{~cm}$. For the $300 \mathrm{~cm}$ leachate head, it was observed that after 1 year most 


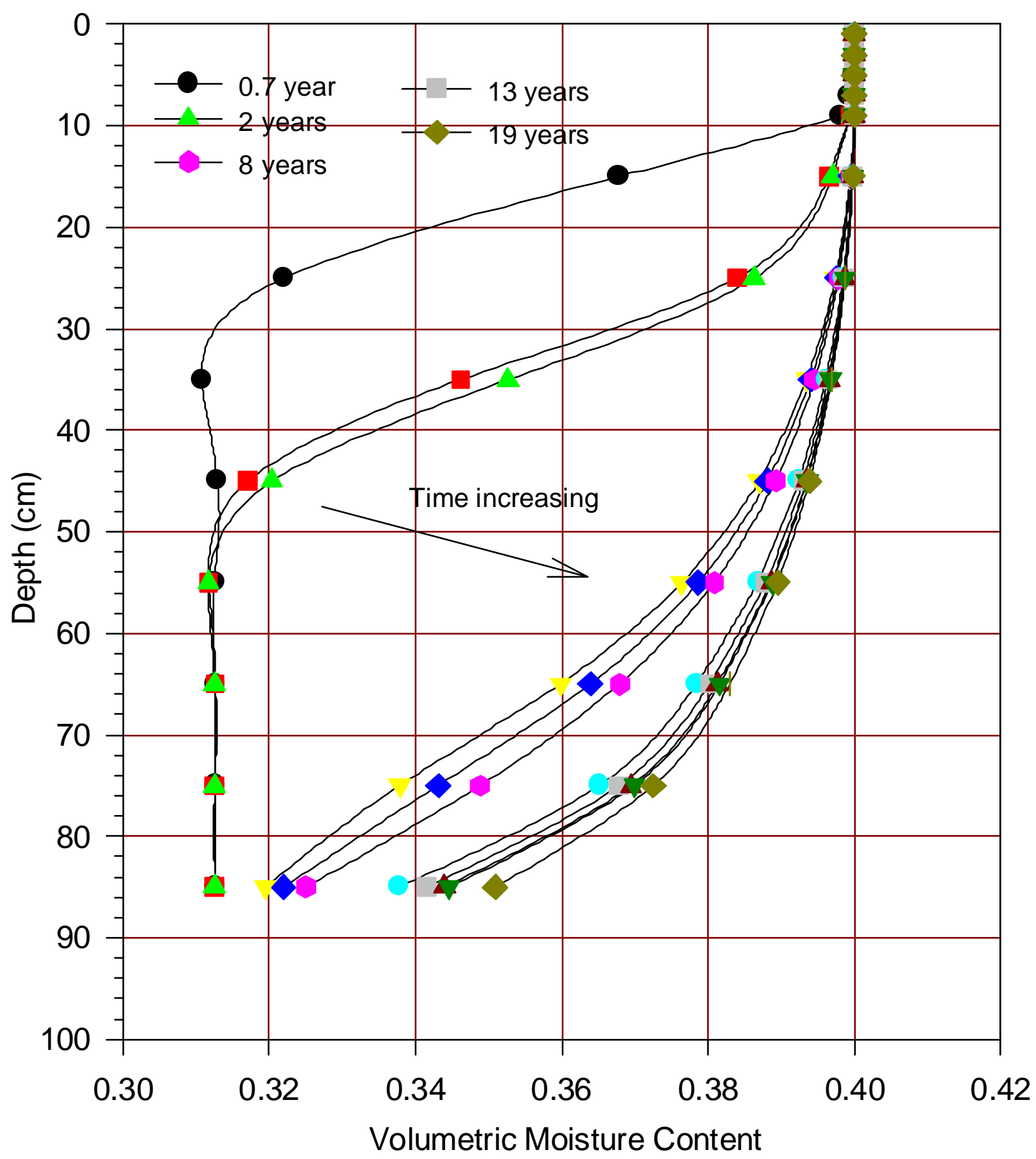

Figure 4.17 Volumetric moisture content variation with $3 \mathrm{~cm}$ leachate height 


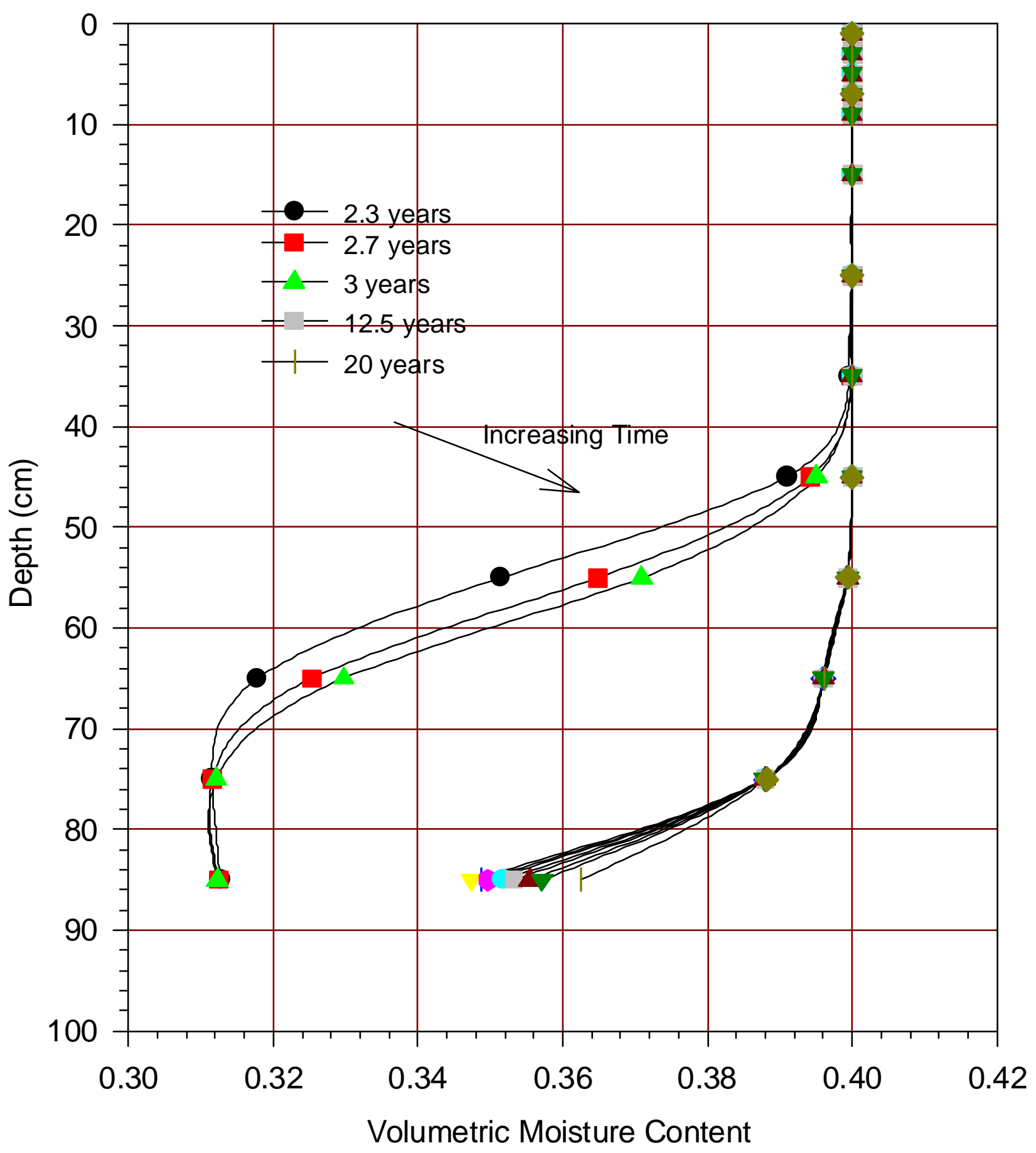

Figure 4.18 Volumetric moisture content variation with $30 \mathrm{~cm}$ leachate height 


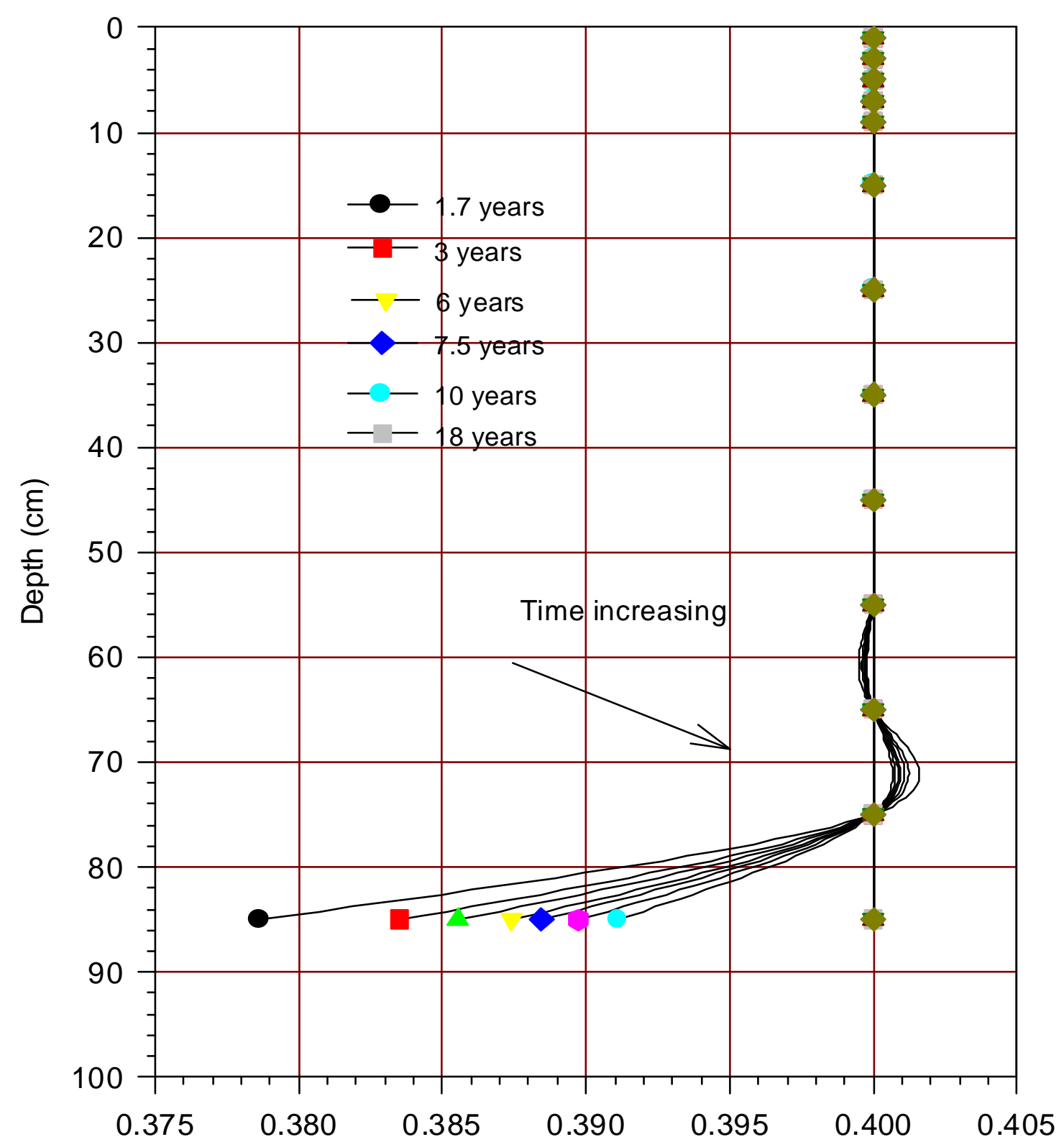

Volumetric moisture content

Figure 4.19 Volumetric moisture content variation with $300 \mathrm{~cm}$ leachate head 
of the soil profile was saturated, which indicates that a higher depth of impoundment yields faster wetting front movements as expected. Obviously, the head of pounded leachate on the soil liner strongly affects the rate of movements of the saturated wetting front.

The next step of the stability analyses was to study the effect of hydraulic conductivity variation in the soil barrier. The saturated hydraulic conductivity was varied as follows: $1 \times 10^{-4} \mathrm{~cm} / \mathrm{sec}$, $1 \times 10^{-7} \mathrm{~cm} / \mathrm{sec}$ and $1 \times 10^{-10} \mathrm{~cm} / \mathrm{sec}$ as shown in Figure 4.20 through 4.22. It can be seen from these figures that the wetting front reaches the collection layer after one year. If the soil barrier has a very high hydraulic conductivity value as in this case, the wetting front moves rapidly down in the soil as compared to the case with a very low hydraulic conductivity soil. For a normal case of hydraulic conductivity, the behavior is reasonable where the soil is saturated up to the depth of $45 \mathrm{~cm}$. The part of the soil profile which is under that depth still has the initial volumetric moisture content value.

The final stability examination of COMPBAR evaluated the effect of variation of grid sizes of the finite element mesh used for simulation (Figure 4.23 to 4.25). A grid size of $200 \mathrm{~cm}$ was employed to conduct all the analyses in this study. In addition, two different grid sizes were also used as $100 \mathrm{~cm}$ and $300 \mathrm{~cm}$. It can be seen from all obtained figures for all time increment that the volumetric moisture content versus depth trends are similar for the three different grid sizes, $100 \mathrm{~cm}, 300 \mathrm{~cm}$, and $600 \mathrm{~cm}$. Therefore, the $200 \mathrm{~cm}$ grid size was used throughout this study.

\subsection{Results of Parametric Analyses}

These examples simulate different conditions of soil-geomembrane contact, slit size, and different leachate head for a given and hydraulic conductivity of the soil barrier. Twenty variations were studied, including Examples 1 and 2, which are shown in Tables 4.9 and Figure 4.16. The overall flow rate values as defined by Giroud and Bonaparte (1989 a, b) (see Equations 2.1 and 2.2 in Chapter 2) can be observed from this table. The selected outputs of several examples were also presented in tables and figures in Section 4.2 in this chapter. 


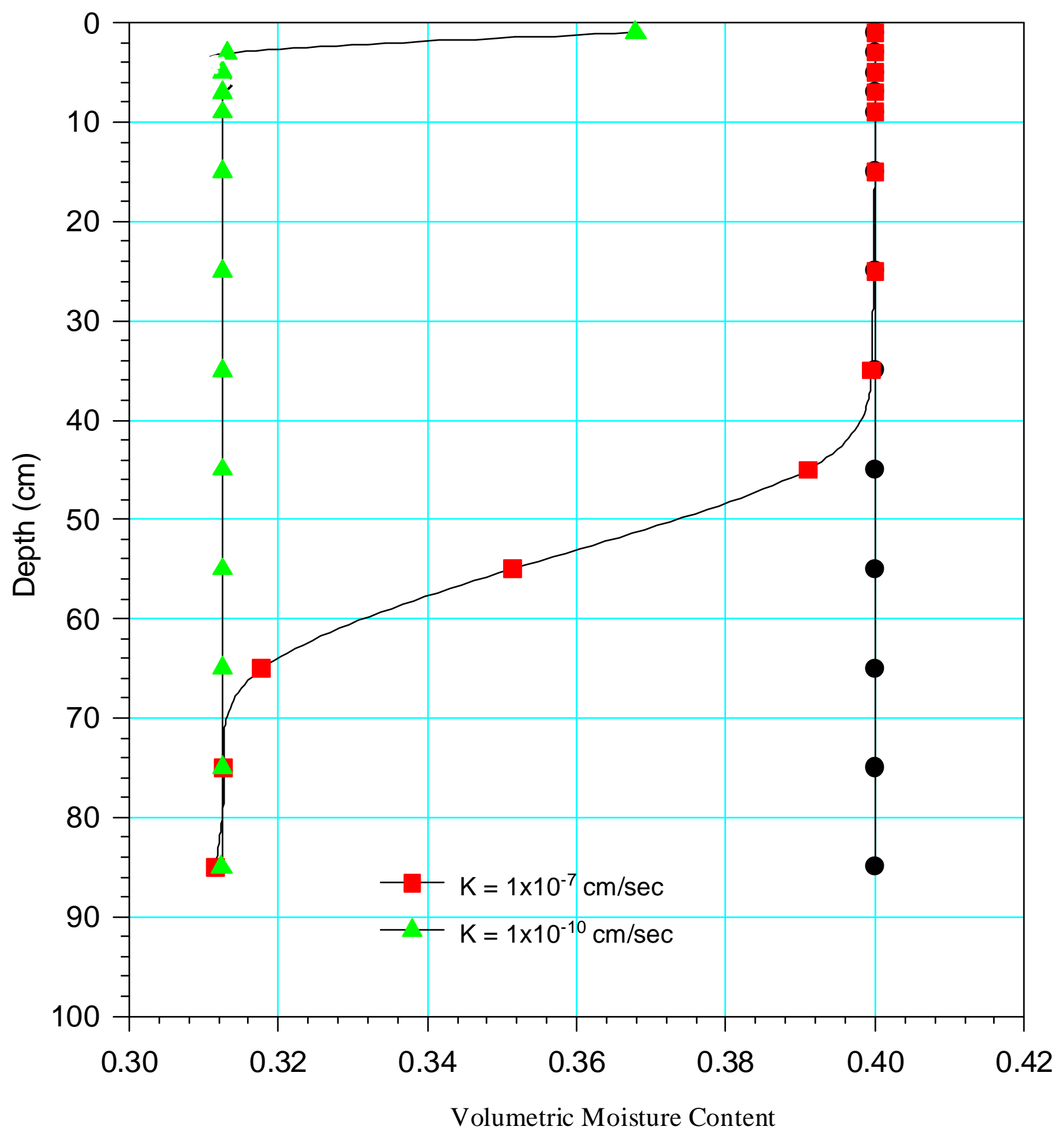

Figure 4.20 Change of volumetric moisture content with depth below the slit after 1 year 


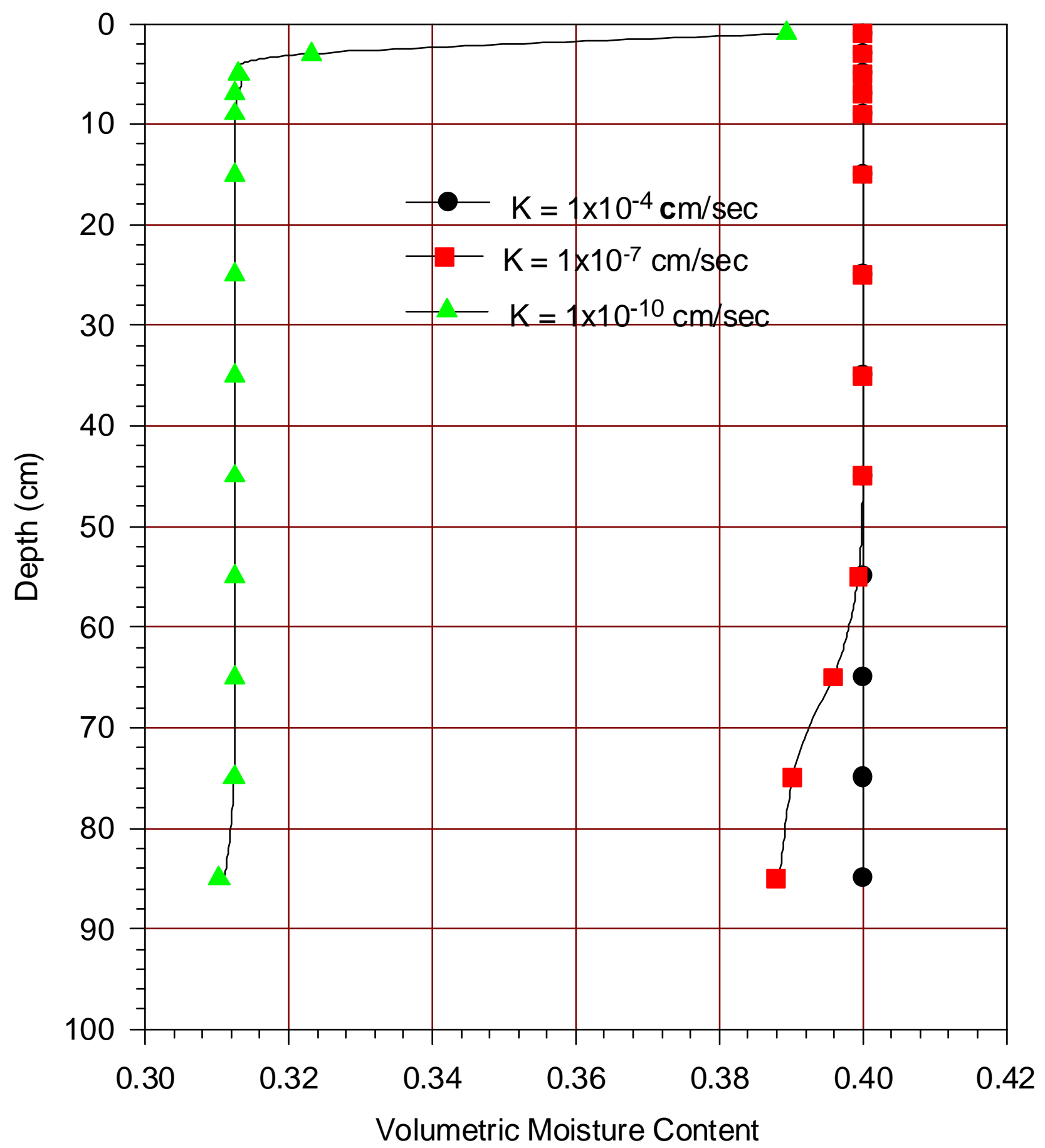

Figure 4.21 Change of volumetric moisture content with depth below the slit after 8 years 


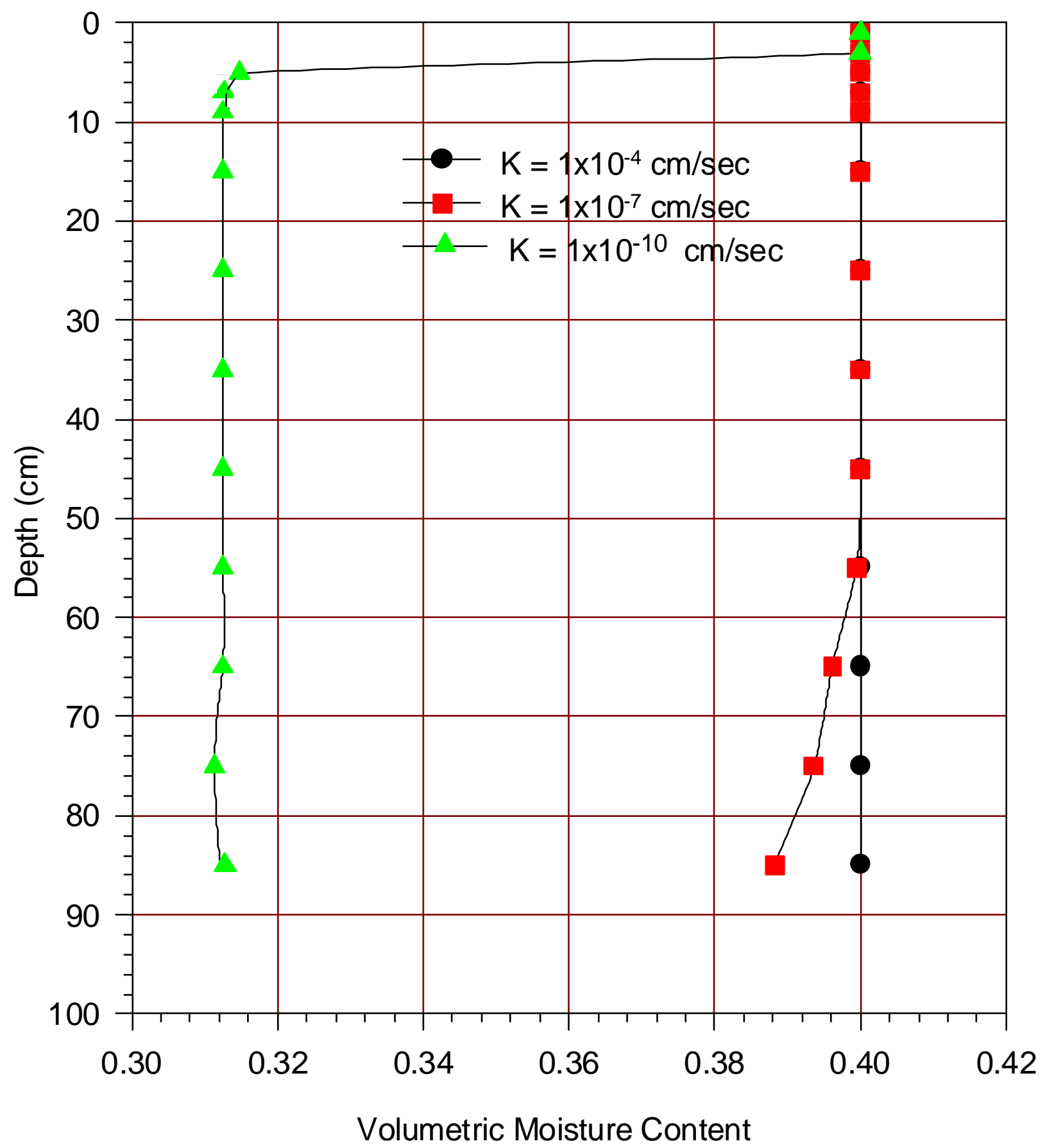

Figure 4.22 Change of volumetric moisture content with depth below the slit after 21 years 


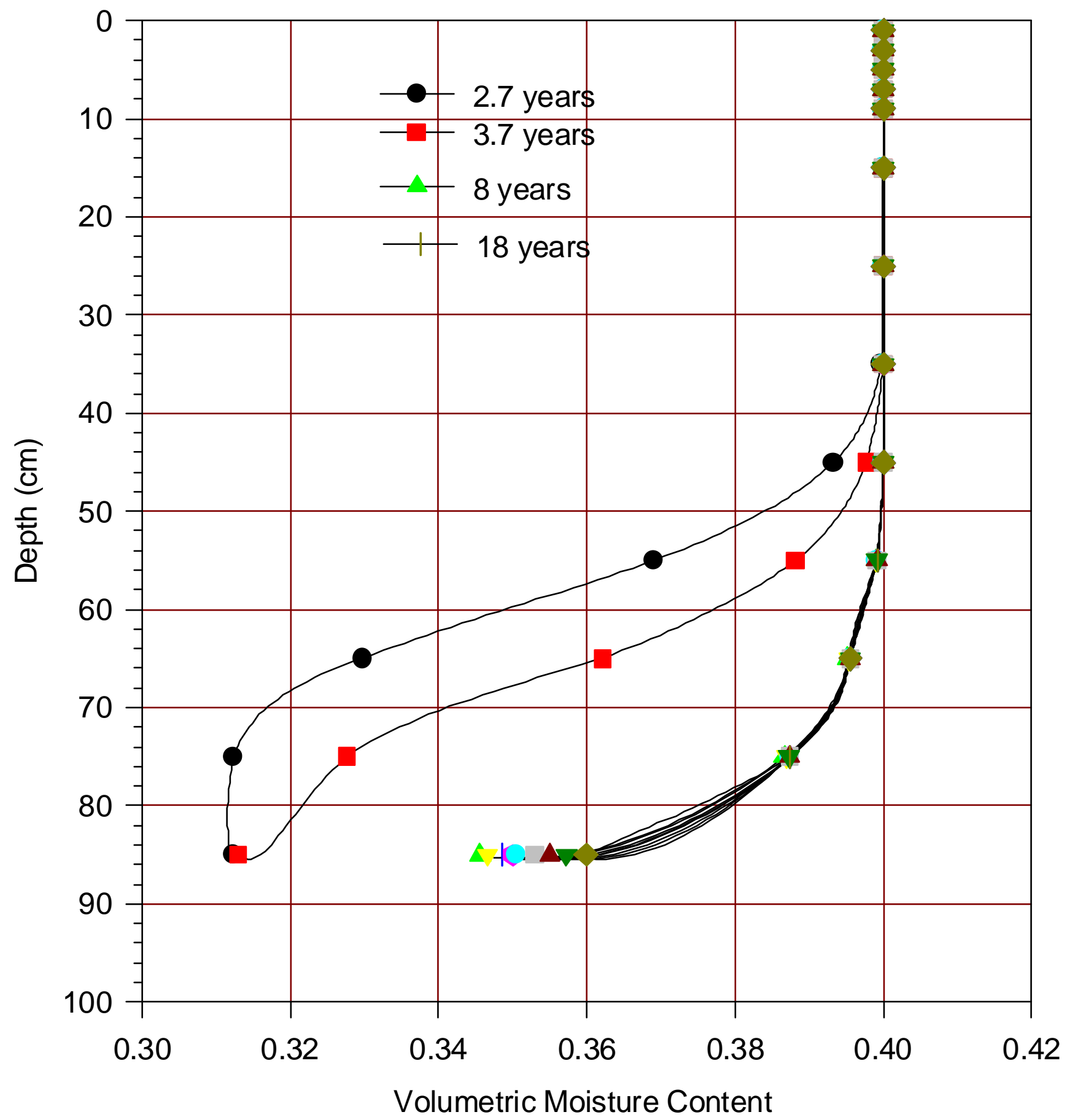

Figure 4.23 Volumetric moisture content variation by using $100 \mathrm{~cm}$ grid size 


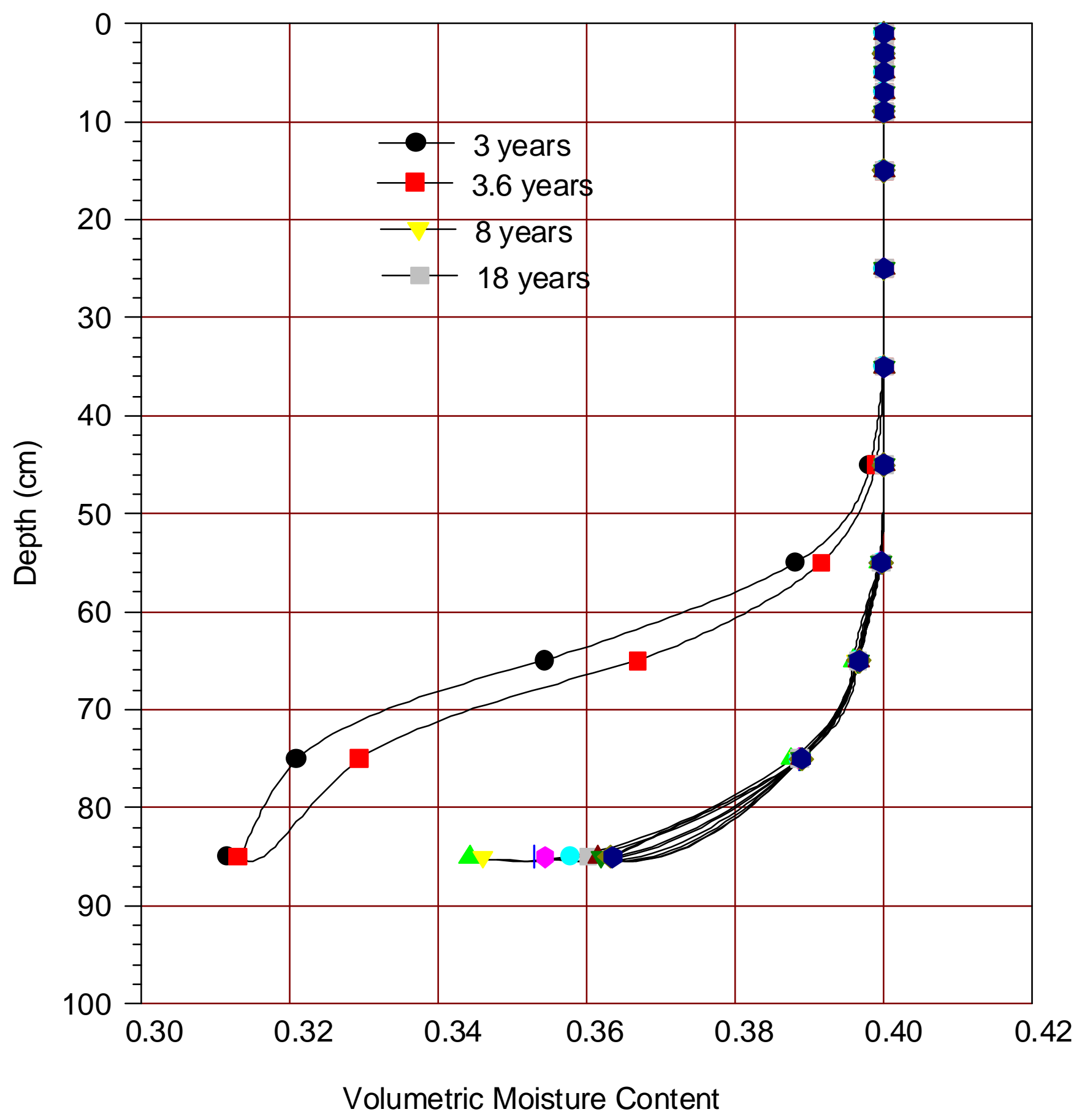

Figure 4.24 Volumetric moisture content variation by using $300 \mathrm{~cm}$ grid size 


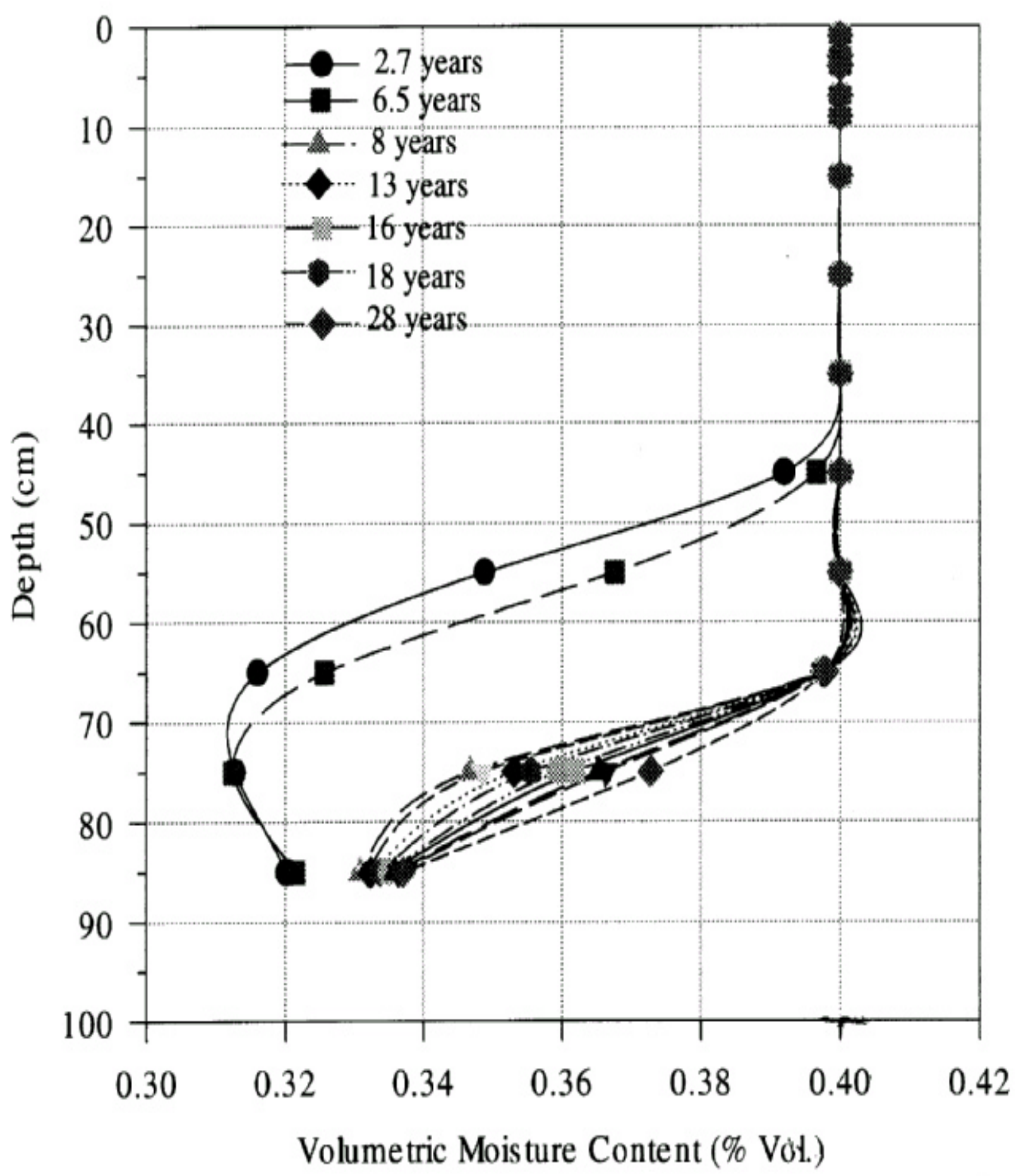

Figure 4.25 Volumetric moisture content variation using a $600 \mathrm{~cm}$ grid size 
The solution obtained from the iterative procedure from the finite element program provides the values of pressure head $(\psi)$ at the nodes. Volumetric moisture content $(\theta)$, hydraulic conductivity (K), and flow rate (q) were obtained from equations that are functions of pressure head. The comparison of the different cases that are given in Table 4.9 will be based on pressure head values. The comparison of pressure head under different conditions of composite barrier are shown in Figure 4.26 through 4.34.

It can be seen in Figure 4.26 that pressure head values for good contact and poor soilgeomembrane contact are similar after one year. There is a maximum value close to the geomembrane and decreases mnlinearly to the minimum value in both cases. From the same figure, after one year and at a depth of $40 \mathrm{~cm}$, pressure head value is $-36 \mathrm{~cm}$ for poor contact and $-27 \mathrm{~cm}$ for good contact. This indicates that, at the same location, the moisture content levels for the poor contact were slightly higher than those for good contact. For different time periods, for example, after 10 years and at a depth of $60 \mathrm{~cm}$ good contact conditions produce -4 $\mathrm{cm}$ and $-1 \mathrm{~cm}$ of the pressure head, respectively. The slight difference in pressure head between a good soil-geomembrane contact and poor contact is significant in determining the effectiveness/longevity of the barrier system. A poor soil-geomembrane contact condition results in slightly higher pressure head and wetting front movement. With a good soilgeomembrane contact condition, the geomembrane will maintain the barrier system effectiveness for a longer period of time.

The results of Figures 4.26 and 4.27 show a slight difference in pressure head comparing poor contact and good soil-geomembrane contact conditions. In Figure 4.26, for example, after one year at a depth of $30 \mathrm{~cm}$ poor and good contact conditions behave the same. Between a depth of $30 \mathrm{~cm}$ and $50 \mathrm{~cm}$, poor soil-geomembrane contact conditions result in a slightly higher pressure head, while from 50 to $90 \mathrm{~cm}$ of depth, the pressure head is the same. After 10 years, the pressure head values behave the same at all depths. Figur т.ц, _umpares poor and good contact conditions with $70 \mathrm{~cm}$ leachate head. The pressure head difference after four years becomes more pronounced because of the higher leachate head resulting driving force. For instance, for good soil-geomembrane contact conditions, after a depth of $50 \mathrm{~cm}$, the pressure head is less than that of the poor soil-geomembrane contact conditions. After 4 years at depth of 


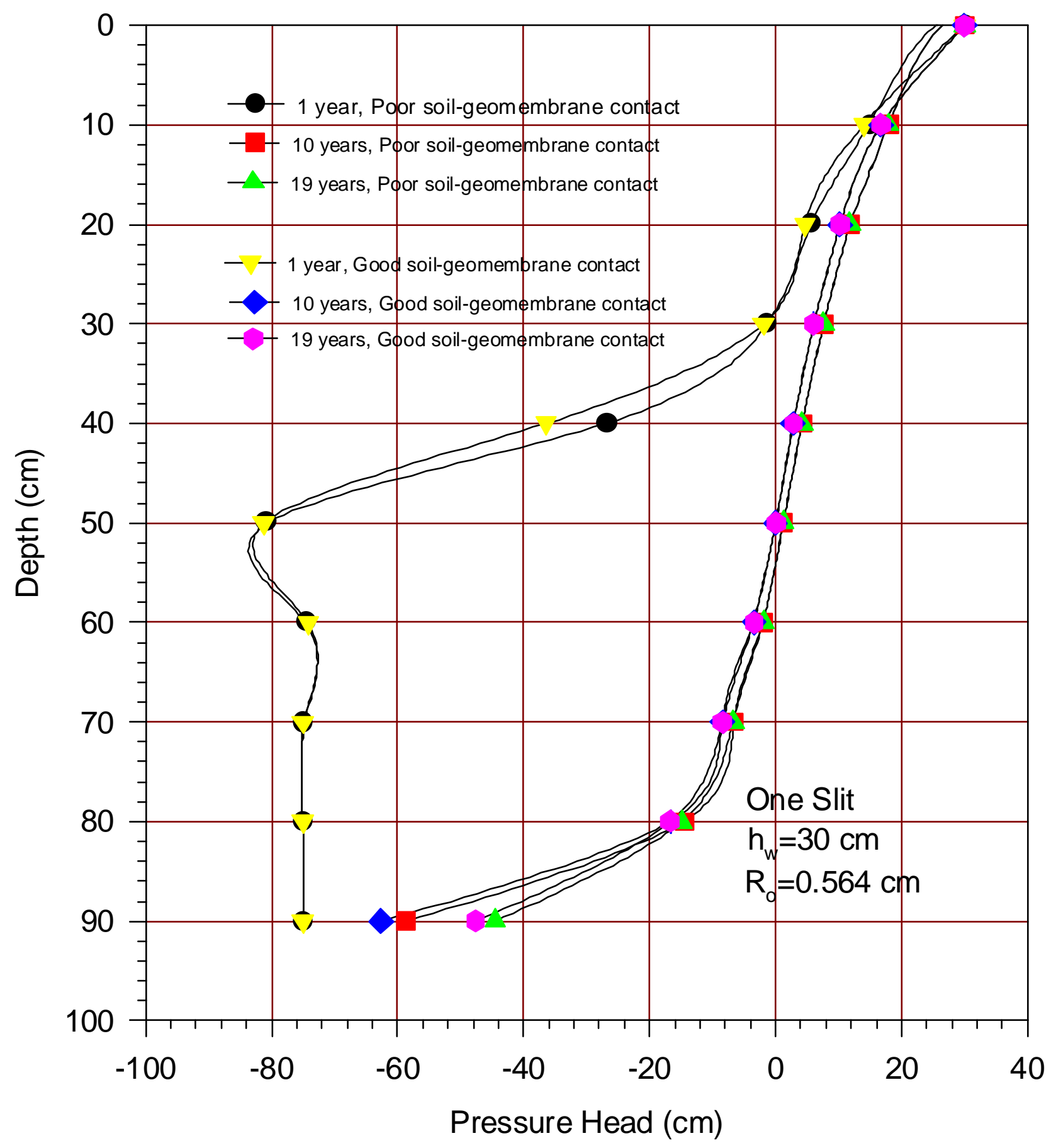

Figure 4.26 Comparison of poor and good soil-geomembrane contact for one slit and $30 \mathrm{~cm}$ of leachate height 


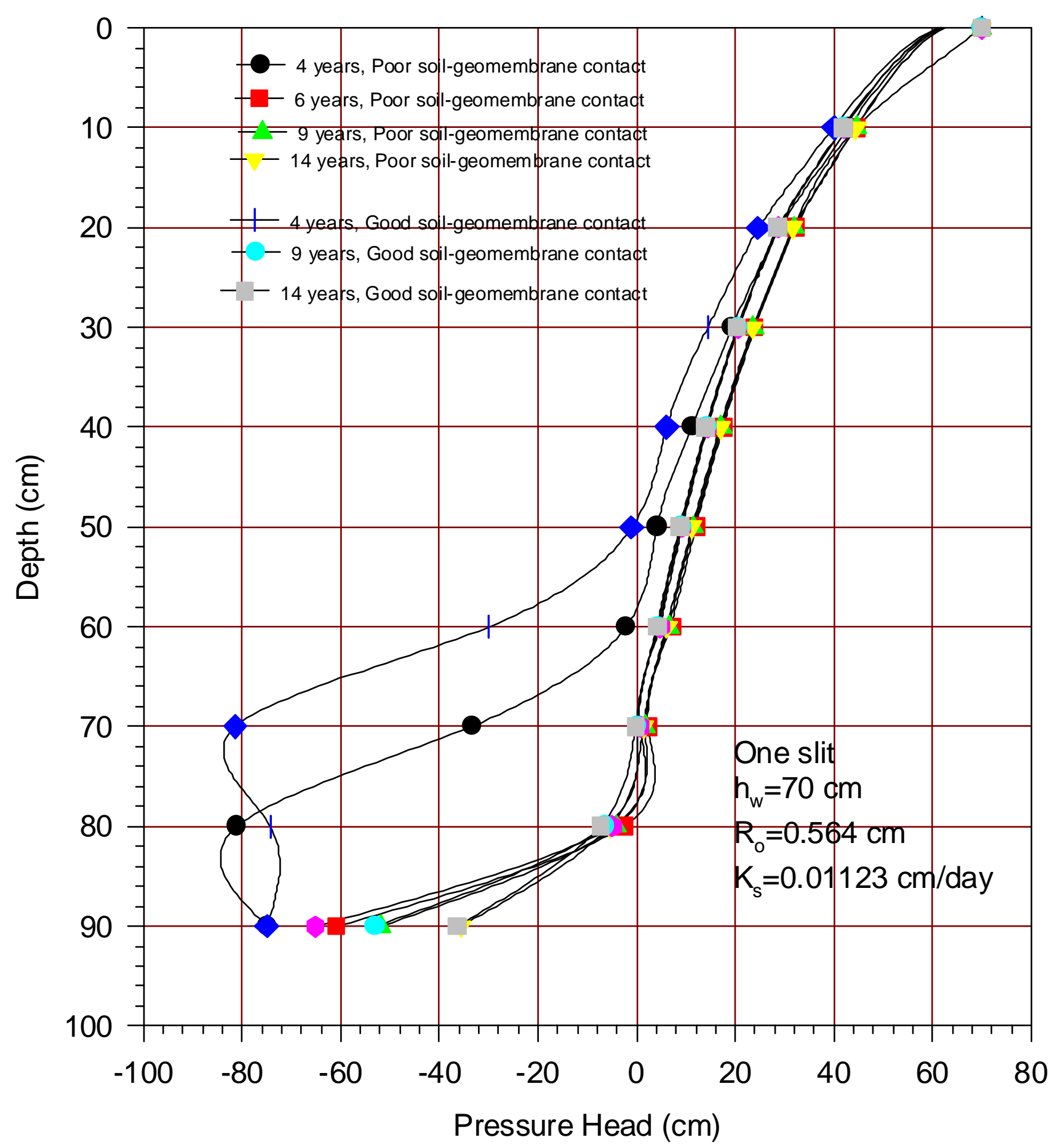

Figure 4.27 Comparison of the poor and good soil-geomembrane contact for one slit and $70 \mathrm{~cm}$ of leachate height 


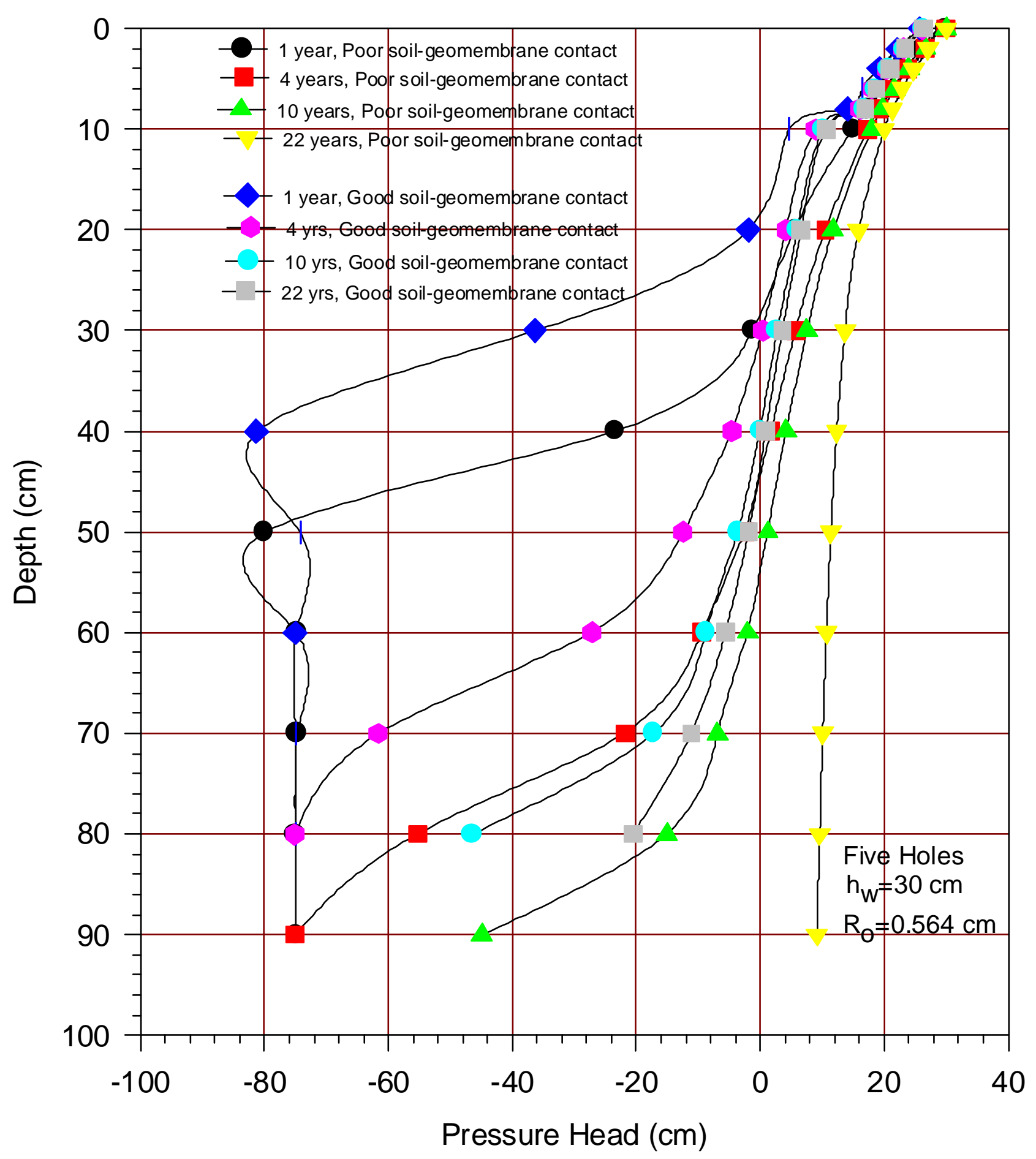

Figure 4.28 Comparison of pressure head for poor and good soil-geomembrane contact for five slits and $30 \mathrm{~cm}$ of leachate height 


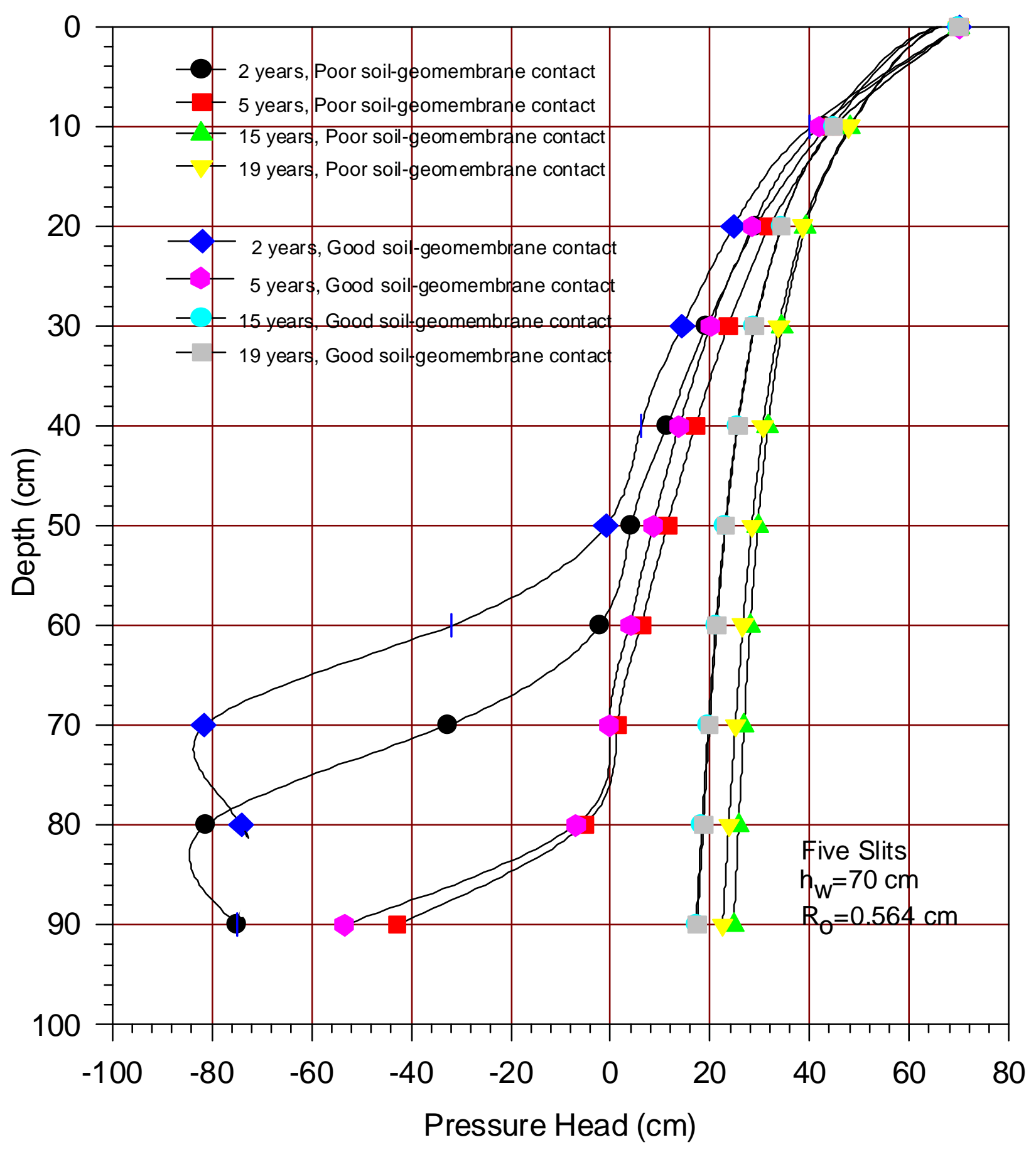

Figure 4.29 Comparison of pressure head of poor and good soil-geomembrane contact for five slits and $70 \mathrm{~cm}$ of leadhate height 


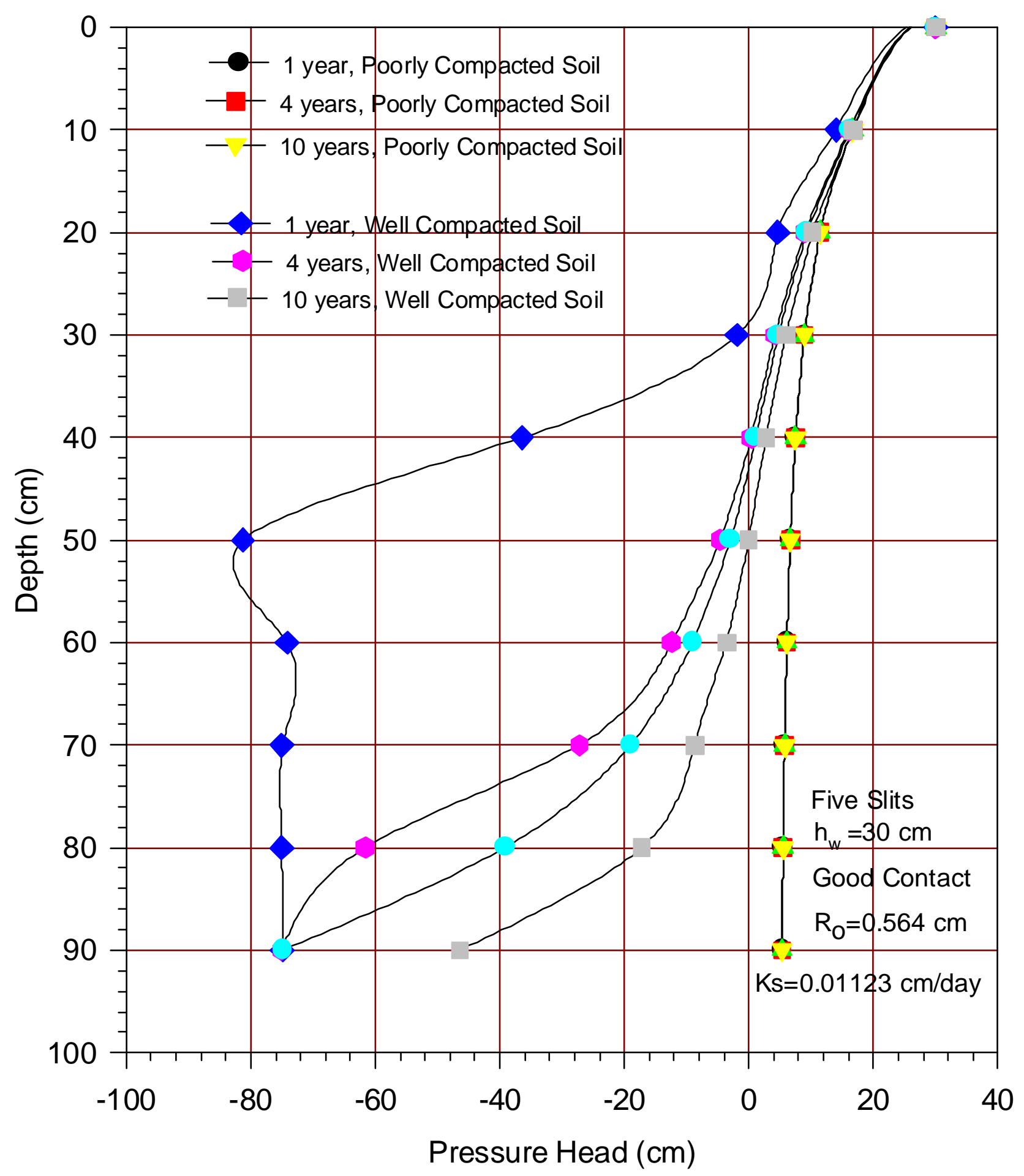

Figure 4.30 Comparison of pressure head variations for porly compacted and well compacted soil 


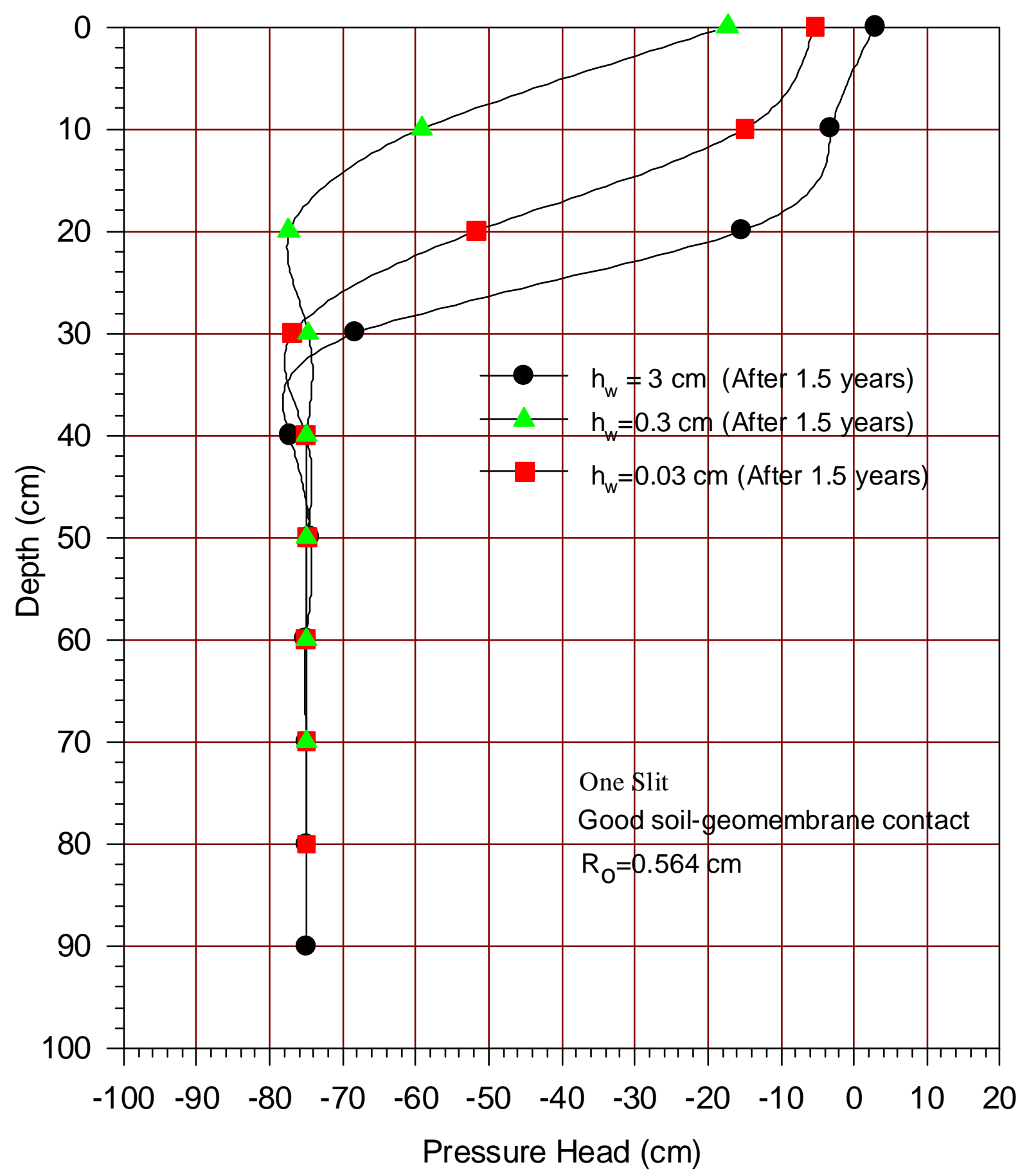

Figure 4.31 The pressure head variations for the $0.03 \mathrm{~cm}, 0.3 \mathrm{~cm}$, and $3 \mathrm{~cm}$ leachate heights 


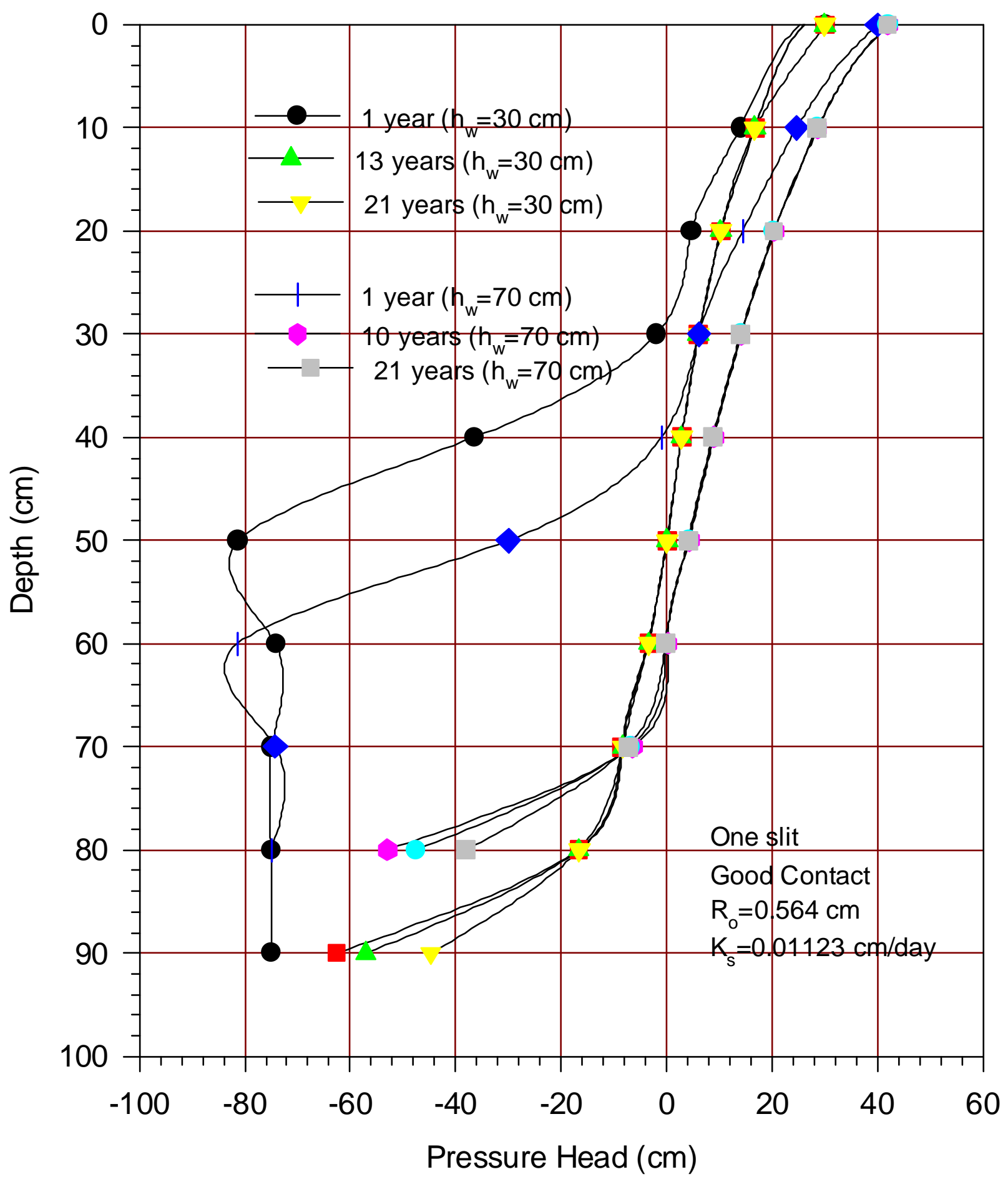

Figure 4.32 Comparison of pressure head with different leachate heights for good contact and one hole. 


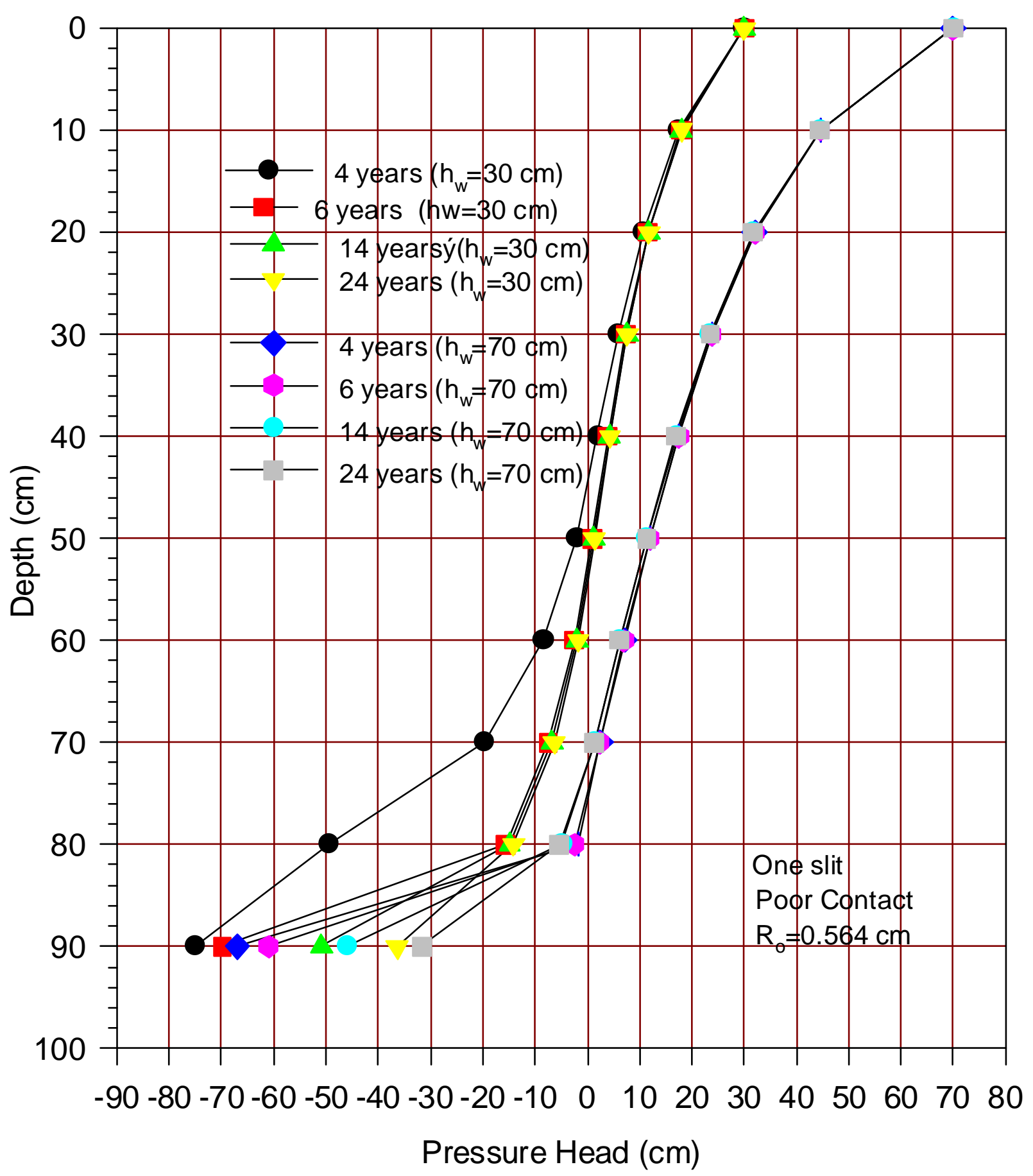

Figure 4.33 Comparison of pres sure head with different leachate heights for poor soil-geomembrane contact and one slit 


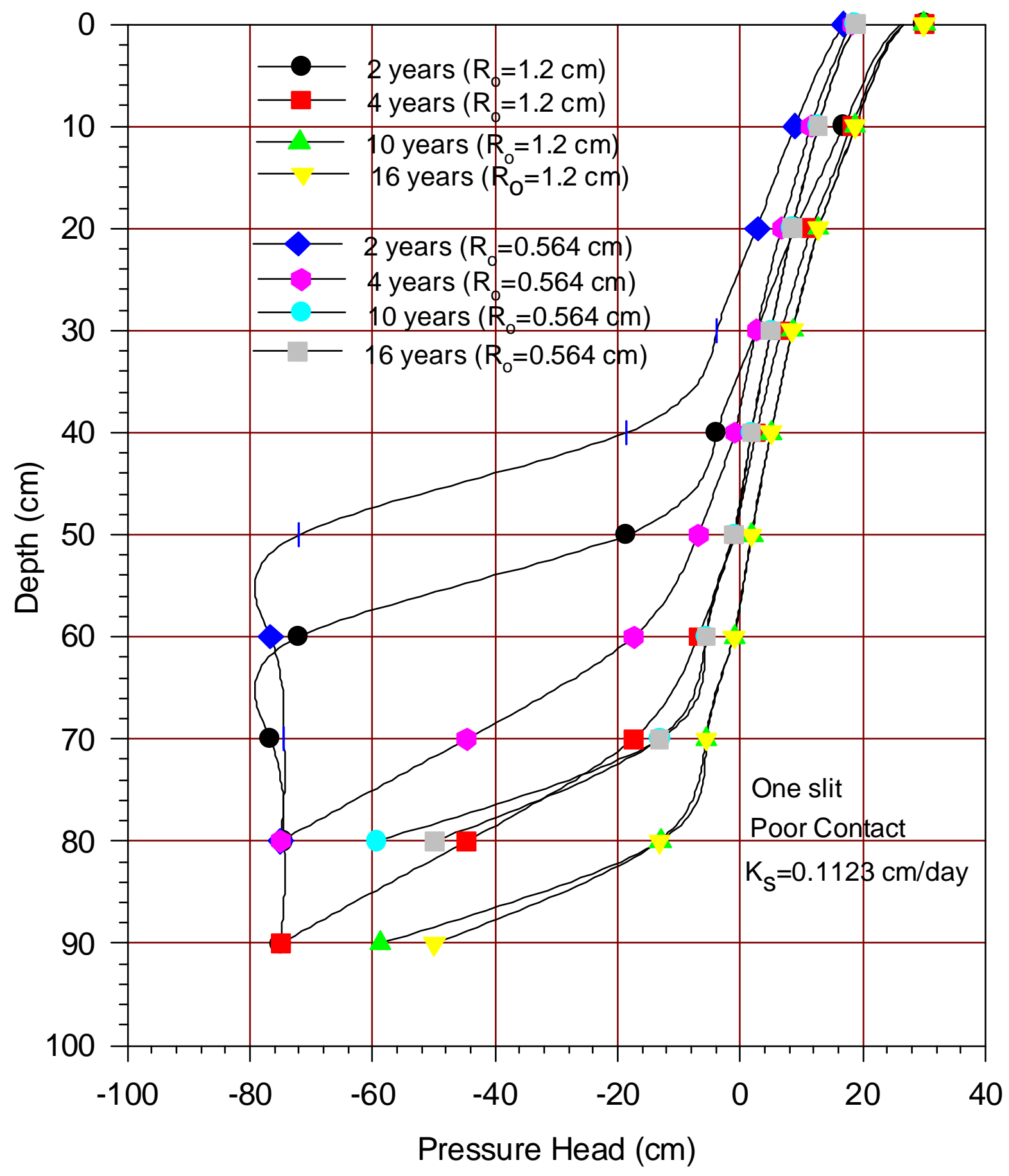

Figure 4.34 Comparison of pressure head with several sizes of slits for one slit and poor soil-geomembrane contact condition 
$60 \mathrm{~cm}$, pressure head $(\psi)$ values have different values. It is concluded that the wetted front movement of the poor contact condition is a little bit faster than that for the good contact.

Next, it was assumed that the geomembrane had five slits at specified locations (see Figure 3.18). A comparison of the cases of poor and good soil-geomembrane contact was conducted (Figure 4.28). It can be seen that the poor contact condition produces higher values of pressure head, which is an indication of higher values of moisture levels and that the wetting front migrates slower through the soil profile with good soil-geomembrane contact than poor contact conditions. For example, after 4 years at depth of $60 \mathrm{~cm}$, pressure head values are $-28 \mathrm{~cm}$ for the good contact and $-10 \mathrm{~cm}$ for poor contact condition. After 22 years, the slit depth of the soil profile is already saturated for the poor contact condition compared to the good contact condition, as indicated by the positive head values.

Similar observations can be also extracted from Figure 4.29. It is shown that the saturation levels are higher in the case with a poor contact than in the case with good contact condition after two years. The pressure head is slightly higher for the poor soil-geomembrane contact conditions, and even more pronounced than in Figure 4.28, due to higher leachate heads.

The COMPBAR program performs another verification of a barrier system by comparing pressure head variations in poorly compacted soil conditions. Figure 4.30 shows that the poorly compacted soil became saturated in a very short time period (as demonstrated by the curve on the right extreme of the figure). After less than one year, the whole soil profile reached saturation, i. e., positive $\psi$ values. In the compacted clay barrier there is gradual movement towards saturation from one to twenty one years. The summary of Figure 4.30 indicates a very short life span of a composite barrier made of loose soil, and also suggests that the degree of compaction is an important point in the construction and performance of the barrier.

The effect of leachate head was also studied. Five different leachate heads on top of the geomembrane have been $(0.03 \mathrm{~cm}, 0.3 \mathrm{~cm}, 3 \mathrm{~cm}, 30 \mathrm{~cm}$, and $70 \mathrm{~cm})$ were utilized. In Figure 4.31, the three lowest leachate head are compared. Pressure head varies considerably for each 
leachate head up to a depth of $30 \mathrm{~cm}$. Below that depth, pressure head remains the same for all leachate heads.

Leachate heads of $30 \mathrm{~cm}$ and $70 \mathrm{~cm}$ are compared in Figure 4.32 with good soil-geomembrane contact conditions. After one year, the pressure head is higher with the higher leachate head $(70 \mathrm{~cm}$ ) from a depth between $30 \mathrm{~cm}$ to $50 \mathrm{~cm}$. After a depth of $50 \mathrm{~cm}$ to $60 \mathrm{~cm}$ the pressure head is similar for both leachate heads. At depths between $30 \mathrm{~cm}$ to $50 \mathrm{~cm}$ the higher pressure, head values for $70 \mathrm{~cm}$ of leachate head, as opposed to the values for $30 \mathrm{~cm}$ of leachate, indicate a faster wetting front movement. Figure 4.33 shows results for the same leachate heads as in Figure 4.32. However, it compares pressure head values for the two heads under poor soilgeomembrane contact conditions. It can be seen from Figure 4.33 that the pressure head curves for both leachate heads from the top of the soil to the bottom are almost parallel to each other, demonstrating rapid wetting front movements. When comparing these results with good soilgeomembrane contact conditions (as shown in Figure 4.32), the wetting front progresses more slowly under good soil-geomembrane contact conditions, thus resulting in lower pressure heads. Consequently, the good soil-geomembrane contact condition becomes an important factor in determining the effectiveness and the longevity of a composite barrier system.

The top of the clay layer directly beneath the geomembrane has higher pressure head values for $70 \mathrm{~cm}$ of leachate head than for the $30 \mathrm{~cm}$ of leachate head in Figure 4.33. But the lines start to approach parallel position moving away from the boundary conditions. After 4 years, $30 \mathrm{~cm}$ of leachate head produces lower negative pressure head $(\psi)$ than that of the $70 \mathrm{~cm}$ of leachate head. For instance, at the depth of $80 \mathrm{~cm} \psi=-50 \mathrm{~cm}$ for $30 \mathrm{~cm}$ of leachate head, and $\psi=-5 \mathrm{~cm}$ for $70 \mathrm{~cm}$ of leachate head at the same depth. This comparison indicates that $70 \mathrm{~cm}$ of leachate head produces higher moisture content level and faster wetting front propagation. For a time interval after of 22 years, for $70 \mathrm{~cm}$ of leachate head, the soil over the slit depth became saturated. For $30 \mathrm{~cm}$ of leachate head, the soil became saturated only to a depth of $70 \mathrm{~cm}$. In conclusion, these figures indicate that the leachate head does affect the wetting front propagation pressure head values and moisture content levels at certain locations. Generally, the higher leachate head on top of the geomembrane, the faster the wetting front moves, and the higher the moisture content are levels for the same time and the same location. 
Part of the parametric comparison study has been based on the size of the slit. The small sizes of slit considered were $\mathrm{R}_{0}=0.564 \mathrm{~cm}$ and $1.2 \mathrm{~cm}$ for the parametric analysis. It can be seen from Figure 4.34 that the size of the slit influences the rate that the wetting front moves down into the soil. For example, after two years and at depth of $50 \mathrm{~cm}$ pressure head value for the smaller size slit was $-75 \mathrm{~cm}$, while value for the larger slit pressure head was $-20 \mathrm{~cm}$, which is an indication of higher moisture levels. At the other time intervals, the behavior is the same, but differences are less. For example, after ten years and at the depth of $70 \mathrm{~cm}$, the pressure head was $-8 \mathrm{~cm}$ for the smaller size slit, which indicates that, as time increases, the differences in the behavior becomes smaller. The size of the slit affects the leachate migration through the soil profile. Figure 4.34 shows that, for different time intervals, a higher amount of leakage occurs for larger slit sizes. 


\section{CHAPTER 5 \\ CONCLUSIONS}

In this study, a finite element computer program was developed (COMPBAR) to model flow through a composite barrier with a damaged geomembrane. The model may be used to solve the unsaturated transient flow condition as defined by Richards' equation. The model enables one to study the progress of a wetting front as it passes through the soil barrier component of a composite barrier. Using this model, one is able to estimate the following:

- Pressure head values at different locations in the soil profile as a function of time.

- Volumetric moisture content at different locations in the soil profile as a function of time.

- Values of hydraulic conductivity and flow rate throughout the depth of the soil profile as a function of time.

- Wetting front profiles as a function of time.

- The time required for the wetting front to reach the leachate detection layer and the amount of flow that reaches the leachate detection layer.

- The model can also be used to perform parametric studies of variables in the composite barrier system.

After analyzing different configurations of composite barriers with a damaged geomembrane, the following observations can be made.

- Pressure head values for the poor soil-geomembrane contact condition are less negative than 
pressure head values for the good soil-geomembrane contact condition at the same location and same time. This observations implies that a smooth soil surface with good soilgeomembrane contact results in longer life of the composite barrier system.

- At the same location, the volumetric moisture contents for the poor soil-geomembrane contact case are higher than those for the good soil-geomembrane contact, thus indicating that saturation levels are higher in the poor contact case than for the good contact case.

- The wetting front migrates slower through the soil in the good soil-geomembrane contact case than in the poor soil-geomembrane contact case.

- In poorly compacted soil, the wetting front moves rapidly while in the compacted clay barrier, there is gradual movement of the wetting front towards saturation.

- The higher the leachate head on top of the goemembrane, the faster the wetting front moves through the leachate detection layer. This observation implies that the pumping of excess leachate from the top of the geomembrane affects the leachate head which in turn affects the quantity of leachate through the geomembrane slits and into the soil profile.

- When the wetting radii of two different slits in the geomemnbrane overlap, the wetting front movement increases. Therefore, the more slits with close proximity, the more the flow rate of the wetting front movement is increased. This observation implies that careful monitoring of the condition of the geomembrane to detect slits, and all kinds of damage and the consequent wetting front movement, can help determine the effectiveness and longevity of the composite barrier system.

- The computer code, COMPBAR, has unique capabilities to model leachate flow through a composite barrier system in which multiple defects in the form of slits appear. 


\section{CHAPTER 6 \\ RECOMMENDATIONS}

The future research work should include the following.

- Expanding the model from its present two-dimensional capability to a three-dimensional capability so that more accurate results can be obtained.

- Determining the results of different configurations and sizes of damage in the geomembrane. A new model for leachate head must be developed because COMPBAR gives results with limited size and shape of geomembrane damage.

- It was assumed in this work that the head of the leachate was kept constant with time. A more precise approximation of wetting front movement would be obtained if a similar approximation for leachate head h ( $\mathrm{r}$ ) were obtained assuming transient conditions. To more accurately determine actual field conditions, a future finite element model should account for varying liquid levels over time, to simulate the evaporation or precipitation that naturally occurs on the composite barrier system.

- Developing small scale and large scale physical models, as well as actual composite barrier systems, to verify the results of the finite element program COMPBAR. 


\section{REFERENCES}

August, H. and Tatzky, R. (1984). "Permeabilities of commercially available polymeric liners for hazardous landfill leachate organic constituents," Proceedings of the International Conference on Geomembrane, 1, IFAI, St. Paul, Minnesota, 163-168.

Bear J. (1979). Hydraulics of groundwater. McGraw-Hill, New York.

Blake, G.E. Schlichting, and Zimmermann, U. (1973). "Water recharge in a soil with shrinkage cracks," Proceedings, Soil Science Society of America, 37: 669-672.

Bonaparte, R., Giroud, J. P. and Gross, B. A. (1989). "Rates of leakage through Landfill Liners," Proceedings of Geosynthetics' 89, 1, IFAI, St. Paul, Minnesota, 1829.

Bowders, J. J., and Daniel, D. E. (1987). "Hydraulic conductivity of compacted clay to dilute organic chemicals," Journal of Geotechnical Engineering, 117(12), 1432-1448.

Boynton, S.S. and Daniel, D.E. (1985). "Hydraulic conductivity tests on compacted clay," Journal of Geotechnical Engineering, ASCE 111(4): 465-478.

Brown, K. W., Thomas, J. C., Lyhon, R. L., Jayawickrama P., and Bahrt, S. C. (1987). "Quantification of leak rates through holes in landfill liners," USEPA Report, CR 810940, Cincinnati, OH, 147.

Burdine, N. T. (1953). "Relative permeability calculations from pore-size distribution data," Petr. Trans., Am. Inst. Mining Metall. Eng. 198, 71-77. 
Daniel, D.E. (1984). "Predicting hydraulic conductivity of clay liners," Journal of Geotechnical Engineering, 110(4), 465-478.

Daniel, D.E., and Liljestrand H.M. (1984). "Effects of landfill leachates on natural liner systems," Geotechnical Engineering Report, GR83-6, Geotechnical Engineering Center, Civil Engineering Department, University of Texas, Austin Texas.

Edwards, W. M., Van Der Ploeg, R.R., and Ehlers, W. (1979). "A numerical study of the effects of non-capillary sized pores upon infiltration," Soil Science Society of America Journal, 43, 851-856.

Faure, Y.H. (1984). "Design of drains beneath geomembranes: discharge estimation and flow patterns in case of leak," Proceedings of the International Conference on Geomembrane, 2, IFAI, St. Paul, Minnesota, 463-468.

Fenn, D.G., Hanley, K., J. and DeGeare, T.V. (1975). "Use of the water balance method for predicting leachate generation from solid waste disposal sites," U.S. Environmental Protection Agency Report, SW 168.

Freeze, R.A., Cherry, J.A. (1979). "Groundwater," Prentice-Hall, Englewood Cliffs, New Jersey, 38-70.

Fukuoka, M. (1988). "Large scale permeability tests for geomembrane-subgrade system," Proceedings of the Third International Conference on Geotextiles, 3, Vienna, Austria, 917-922.

Gardner, W.R. (1962). "Approximate solution of a non-steady-state drainage problem," Soil Science Society of America, 26(2), 129-132.

Gee, J. (1981). "Prediction of leachate accumulation in sanitary landfills," Gas and Leachate Management Conference, University of Wisconsin. 
Gibson, A.C. and Malone, P.C. (1982). "Verification of the U.S. EPA HSSWDS Hydraulic Simulation Model," Proceedings of the 8th Annual Research Symposium on Land Disposal of Hazardous Wastes, EPA-600/9-82-002, March.

Giroud, J.P. and Bonaparte, R. (1989a). "Leakage through liners constructed with geomembranes-part I. Geomembrane liners," Geotextile and Geomembranes, 8(1), 27-67.

Giroud, J. P. and Bonaparte, R. (1989b). "Leakage through liners constructed with geomembranes-part II. Composite liners," Geotextile and Geomembranes, 8(2), 71111.

Giroud, J.P., Badu-Tweneboah, K., and Bonaparte, R. (1992). "Rate of leakage through a composite liner due to geomembrane defects," Geotextile and Geomembranes, 2(1), 1-28.

Giroud, J.P., Khatami, A., and Badu-Tweneboah, K. (1989). "Evaluation of the rate of leakage through composite liners," Geotextile and Geomembranes, 8(4), 337340.

Goode, D. and Smith (1986). "SOILINER model-documentation and user's guide (Version 1)," U.S. Environmental Protection Agency, Cincinnati, OH.

Gray, D. H. (1984). "Adequacy of sanitary and hazardous landfill liner design criteria," Final report submitted to the State of Michigan Toxic Substance, Control Commission.

Haxo Jr, H.E., Miedema, J. A. and Nelson, N. A. (1984). "Permeability of polymeric membrane lining materials," Proceedings of the International Conference on Geomembranes, IFAI, St. Paul, Minnesota, 151-156. 
Istok, J. (1989). "Groundwater modeling by the finite element method," Water Resources Monograph Board, 13, Washington DC, 3-252.

Jayawickrama, P., Brown, K.W, Thomas, J.C. and Lytton, R.L. (1988). "Leakage rates through flaws in geomembrane liners," Journal of Environmental Engineering, ASCE, 114(6), 1401-20, 1401-1420.

Klute, A., Whisler, F.D., and Scott, E.J. (1965). "Numerical solution of the nonlinear diffusion equation for water flow in a horizontal soil column of finite length," Soil Society of America Proceedings, 29, 353-358.

Miller, C. J., and Manoj, M. (1989). "Modeling of leakage through cracked clay liners-II: A new perspective," Water Resources Bulletin, American Water Resources Association, 25(3), 557-563.

Miller, C. J. (1984). "Leakage through clay liners," Ph.D. Dissertation, The University of Michigan, Ann Arbor, Michigan.

Miller, C . J., and Mishra (1989). "Hazardous waste containment using clay liners," Proceedings of the symposium on Ground water management; quantity and quality, 188 , 191-199.

Mualem, Y. (1976). "A new model for predicting the hydraulic conductivity of unsaturated porous media," Water Resources Research, 12, 513-522.

Neuman S. P. (1973). "Saturated-unsaturated seepage by finite elements," Proceedings American Society of Civil Engineers, 99(HY12), 2233-2250.

Neuman, S.P., Feddes R.E., and Bresler, E. (1975). "Finite element analysis of two-dimensional flow in soils considering water uptake by roots: II. Field applications," Soil Science Society of America, 39(2), 231-237 
Paniconi, C., Aldama A. A., and Wood, E. F. (1991). "Numerical evaluation of iterative and noniterative methods for the solution of the nonlinear Richards equation," Water Resources Research, 27(6), 1147-1163.

Parlange, J.-Y., and Aylor, D. (1972). "Theory of water movement in soils: 9. The dynamics of capillary rise," Soil Science Society of America, 114(2), 79-81.

Parlange, J. Y. (1975). "On solving the flow equation in unsaturated soils by optimization: Horizontal infiltration," Soil Science Society of America, 39(3), 415423.

Perrier, E. R. and Gibson, A.C. (1980). "Hydrologic simulation on solid waste disposal sites," USEPA SW 868, Cincinnati, Ohio.

Peyton, R.L., and Schroeder, P.R. (1988). "Field verification of HELP model for landfills," Journal of Environmental Engineering, ASCE, 114(2), 247-269.

Philip, J.R. (1969). "Theory of Infiltration," Advances in Hydroscience, 5, 215-305.

Quisenberry, V. L. and Phillips, R.E. (1976). "Percolation of surface applied water in the field," Journal of the Soil Science Society of America 40:484-489.

Remson, I., Fungaroli, A.A., and Lawrence, A,W. (1968). "Water movement in an unsaturated sanitary landfill," Journal of Sanitary Engineering Division, ASCE, 94(SA2): 307-317.

Richard, L.A. (1931). "Capillary conduction of liquid through porous media," Physics $1, \quad 318-333$. 
Ritchie, J.T., Kissel, D.E., and E. Burnett. (1972). "Water movement in undisturbed swelling clay soil," Proceedings, Soil Science Society of America 36:874-879.

Schroeder, P.R. (1984). "The hydrologic evaluation of landfill performance (HELP) Model. User's Guide for Version I," EPA/530-SW-84-009,1, U.S. EPA, Office of Solid Waste and Emergency Response, Washington, D.C.

Schackelford C.D. (1992). "Performanced based design of soil liners," Proceedings of Mediterranean Conference on Environmental Geotechnology, Rotterdam; Brookfield, Cesme, Turkey.

Schackelford C.D. (1994). "Hydrogeotechnics of clay liners for waste disposal," Proceedings, Conference on Tailings and Mine Waste'94, Colorado State University, Fort Collins, CO, January 19-21, 1994, 9-22.

Schroeder, P.R., Gibson, A.C., and Smolen, M.D. (1984). "The hydraulic evaluation of landfill performance (HELP) model. Documentation for Version I," EPA/530-SW-84-010, 2, U.S. EPA, Office of Solid Waste and Emergency Response, Washington, D.C.

Sherard, J. L. (1985). "The upstream zone in concrete-face rockfill dams," Proceedings of a Symposium on Concrete Face Rockfill Dams-Design, Construction and Performance," ASCE, 618-641.

Skaggs, R.W. (1980). "A water management model for artificially drained soils," North Carolina Agricultural Research Service, Technical Bulletin, No. 267.

Van Genuchten, R. (1980). "A closed-form equation for predicting the hydraulic conductivity of unsaturated soils," Soil Science Society of America, Madison, WI, 44, 892-898. 
APPENDIX A

APPENDIX A

APPENDIX A

APPENDIX A

APPENDIX A

APPENDIX A

APPENDIX A

APPENDIX A

APPENDIX A

APPENDIX A

APPENDIX A

APPENDIX A

APPENDIX A

APPENDIX A

APPENDIX A 


\section{APPENDIX A COMPUTER PROGRAM}

\section{A.1 Overview}

The computer program COMPBAR was developed to analyze the wetting front of the damaged composite barrier. The source code for the COMPBAR is written in Fortran 77 presented with all the subroutines needed to run the program.

\section{A.2 Program Compbar}

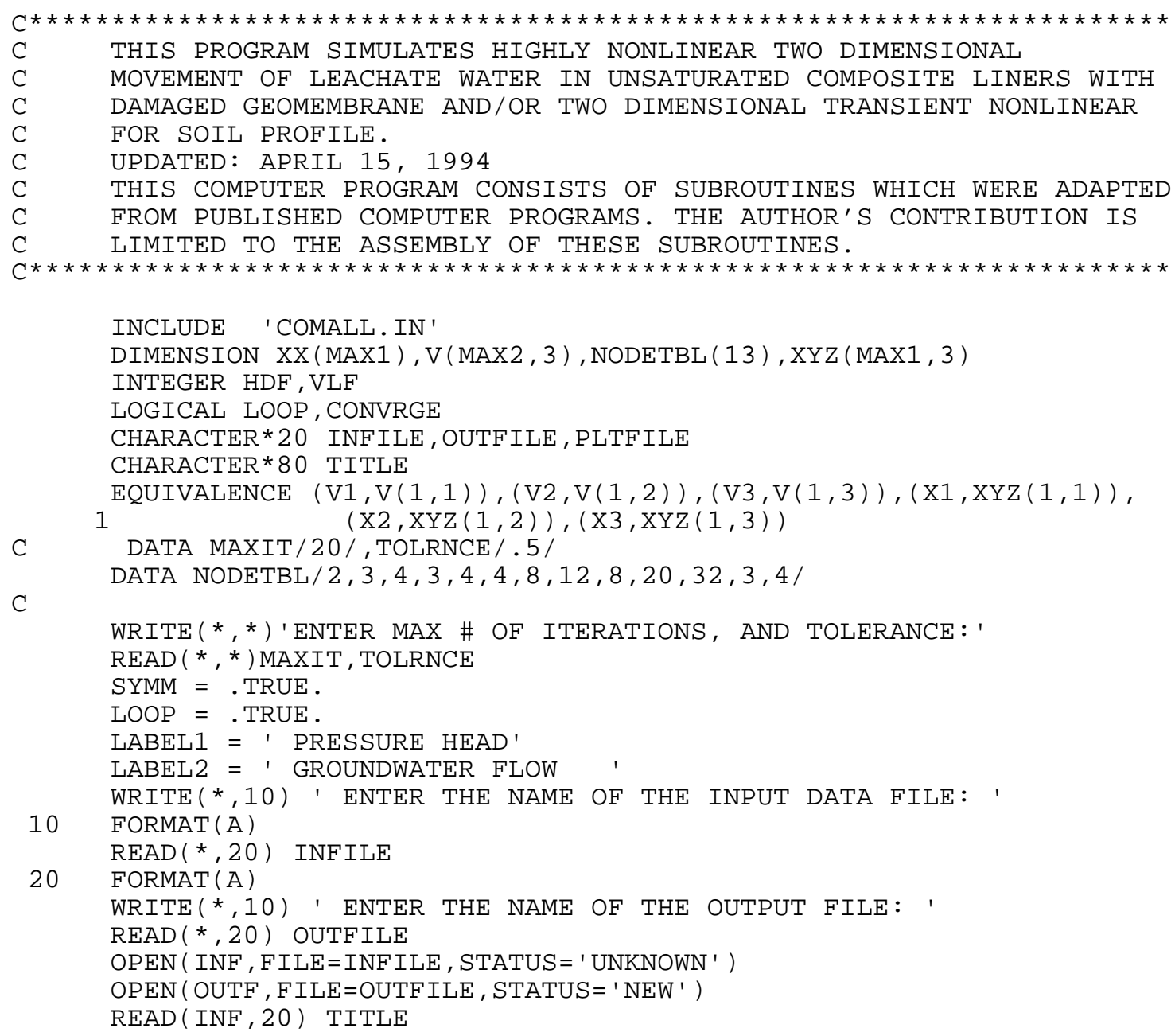




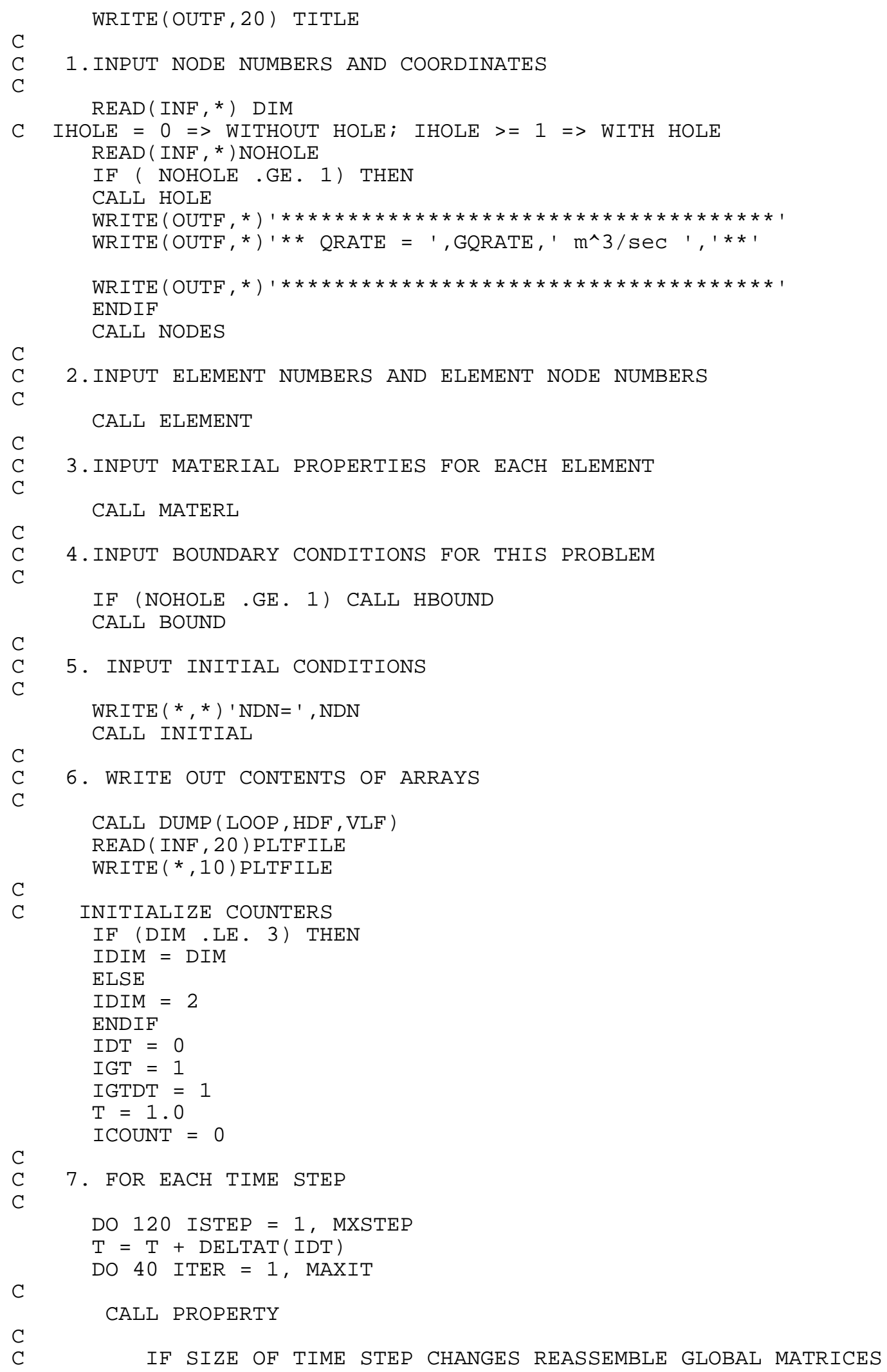




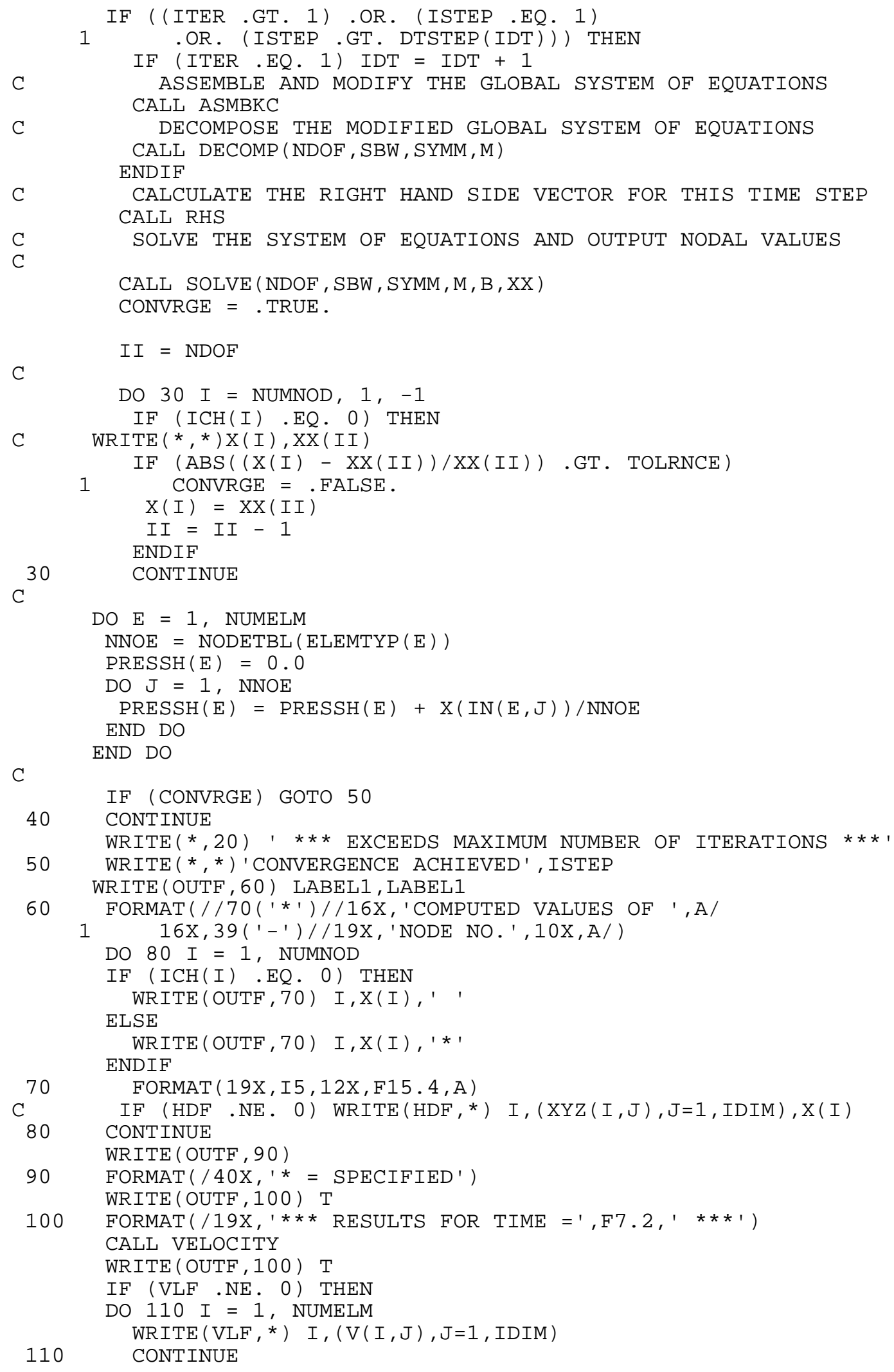


C

REAL MM, NN, ALPHA

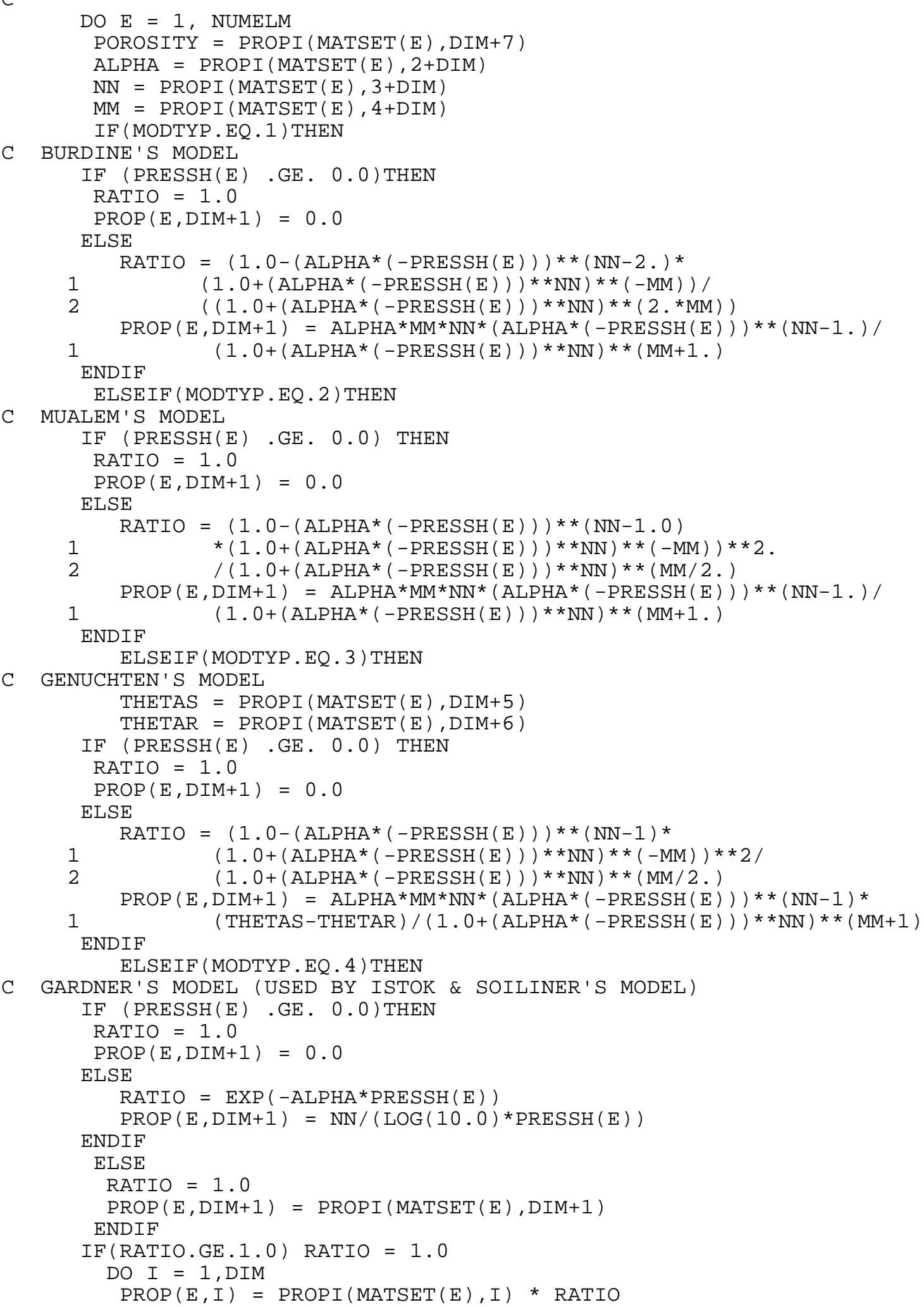



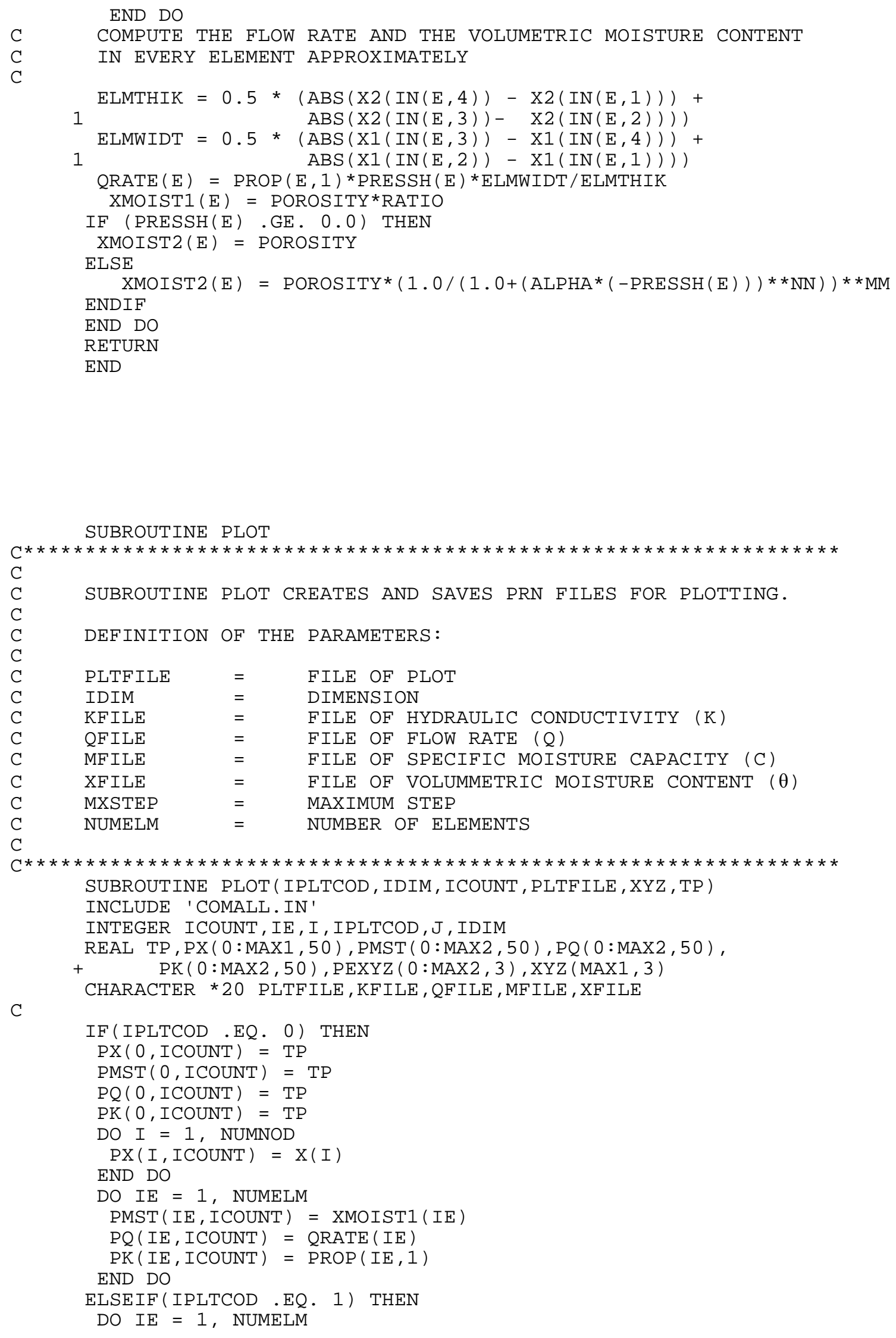


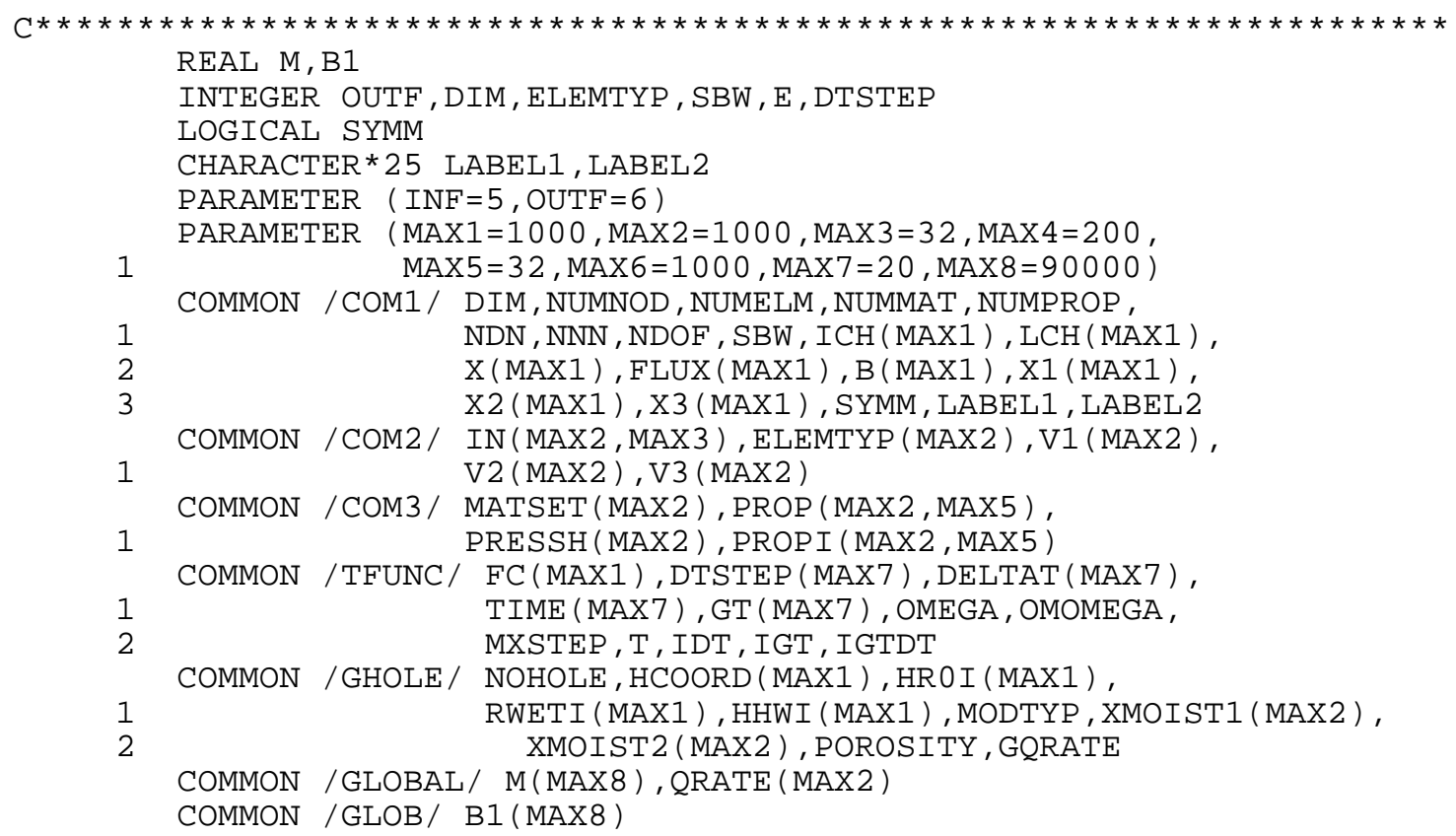

SUBROUTINE HOLE

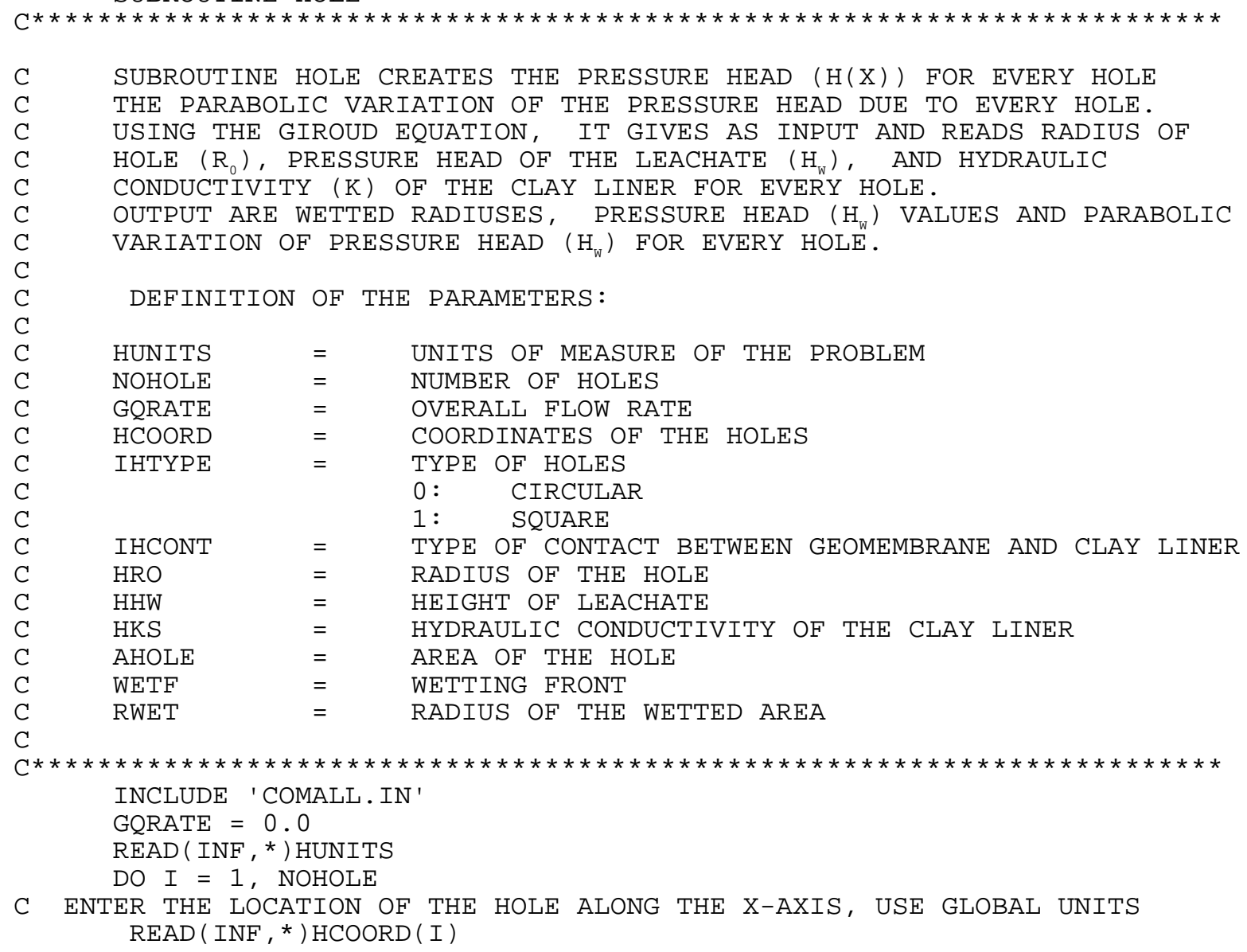




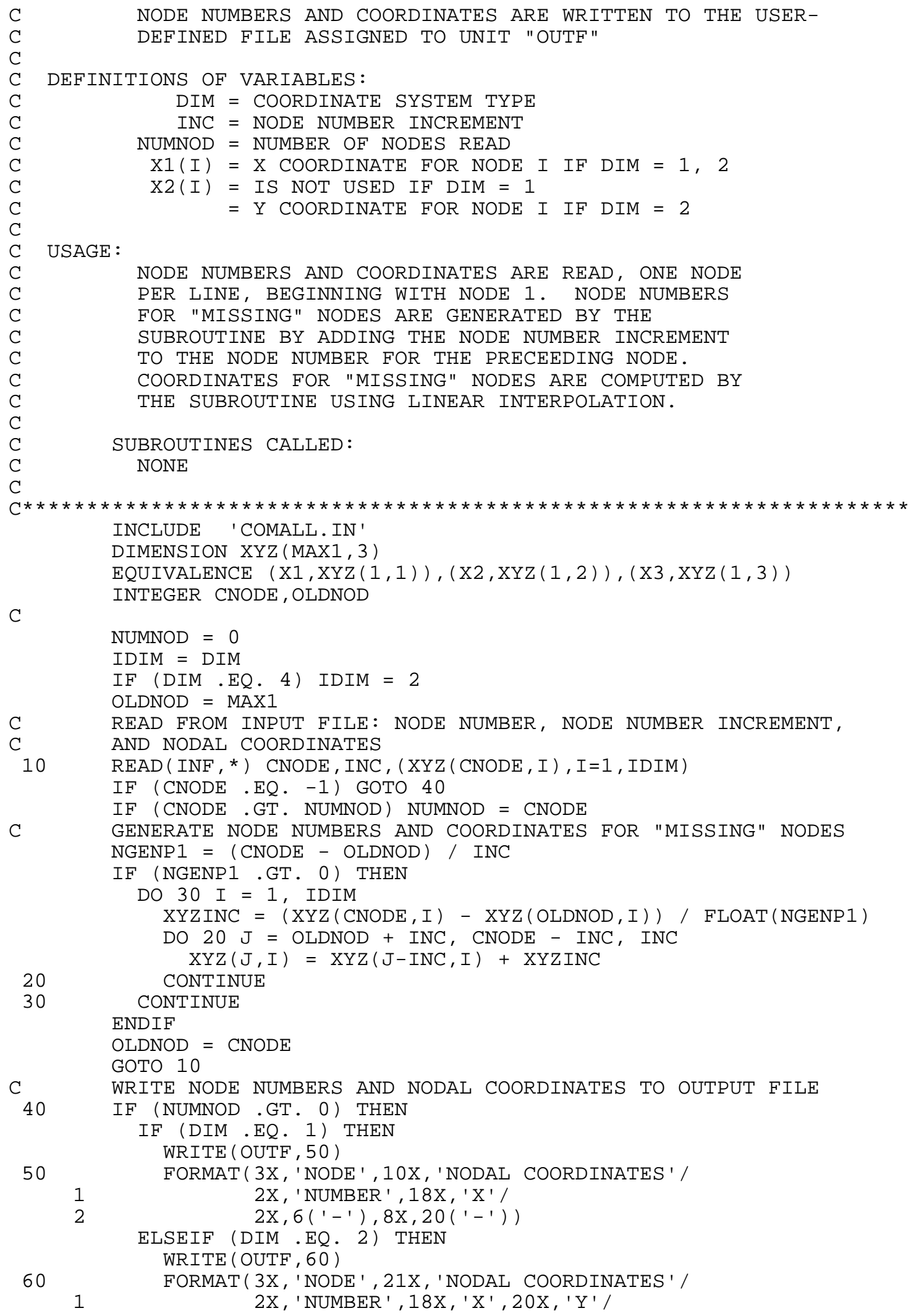




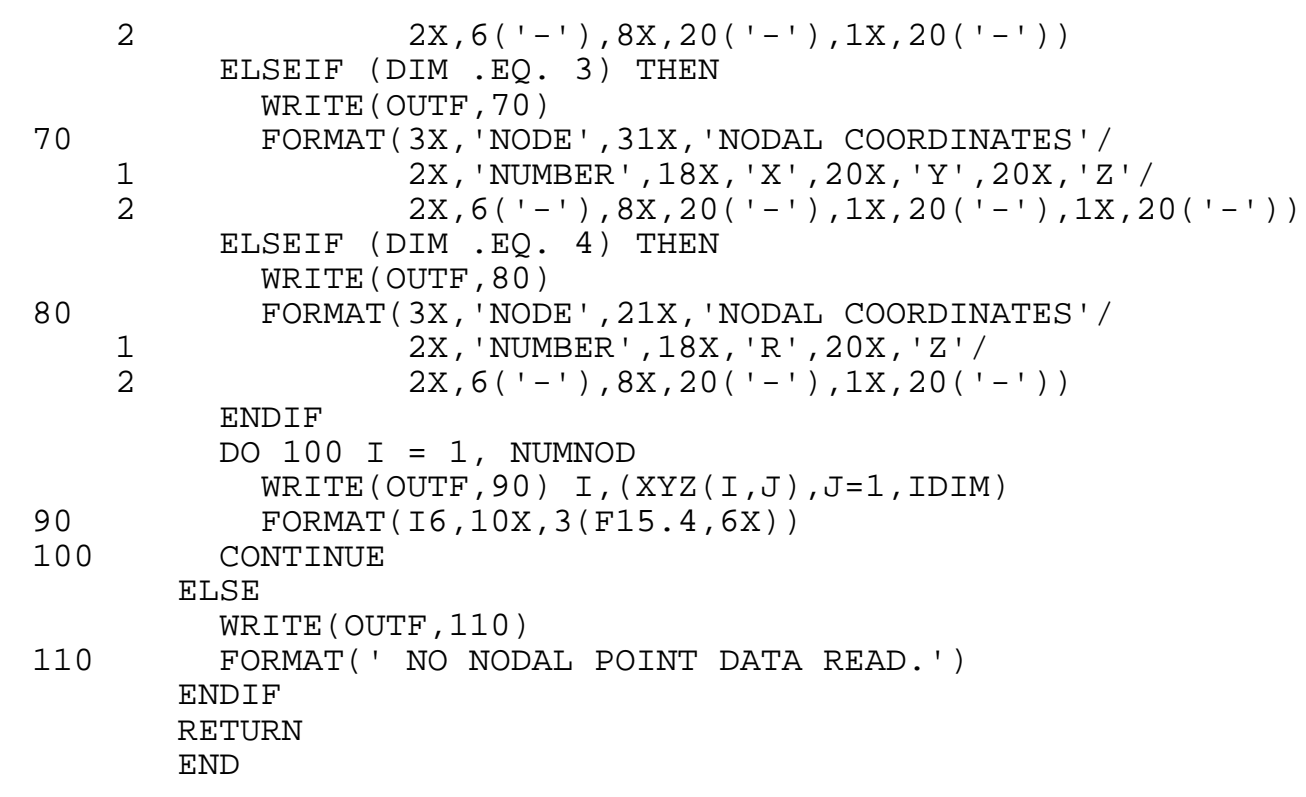

SUBROUTINE ELEMENT

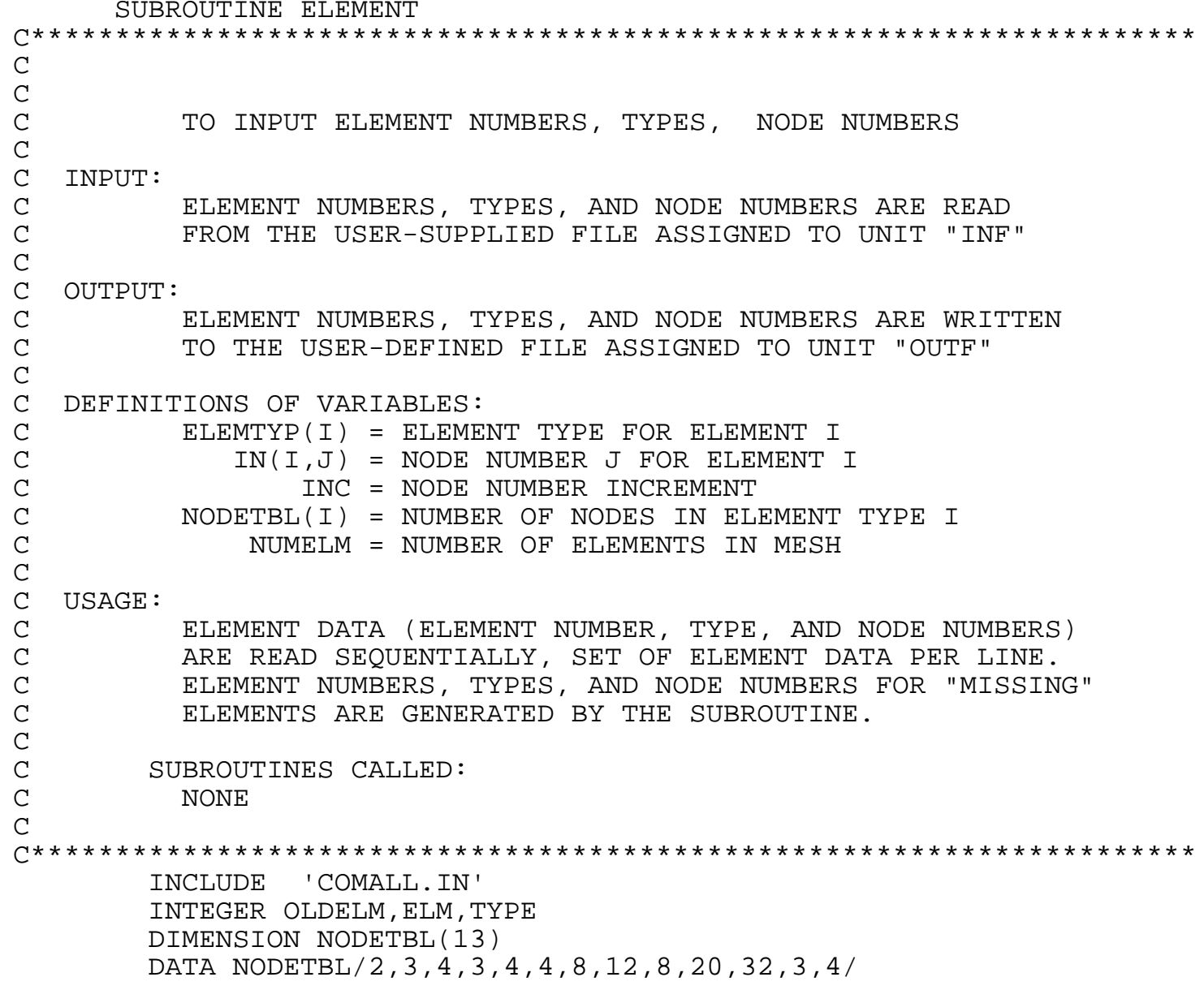




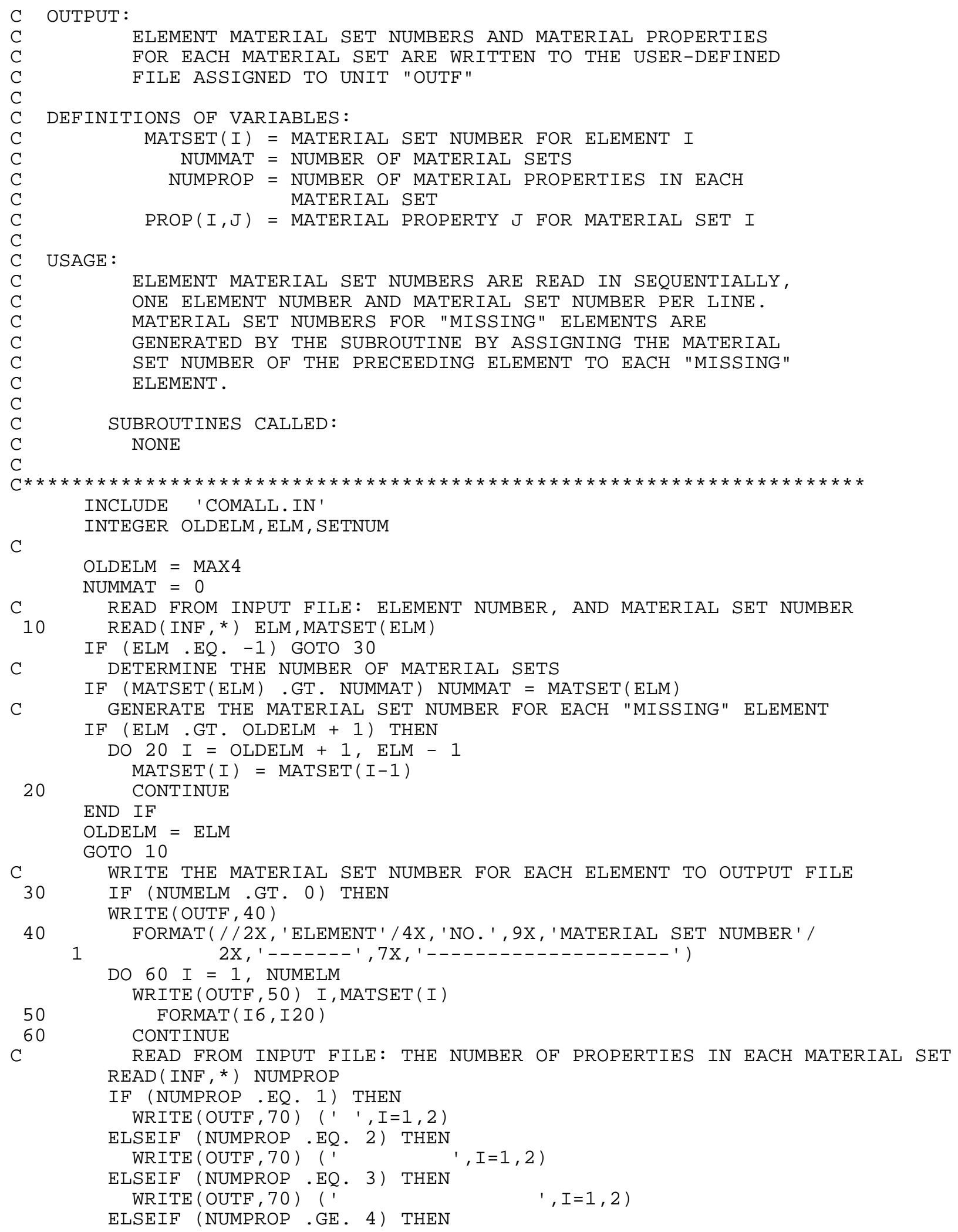




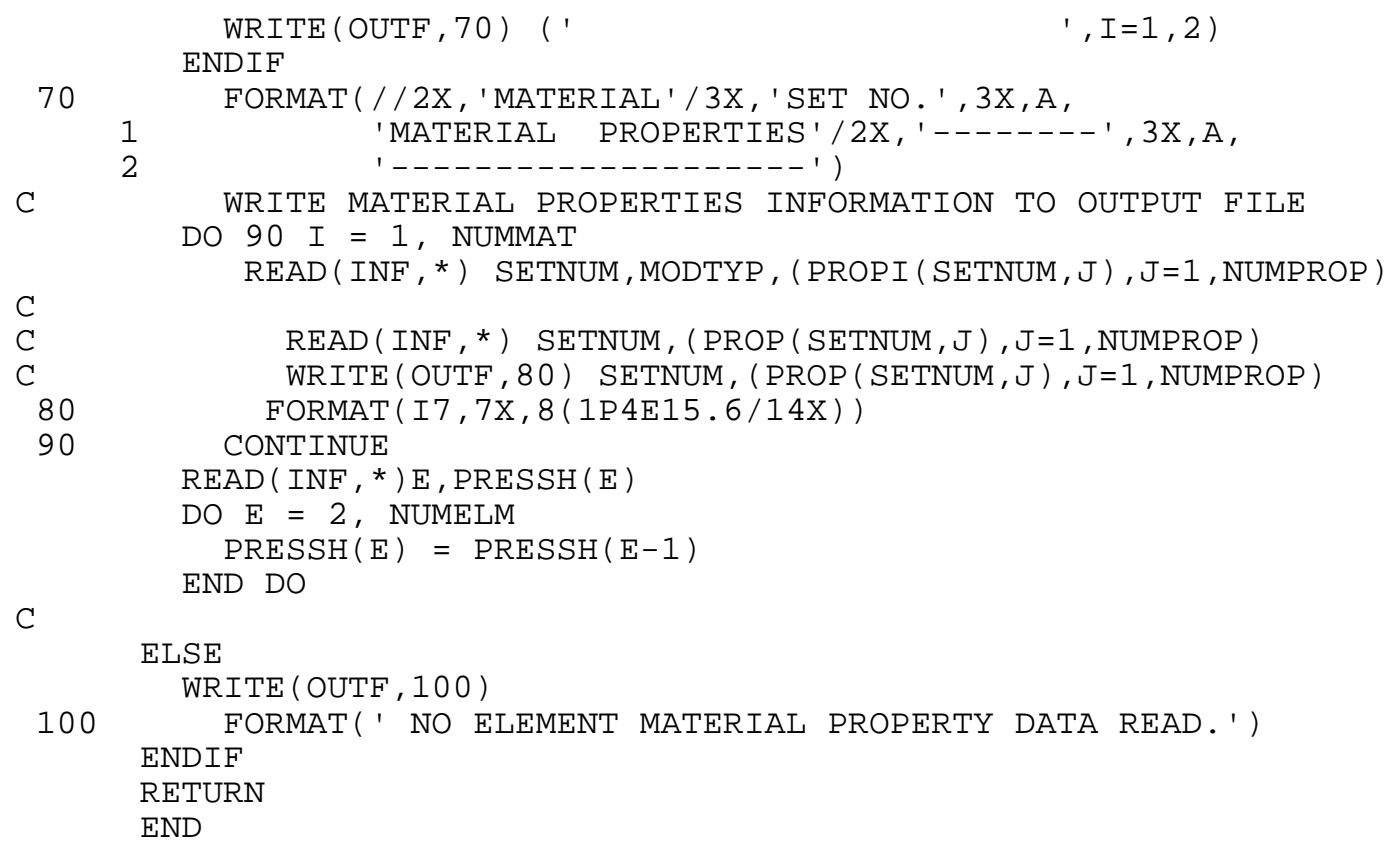




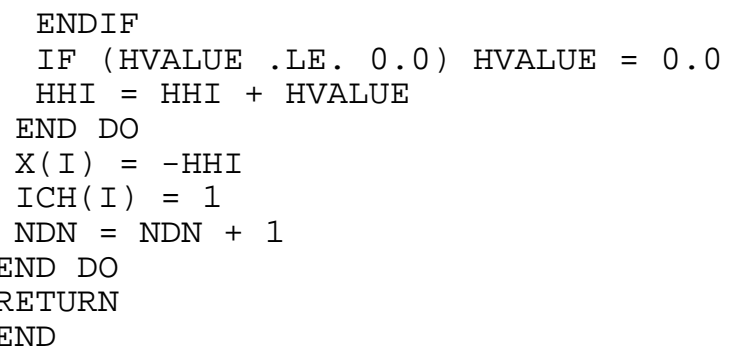

SUBROUTINE BOUND

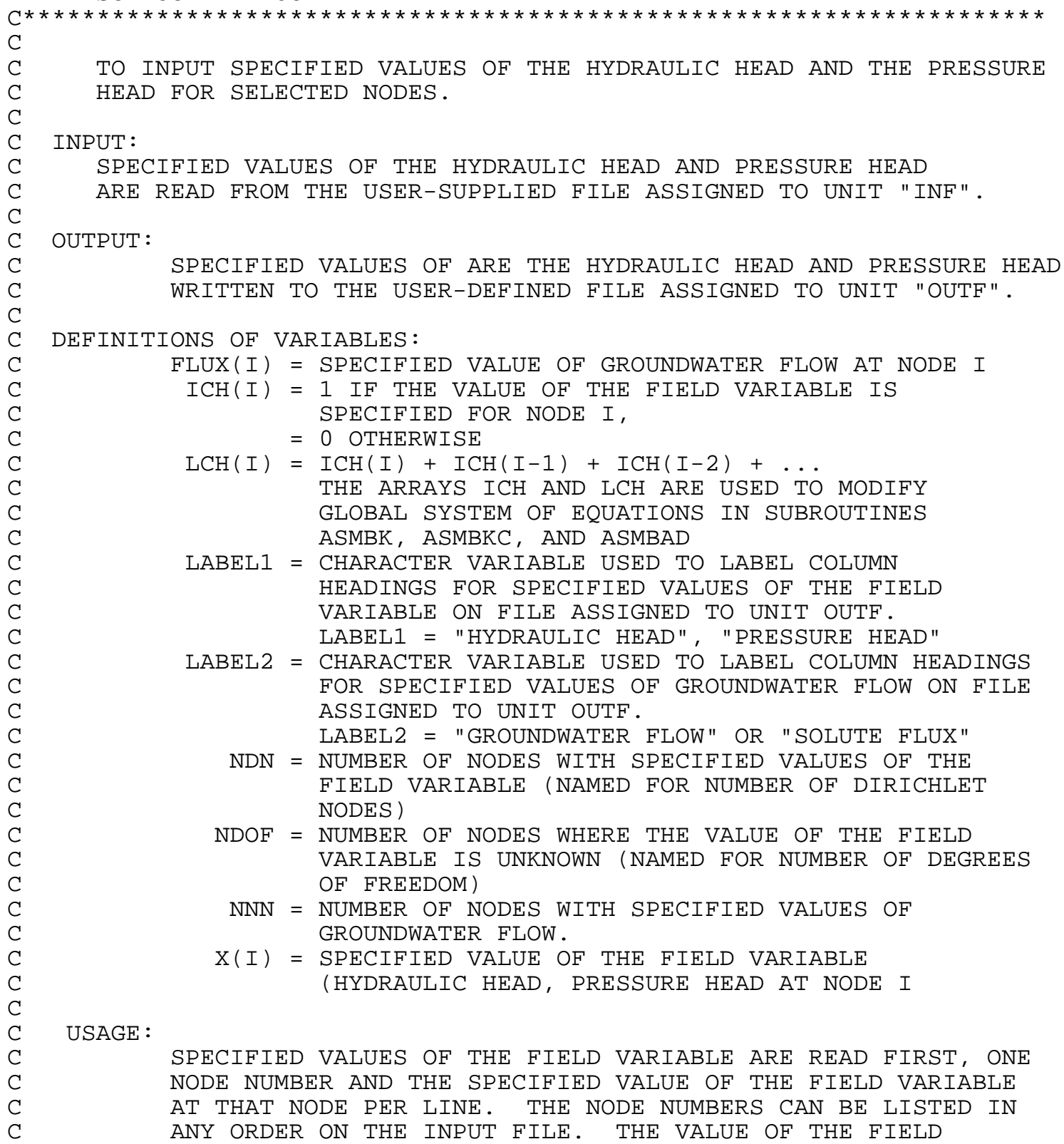




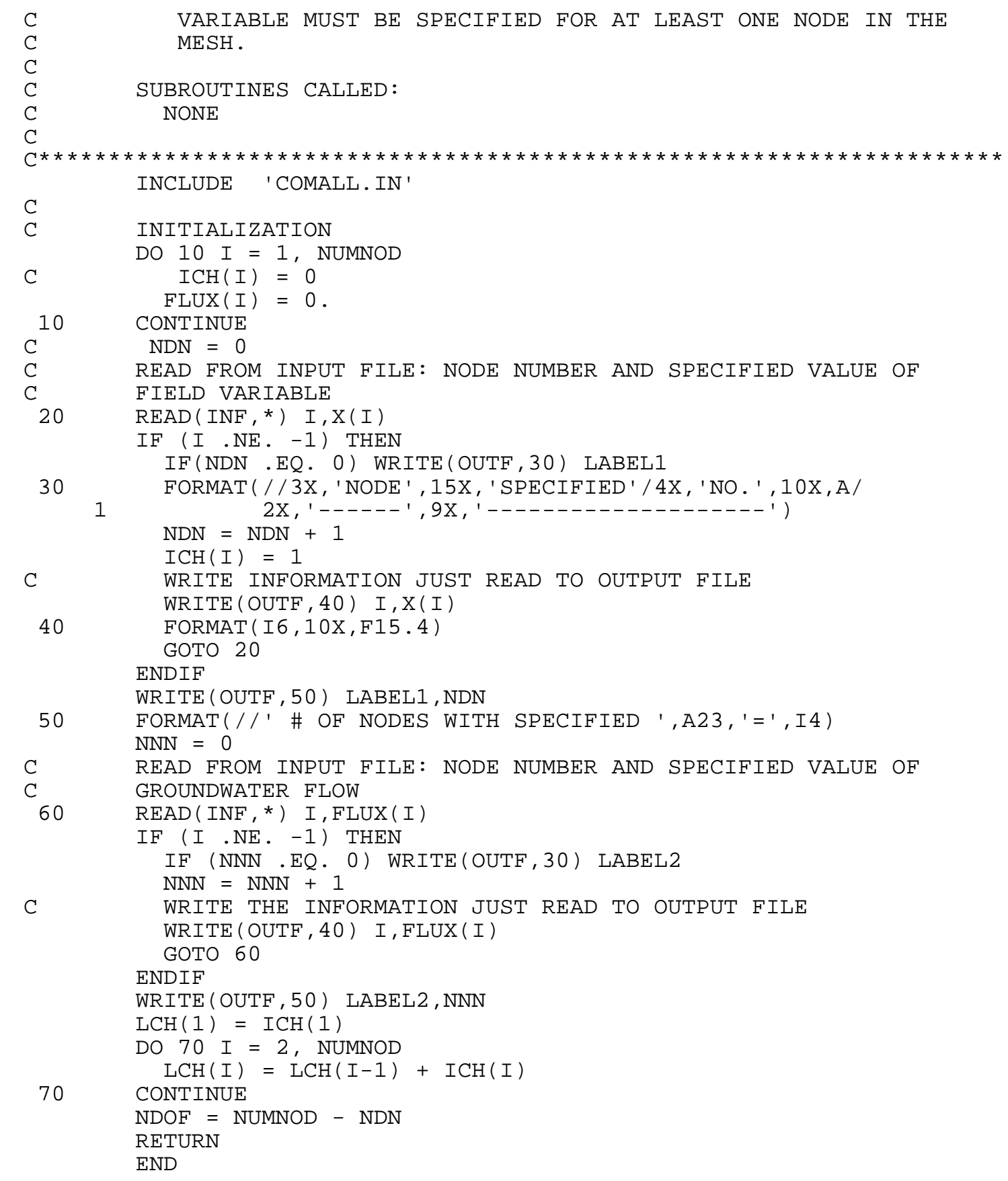


SUBROUTINE INITIAL

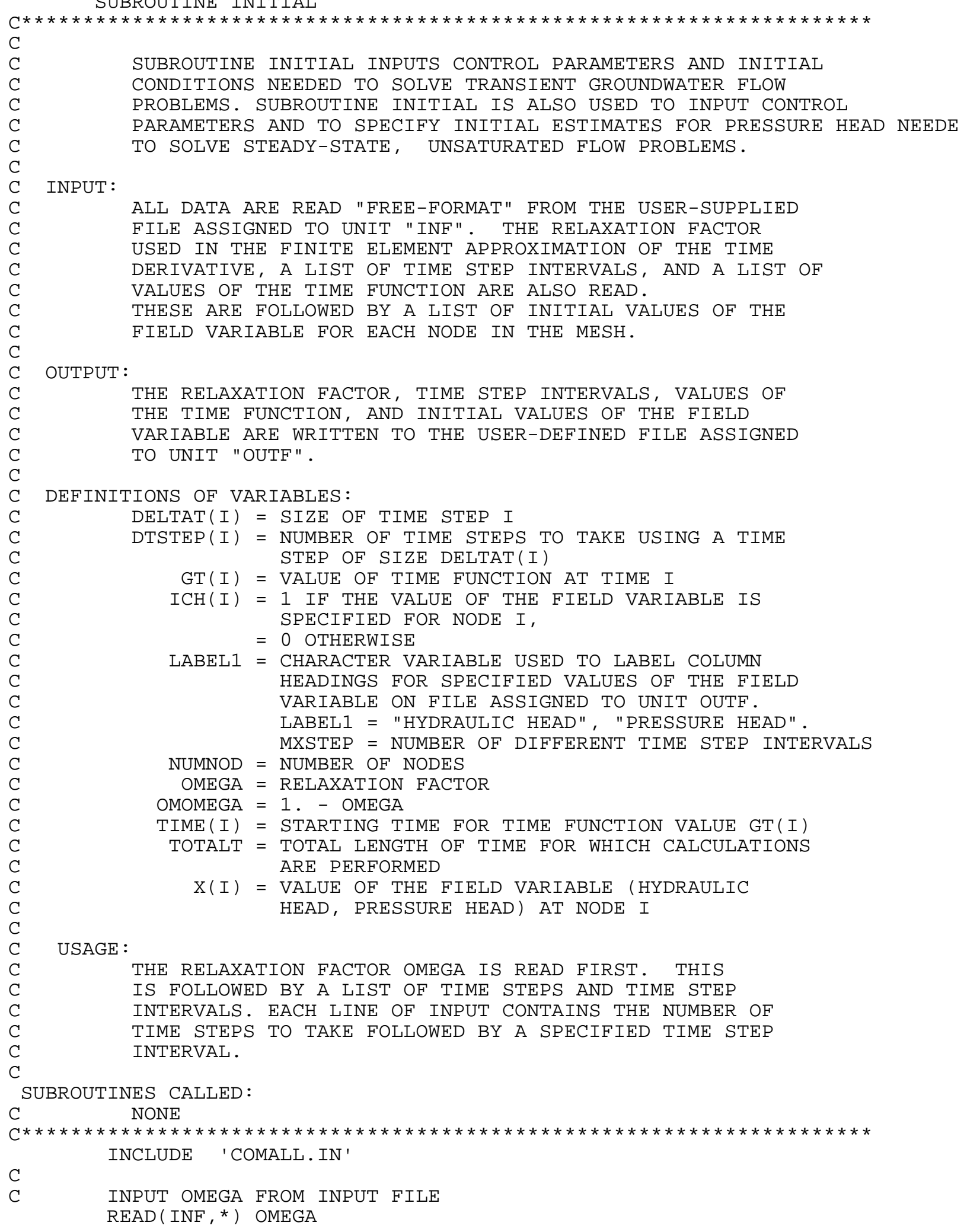




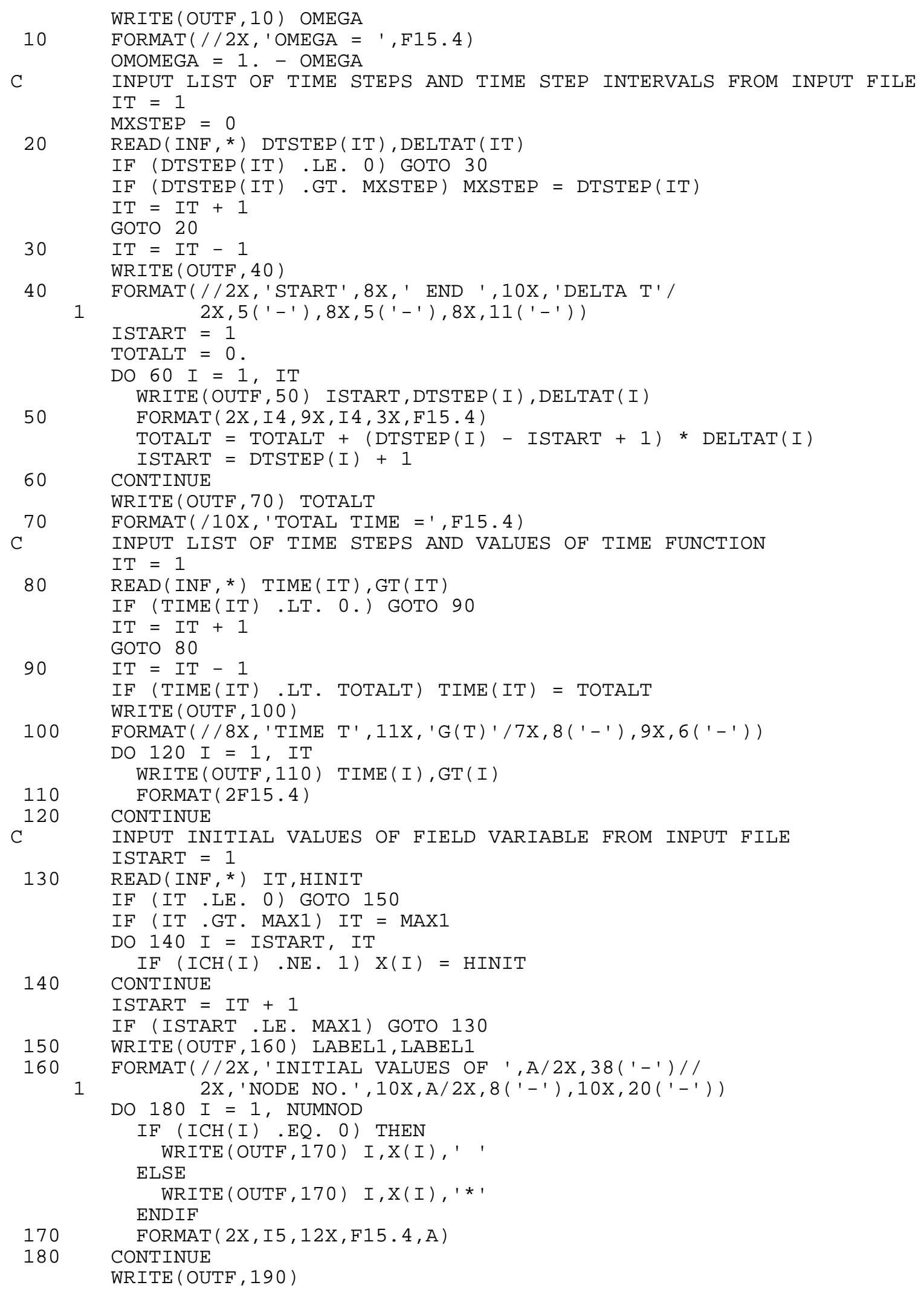


RETURN

END

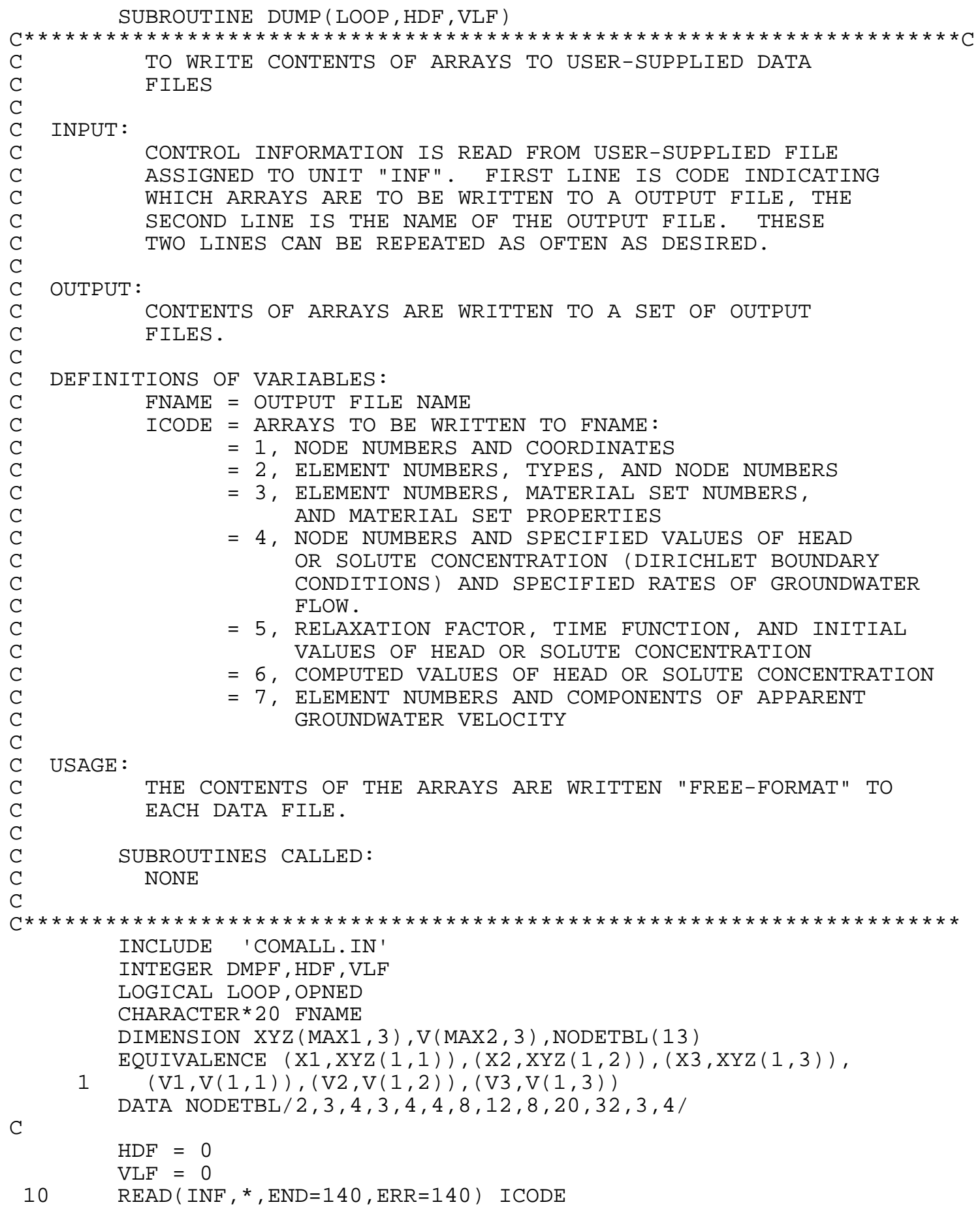




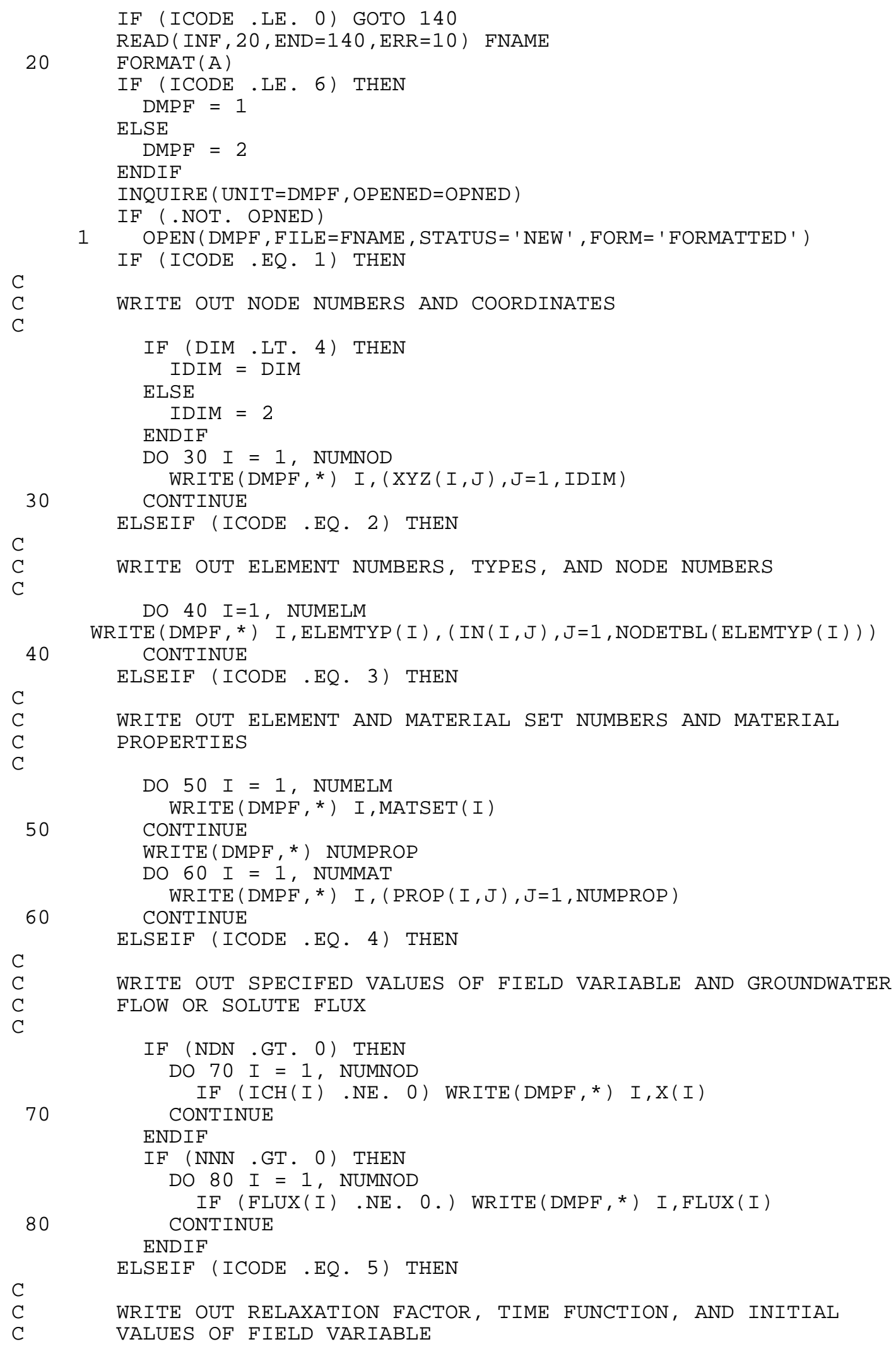


C

IF (LOOP) THEN
WRITE (DMPF, *) OMEGA

$\operatorname{ISTART}=1$

$\mathrm{IT}=1$

TOTALT $=0$.

90

WRITE (DMPF， *) ISTART, DTSTEP (IT), DELTAT (IT)

TOTALT $=$ TOTALT $+($ DTSTEP $(I T)-\operatorname{ISTART}+1) \star \operatorname{DELTAT}(I T)$

IF (DTSTEP (IT) .LT. MXSTEP) THEN

ISTART $=\operatorname{DTSTEP}($ IT $)+1$

$I T=I T+1$

GOTO 90

ELSE

WRITE (DMPF, *) TOTALT

$I T=1$

100 WRITE (DMPF, *) TIME (IT), GT (IT)

IF (TIME (IT) . GE. 0. .AND. TIME (IT) .LT. TOTALT) THEN

$\mathrm{IT}=\mathrm{IT}+1$

GOTO 100

ELSE

DO $110 I=1$, NUMNOD

110

IF (ICH (I) .EQ. 0) WRITE (DMPF, *) I, X (I)

ENDIF CONTINUE

ENDIF

ENDIF

ELSEIF (ICODE .EQ. 6) THEN

C

WRITE OUT COMPUTED VALUES OF FIELD VARIABLE

C

C

IF (LOOP) THEN

$\mathrm{HDF}=\mathrm{DMPF}$

ELSE

IF (DIM .LT. 4) THEN

$I D I M=D I M$

ELSE

$\operatorname{IDIM}=2$

ENDIF

DO $120 I=1$, NUMNOD

WRITE (DMPF, *) I, X (I)

120 CONTINUE

ENDIF

ELSEIF (ICODE .EQ. 7) THEN

C

C WRITE OUT ELEMENT NUMBERS AND COMPUTED COMPONENTS

C OF APPARENT GROUNDWATER VELOCITY

C

$$
\begin{gathered}
\text { IF (LOOP) THEN } \\
\text { VLF }=\text { DMPF }
\end{gathered}
$$

ELSE

IF (DIM . LT. 4) THEN

$I D I M=D I M$

ELSE

$\operatorname{IDIM}=2$

ENDIF

DO $130 I=1$, NUMELM

130

WRITE $(\mathrm{DMPF}, *) \quad \mathrm{I},(\mathrm{V}(\mathrm{I}, \mathrm{J}), \mathrm{J}=1, \mathrm{IDIM})$

ENDIF

ENDIF 


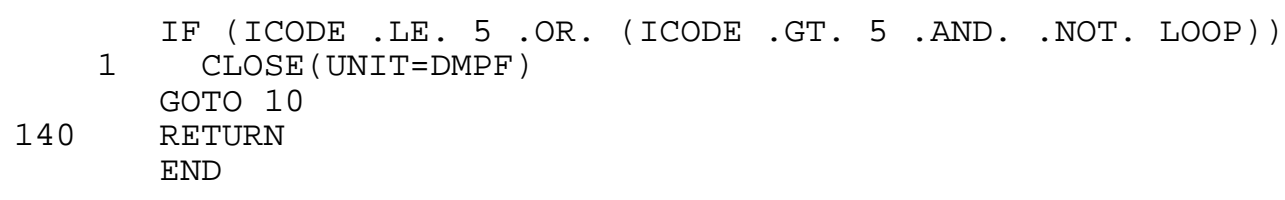

SUBROUTINE ASMBKC

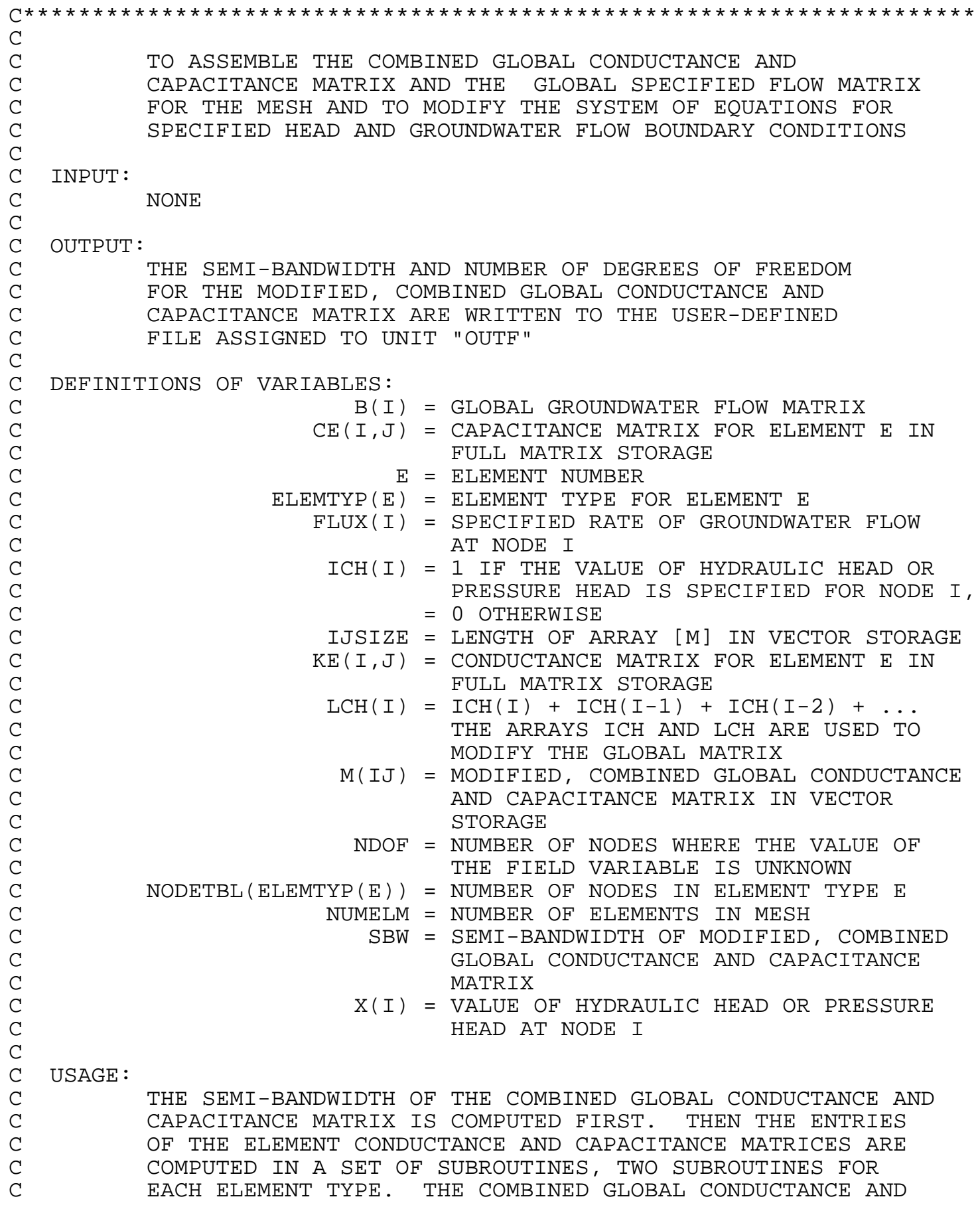




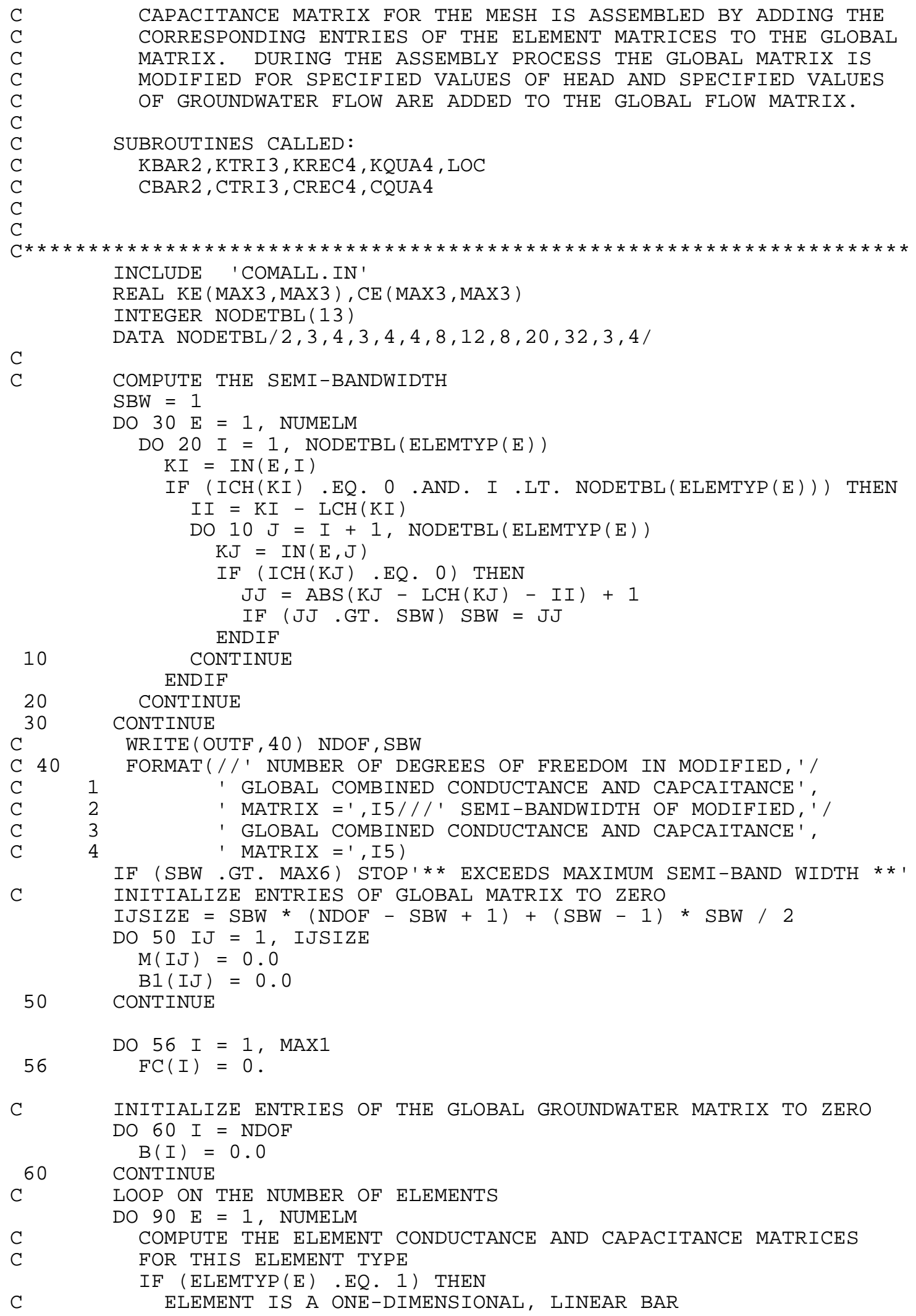




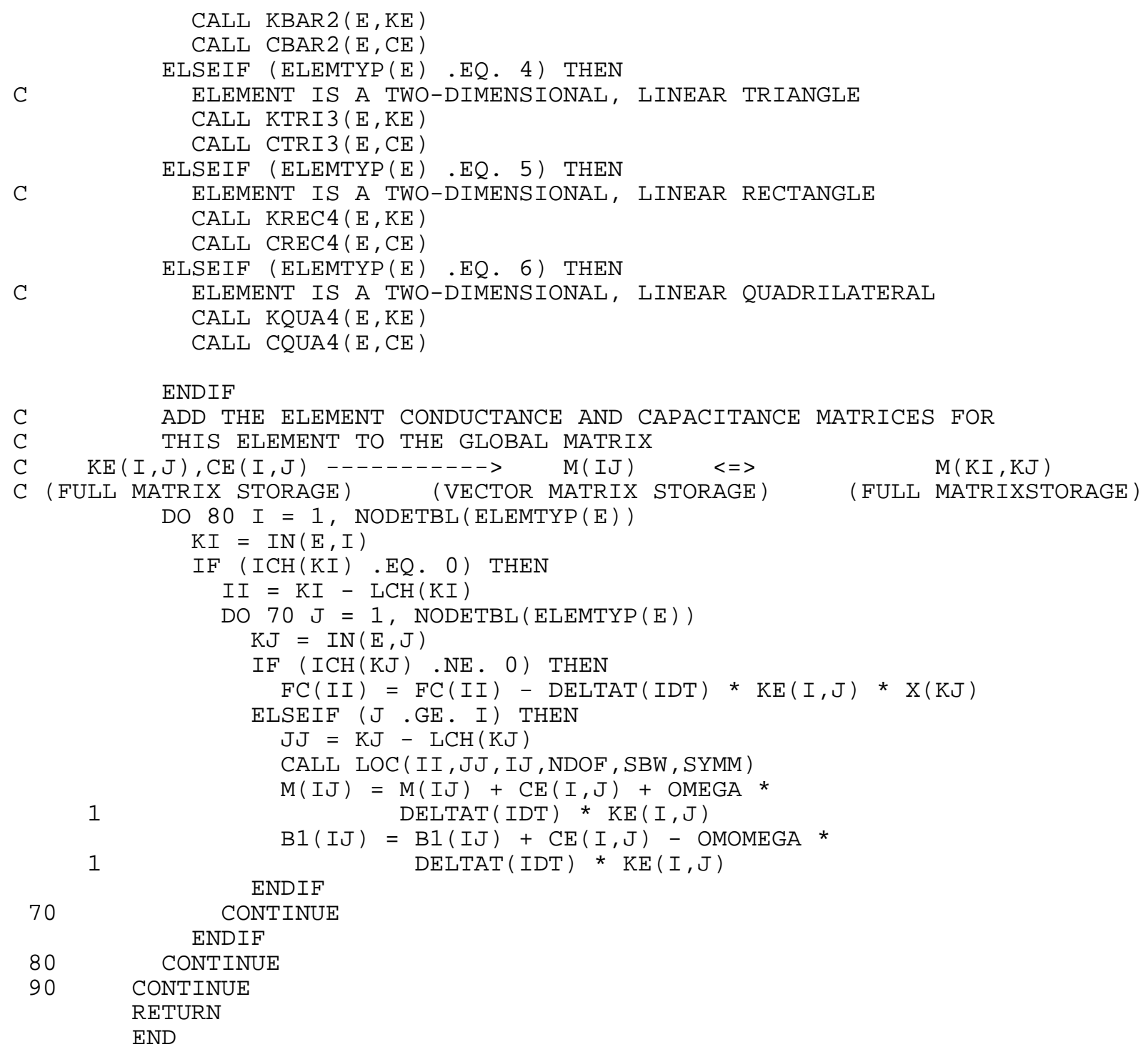

SUBROUTINE LOC ( I, J, I J, NDOF, SBW, SYMM)

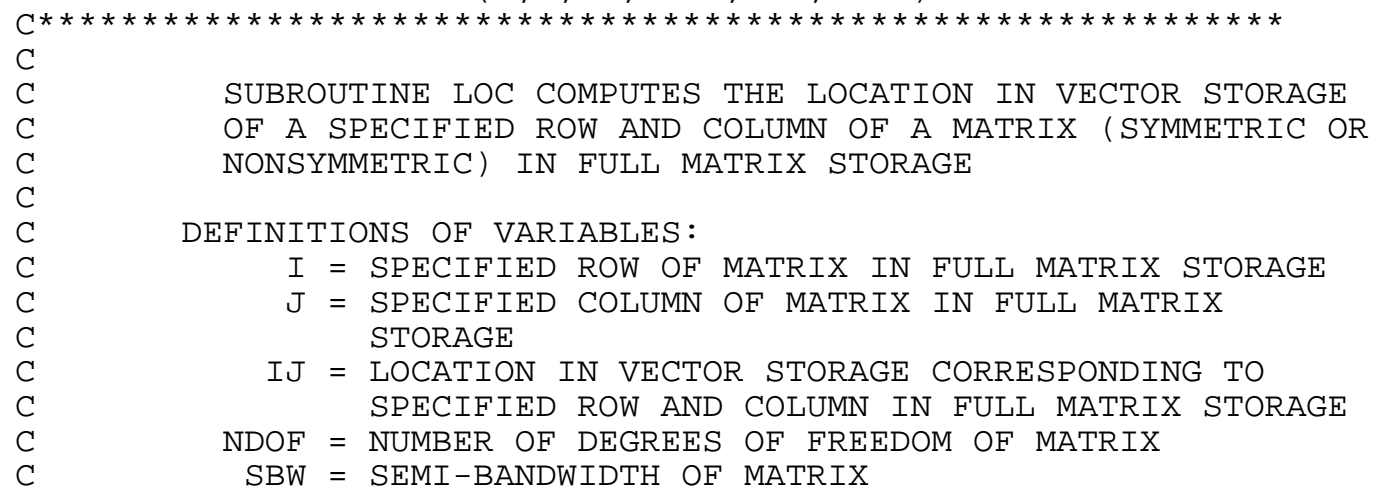




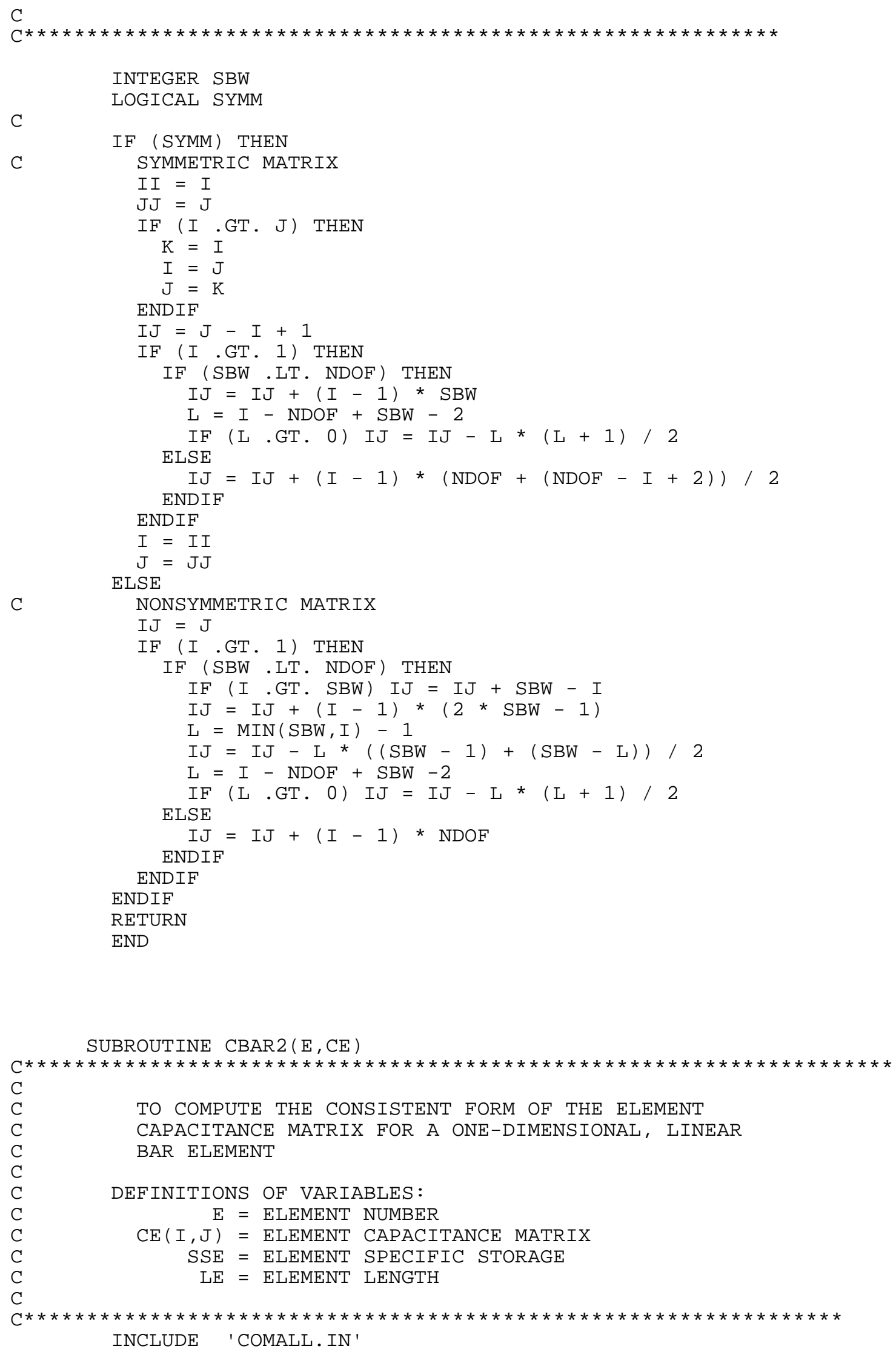




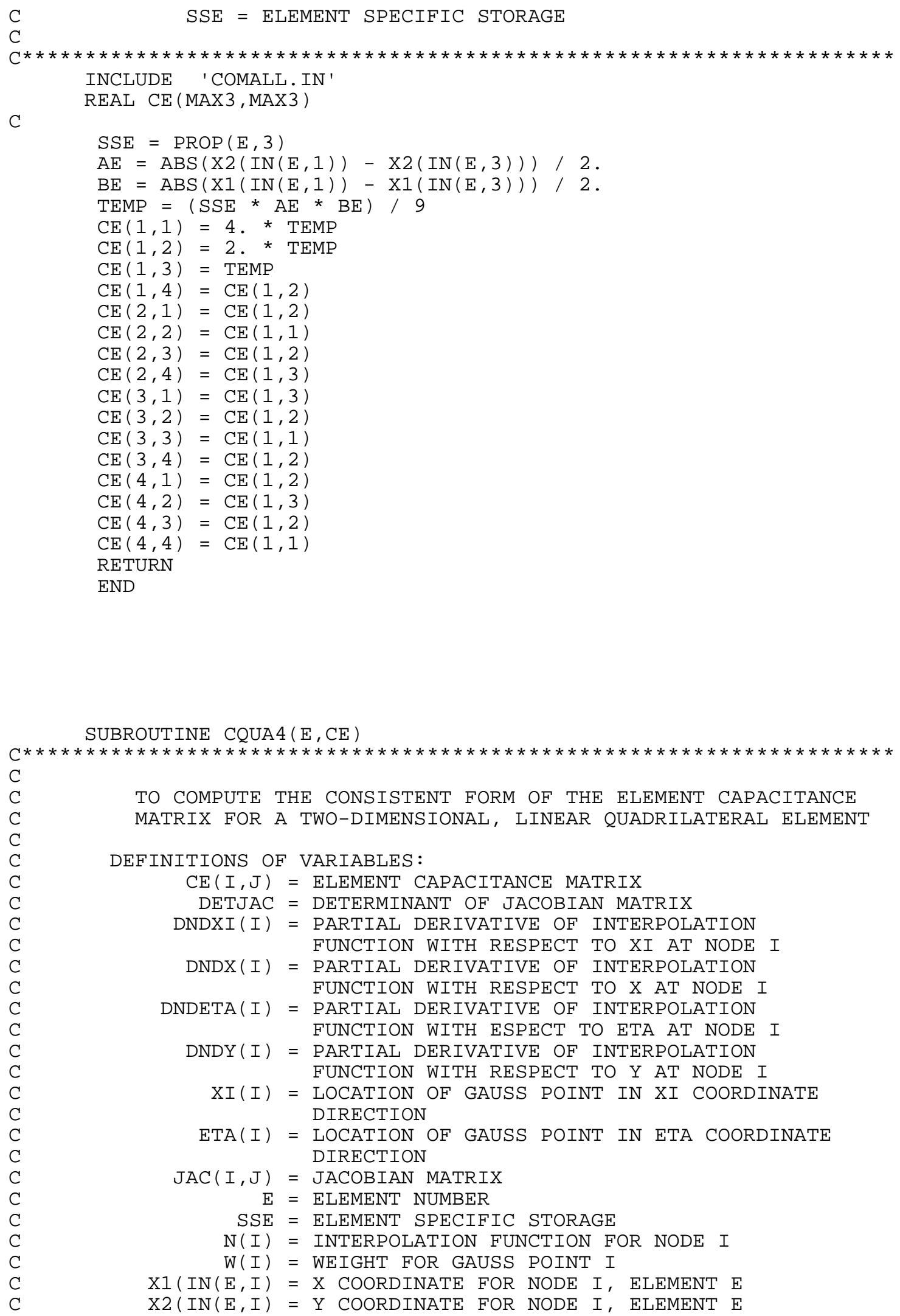


$\mathrm{C}$

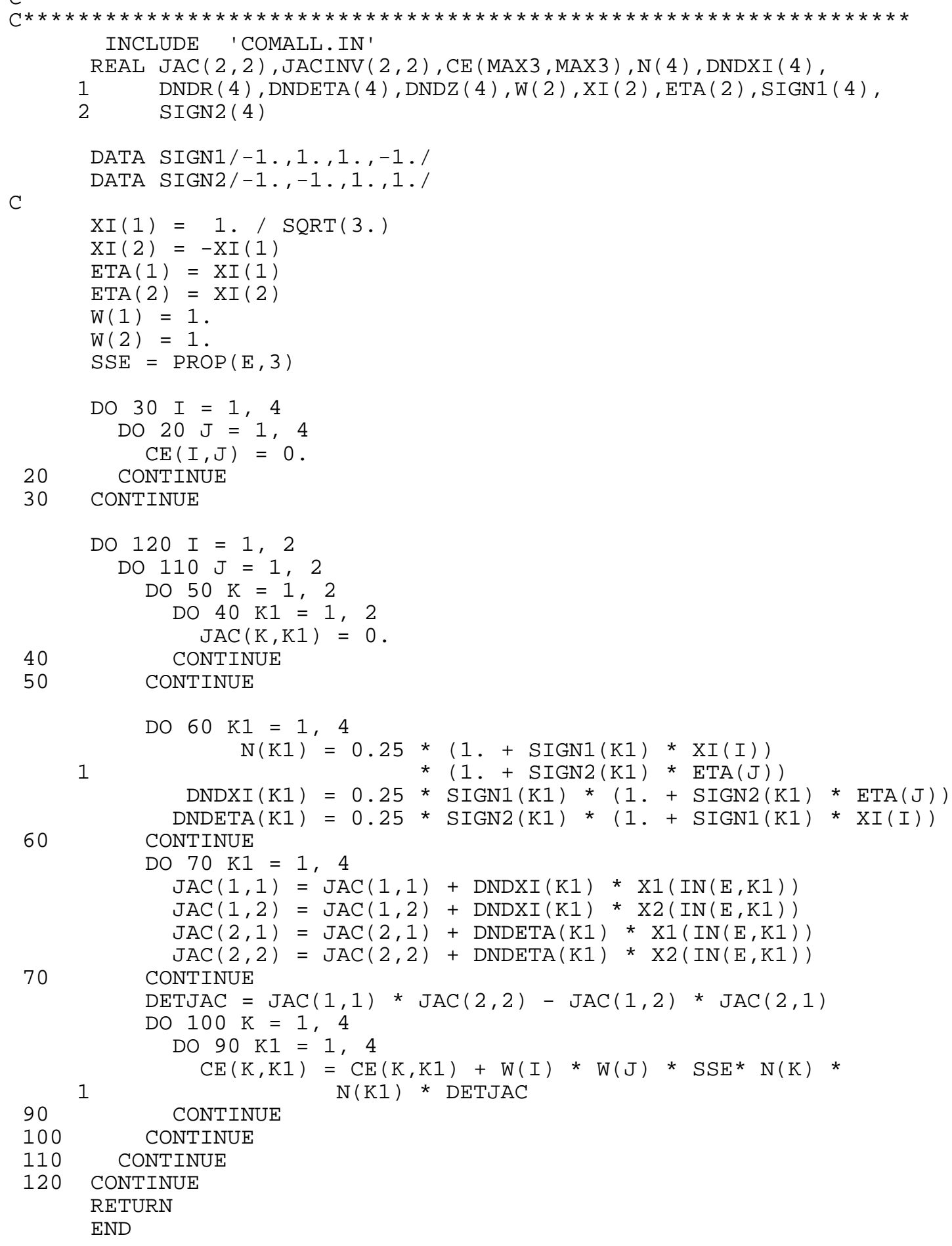




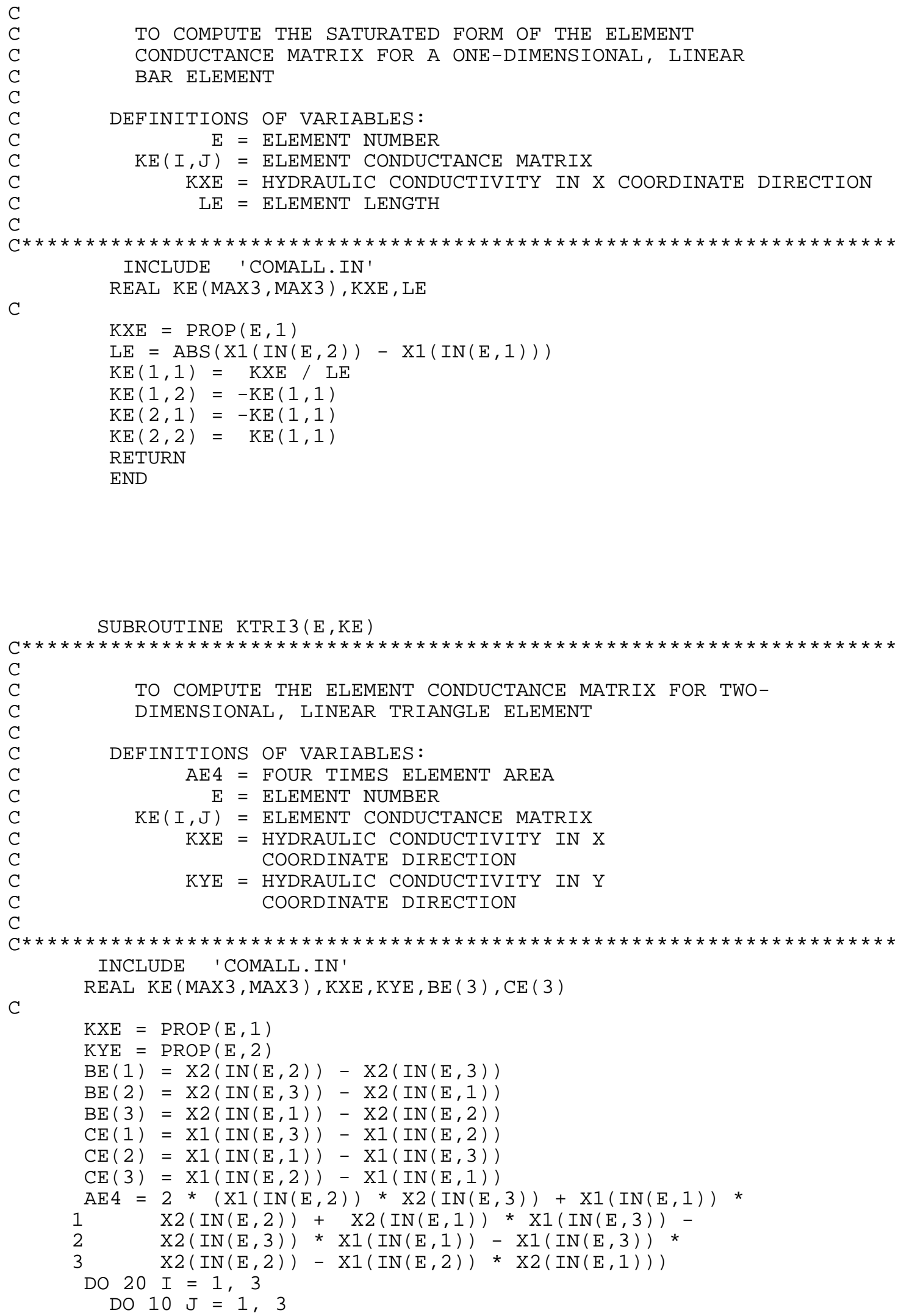




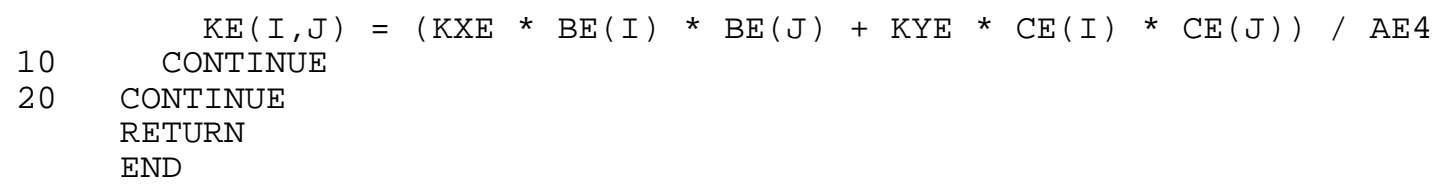

SUBROUTINE KREC4 (E, KE)

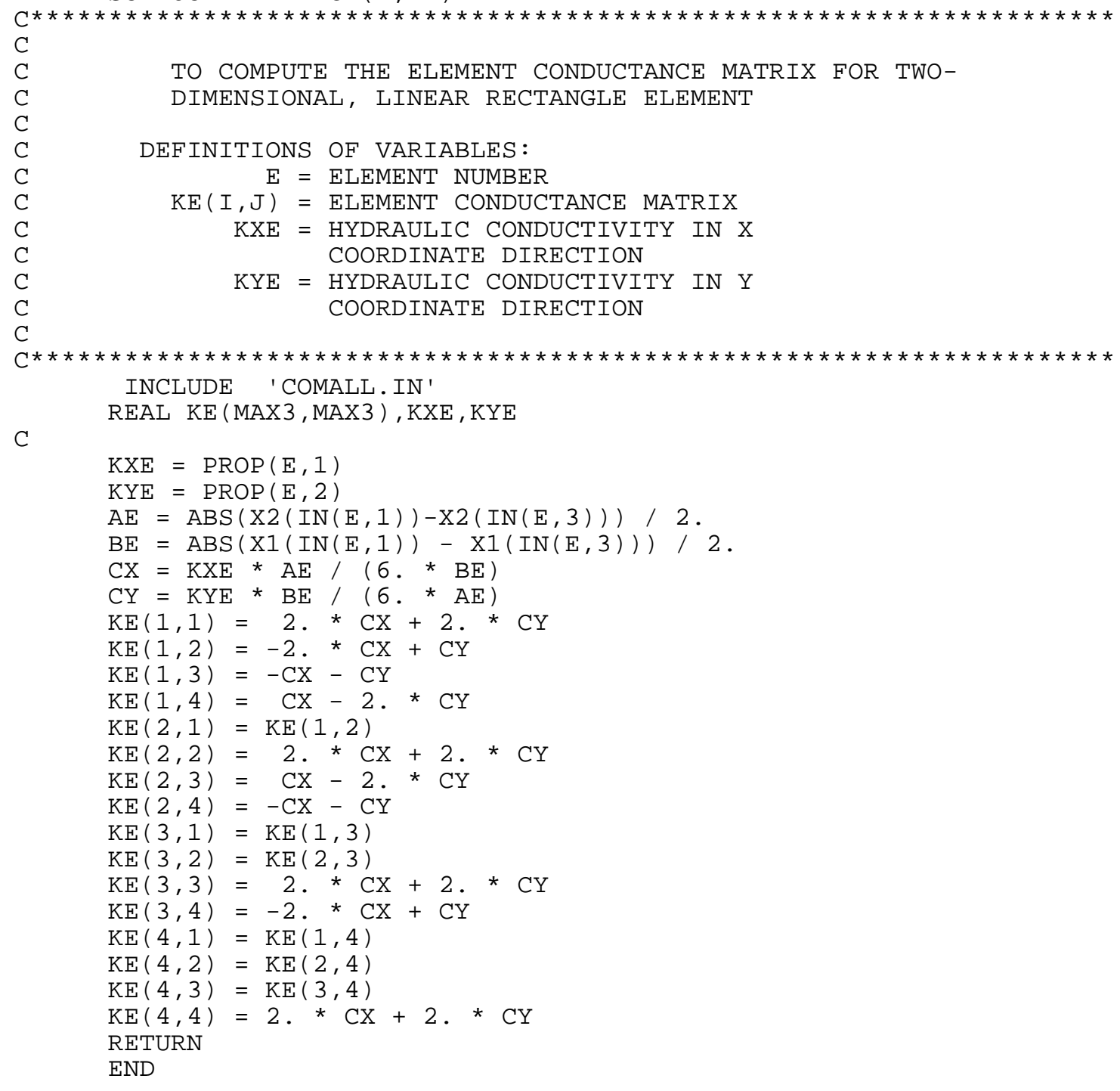


SUBROUTINE KQUA4 (E, KE)

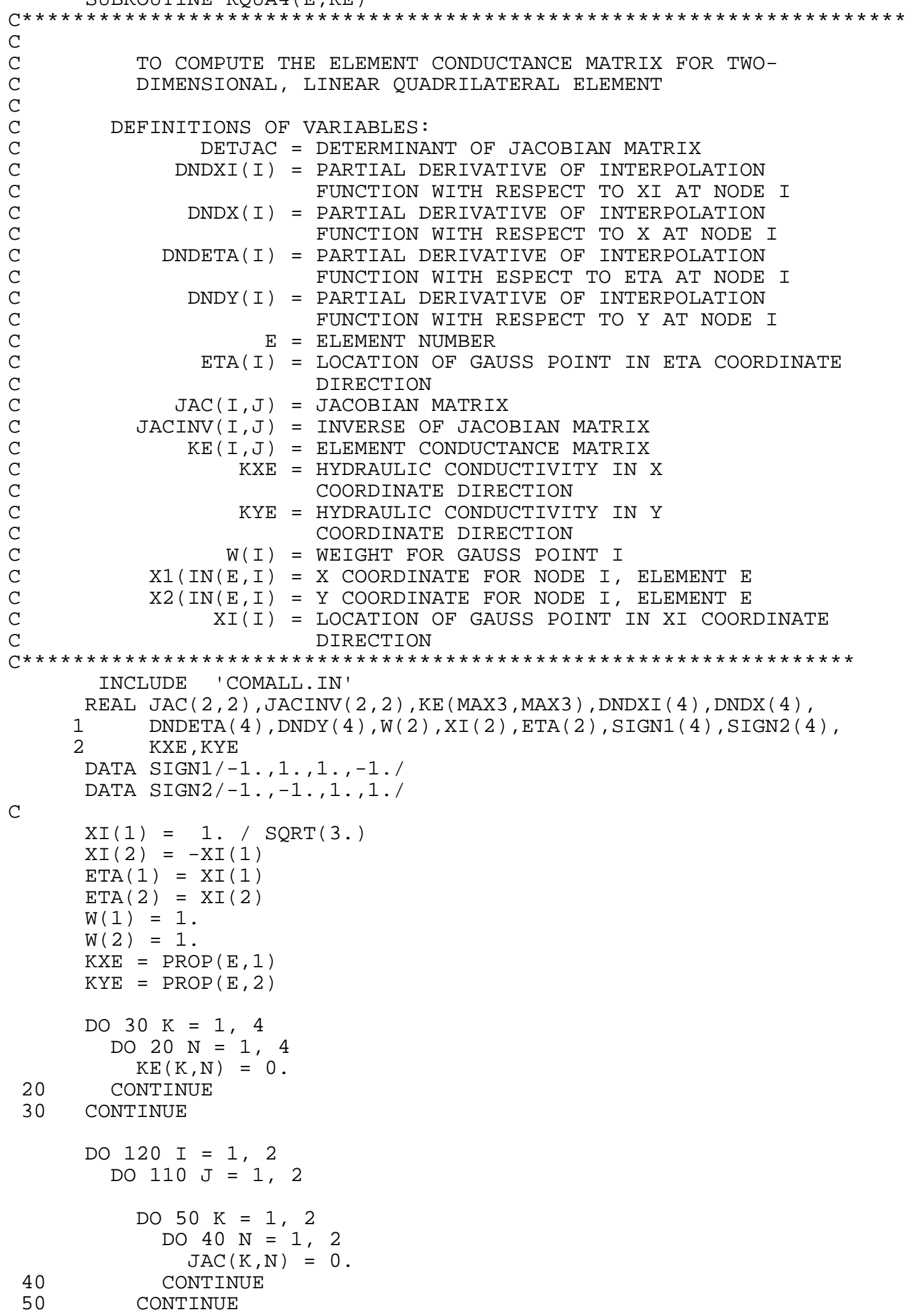




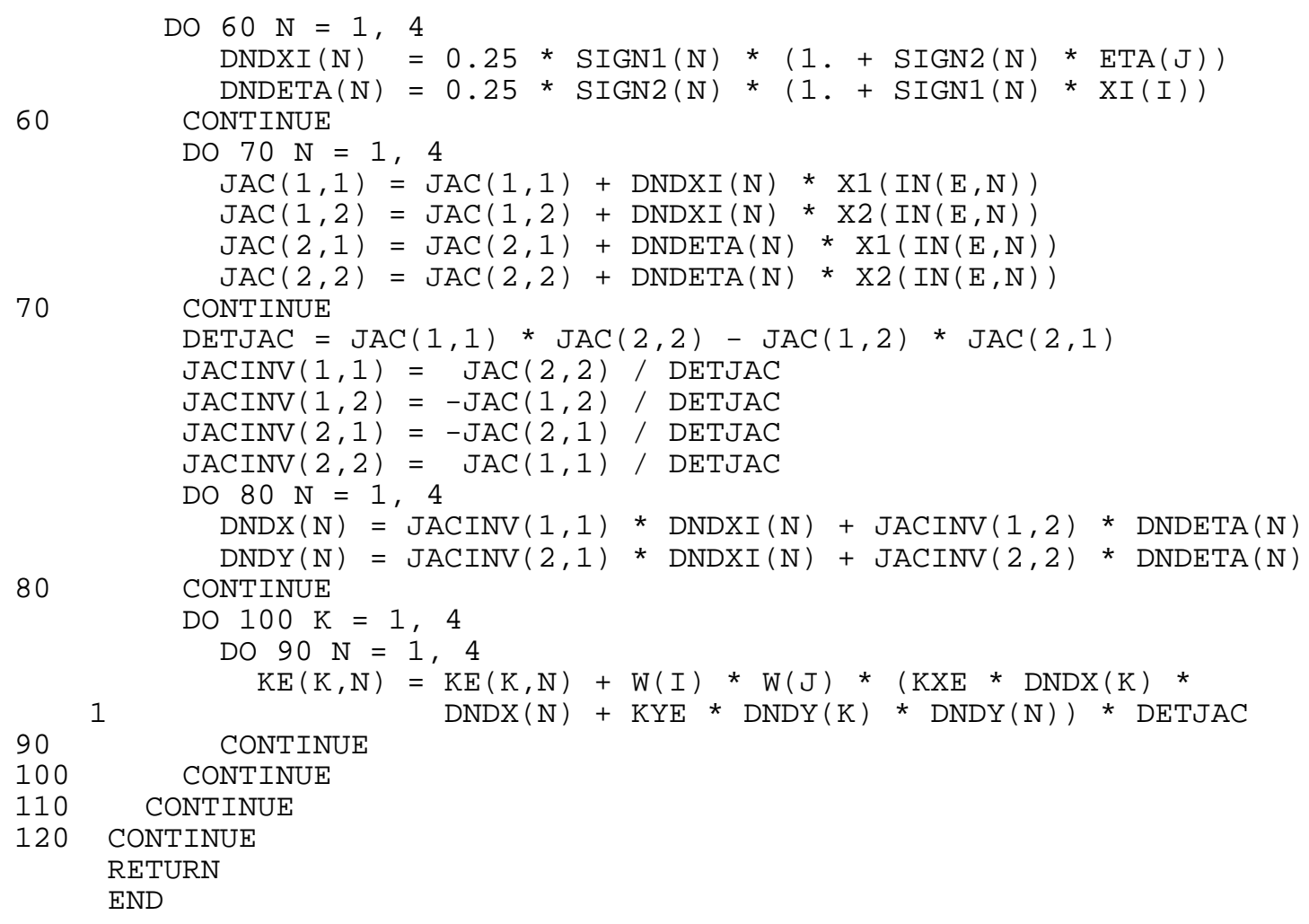

SUBROUTINE DECOMP (NDOF, SBW, SYMM, M)

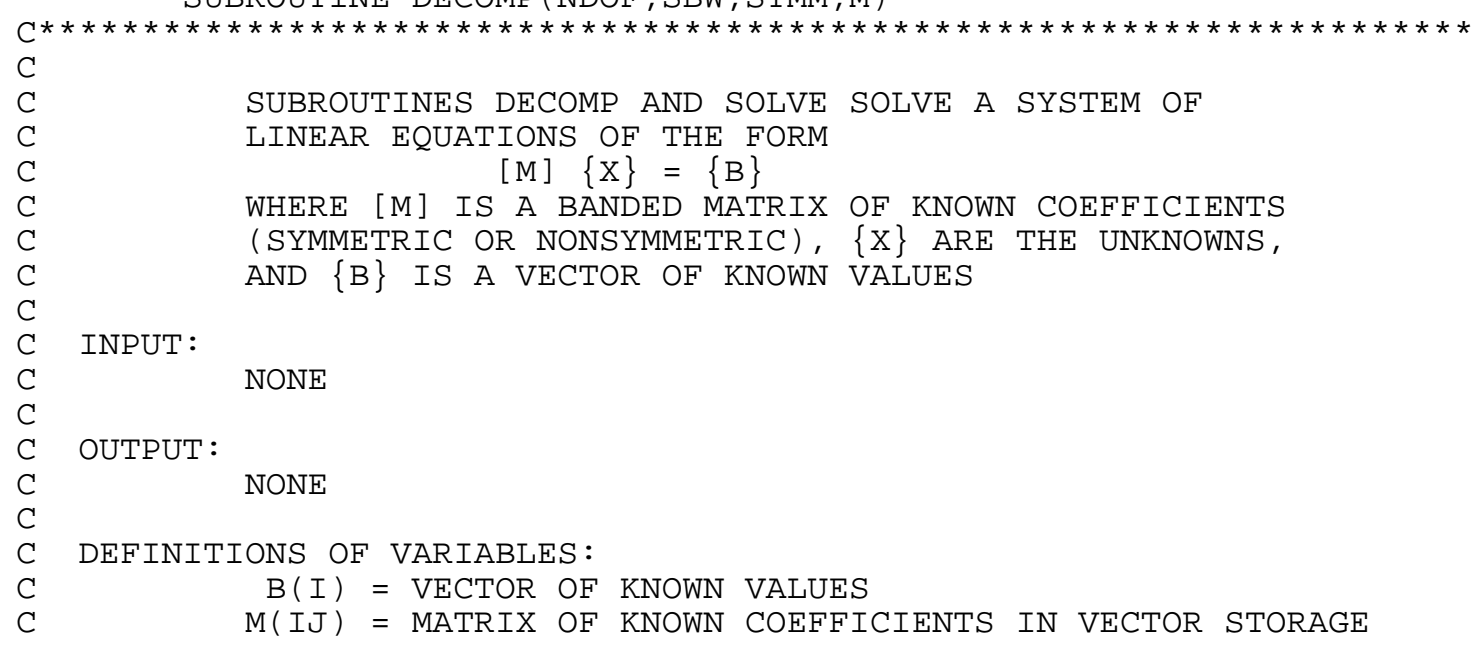




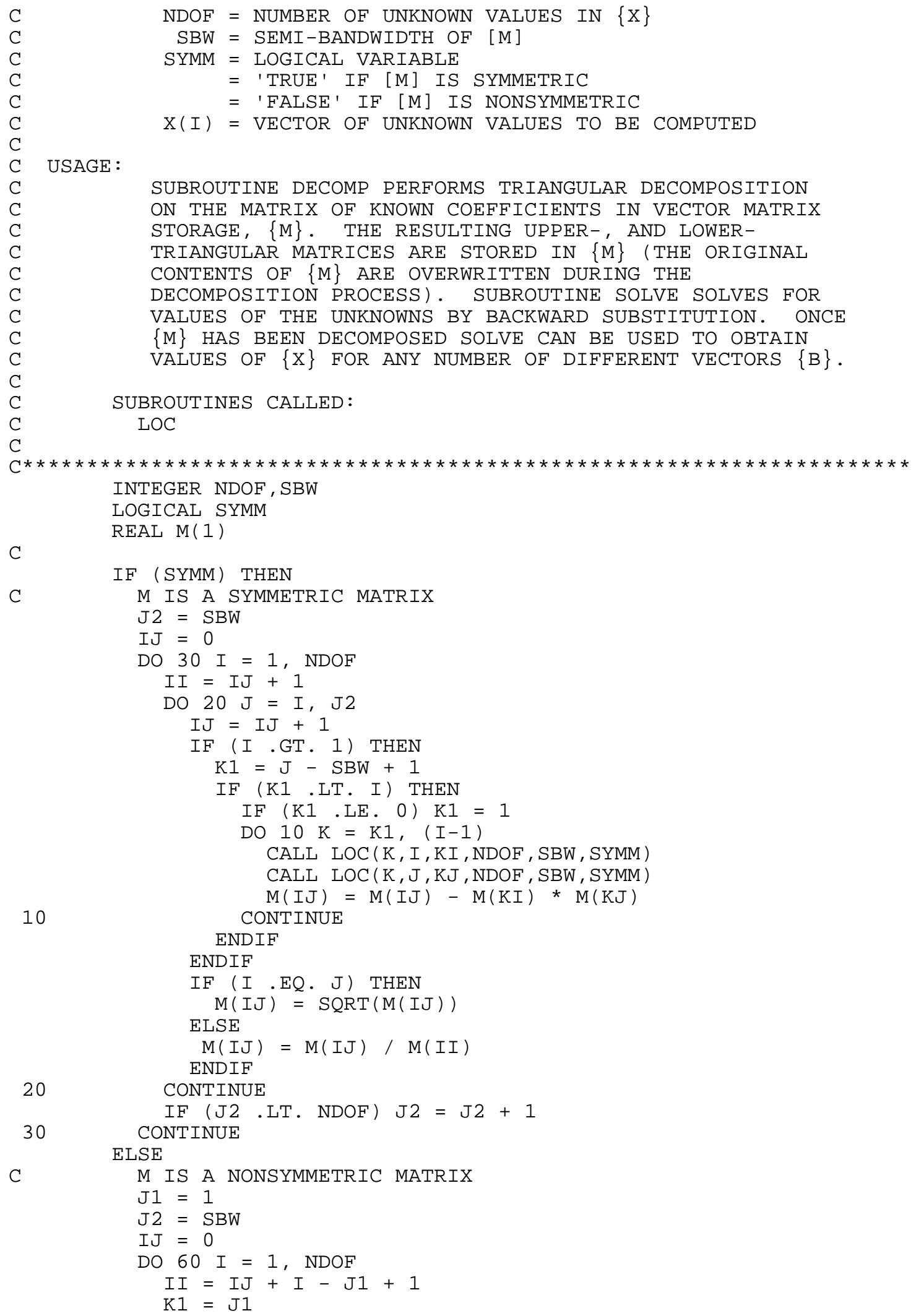


60

$\mathrm{IF}$ (J2.LT. NDOF) J2 = J2 +1

ENDIF

RETURN

END 
SUBROUTINE RHS

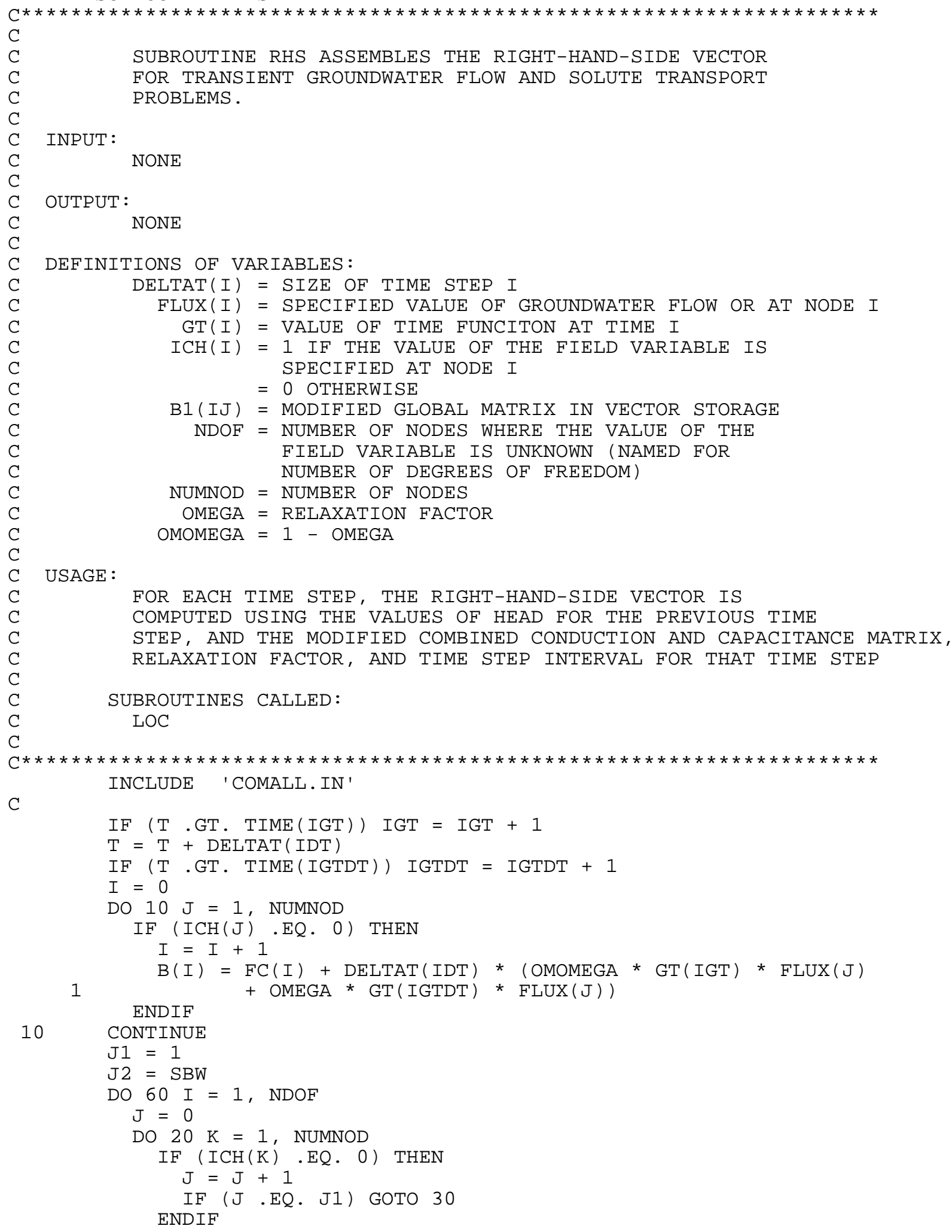




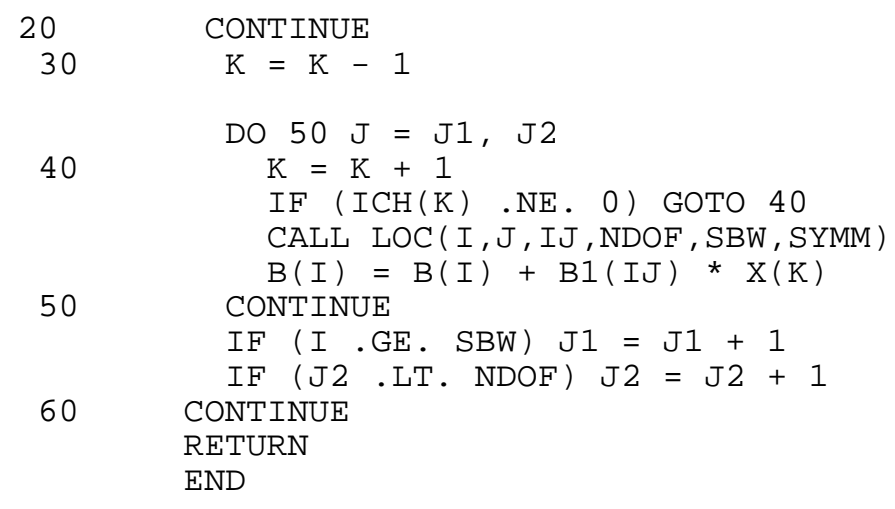

SUBROUTINE VELOCITY

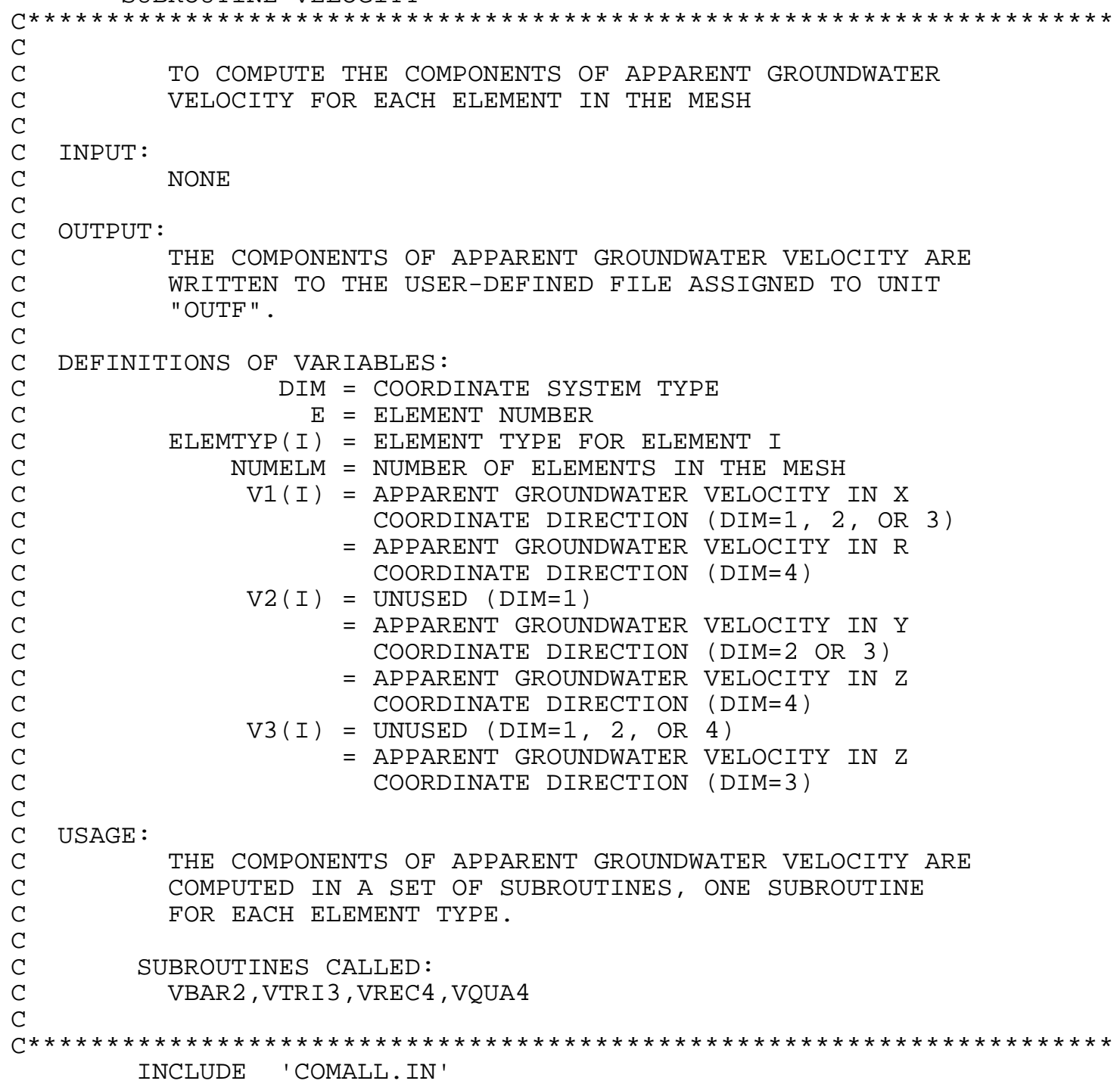



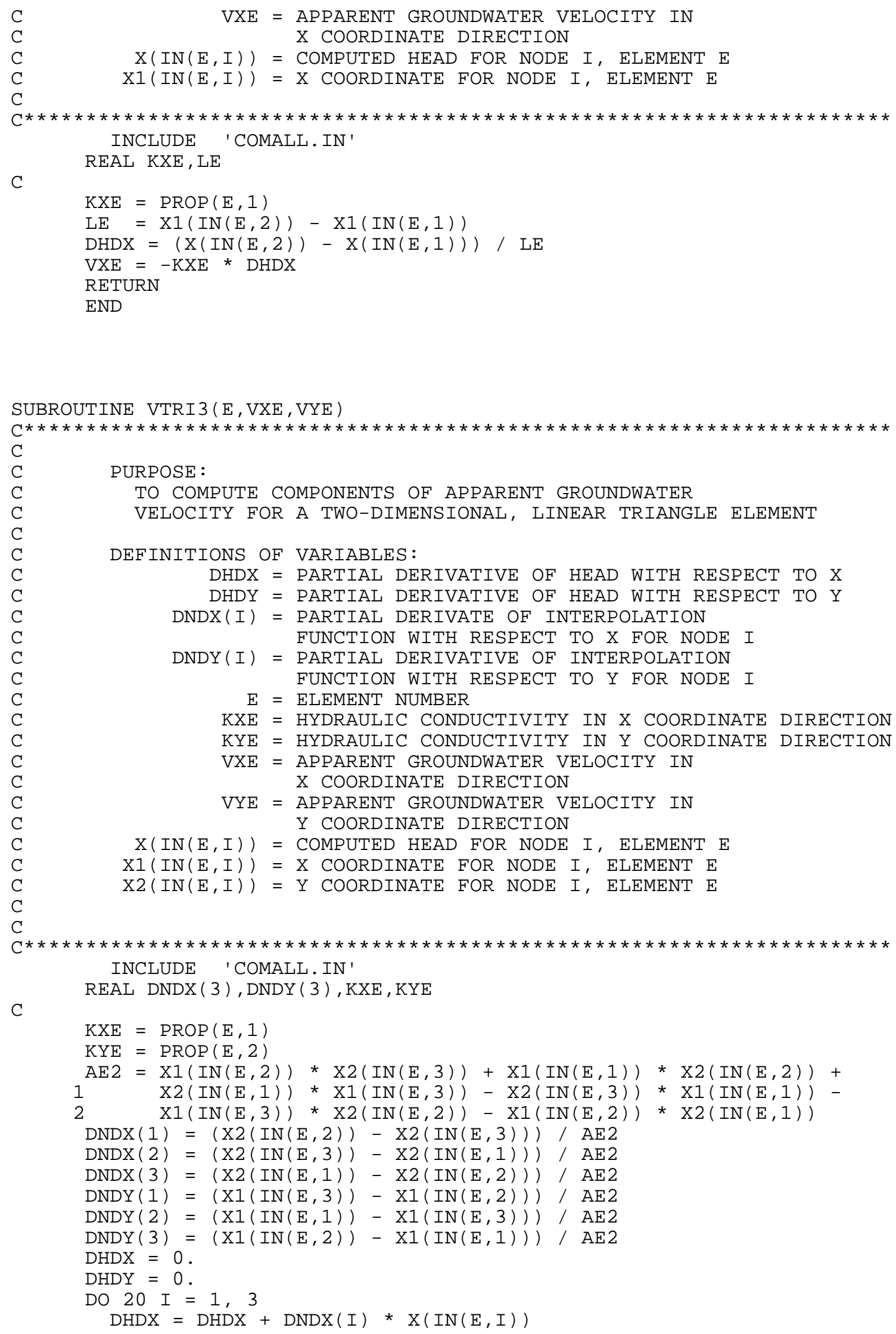
$\operatorname{DHDY}=\operatorname{DHDY}+\operatorname{DNDY}(I) \star X(I N(E, I))$

20 CONTINUE

$\mathrm{VXE}=-\mathrm{KXE} * \mathrm{DHDX}$

$\mathrm{VYE}=-\mathrm{KYE} * \mathrm{DHDY}$

RETURN

END

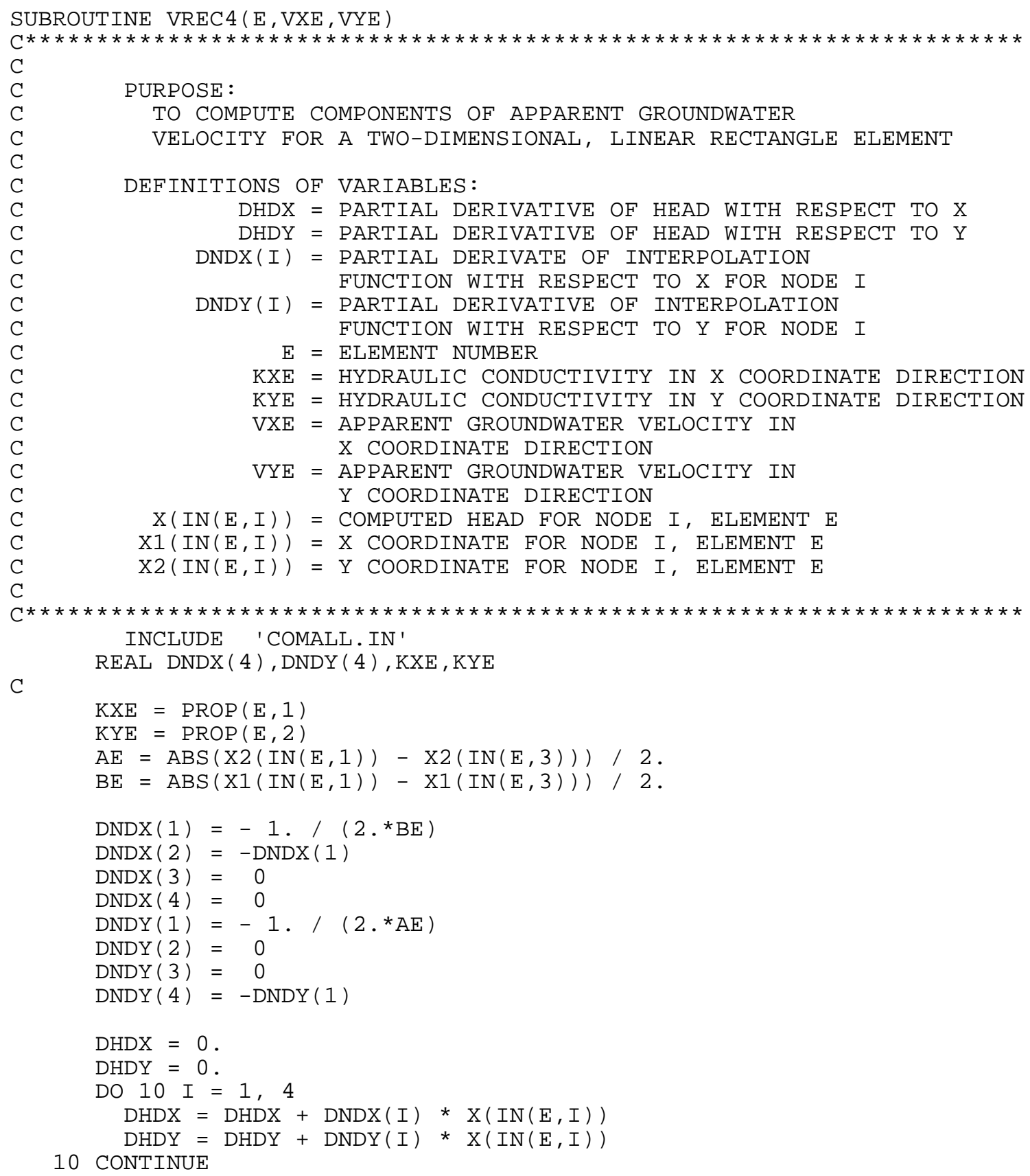


$\mathrm{VXE}=-\mathrm{KXE} * \mathrm{DHDX}$

$\mathrm{VYE}=-\mathrm{KYE} * \mathrm{DHDY}$

RETURN

END

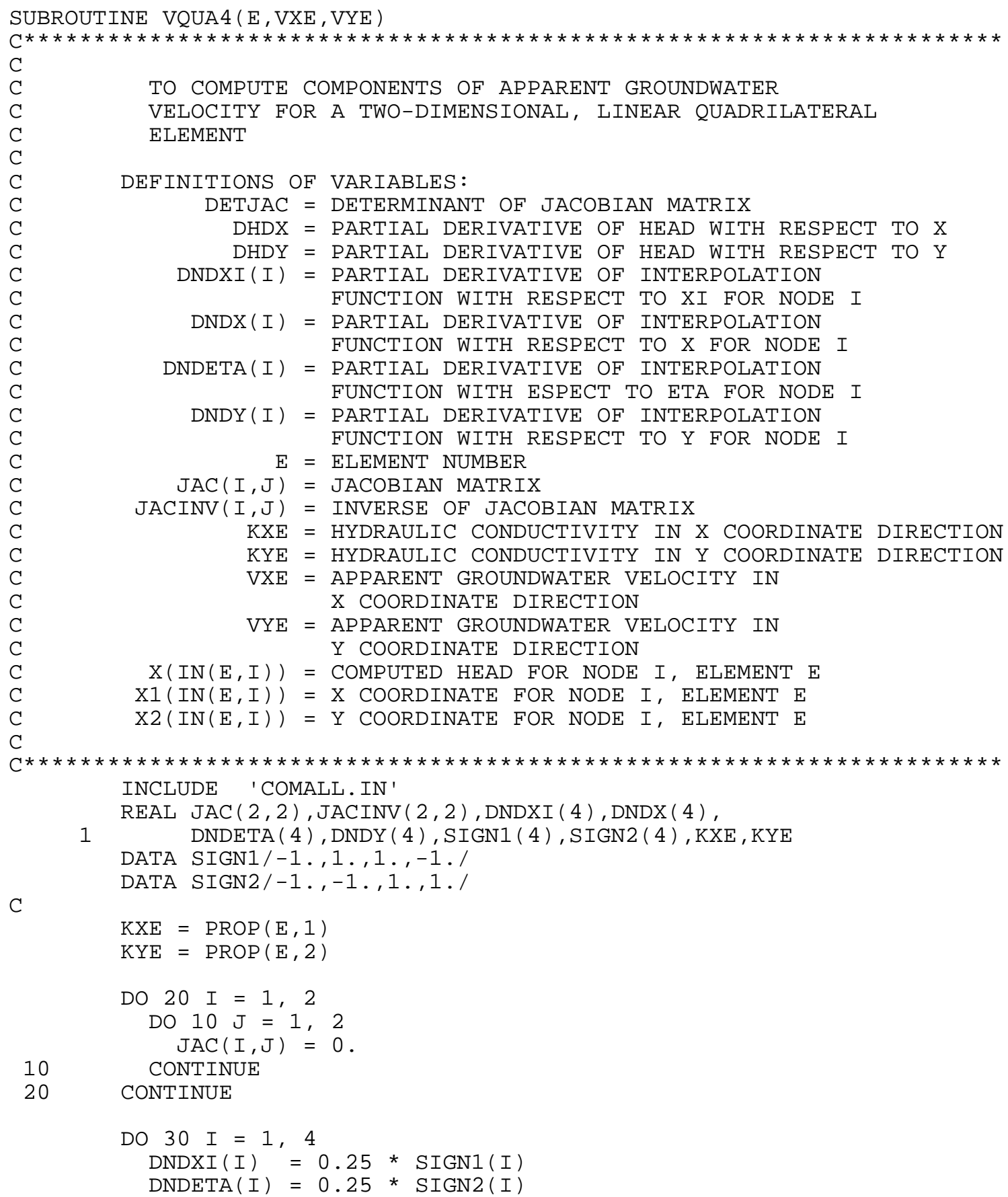




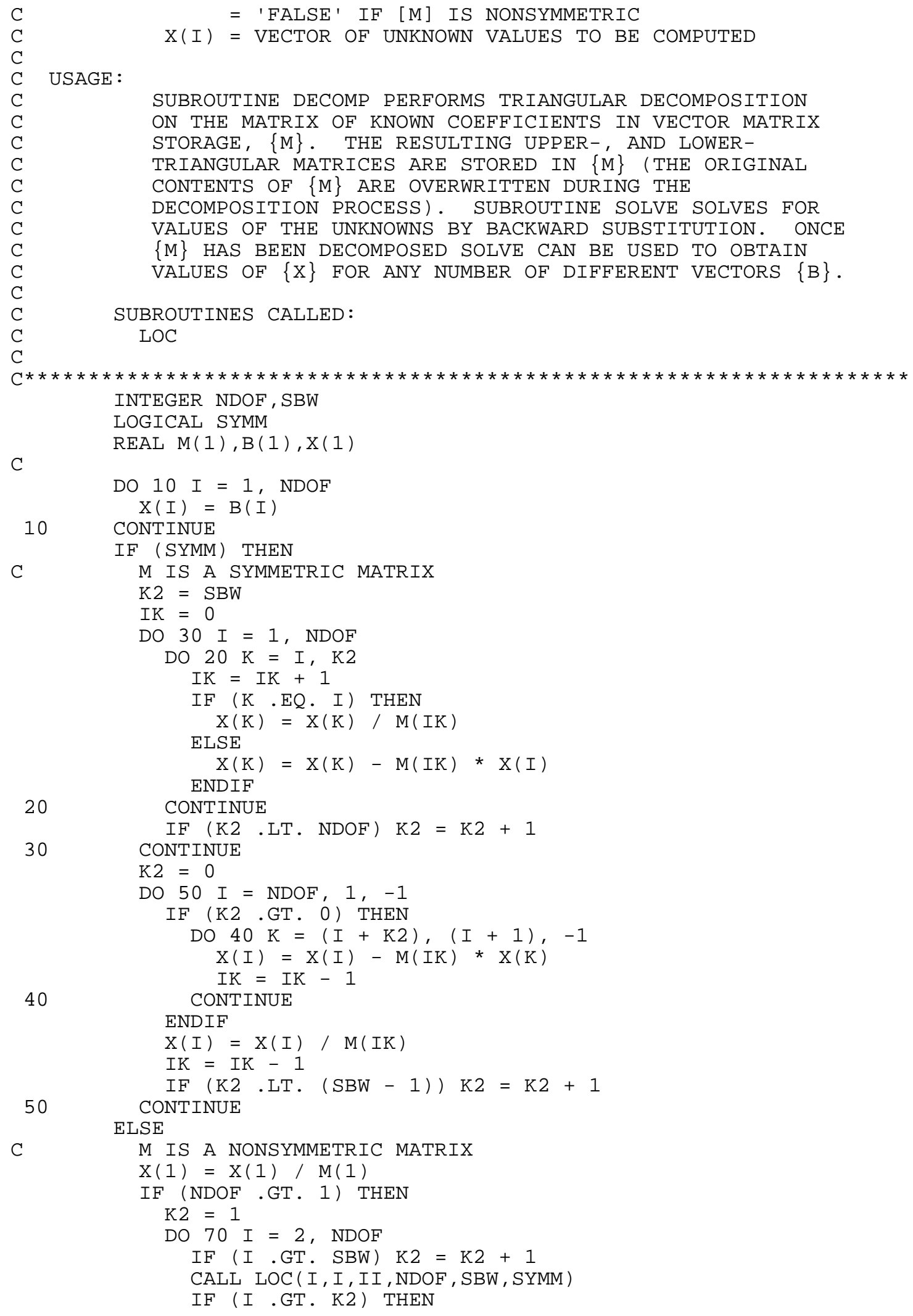


$I K=I I-1$

DO $60 \mathrm{~K}=(\mathrm{I}-1), \mathrm{K} 2,-1$

$X(I)=X(I)-M(I K) * X(K)$

$\mathrm{IK}=\mathrm{IK}-1$

ENDIF
$\mathrm{X}(\mathrm{I})$

70$$
X(I) / M(I I)
$$

ENDIF

$\mathrm{J}=\mathrm{NDOF}-\mathrm{SBW}+1$

$\mathrm{K} 2=\mathrm{NDOF}$

IF (NDOF.GT. 1) THEN

DO $90 \mathrm{I}=(\mathrm{NDOF}-1), 1,-1$

$\mathrm{IF}(\mathrm{I} . \mathrm{LT} . \mathrm{J}) \mathrm{K} 2=\mathrm{K} 2-1$

IF (I .LT. K2) THEN

CALL LOC ( I, I, II, NDOF, SBW, SYMM)

$I K=I I+1$

DO $80 \mathrm{~K}=(\mathrm{I}+1), \mathrm{K} 2$

$X(I)=X(I)-M(I K) \star X(K)$

$I K=I K+1$

80

ENDIF

90 CONTINUE

ENDIF

ENDIF

RETURN

END 


\section{A.3 Data and Output Files of the Example}

Several examples were performed using the COMPBAR computer program. One of the examples of the data files and output files are presented next.

\section{A.3.1 Data File of the Example 1}

\begin{tabular}{|c|c|c|c|c|c|c|}
\hline \multicolumn{7}{|c|}{ GOOD CONTACT CONDITION } \\
\hline 2 & \multicolumn{6}{|c|}{ DIM } \\
\hline 5 & \multicolumn{6}{|c|}{ \# OF HOLES } \\
\hline $1,-2$ & \multicolumn{6}{|c|}{ UNITS $(0-\mathrm{m}, 1-\mathrm{cm}, 2-\mathrm{ft}, \&$ 3-in), INITIAL PRESSURE FOR TOP NODES } \\
\hline 400 & \multicolumn{6}{|c|}{ X COORDINATE LOCATION FOR THE FIRST HOLE ! } \\
\hline 0,0 & \multicolumn{6}{|c|}{ TYPE \& CONTACT OF THE HOLE ! REPEAT FOR EVERY HOLE } \\
\hline \multicolumn{7}{|c|}{$\mathrm{R} 0$, hw, \& Kw ALL IN m \& m/sec! } \\
\hline 900 & \multicolumn{6}{|c|}{ X COORDINATE LOCATION FOR THE SECOND HOLE ! } \\
\hline 0,0 & \multicolumn{6}{|c|}{ TYPE \& CONTACT OF THE HOLE! } \\
\hline \multicolumn{7}{|c|}{$\begin{array}{ll}0,0 & \\
0.00564,0.3,1.3 \mathrm{E}-9 & \mathrm{R} 0, \mathrm{hw}, \& \mathrm{Kw} \text { ALL IN } \mathrm{m} \& \mathrm{~m} / \mathrm{sec} !\end{array}$} \\
\hline 1400 & \multicolumn{6}{|c|}{ X COORDINATE LOCATION FOR THE THIRD HOLE ! } \\
\hline 0,0 & \multicolumn{6}{|c|}{ TYPE \& CONTACT OF THE HOLE ! } \\
\hline 0.00 & 54,0 & $3,1.3 \mathrm{E}-9$ & R0, & Kw ALL IN & $\& \mathrm{~m} / \mathrm{s}$ & \\
\hline 2000 & \multicolumn{6}{|c|}{ X COORDINATE LOCATION FOR THE FOURTH HOLE ! } \\
\hline \multirow{2}{*}{\multicolumn{7}{|c|}{$\begin{array}{l}0,0 \quad \text { TYPE \& CONTACT OF THE HOLE } ! \\
0.00564,0.3,1.3 \mathrm{E}-9 \quad \text { R0, hw, \& Kw ALL IN } \mathrm{m} \& \mathrm{~m} / \mathrm{sec} !\end{array}$}} \\
\hline & & & & & & \\
\hline 2600 & \multicolumn{6}{|c|}{ X COORDINATE LOCATION FOR THE FIFTH HOLE ! } \\
\hline 0,0 & \multicolumn{6}{|c|}{ TYPE \& CONTACT OF THE HOLE! } \\
\hline \multicolumn{7}{|c|}{$0.00564,0.3,1.3 \mathrm{E}-9 \quad \mathrm{R} 0, \mathrm{hw}, \& \mathrm{Kw}$ ALL IN $\mathrm{m} \& \mathrm{~m} / \mathrm{sec} !$} \\
\hline 1 & 1 & 0 & 0 & NODE 1 , & $\mathrm{INC}$ & XYZ COORDINATE \\
\hline 12 & 1 & 0 & 110 & $"$ & $"$ & $"$ \\
\hline 17 & 1 & 0 & 120 & $"$ & $"$ & $"$ \\
\hline 18 & 1 & 200 & 0 & $"$ & $"$ & $"$ \\
\hline 29 & 1 & 200 & 110 & $"$ & $"$ & $"$ \\
\hline 34 & 1 & 200 & 120 & $"$ & $"$ & $"$ \\
\hline 35 & 1 & 400 & 0 & $"$ & $"$ & $"$ \\
\hline 46 & 1 & 400 & 110 & " & " & $"$ \\
\hline 51 & 1 & 400 & 120 & " & " & $"$ \\
\hline 52 & 1 & 600 & 0 & " & " & " \\
\hline 63 & 1 & 600 & 110 & $"$ & $"$ & $"$ \\
\hline 68 & 1 & 600 & 120 & $"$ & $"$ & $"$ \\
\hline 69 & 1 & 800 & 0 & $"$ & $"$ & $"$ \\
\hline 80 & 1 & 800 & 110 & " & " & " \\
\hline 85 & 1 & 800 & 120 & $"$ & $"$ & $"$ \\
\hline 86 & 1 & 820 & 0 & " & $"$ & $"$ \\
\hline 97 & 1 & 820 & 110 & " & " & " \\
\hline 102 & 1 & 820 & 120 & " & " & $"$ \\
\hline 103 & 1 & 840 & 0 & $"$ & $"$ & $"$ \\
\hline 114 & 1 & 840 & 110 & " & " & $"$ \\
\hline
\end{tabular}




$\begin{array}{llll}119 & 1 & 840 & 120 \\ 120 & 1 & 860 & 0 \\ 131 & 1 & 860 & 110 \\ 136 & 1 & 860 & 120 \\ 137 & 1 & 880 & 0 \\ 148 & 1 & 880 & 110 \\ 153 & 1 & 880 & 120 \\ 154 & 1 & 900 & 0 \\ 165 & 1 & 900 & 110 \\ 170 & 1 & 900 & 120 \\ 171 & 1 & 920 & 0 \\ 182 & 1 & 920 & 110 \\ 187 & 1 & 920 & 120 \\ 188 & 1 & 940 & 0 \\ 199 & 1 & 940 & 110 \\ 204 & 1 & 940 & 120 \\ 205 & 1 & 960 & 0 \\ 216 & 1 & 960 & 110 \\ 221 & 1 & 960 & 120 \\ 222 & 1 & 980 & 0 \\ 233 & 1 & 980 & 110 \\ 238 & 1 & 980 & 120 \\ 239 & 1 & 1000 & 0 \\ 250 & 1 & 1000 & 110 \\ 255 & 1 & 1000 & 120 \\ 256 & 1 & 1200 & 0 \\ 267 & 1 & 1200 & 110 \\ 272 & 1 & 1200 & 120 \\ 273 & 1 & 1400 & 0 \\ 284 & 1 & 1400 & 110 \\ 289 & 1 & 1400 & 120 \\ 290 & 1 & 1600 & 0 \\ 301 & 1 & 1600 & 110 \\ 306 & 1 & 1600 & 120 \\ 307 & 1 & 1800 & 0 \\ 318 & 1 & 1800 & 110 \\ 323 & 1 & 1800 & 120 \\ 324 & 1 & 2000 & 0 \\ 335 & 1 & 2000 & 110 \\ 340 & 1 & 2000 & 120 \\ 341 & 1 & 2200 & 0 \\ 352 & 1 & 2200 & 110 \\ 357 & 1 & 2200 & 120 \\ 358 & 1 & 2400 & 0 \\ 369 & 1 & 2400 & 110 \\ 374 & 1 & 2400 & 120\end{array}$




$\begin{array}{lllllll}375 & 1 & 2600 & 0 & " & " & " \\ 386 & 1 & 2600 & 110 & " & " & " \\ 391 & 1 & 2600 & 120 & " & " & " \\ 392 & 1 & 2800 & 0 & " & " & " \\ 403 & 1 & 2800 & 110 & " & " & " \\ 408 & 1 & 2800 & 120 & " & " & " \\ 409 & 1 & 3000 & 0 & " & " & " \\ 420 & 1 & 3000 & 110 & 4 & " & "\end{array}$

$\begin{array}{llllll}-1 & -1 & -1 & -1 & \text { TO END READING NODES DATA }\end{array}$

$\begin{array}{llllllll}1 & 5 & 17 & 1 & 18 & 19 & 2 & \text { EL DATA: ELM, TYPE, NODE INC., \#OF ELEM }\end{array}$

$\begin{array}{llllll}24 & 517 & 392409410393\end{array}$

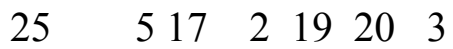

$\begin{array}{lllllll}48 & 517 & 393410411394\end{array}$

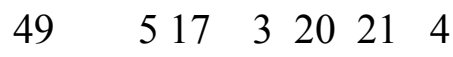

$\begin{array}{lllll}72 & 517 & 394411412395\end{array}$

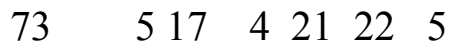

$\begin{array}{llllll}96 & 517 & 395412413 & 396\end{array}$

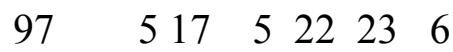

$\begin{array}{llllll}120 & 517 & 396413414397\end{array}$

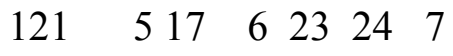

$\begin{array}{llllll}144 & 517 & 397414 & 415398\end{array}$

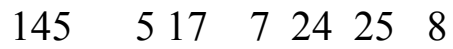

$\begin{array}{llllll}168 & 517 & 398415416399\end{array}$

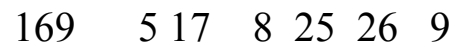

$\begin{array}{lllllll}192 & 517 & 399416417400\end{array}$

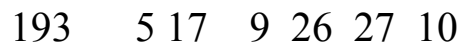

$\begin{array}{llllll}216 & 517 & 400417418401\end{array}$

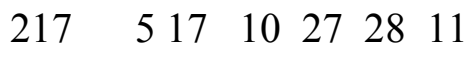

$\begin{array}{llllll}240 & 5 & 17 & 401418419402\end{array}$

$\begin{array}{lllllll}241 & 5 & 17 & 11 & 28 & 29 & 12\end{array}$

$\begin{array}{llllll}264 & 517 & 402419420403\end{array}$

$\begin{array}{llllllllll}265 & 5 & 17 & 12 & 29 & 30 & 13 & & & \end{array}$

$\begin{array}{lllll}288 & 517 & 403420421404\end{array}$

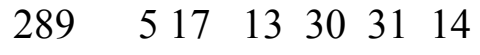

$\begin{array}{llllll}312 & 517 & 404421422405\end{array}$

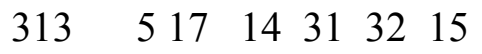

$\begin{array}{llllll}336 & 517 & 405422423 & 406\end{array}$

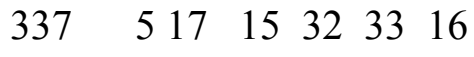

$\begin{array}{lllllll}360 & 517 & 406423 & 424 & 407\end{array}$

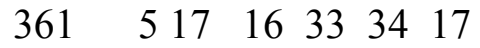

$\begin{array}{lllllll}384 & 517 & 407 & 424 & 425 & 408\end{array}$

$\begin{array}{llllllll}-1 & -1 & -1 & -1 & -1 & -1 & -1 & \text { TO END READING ELEMENT DATA }\end{array}$

$1 \quad 1 \quad$ ELEMENT \#, MATERIAL SET \#

$72-1$

$73 \quad 2$ 


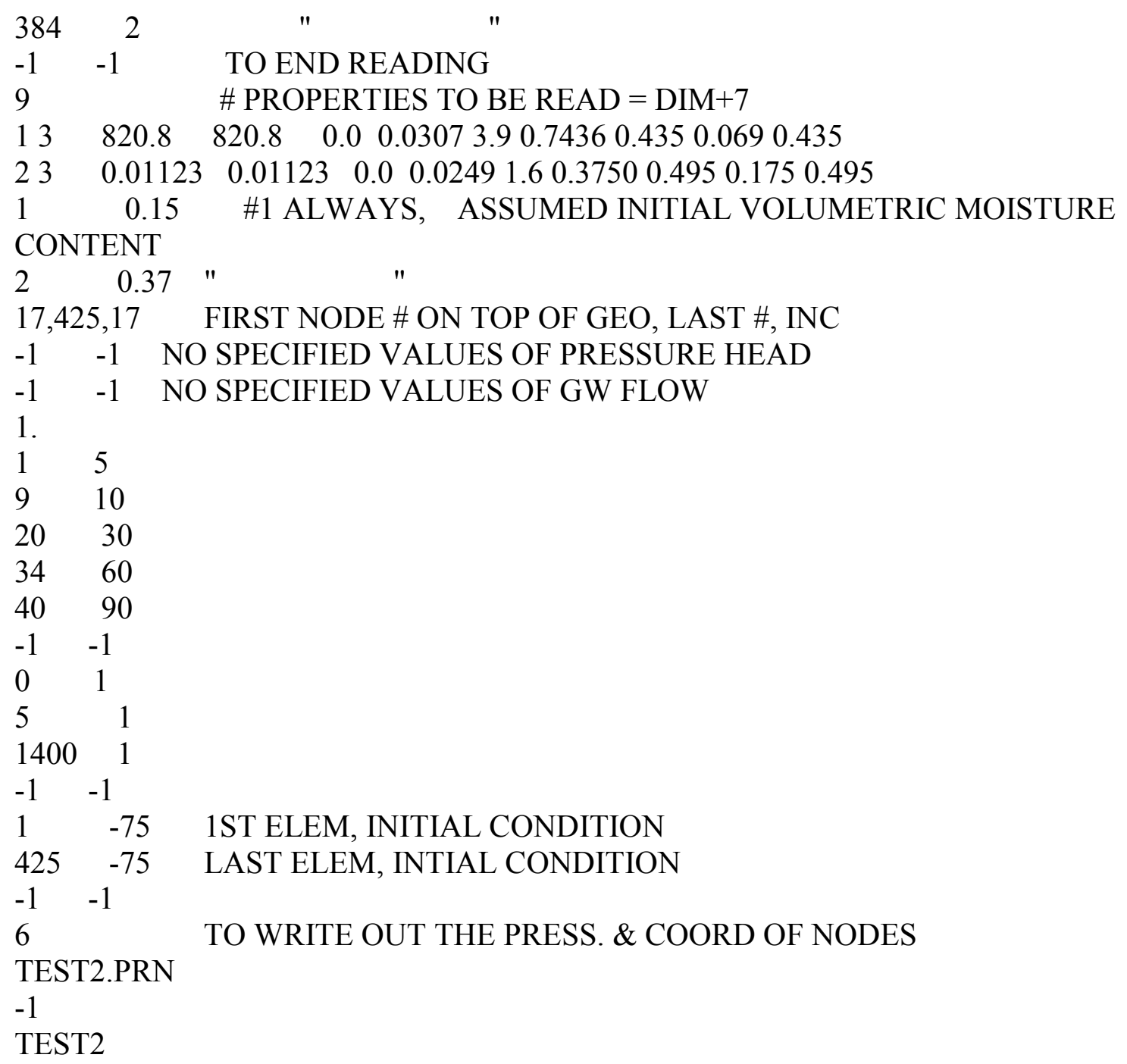




\section{A.3.2 Output of the Example 1}

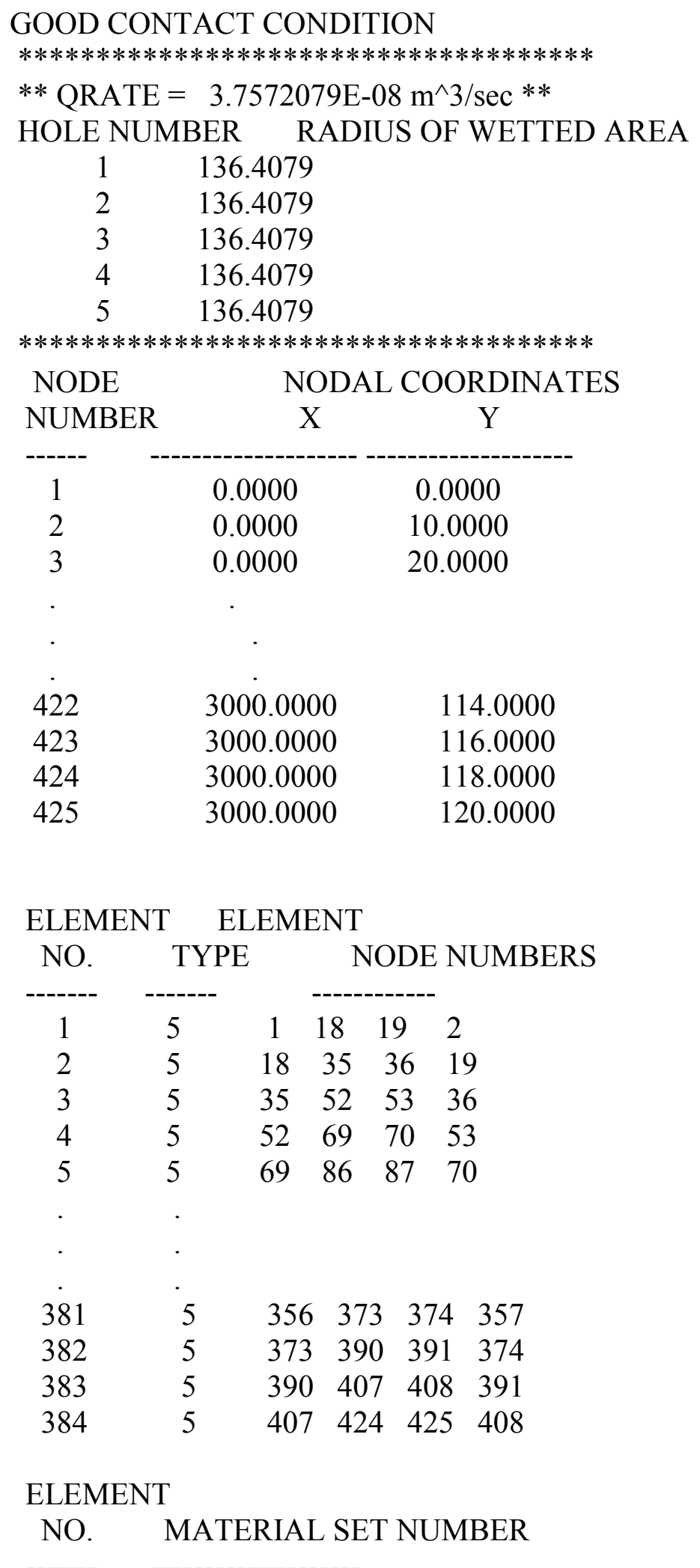




$\begin{array}{cc}1 & 1 \\ 2 & 1 \\ 3 & 1 \\ 4 & 1 \\ 5 & 1 \\ . & \cdot \\ \cdot & \cdot \\ . & \cdot \\ 381 & 2 \\ 382 & 2 \\ 383 & 2 \\ 384 & 2\end{array}$

MATERIAL SET NO. MATERIAL PROPERTIES

\# OF NODES WITH SPECIFIED PRESSURE HEAD $=25$

\# OF NODES WITH SPECIFIED GROUNDWATER FLOW $=0$

OMEGA $=\quad 1.0000$

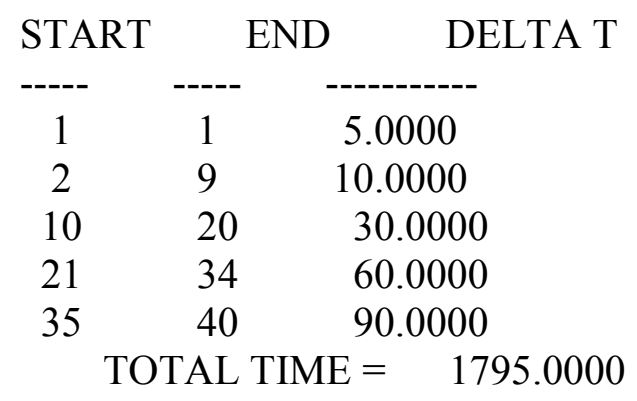

$\begin{array}{cc}\text { TIME T } & \text { G(T) } \\ ----- & --000 \\ 0.0000 & 1.0000 \\ 5.0000 & 1.0000 \\ 1795.0000 & 1.0000\end{array}$

INITIAL VALUES OF PRESSURE HEAD

NODE NO. PRESSURE HEAD 


$\begin{array}{cc}1 & -75.0000 \\ 2 & -75.0000 \\ 3 & -75.0000 \\ . & \cdot \\ . & \cdot \\ . & \cdot \\ 423 & -75.0000 \\ 424 & -75.0000 \\ 425 & -2.0000^{*} \\ & *=\text { SPECIFIED }\end{array}$

$* * * * * * * * * * * * * * * * * * * * * * * * * * * * * * * * * * * * * * * * * * * * * * * * * * * * * * * * * * * * * * * * * * * * * *$

COMPUTED VALUES OF PRESSURE HEAD

NODE NO. PRESSURE HEAD

$\begin{array}{cc}1 & -45.5033 \\ 2 & -45.5033 \\ 3 & -45.5033 \\ \cdot & \\ . & \\ 423 & -2.8894 \\ 424 & -2.4394 \\ 425 & -2.0000^{*} \\ & *=\text { SPECIFIED } \\ & \\ * * * \text { RESULTS FOR TIME }= & 3740.00 * * *\end{array}$

COMPUTED VALUES OF APPARENT GROUNDWATER VELOCITY

ELEMENT $\quad$ VX
$\begin{array}{ccc} & \text { VY } \\ 1 & -5.264343 \mathrm{E}-03 & -1.175029 \mathrm{E}+01 \\ 2 & -8.205965 \mathrm{E}-03 & -1.199063 \mathrm{E}+01 \\ 3 & -2.613687 \mathrm{E}-03 & -1.218293 \mathrm{E}+01 \\ \cdot & \cdot & \\ \cdot & \cdot & \\ . & \cdot & \\ 381 & -2.754702 \mathrm{E}-07 & -8.445765 \mathrm{E}-03\end{array}$




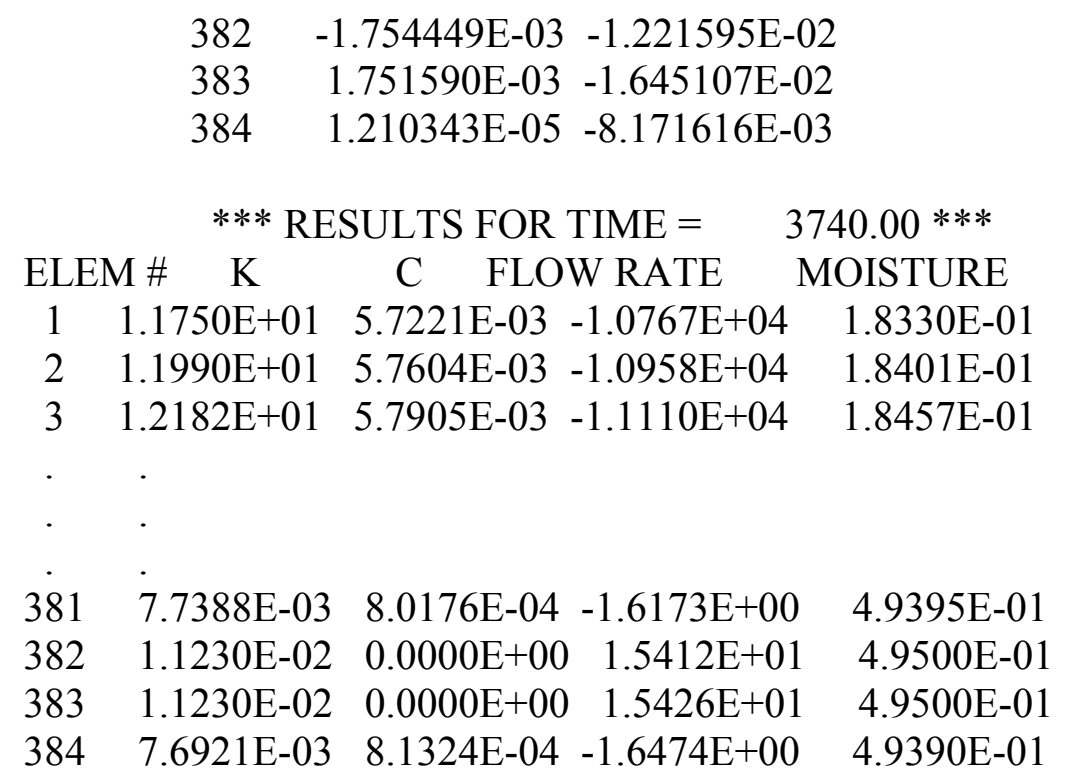




\section{VITA}

Mustafa Eftelioglu was born in Manisa, Turkey on January, 02, 1954. He attended Geology, Sciences Faculty, Aegean University in Izmir, Turkey and received the Bachelor of Science in Geology in 1978. After taking extra engineering courses, he received a diploma in Geological Engineering from the same university in 1979. He completed a Masters degree Program in 1983 in Sedimentology at the Institute of Marine Science and Technology, Dokuz Eylul University, Izmir, Turkey. He has participated about 50 scientific projects at the Institute of Marine Sciences and Technolgoy related with Oceanograpy and Geotechniques. He has also been teaching American Nato soldiers at Maryland University in Izmir for six years. 